\title{
norden
}

\section{A Nordic textile strategy}

Part II: A proposal for increased collection, sorting, reuse and recycling of textiles

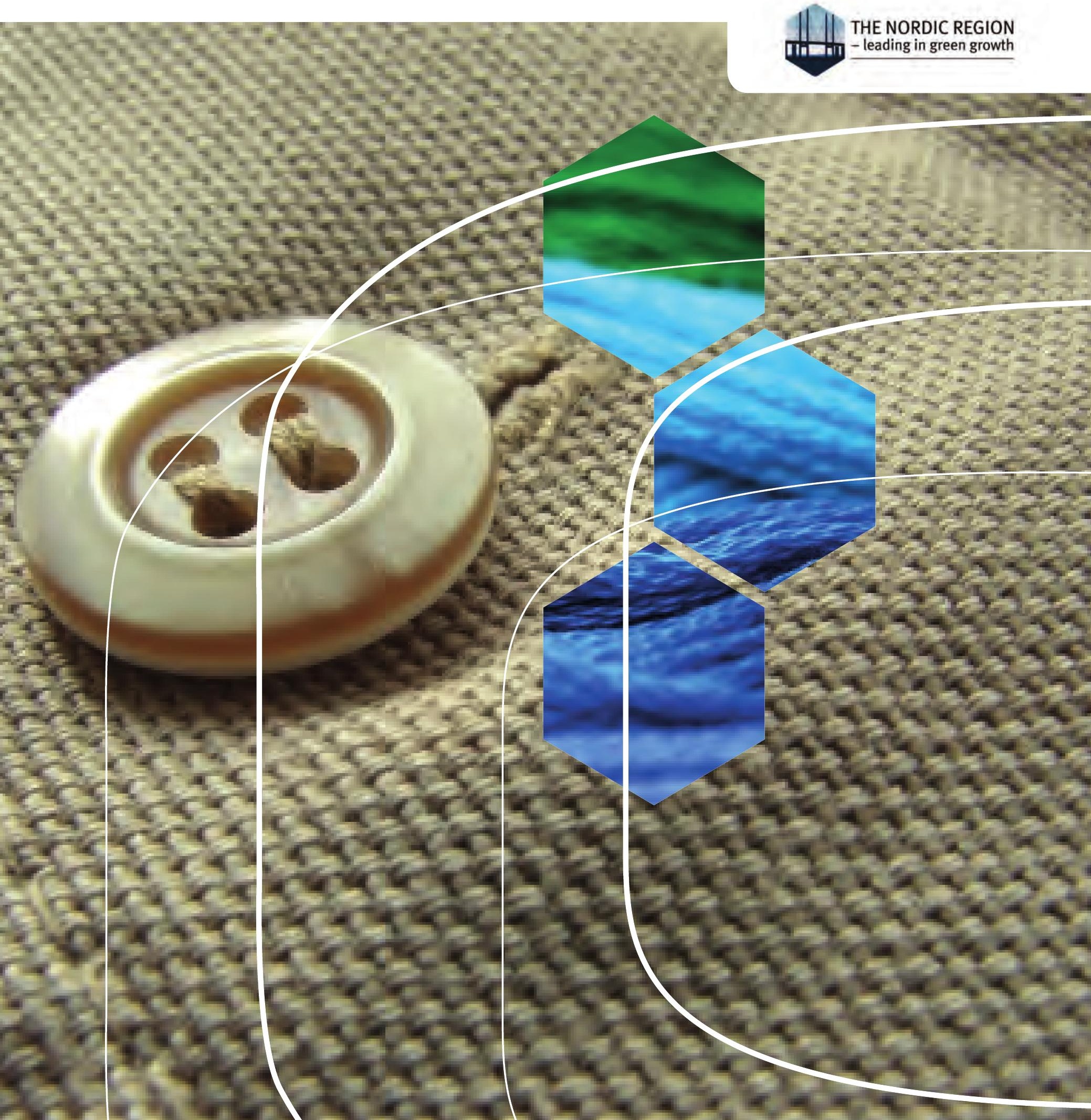



2 norden 



\section{A Nordic textile strategy}

Part II: A proposal for increased collection, sorting, reuse and recycling of textiles

David Palm, Maria Elander, David Watson, Nikola Kiørboe, Hanna Salmenperä, Helena Dahlbo, Synnøve Rubach, Ole-Jørgen Hanssen, Stefán Gíslason, Are-Severin Ingulfsvann and Øystein Nystad 
A Nordic textile strategy

Part II: A proposal for increased collection, sorting, reuse and recycling of textiles

David Palm, Maria Elander, David Watson, Nikola Kiørboe, Hanna Salmenperä, Helena Dahlbo,

Synnøve Rubach, Ole-Jørgen Hanssen, Stefán Gíslason, Are-Severin Ingulfsvann and Øystein Nystad

ISBN 978-92-893-3968-1 (PRINT)

ISBN 978-92-893-3970-4 (PDF)

ISBN 978-92-893-3969-8 (EPUB)

http://dx.doi.org/10.6027/ANP2015-513

TemaNord 2015:513

ISSN 0908-6692

(C) Nordic Council of Ministers 2014

Layout: Hanne Lebech

Cover photo: Signelements

Print: Rosendahls-Schultz Grafisk

Printed in Denmark

This publication has been published with financial support by the Nordic Council of Ministers. However, the contents of this publication do not necessarily reflect the views, policies or recommendations of the Nordic Council of Ministers.

\section{www.norden.org/en/publications}

\section{Nordic co-operation}

Nordic co-operation is one of the world's most extensive forms of regional collaboration, involving Denmark, Finland, Iceland, Norway, Sweden, and the Faroe Islands, Greenland, and Åland.

Nordic co-operation has firm traditions in politics, the economy, and culture. It plays an important role in European and international collaboration, and aims at creating a strong Nordic community in a strong Europe.

Nordic co-operation seeks to safeguard Nordic and regional interests and principles in the global community. Common Nordic values help the region solidify its position as one of the world's most innovative and competitive.

\section{Nordic Council of Ministers}

Ved Stranden 18

DK-1061 Copenhagen $\mathrm{K}$

Phone (+45) 33960200

www.norden.org 


\section{Content}

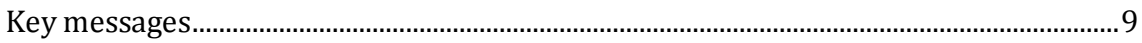

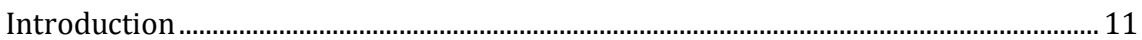

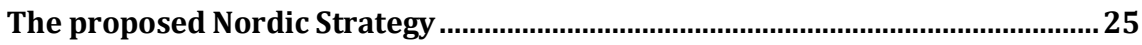

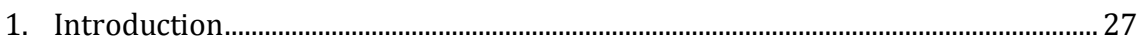

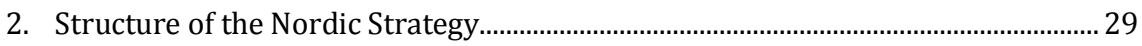

3. Targets giving direction for the Nordic region......................................................... 31

4. Necessary changes for reaching the Nordic targets ................................................... 33

5. Policy measures facilitating change ........................................................................... 35

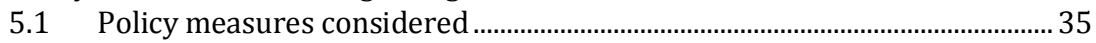

5.2 Evaluation and selection of policy measures.................................................... 35

5.3 Description of selected policy measures.......................................................... 37

5.4 Assessment of the selected policy mix.............................................................. 44

6. Supporting structures for implementation .................................................................. 51

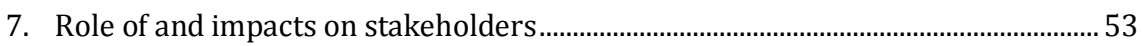

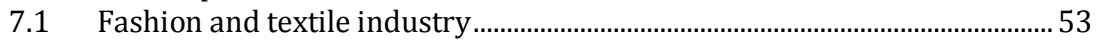

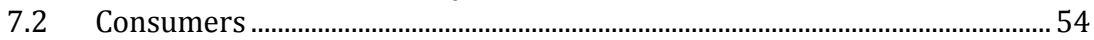

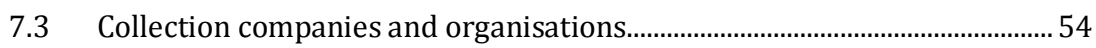

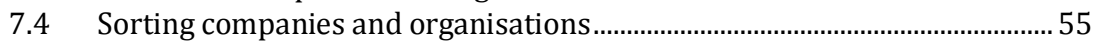

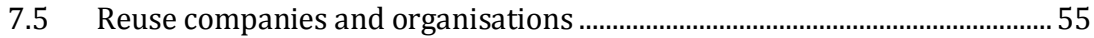

7.6 Recycling companies and organisations ...........................................................56

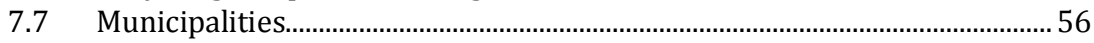

7.8 Entrepreneurs................................................................................................. 57

8. Key actors for successful implementation of the Nordic Strategy ...........................59

8.1 The NCM/NAG and a Nordic coordinating body for textiles........................... 59

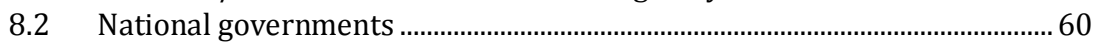

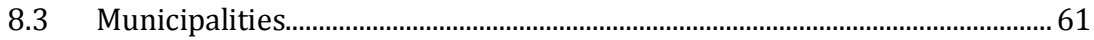

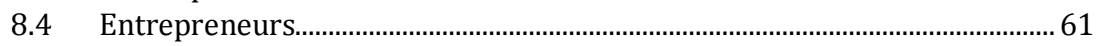

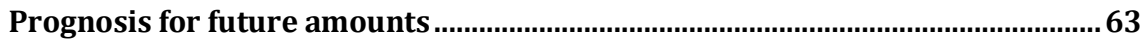

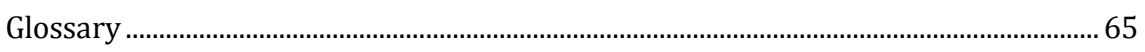

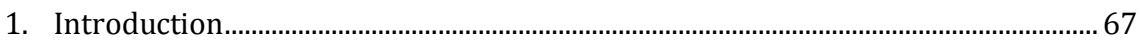

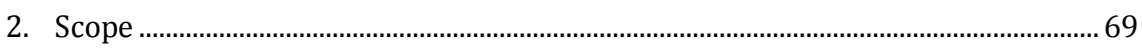

3. Current trends in net imports of new textiles......................................................... 71

3.1 Method and data availability …………...................................................... 71

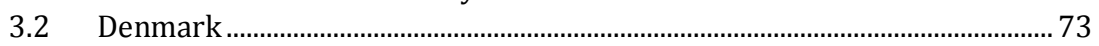

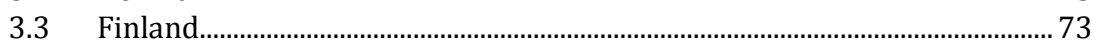

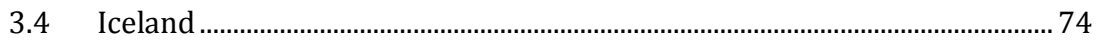

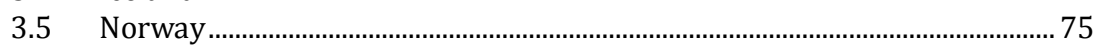

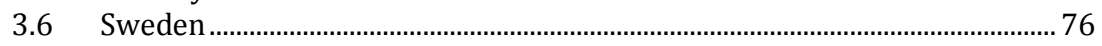

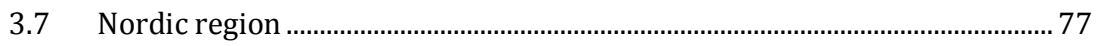


4. Current trends in production of new textiles.............................................................. 79

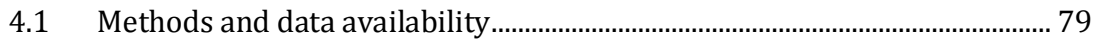

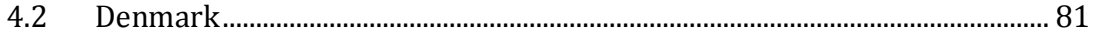

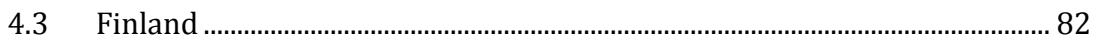

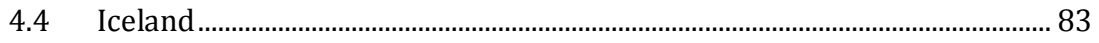

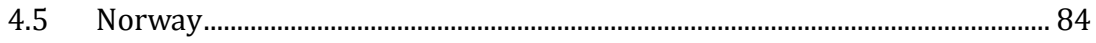

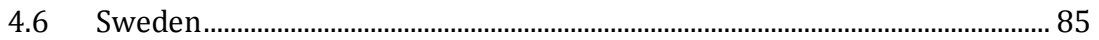

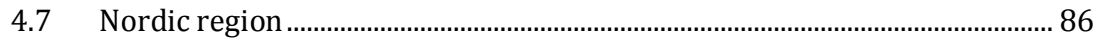

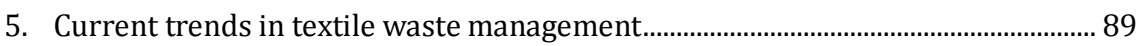

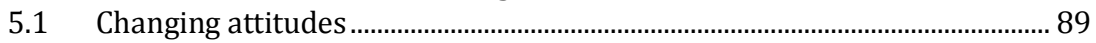

5.2 Trends in sorting and recycling of used textiles ............................................. 91

6. Prognosis of future net imports of new textiles ......................................................... 93

6.1 Method for making prognosis................................................................................. 93

6.2 Denmark ......................................................................................................... 94

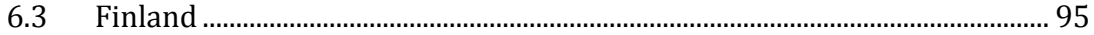

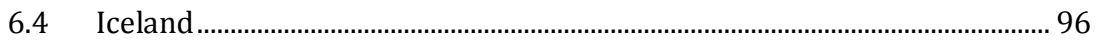

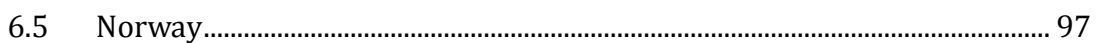

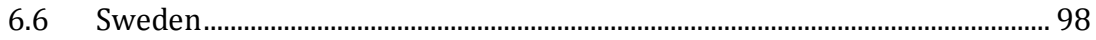

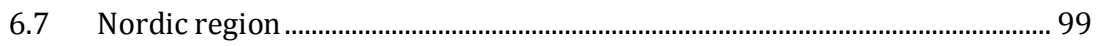

7. Prognosis of future production of new textiles ............................................................101

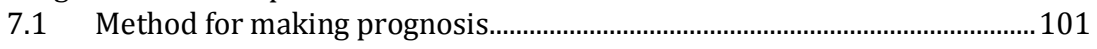

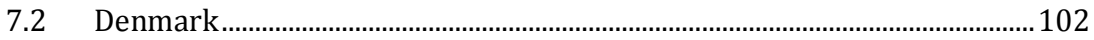

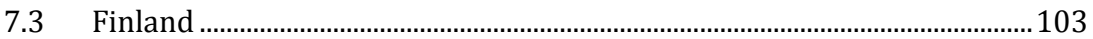

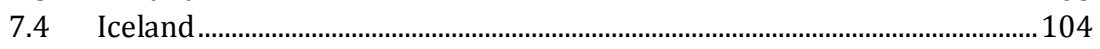

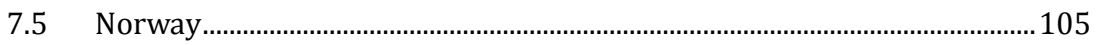

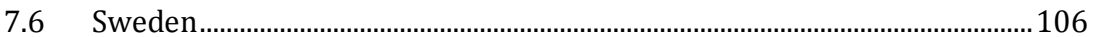

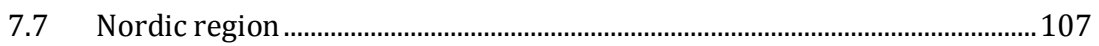

8. Prognosis for total consumption of new textiles.......................................................109

9. Expected future amounts of used textiles potentially available for reuse

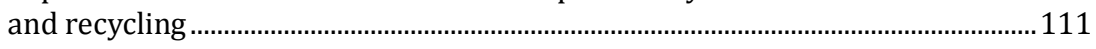

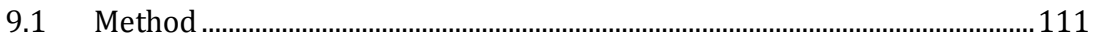

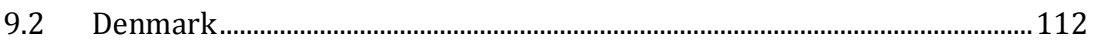

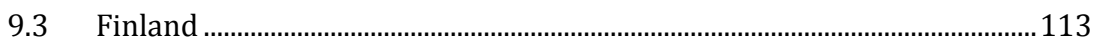

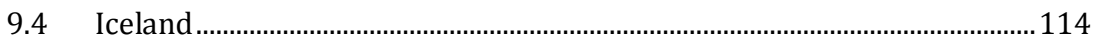

9.5 Norway................................................................................................................... 115

9.6 Sweden ...........................................................................................................116

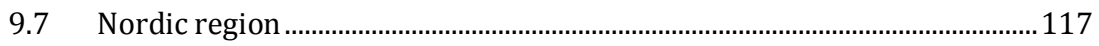

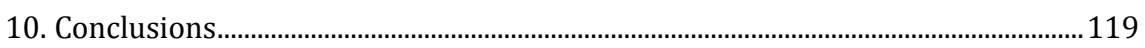

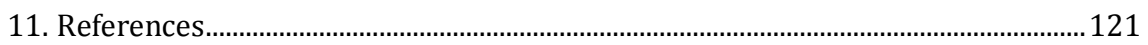

Collection, sorting, reuse and recycling scenarios........................................... 123

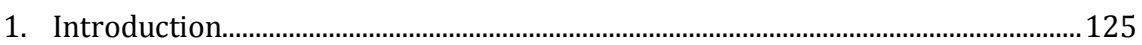

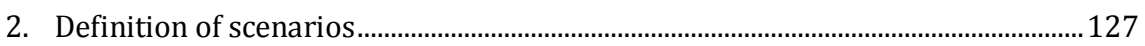

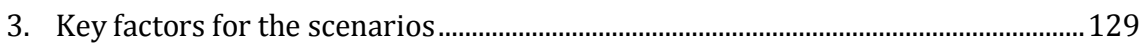

4. Different parts of the value chain for used textiles and textile wastes ..................131

4.1 Pre-consumer textile wastes.............................................................................131

4.2 Post-consumer used textiles and textile wastes ..........................................132 


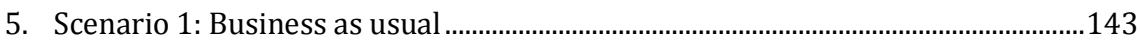

$5.1 \quad$ Description of the scenario ........................................................................ 143

5.2 Supporting incentives, instruments and measures.......................................146

5.3 Implications on the key factors ....................................................................147

5.4 Winners and losers in the value chain ..........................................................149

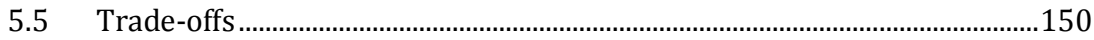

5.6 Effects on collection, sorting, reuse and recycling in summary...................150

6. Scenario 2: Nordic cooperation ..............................................................................153

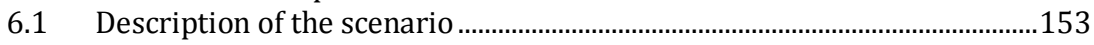

6.2 Supporting incentives, instruments and measures......................................161

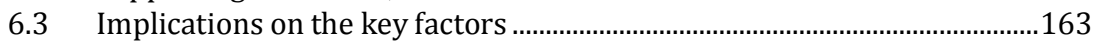

6.4 Winners and losers in the value chain ............................................................166

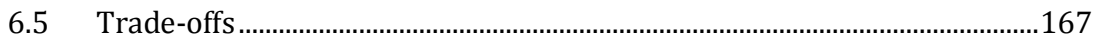

6.6 Effects on collection, sorting, reuse and recycling in summary...................168

7. Scenario 3: Multiple strategies............................................................................... 171

7.1 Description of the scenario ............................................................................171

7.2 Supporting incentives, instruments and measures.......................................175

7.3 Implications on the key factors .................................................................177

7.4 Winners and losers in the value chain .........................................................179

7.5 Trade-offs ...........................................................................................................180

7.6 Effects on collection, sorting, reuse and recycling in summary....................181

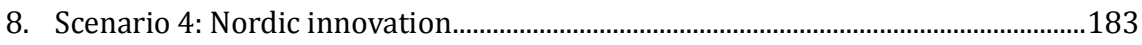

8.1 Description of the scenario .............................................................................183

8.2 Supporting incentives, instruments and measures........................................189

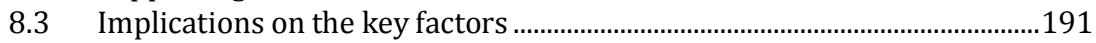

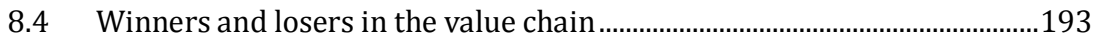

8.5 Trade-offs .........................................................................................................194

8.6 Effects on collection, sorting, reuse and recycling in summary...................194

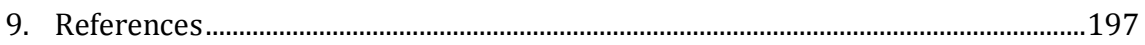

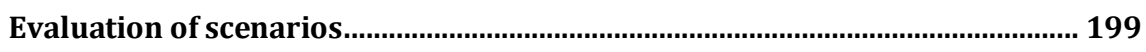

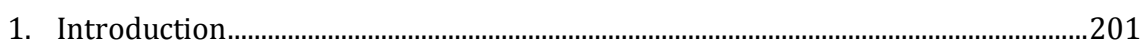

2. Scenario 1: Business as usual ........................................................................................203

2.1 Effect on collection rates as a whole and of different fractions of

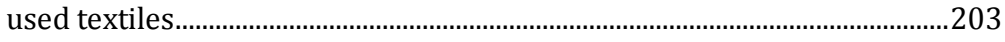

2.2 Effect on reuse compared to recycling.........................................................203

2.3 Effect on recycling compared to down-cycling for the recycled

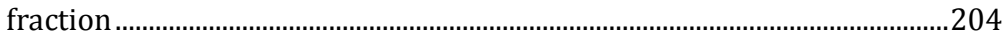

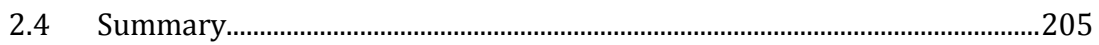

3. Scenario 2: Nordic Cooperation................................................................................20

3.1 Effect on collection rates as a whole and of different fractions of

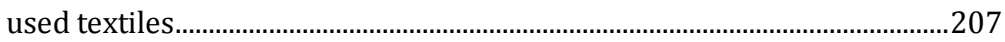

3.2 Effect on reuse compared to recycling..............................................................2209

3.3 Effect on closed loop recycling compared to down-cycling for the

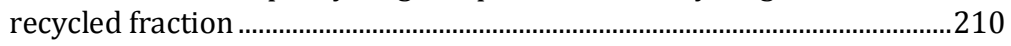

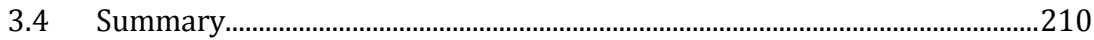


4. Scenario 3: Multiple strategies

4.1 Effect on collection rates as a whole and of different fractions of used textiles..

4.2 Effect on reuse compared to recycling ..........................................................2214

4.3 Effect on closed loop recycling compared to down-cycling for the

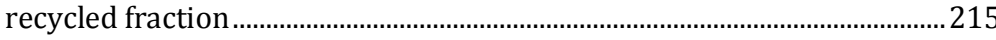

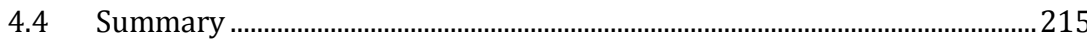

5. Scenario 4: Nordic innovation ................................................................................2 217

5.1 Effect on collection rates as a whole and of different fractions of used textiles...

5.2 Effect on reuse compared to recycling .............................................................2219

5.3 Effect on closed loop recycling compared to down-cycling for the recycled fraction ...............................................................................................220

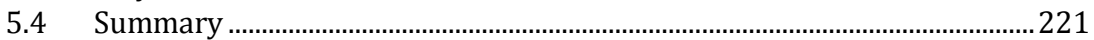

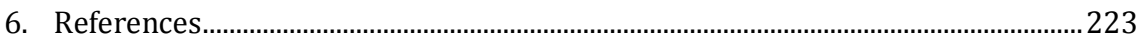

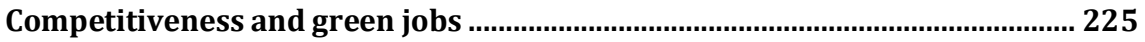

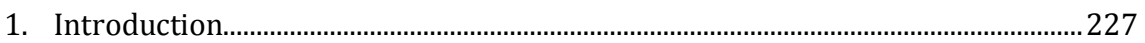

2. Possible consequences and impacts on competitive advantage for the Nordic countries

2.1 Examples for increased competitiveness using the Strategy measures ..................................................................................................................2230

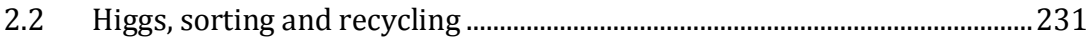

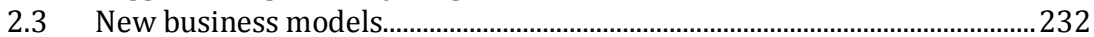

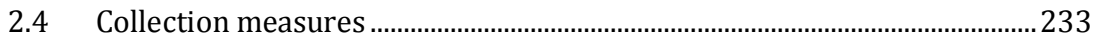

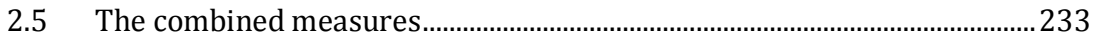

3. Effect on labour and potential for creating green jobs ..............................................2. 237

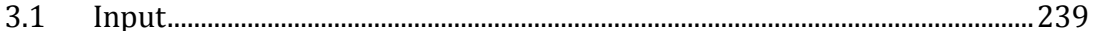

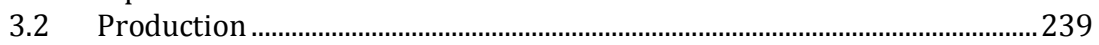

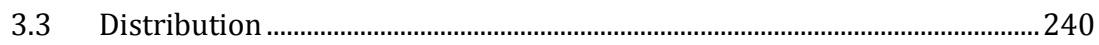

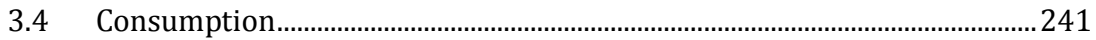

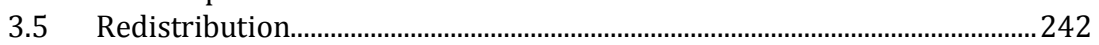

4. Possible need for new incentives, instruments and measures ................................243

$4.1 \quad$ Incentives and instruments for producers....................................................243

4.2 Incentives and instruments for consumers ...................................................24

4.3 Incentives and instruments for reuse traders ...............................................245

5. Conclusion.............................................................................................................. 247

6. References......................................................................................................... 249

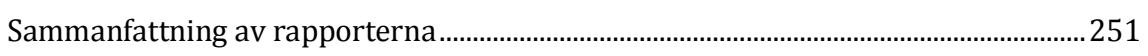

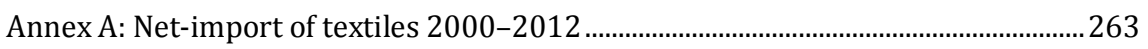

Annex B: Test of different types of models for prediction of future trends in production of textile and clothes ...............................................................................267

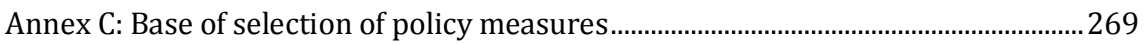

Annex D: Additional policy measures........................................................................... 271 


\section{Key messages}

The proposed Nordic textile strategy provides a starting point for the work towards a more sustainable textile and fashion sector in the Nordic region. It is focused on the increased collection, sorting, reuse and recycling within the Nordic region and thereby provides one part in the sustainability puzzle for the sector. There is a larger picture which is touched upon in the sub-report of green jobs and competitiveness of Nordic region which to a further extent include consumption, design and other relevant areas that have largely been outside the scope of the project.

The greatest potential for green jobs are connected to increased collection, sorting and sales of used textiles with possibly over 4,000 jobs and 30,000 work training opportunities. The key for increasing the Nordic regions competitive advantage is in making Nordic textile companies more profitable in the sustainability segment of textiles.

The proposed strategy includes targets for collection, sorting, reuse and recycling of textiles. The format for the targets are suggested, but actual target levels should be discussed and negotiated with all relevant actors in the textile and fashion sector. Clear and ambitious targets are key for a successful implementation of the strategy.

A total of 13 necessary changes for increased collection, sorting, reuse and recycling have been identified. They relate to increased transparency, consumer behavior, increased active lifetime of textiles, increased levels and quality of collection, sorting, reuse and recycling and a reduced use of toxic compounds in textiles.

The strategy consists of 14 proposed policy measures divided into the four categories Nordic commitment, measures supporting increased collection of textiles, measures supporting new business models and other measures. The Nordic commitment is covered in the sister project the Nordic textile reuse and recycling commitment and suggestions for expansion of this are suggested here. The group other measures include measures to support increased sorting and high grade recycling of textiles. The 14 measures are diverse i character and range from investment to information to cover the complex issues of the textile and fashion sector and affect a wide range of actors. 
The flows of textiles, whether new, used or in the form of waste will likely continue to increase slightly for the coming years for all Nordic countries. 


\title{
Introduction
}

\author{
Background
}

This is the second report in the project $A$ Nordic strategy for collection, sorting, reuse and recycling of textiles. The first report is published titled Towards a Nordic textile strategy: Collection, sorting, reuse and recycling of textiles, TemaNord 2014:538 giving background information to the project.

This project is one of three projects to increase the reuse and recycling of textiles in the Nordic region financed by the Nordic Council of Ministers and proposed by the Nordic Waste group. All three projects are part of the Nordic Prime Minister's inititiave, The Nordic Region leading in green growth, which identifies eight priorities aimed at increasing green growth in the region. The other textile projects are: The Nordic reuse and recycling commitment and An extended producer responsibility (EPR) system and new business models to increase reuse and recycling of textiles in the Nordic region.

The aim of the project as stated in the tender from the Nordic waste group:

Develop a proposal for a common Nordic strategy for improving infrastructure for collection, sorting and reuse/recycling of textiles in the Nordic region that can also represent a competitive advantage for Nordic business within the textile sector. [...]

(Tender published by the Nordic waste group, April 2013).

\section{The project}

The project is carried out by a consortium with IVL Swedish Environmental Research Institute (Sweden), Copenhagen Resource Institute (Denmark), Ostfold Research (Norway), SYKE Finnish Environment Institute (Finland), Environice (Iceland) and University of Nordland (Norway). David Palm at IVL acts as project manager.

The work is performed in close connection with the Nordic waste group and Coordinator Yvonne Augustsson and also has a reference group connected to the project to ensure the outcome of the project. Related to 
this project are also two Nordic workshops organized by the Sustainable Fashion Academy on behalf of the Nordic Council of Ministers.

The project was performed June 2013 to December 2014.

The reference group members were:

- Anna Bengtsson, Ragn-Sells, Sweden.

- Arnt-Willy Hjelle, Fretex, Norway.

- Dan Boding-Jensen, former at Vestforbrænding, Denmark.

- Elisabeth Dahlin, Swedish Red Cross, Sweden.

- Emma Enebog, Myrorna, Sweden.

- Erik Hove, Danish Red Cross, Denmark.

- Ingun Klepp Grimstad, SIFO, Norway.

- John Hansen, Teknologisk Institut, Denmark.

- Jon Nilsson-Djerf, Waste Management Sweden, Sweden.

- Kristiina Aalto, Konsumentforskningscentralen, Finland.

- Marja Pitkänen, VTT, Finland.

- Ólafur Kjartansson, Icelandic Recycling Fund, Iceland.

- Päivi Talvenmaa, Tampere University of Technology, Finland.

Some organisations have been represented also by other colleagues for part of the work.

\section{Summary of the reports}

This report presents the work from the final year of the project and its subreports covering the road towards a Nordic strategy as input to a coming Nordic Action Plan for the textile and fashion sector.

The sub-reports included in this report are:

- The proposed Nordic Textile Strategy.

- Prognosis for future amounts.

- Collection, sorting, reuse and recycling scenarios.

- Evaluation of scenarios.

- Competitiveness and green jobs.

The report is part of the Nordic Prime Minister's overall green growth initiative: "The Nordic Region - leading in green growth". Read more in the web magazine "Green Growth the Nordic Way" at www.nordicway.org or at www.norden.org/greengrowth 


\section{The proposed Nordic Textile Strategy}

The proposed strategy includes incentives, policy measures and measures needed on local, regional, national and Nordic levels to ensure successful implementation. It includes national differences in implementation as well as overarching solutions for the Nordic region. The role of current actors involved in collection, reuse and recycling of textiles in the implementation of the Nordic Strategy as well as probable and possible effects on these stakeholders were evaluated. Finally, key actors for successful implementation of the Nordic Strategy were identified.

The Nordic countries are at different stages in considering and evaluation of policy measures for increasing collection, reuse and recycling of textiles and textile wastes. As a result, the Nordic Strategy aims to formulate (short term) objectives and measures that are considered realistic for implementation in all Nordic countries. The Nordic Strategy could serve as a starting point for future strategic collaboration in the area of textiles and textile wastes.

\section{Targets}

It is recommended to develop and formulate a set of targets regarding:

- Collection as share of textiles put on market.

- Reuse as share of textiles put on market.

- Reuse on national/Nordic markets as share of total reuse.

- Recycling as share of textiles put on market.

- Textiles-to-textiles recycling as share of total recycling.

- Number of municipalities with certified collection points.

- Share/number of collection points operated by certified organisations (e.g. engaged in the Nordic Commitment).

\section{Necessary Changes}

To reach the aim of the project 13 necessary changes have been identified. The necessary changes are:

1. Increased transparency, e.g. in terms of textile flows and data collection.

2. Increased active life time of textile products, i.e. how long the textile products are used in practice.

3. Changed consumer behaviour for textile products, e.g. (active) life time, collective use, reuse and discard behaviour. 
4. Increased attractiveness of collection, e.g. consumer convenience as well as trust and reliability in collection.

5. Increased collection of used textiles.

6. Introduced/increased services for (certified) de-branding of corporate textiles for recycling in the Nordic region.

7. Increased reuse, particularly in the Nordic region.

8. Increased and improved sorting of collected textiles.

9. Improved management of used textile and textile waste flows for more coordinated and efficient handling.

10.Increased recycling, particularly in the Nordic region.

11.Increased share of textile-to-textile recycling.

12.Increased market for recycled textiles.

13. Reduced use of toxic compounds in textiles.

\section{Proposed policy measures}

In the Nordic Strategy fourteen policy measures are suggested. The policy measures are considered to cover all necessary changes as defined above, give priority to reuse as well as giving the possibility to increase requirements in several cases. The policy measures are divided into four different sections as listed in the following.

\section{The Nordic Commitment}

The Nordic Commitment (see the subreports on "Voluntary Commitment", "Code of conduct for management of used textiles", "Certification and system operation" and "Implementation and operation guidelines" developed in the project The Nordic textile reuse and recycling commitment) can be separated into four different parts:

- Launch of the Nordic Commitment.

- Expansion of the Nordic Commitment to include de-branding services.

- Engagement of municipalities in the Nordic Commitment.

- Further development of the Nordic Commitment to more actively involve and include textile producers. 


\section{Measures supporting increased collection of textiles}

- Obligation for municipalities to secure that collection containers for textiles are available at all (municipal) recycling centres.

- Obligation to collect used textiles from public activities and public businesses.

- Introduction of a voluntary commitment for private companies to collect used textiles.

\section{Measures supporting new business models}

- Evaluation of business models in the field of collective use, reuse and prolonged (active) lifetime of textiles.

- Government funding for start-ups in the field of collective use, reuse and prolonged (active) lifetime of textiles.

\section{Other supporting measures}

- Consumer information campaign.

- Nordic Task Force for the Higg index.

- Public procurement for reuse of textiles and textiles with recycled content.

- Investigation of the need for and potentials of establishing an (automatic) sorting facility in the Nordic region.

- Financial assistance for establishing one chemical recycling facility on an industrial scale in the Nordic region.

\section{Key actors for successful implementation}

The project identified four main key actors for successful implementation of the Nordic Strategy:

- The Nordic Council of Ministers, the Nordic Waste Group and a Nordic coordinating body for textiles.

- National governments.

- Municipalities.

- Entrepreneurs interested in engaging and applying new business opportunities within the field of textiles and textile wastes. 


\section{Prognosis for future amounts}

This subreport gives an insight into possible future amounts of textiles and textile waste by studying:

- Current trends in net import of new textiles.

- Current trends in production of new textiles.

- Current trends in textile waste management.

- Prognosis of future net imports of new textiles.

- Prognosis of future production of new textiles.

- Prognosis for total consumption of new textiles.

- Expected future amounts of used textiles potentially available for reuse and recycling.

The production of clothes and household textiles is small compared to the total textile industry in each country and especially compared to the net import. The prognoses illustrate that the proportion of production of total consumption of new textiles in the Nordic region will decrease from $10 \%$ in 2012 to $7 \%$ in 2015 and 2020 respectively. The only exemption is Iceland. However, the total consumption of textiles in Iceland corresponds to only $2 \%$ of the total consumption of textiles in the Nordic region.

\section{Main conclusions}

- The overall economic development has an impact on the consumtion of new textiles. This has a direct impact on the textiles available for reuse and recycling.

- The overall trend is an increasing consumption of textiles but with effects of overall economic development, the increase is slower than in the past decade.

- The amount of textiles produced in the Nordic region is continuing a decrease in all countries but Iceland.

\section{Collection, sorting, reuse and recycling scenarios and evaluation of scenarios}

This short summary includes both the developed scenarios and the evaluation of the scenarios performed in a separate sub-report. The evaluation is summarized at the end of the scenario descriptions. 
The scenarios have been qualitatively evaluated with respect to the degree to which they promote:

- Increased collection rates as a whole, and of different fractions of used textiles.

- Reuse rather than recycling as far as possible.

- Recycling rather than down-cycling of the recycled fraction.

The different scenarios will affect different parts in the value chain in different ways; there will be winners and losers; trade-offs might be necessary to reach a positive development of key factors.

The figure below describes the four developed scenarios:

- Scenario 1: Business as usual.

- Scenario 2: Nordic cooperation.

- Scenario 3: Multiple strategies.

- Scenario 4: Nordic innovation.

\begin{tabular}{|c|c|c|c|}
\hline & High & $\begin{array}{c}\text { Scenario 3: } \\
\text { Multiple strategies }\end{array}$ & $\begin{array}{c}\text { Scenario 4: } \\
\text { Nordic innovation }\end{array}$ \\
\hline & Low & $\begin{array}{c}\text { Scenario 1: } \\
\text { Business as usual }\end{array}$ & $\begin{array}{c}\text { Scenario 2: } \\
\text { Nordic cooperation }\end{array}$ \\
\hline & & Low & High \\
\hline
\end{tabular}




\section{Scenario 1: Business as usual}

The scenario reflects the likely development in collection, sorting, reuse and recycling of textiles under the assumption that current trends and developments continue, but no major change in technologies, structures and policy are implemented in the Nordic region.

The table below indicates changes in the scenario

\begin{tabular}{lcc} 
& \\
& Changes in amounts & Changes in quality \\
\hline Collection & + & 0 \\
Pre-sorting & 0 & 0 \\
Sorting in total, thereof & + & + \\
in Nordic region & 0 & 0 \\
in other countries & + & + \\
Reuse in total, thereof & + & 0 \\
in Nordic region & + & 0 \\
in other countries & + & 0 \\
Recycling in total, thereof & + & + \\
in Nordic region & 0 & 0 \\
in other countries & + & + \\
\hline
\end{tabular}

Changes range from --- to +++.

0 indicate no or very little change.

\begin{tabular}{ll}
\hline Evaluation & Effect \\
\hline Increased collection & Minor increase in collection of household textiles \\
Reuse before recycling & $\begin{array}{l}\text { Increase on reuse and recycling on markets abroad. No major change } \\
\text { on Nordic market. }\end{array}$ \\
Recycling before down-cycling & $\begin{array}{l}\text { Very little, positive effect on upcycling or closed loop recycling is } \\
\text { expected. Down-cycling continues to dominate. }\end{array}$ \\
\hline
\end{tabular}

\section{Scenario 2: Nordic cooperation}

In this scenario, the Nordic countries established common goals and strategies for collection, reuse and recycling of used textiles and textile wastes in 2015. However, except for the establishment of a common voluntary certification system for collection, de-branding, sorting, transport, reuse and recycling of used textiles and textile waste only minor changes has been carried out compared to the current situation. 


\begin{tabular}{lcc} 
& Changes in amounts & Changes in quality \\
\hline Collection & $+/++$ & + \\
Pre-sorting & 0 & 0 \\
Sorting in total, thereof & $+/++$ & + \\
in Nordic region & $0 /+$ & $0 /+$ \\
in other countries & $+/++$ & + \\
Reuse in total, thereof & $+/++$ & 0 \\
in Nordic region & $0 /+$ & + \\
in other countries & $+/++$ & $0 /+$ \\
Recycling in total, thereof & $+/++$ & + \\
in Nordic region & $0 /+$ & 0 \\
in other countries & $+/++$ & + \\
\hline
\end{tabular}

Changes range from --- to +++.

0 indicate no or very little change.

\begin{tabular}{ll}
\hline Evaluation & Effect \\
\hline Increased collection & $\begin{array}{l}\text { Overall increase in collected volumes is expected. Non- } \\
\text { reusable textiles are likely to increase significantly, while } \\
\text { recovered reusable textiles will only increase moderately. }\end{array}$ \\
Reuse before recycling & $\begin{array}{l}\text { Although a significant increase in collected recyclable textiles is } \\
\text { expected, only a medium increase in textiles actually recycled } \\
\text { is likely due to a continued low market price. The quantity of } \\
\text { reused textiles is expected to increase moderately. }\end{array}$ \\
Closed loop recycling before down-cycling & $\begin{array}{l}\text { A slight increase in upcycled and closed loop recycled textile } \\
\text { waste is expected. However, most recycled textiles are still } \\
\text { expected to be down-cycled. }\end{array}$ \\
\hline
\end{tabular}

\section{Scenario 3: Multiple strategies}

In this scenario, each Nordic country has its own strategy for textile collection, reuse and recycling. Hence the detailed contents of systems may vary from country to country. The system is based on voluntary commitments of the different operators. The collection and sorting phases include the current players and new ones. Existing container network of charity organizations will be maintained or even boosted. Extra collection is provided by private companies. Municipalities are also allowed to participate. Collection is wide-ranging and diverse, and sites are located close to the textile waste producers making disposal attractive and convenient. 
The table below indicates changes in the scenario

\begin{tabular}{lcc} 
& Changes in amounts & Changes in quality \\
\hline Collection & ++ & + \\
Pre-sorting & ++ & ++ \\
Sorting in total, thereof & ++ & ++ \\
in Nordic region & ++ & $\%$ \\
in other countries & 0 & $\%$ \\
Reuse in total, thereof & 0 & 0 \\
in Nordic region & 0 & $\%$ \\
in other countries & 0 & $\%$ \\
Recycling in total, thereof & ++ & ++ \\
in Nordic region & ++ & $\%$ \\
in other countries & ++ & $\%$ \\
\hline
\end{tabular}

Changes range from --- to +++.

0 indicate no or very little change.

./. indicate change that could not be assessed within this project.

Evaluation

\begin{tabular}{ll}
\hline Factor & Effect \\
\hline Increased collection & $\begin{array}{l}\text { A higher flow of collected amounts is expected, mainly due to } \\
\text { increased collection from private companies and public institutions }\end{array}$ \\
Reuse before recycling & $\begin{array}{l}\text { The system will give moderate increases in textiles for reuse, and } \\
\text { a medium to high increase in textiles for recycling. }\end{array}$ \\
Closed loop recycling before down cycling & Only a moderate increases in closed loop recycling is expected. \\
\hline
\end{tabular}

\section{Scenario 4: Nordic innovation}

Nordic countries have a common Nordic strategy for textile collection, reuse and recycling. Due to the common targets of the Nordic commitment, the level of co-operation between Nordic countries is high. Policy measures in use to promote textile waste reuse and recycling are stronger than today and new business around textiles arise. Measures that have been successful in one Nordic country is quickly copied and adapted to the other Nordic countries and operations where cooperation is needed to reach sufficient flows and scale effects are multiplying in the region. 


\begin{tabular}{lcc} 
& Changes in amounts & Changes in quality \\
\hline Collection & +++ & ++ \\
Pre-sorting & ++ & ++ \\
Sorting in total, thereof & +++ & +++ \\
in Nordic region & +++ & $/$ \\
in other countries & 0 &.$/$ \\
Reuse in total, thereof & +++ & ++ \\
in Nordic region & +++ &.$/$ \\
in other countries & + &. \\
Recycling in total, thereof & +++ & ++ \\
in Nordic region & +++ &.$/$. \\
in other countries & ++ &.$/$ \\
\hline
\end{tabular}

Changes range from --- to +++.

0 indicate no or very little change.

./. indicate change that could not be assessed within this project.

\begin{tabular}{ll}
\hline Evaluation & Effect \\
\hline Increased collection & $\begin{array}{l}\text { A significant increase in the share of new textiles put on the } \\
\text { market which is separately collected. Total volumes of new textiles } \\
\text { put on the market is expected to drop but, the net volumes of } \\
\text { separately collected textiles is will increase moderately. }\end{array}$ \\
Reuse before recycling & $\begin{array}{l}\text { The net quantity of reused textiles is expected to increase. This } \\
\text { will result in an increasing share of reuse within the Nordic } \\
\text { region rather than being exported for reuse elsewhere. }\end{array}$ \\
Closed loop recycling before down-cycling & $\begin{array}{l}\text { A significant increase in closed loop recycling and upcycling at } \\
\text { the expense of down-cycling or incineration is expected. }\end{array}$ \\
\hline
\end{tabular}

\section{Competitiveness and green jobs}

\section{Competitiveness}

Competitiveness depends on the consumers, and some groups are more concerned with environmental issues than others. Middlemiss (2011) has constructed an ecological footprint describing our responsibilities as consumers to be built up by four different capacities.

These are:

- Our organizational capacity.

- Our cultural capacity.

- Our personal capacity.

- Infrastructural capacity.

An increased opportunity to reuse and recycle textiles or buy reused and recycled textiles will in this picture increase the infrastructural capacity, but it also demands that the consumers achieve information (increase 
knowledge) about the opportunities and consequences of choosing to do it. It is also needed to be embedded in culture how to choose and what to do when the product has reached its end of use the first time. Therefore it is important to see the proposed measures as a unit rather than separate parts. The Nordic Commitment can together with measures supporting increased collection of textiles support both the infrastructural capacity and the personal capacity by making it easier to donate used textiles and by clearly showing the benefits for others of doing so. The consumer information campaign can help us find and understand the hows and whys of textile collection. Measures for sorting and recycling (measures 13 and 14) are needed to enable changing business models but must be combined with longer lifetimes by e.g. collective use and reuse (measures 8 and 9) not to create a suboptimized system. This while measures for public textile collection (measure 6) and public procurement of textiles with recycled content (measure 12) are needed as enablers for increased and improved recycling in the initial phase.

Measure 10 is probably one of the most crucial measures to be taken together with other measures, and very few of the measures would work if the consumers are not taking part.

\section{Green jobs}

\section{Input and production}

The Higg index is still under development and with a Nordic push it can be expanded to include life cycle assessment or similar tools to show environmental hotspots for input materials. The obvious example here is to closely investigate the environmental performance of different new recycling technologies and be the frontrunner in developing them. This can in turn create high tech jobs in environmental assessment and development of recycling technology in the short term and possibly industrial jobs connected to a chemical textile recycling facility. The latter will likely be less that what one might expect since the processing is similar to paper pulp with maybe 40 jobs for one facility.

\section{Distribution}

The sales of second hand textiles are traditionally done with a high degree of job training and volunteers which makes the direct translation into green jobs difficult. The Nordic Commitment in measure 1 has a goal doubling the share of separate collection of used textiles and textile waste within ten years from roughly $30 \%$ in 2012 to $60 \%$ in 2022. If the target is reached and by using the employee figures for Myrorna (2014) 
and putting it in relation to their collected amounts (about 11,000 tonnes), this would imply creating 4,400 jobs and 30,000 work training opportunities, internships and community service opportunities. This is of course a very rough estimate including also jobs in collection and sorting (redistribution below). If if was to be calculated based on the Swedish Red Cross, which is based solely on volunteers, the result would obviously be much different.

\section{Redistribution}

Based on sorting performance given by UFF Norway on a Slovenian sorting facility the current collection levels $(120,000$ tonnes) in the Nordic region corresponds to about 1,400 person-years of labour in sorting. An estimate for an automated sorting facility would be do base the size of the sorting facility on the flow of recyclable textiles to be sorted automatically. Since no functional facility for automated textile sorting exists, a sorting facility for plastics could be used as a base. With an estimated $50 \%$ of collected textiles being reuseable (Palm et al. 2014), the sorting facility would then be designed for 80,000 tonnes annually. This would then equal creating around 900 jobs in sorting.

\section{Conclusion}

The consequences of adopting the strategy, taking in the aspects from the examples, are that it can lead to a more competitive sector. For the Nordic region it will be a competitive advantage if one is able to lead the purchasing power towards the brands and producers which is based in the Nordic region, whether selling high quality new products or reused and recycled products.

The proposed strategy provides measures that can create new green jobs. The clear opportunities are mostly in sorting and trading of reused textiles. These jobs are however not the most high-end which instead can be found in recycling R\&D and environmental assessment. A sorting and recycling facility in the Nordic region can be the basis for a new Nordic industry but require further evaluation and studies both from an economical and technical standpoint. 

The proposed Nordic Strategy 



\section{Introduction}

A Nordic strategy for improved collection, sorting, reuse and recycling of textiles in the Nordic region (Nordic Strategy) is presented in this report. The strategy is an elaboration of the most promising scenario "Nordic innovation" presented in the scenario subreport, and specific aspects of the other three scenarios. In addition, experiences made in the two projects The Nordic textile reuse and recycling commitment and An extended producer responsibility (EPR) system and new business models to increase reuse and recycling of textiles in the Nordic region fed into the development of the strategy. The projects are part of the Nordic Prime Minister's initiative, The Nordic Region - leading in green growth, which identifies eight priorities aiming at increasing green growth in the region.

The strategy includes incentives, policy measures and measures needed on local/regional, national and Nordic levels to ensure successful implementation. It includes national differences in implementation as well as overarching solutions for the Nordic region. The role of current actors involved in collection, reuse and recycling of textiles in the implementation of the Nordic Strategy as well as probable and possible effects on these stakeholders were evaluated. Finally, key actors for successful implementation of the Nordic Strategy were identified.

The Nordic countries are at different stages in considering and evaluation of policy measures for increasing collection, reuse and recycling of textiles and textile wastes. As a result, the Nordic Strategy aims to formulate (short term) objectives and measures that are considered realistic for implementation in all Nordic countries. The Nordic Strategy could serve as a starting point for future strategic collaboration in the area of textiles and textile wastes. If one or a few of the Nordic countries decide to evaluate, test and implement more extensive policy measures, these experiences should be used by the entire Nordic region and potentially transformed to other Nordic countries.

The Nordic Strategy should be revised by 2020 by the latest. 



\section{Structure of the Nordic Strategy}

Targets for collection, reuse and recycling of textiles and textile wastes pose the centre of the Nordic Strategy as illustrated in Figure 1. The targets will be reached by changes to the current situation in terms of both volumes and quality of collected, reused and recycled textiles and textile wastes. These changes might to some extent derive from the targets themselves. However, the introduction of additional policy measures will be necessary in order to trigger the changes necessary for reaching the targets. It is crucial that the implementation of the targets and policy measures is supported and strengthened by appropriate structures, coordination, allocation of responsibilities, milestones and follow-ups.

Figure 1. Structure of the Nordic Strategy

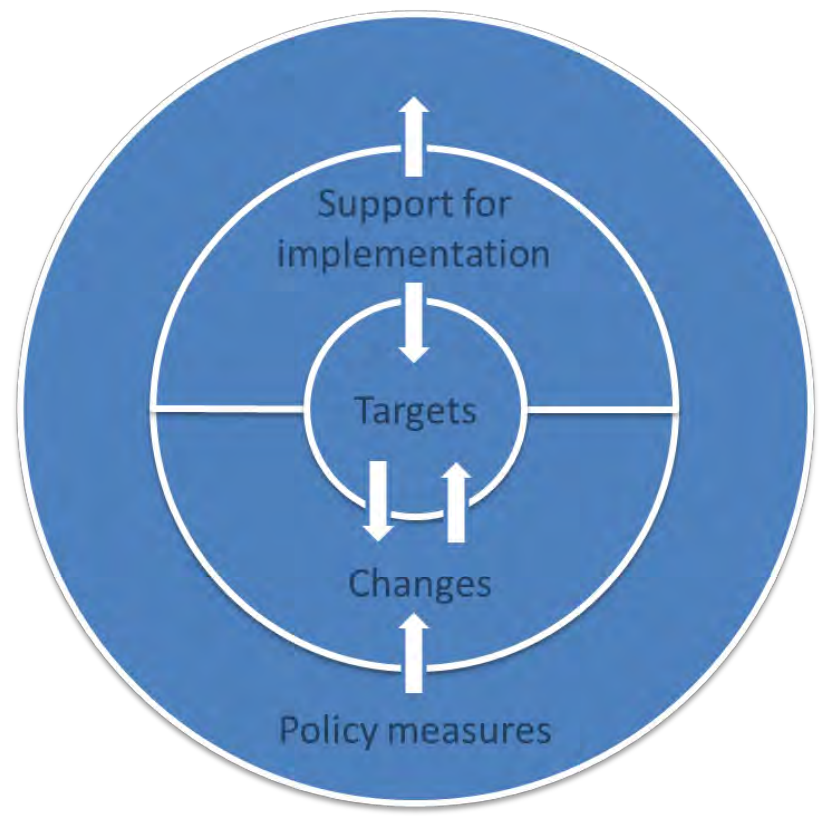





\section{Targets giving direction for the Nordic region}

Targets indicate, in a simplified way, what should be changed and in what timeframe it should be changed. The type and level of targets influence what policy measures (or combinations of measures) are needed to reach the targets set. The success of such policy measures (or combinations of measures) is measured against the degree to which the set targets are met.

By setting targets for collection, reuse and recycling, the Nordic countries clearly indicate the politically desired direction for the handling of textiles and textile wastes. On one hand, the targets must be ambitious in order to reflect the necessary reductions of environmental impacts from textiles and textile wastes. On the other hand, they have to be realistic in order to gain acceptance for the targets themselves as well as for the policy measures (or combinations of measures) introduced to reach these targets.

The formulation of targets is generally a result of political processes, preparatory studies and stakeholder consultations. This was not carried out as part of the project. It is, however, recommended to develop and formulate a set of targets regarding: 1

- Collection as share of textiles put on market.

- Reuse as share of textiles put on market.

- Reuse on national/Nordic markets as share of total reuse.

- Recycling as share of textiles put on market.

- Textiles-to-textiles recycling as share of total recycling.

- Number of municipalities with certified collection points.

- Share/number of collection points operated by certified organisations (e.g. engaged in the Nordic Commitment).

1 Within the Nordic Commitment developed in the NCM project The Nordic textile reuse and recycling commitment, it has been proposed to double the collection of used textiles in ten years, to reuse minimum $50 \%$ of the collected textiles and to reuse and recycle minimum $90 \%$ of the collected textiles. 
The targets should be common minimum targets for all Nordic countries. Individual countries could adopt more ambitious targets on a national level. The targets should be incorporated in national legislation in all Nordic countries.

The targets should be related to a specific year of latest fulfilment. For each target, interim targets should be formulated, enabling an early assessment of whether selected policy measures (or combinations of measures) are likely to secure achievement of the targets. 


\section{Necessary changes for reaching the Nordic targets}

The targets indicated in section 3 illustrate how the desired results for improved collection, reuse and recycling of textiles and textile wastes could be formulated. Given the current levels of collection, reuse and recycling of textiles in the Nordic region, several changes are necessary.

The proposed policy measures listed in section 5 are selected to support and facilitate a range of necessary changes, primarily:

- increased transparency, e.g. in terms of textile flows and data collection

- increased active life time of textile products, i.e. how long the textile products are used in practice

- changed consumer behaviour for textile products, e.g. (active) life time, collective use, reuse and discard behaviour

- increased attractiveness of collection, e.g. consumer convenience as well as trust and reliability in collection

- increased collection of used textiles

- introduced/increased services for (certified) de-branding of corporate textiles for recycling in the Nordic region

- increased reuse, particularly in the Nordic region

- increased and improved sorting of collected textiles

- improved management of used textile and textile waste flows for more coordinated and efficient handling

- increased recycling, particularly in the Nordic region

- increased share of textile-to-textile recycling

- increased market for recycled textiles

- reduced use of toxic compounds in textiles. 



\section{Policy measures facilitating change}

Based on the targets and necessary changes reflected on in sections 3 and 4, this section lists a selected set of policy measures, which are considered important and relevant in order to achieve improvements in collection, sorting, reuse and recycling of textiles in the Nordic region. The suggested policy measures cover both Nordic, national as well as local/regional levels of implementation. In addition, supporting measures for a harmonised and efficient implementation on Nordic level are listed in section 6.

\subsection{Policy measures considered}

In the development of the Nordic Strategy, initially a large pool of potential policy measures was considered. This pool is a collection of policy measures reflected on in the development of the scenarios in the project as well as experiences from the two NCM financed projects The Nordic textile reuse and recycling commitment and An extended producer responsibility (EPR) system and new business models to increase reuse and recycling of textiles in the Nordic region.

The policy measures considered include measures which both focus on increasing collection, reuse, collective use, recycling and prolonged active lifetime as well as a range of more "overarching" measures. The full list of policy measures, which have been under consideration in the development of the Nordic Strategy, is presented in Annex C.

\subsection{Evaluation and selection of policy measures}

All policy measures listed in Annex C were evaluated regarding:

- Type of policy measure.

- National or Nordic measure.

- Priority to reuse. 
- Expected timeline for implementation.

- Impacts on the necessary changes defined in section 4 .

- Possibility to increase requirements.

- Effects on different actors in the value chain.

The evaluation gave a short overview of the various characteristics of the policy measures, as well as of their main effects. It enabled a comparison of the policy measures that was used to make sure that complementing measures with regard to impacts on the necessary changes as well as effects on different actors in the value chain were selected.

In order to establish a recommendation for a relevant set of policy measures, four main priorities for the policy package were identified according to the project description as well as the suggested strategy:

1. Coverage of all necessary changes defined in section 4 .

2. Priority to reuse.

3. Possibility to increase requirements.

4. Effects on different actors in the value chain.

In the Nordic Strategy fourteen policy measures are suggested. The policy measures are considered to cover all necessary changes as defined in section 4, give priority to reuse as well as giving the possibility to increase requirements in several cases. The policy measures are divided into four different sections as listed in the following. The policy measures are shortly described in section 5.3.

\subsubsection{The Nordic Commitment}

The Nordic Commitment (see the documents "Voluntary Commitment", "Code of conduct for management of used textiles", "Certification and system operation" and "Implementation and operation guidelines" developed in the project The Nordic textile reuse and recycling commitment) can be separated into four different parts:

1. Launch of the Nordic Commitment.

2. Expansion of the Nordic Commitment to include de-branding services.

3. Engagement of municipalities in the Nordic Commitment.

4. Further development of the Nordic Commitment to more actively involve and include textile producers. 


\subsubsection{Measures supporting increased collection of textiles}

- Obligation for municipalities to secure that collection containers for textiles are available at all (municipal) recycling centres.

- Obligation to collect used textiles from public activities and public businesses.

- Introduction of a voluntary commitment for private companies to collect used textiles.

\subsubsection{Measures supporting new business models}

- Evaluation of business models in the field of collective use, reuse and prolonged (active) lifetime of textiles.

- Government funding for start-ups in the field of collective use, reuse and prolonged (active) lifetime of textiles.

\subsubsection{Other supporting measures}

- Consumer information campaign.

- Nordic Task Force for the Higg index. ${ }^{2}$

- Public procurement for reuse of textiles and textiles with recycled content.

- Investigation of the need for and potentials of establishing an (automatic) sorting facility in the Nordic region.

- Financial assistance for establishing one chemical recycling facility on an industrial scale in the Nordic region.

\subsection{Description of selected policy measures}

In the following, the fourteen different policy measures and initiatives are presented in short. For each measure the type of the measure, affected actors and necessary changes are described as well as potential options for increasing the requirements. This allows a short overview of the suggested mix of policy measures as well as of each of their individual contribution to the Nordic Strategy.

${ }^{2}$ See description of Higg index in section 5.3. 
For further descriptions and discussions of each of the individual initiatives and measures, please refer to the discussions and results presented in the projects Towards a Nordic textile strategy - Collection, sorting, reuse and recycling of textiles as well as An extended producer responsibility (EPR) system and new business models to increase reuse and recycling of textiles in the Nordic region.

\begin{tabular}{|c|c|}
\hline \multicolumn{2}{|c|}{ 1. Launch of the Nordic Commitment } \\
\hline Short description & $\begin{array}{l}\text { The Nordic Commitment was developed in the project The Nordic textile reuse } \\
\text { and recycling commitment. The launch includes setting up, running and evaluat- } \\
\text { ing the Nordic Commitment, comprising a Voluntary Agreement }(\mathrm{VC}) \text { open for all } \\
\text { actors in the textile value chain as well as a Code of Conduct ( } \mathrm{CoC} \text { ) for all actors } \\
\text { engaged in collection, sorting, selling-for-reuse, recycling and waste manage- } \\
\text { ment of textiles and textile wastes. The Nordic Commitment also includes a } \\
\text { proposed methodology for calculating and reporting textile flows. }\end{array}$ \\
\hline Type of instrument & Voluntary commitment. \\
\hline Main actors affected & $\begin{array}{l}\text { Producers, importers, consumers (private consumers), private companies, } \\
\text { collectors, sorters, recyclers, traders, municipalities, other public entities and } \\
\text { waste management companies. }\end{array}$ \\
\hline $\begin{array}{l}\text { Main affected necessary } \\
\text { changes }\end{array}$ & $\begin{array}{l}\text { Increased transparency, attractiveness of collection, reuse and recycling as well } \\
\text { as possibly increased collection, improved management of textile waste, } \\
\text { changed consumer (private and/or corporate) behaviour and in- } \\
\text { creased/improved sorting. }\end{array}$ \\
\hline $\begin{array}{l}\text { Options for increasing } \\
\text { requirements }\end{array}$ & $\begin{array}{l}\text { Yes, conditions could be revised and engagement in the Nordic Commitment } \\
\text { could be made mandatory in order to get permit to collect textiles. }\end{array}$ \\
\hline $\begin{array}{l}\text { Key actors for implemen- } \\
\text { tation }\end{array}$ & The NCM/NAG and a Nordic coordinating body for textiles, national governments. \\
\hline \multicolumn{2}{|c|}{ 2. Expansion of the Nordic Commitment to include de-branding services } \\
\hline Short description & $\begin{array}{l}\text { Secured de-branding services, i.e. removal of names, logos and other identifia- } \\
\text { ble material, are needed for most textile waste deriving from corporate con- } \\
\text { sumption. De-branding is already a part of the "Implementation and operation } \\
\text { guidelines" in the Nordic Commitment. However, since it is not specifically } \\
\text { mentioned in the VC and the CoC it is considered important to include as a } \\
\text { support to the Nordic Strategy. }\end{array}$ \\
\hline Type of instrument & Voluntary commitment. \\
\hline Main actors affected & $\begin{array}{l}\text { Consumers (corporate consumers), waste management companies (de-branding } \\
\text { services), recyclers, traders and recyclers. }\end{array}$ \\
\hline $\begin{array}{l}\text { Main affected necessary } \\
\text { changes }\end{array}$ & $\begin{array}{l}\text { Increased attractiveness of collection, increased collection, increased de- } \\
\text { branding, improved management of textile flows, changed consumer behaviour } \\
\text { and increased reuse and recycling. }\end{array}$ \\
\hline $\begin{array}{l}\text { Options for increasing } \\
\text { requirements }\end{array}$ & No. \\
\hline $\begin{array}{l}\text { Key actors for implemen- } \\
\text { tation }\end{array}$ & $\begin{array}{l}\text { The NCM/NAG and a Nordic coordinating body for textiles, national governments } \\
\text { (incl. potential funding), entrepreneurs interested in engaging and applying new } \\
\text { business opportunities within the field of textiles and textile wastes. }\end{array}$ \\
\hline
\end{tabular}




\begin{tabular}{ll}
\hline $\begin{array}{l}\text { 3. Engagement of municipalities in the Nordic Commitment } \\
\text { Short description }\end{array}$ & $\begin{array}{l}\text { Municipalities have a central role in the collection of consumer textiles. A more } \\
\text { clear engagement of municipalities as part of the Nordic Commitment would } \\
\text { contribute to increasing reuse and recycling of textiles collected by municipalities } \\
\text { as well as creating pressure on other actors to sign the Nordic Commitment. }\end{array}$ \\
$\begin{array}{l}\text { Type of instrument } \\
\text { Main actors affected }\end{array}$ & $\begin{array}{l}\text { Municipalities, collectors, consumers (private consumers), sorters, recyclers, traders. } \\
\text { Main affected necessary commitment. } \\
\text { changes }\end{array}$ \\
$\begin{array}{l}\text { Increased transparency, reuse and recycling. } \\
\text { Options for increasing } \\
\text { requirements }\end{array}$ \\
$\begin{array}{l}\text { Key actors for imple- } \\
\text { mentation }\end{array}$ \\
\hline
\end{tabular}

4. Further development of the Nordic Commitment to more actively involve and include textile producers

Short description This measure includes defining requirements for producers in the Nordic Commitment, e.g. regarding modes of collection and collection levels as well as design and production for increased active lifetime, reuse and recycling. This further development of the Nordic Commitment could serve as a first step in creating prerequisites for a voluntary system for extended producer responsibility (EPR) and, potentially, even a mandatory EPR.

Type of instrument Voluntary commitment.

Main actors affected Producers, retailers and importers.

Main affected necessary Increased transparency, active lifetime, attractiveness of collection, collection, changes reuse, recycling and share of textile-to-textile recycling.

Options for increasing Yes, could be made mandatory.

requirements

Key actors for imple- $\quad$ The NCM/NAG and a Nordic coordinating body for textiles, national governments, mentation

The NCM/NAG and a Nordic coordinating body for textiles, national governments,
entrepreneurs interested in engaging and applying new business opportunities within the field of textiles and textile wastes. 


\begin{tabular}{|c|c|}
\hline \multicolumn{2}{|c|}{$\begin{array}{l}\text { 5. Obligation for municipalities to secure that collection containers for textiles are available at all } \\
\text { (municipal) recycling centres }\end{array}$} \\
\hline Short description & $\begin{array}{l}\text { Municipalities should be encouraged to seek cooperation with existing and/or } \\
\text { local initiatives for collection and reuse of textiles. Municipalities should also be } \\
\text { encouraged to secure collection containers for textiles at additional places. }\end{array}$ \\
\hline Type of instrument & Regulatory instrument. \\
\hline Main actors affected & Municipalities, consumers (private consumers), sorters and recyclers. \\
\hline $\begin{array}{l}\text { Main affected necessary } \\
\text { changes }\end{array}$ & Increased collection, changed consumer behaviour and attractiveness of collection. \\
\hline $\begin{array}{l}\text { Options for increasing } \\
\text { requirements }\end{array}$ & No. \\
\hline $\begin{array}{l}\text { Key actors for imple- } \\
\text { mentation }\end{array}$ & National governments. \\
\hline
\end{tabular}

\section{Obligation to collect used textiles from public activities and public businesses}

Short description Public institutions represent e.g. public transport, police and other authorities, health and social care, prisons and armed forces.

The collection should be carried out by certified actors, i.e. actors engaged in the Nordic Commitment. This could include private companies, charity organisations or municipalities. Secured de-branding would be an important operation in order for the collection to be attractive.

Type of instrument

Regulatory instrument.

Main actors affected

Municipalities, public entities, collectors, sorters, recyclers.

Main affected necessary changes

Increased attractiveness of collection, increased reuse, changed consumer behaviour, recycling as well as possible increased share of textile-to-textile recycling and improved management of textile waste.

Options for increasing No.

requirements

Key actors for imple- National governments, municipalities.

mentation 


\begin{tabular}{ll}
\hline 7. Introduction of voluntary commitment for private companies to collect used textiles \\
\hline Short description & $\begin{array}{l}\text { Significant textile waste flows are generated in private companies, such as e.g. } \\
\text { transport companies, security companies, restaurants, hotels etc. Collection from } \\
\text { those places will create a clean and homogenous waste which is easier to recycle. } \\
\text { The voluntary commitment should include requirements to only allow certified } \\
\text { actors, i.e. actors engaged in the Nordic Commitment. Secured de-branding is } \\
\text { needed to prevent the misuse of identifiable material. }\end{array}$ \\
$\begin{array}{l}\text { Type of instrument } \\
\text { Main actors affected }\end{array}$ & $\begin{array}{l}\text { Poluntary commitment. } \\
\text { (de-branding services). }\end{array}$ \\
$\begin{array}{l}\text { Main affected necessary } \\
\text { changes }\end{array}$ & $\begin{array}{l}\text { Increased attractiveness of collection, increased reuse and recycling, changed } \\
\text { consumer behaviour as well as possibly also increased share of textile-to-textile } \\
\text { recycling and improved management of this type of textile waste. }\end{array}$ \\
$\begin{array}{l}\text { Options for increasing } \\
\text { requirements }\end{array}$ & $\begin{array}{l}\text { Yes, could be made mandatory. } \\
\text { Key actors for imple- } \\
\text { mentation }\end{array}$ \\
\hline
\end{tabular}

\section{Evaluation of business models in the field of collective use, reuse and prolonged (active) lifetime} of textiles

\begin{tabular}{ll}
\hline $\begin{array}{l}\text { Short description } \\
\text { One objective of the Nordic Strategy is to change consumer behaviour regarding } \\
\text { use of textiles. Several alternative business models involving collective use, reuse } \\
\text { and prolonged (active) lifetime of textiles have been identified. As a prerequisite } \\
\text { for efficient support for such business models and initiatives (including e.g. } \\
\text { funding, see next point), a limited number of promising models should be as- } \\
\text { sessed in order to reveal their potentials to change consumer behaviour. }\end{array}$ \\
$\begin{array}{l}\text { Type of instrument } \\
\begin{array}{l}\text { Main actors affected } \\
\text { Main affected necessary } \\
\text { changes }\end{array}\end{array}$ \\
$\begin{array}{l}\text { Options for increasing } \\
\text { requirements }\end{array}$ \\
$\begin{array}{l}\text { Key actors for imple- } \\
\text { mentation }\end{array}$
\end{tabular}




\begin{tabular}{|c|c|}
\hline \multicolumn{2}{|c|}{$\begin{array}{l}\text { 9. Government funding for start-ups in the field of collective use, reuse and prolonged (active) lifetime } \\
\text { of textiles }\end{array}$} \\
\hline Short description & $\begin{array}{l}\text { A funding pool for promising initiatives and start-up investments in new and } \\
\text { alternative business models regarding collective use, reuse and prolonged (active) } \\
\text { lifetime of textiles. }\end{array}$ \\
\hline Type of instrument & Market based instrument. \\
\hline Main actors affected & $\begin{array}{l}\text { Consumers (private and corporate), private companies and waste management } \\
\text { companies. }\end{array}$ \\
\hline $\begin{array}{l}\text { Main affected necessary } \\
\text { changes }\end{array}$ & Increased reuse and active lifetime. \\
\hline $\begin{array}{l}\text { Options for increasing } \\
\text { requirements }\end{array}$ & Yes, funding could be prolonged and/or increased. \\
\hline $\begin{array}{l}\text { Key actors for imple- } \\
\text { mentation }\end{array}$ & National governments. \\
\hline
\end{tabular}

\section{Consumer information campaign}

Short description

Changing consumer behaviour such as consumption and use of textile products as well as discarding of used textiles and textile wastes is considered crucial. Some of the informative aspects are covered in the Nordic Commitment however, an accompanying consumer information campaign e.g. regarding care instructions, collective use, reuse and pro-longed active lifetime of textiles as well as their related environmental impacts is considered necessary.

Type of instrument Informative instrument.

Main actors affected Consumers.

Main affected necessary changes

Increased active lifetime, changed consumer behaviour, increased collection, reuse and recycling, depending on the aim of the campaign.

Options for increasing No.

requirements

Key actors for implementation

The NCM/NAG and a Nordic coordinating body for textiles, national governments, municipalities. 


\section{Nordic Task Force for the Higg index}

Short description

Main actors affected

Main affected necessary changes

Options for increasing requirements

Key actors for implementation
It is suggested to promote and develop the Higg index via a task force effort. The Higg index is an indicator based assessment tool which asks practice-based, qualitative questions to assess the environmental sustainability performance of a product and drive behaviour for improvement. In addition to the promotion and development, special attention should be given to increase the effectiveness of the labelling, i.e. the effect it has on consumer choices/behaviour.

Informative instrument.

Producers, retailer, importers and consumers.

Reduced use of toxic compounds and increased active lifetime.

Yes, criteria could (and should) be revised continuously.

The NCM/NAG and/or a Nordic coordinating body for textiles.

12. Public procurement for reuse of textiles and textiles with recycled content

$\begin{array}{ll}\begin{array}{l}\text { Short description } \\ \text { Type of instrument }\end{array} & \begin{array}{l}\text { As one contribution to increasing the demand for used textiles and textiles with } \\ \text { recycled content, these aspects should be included in public procurement guide- } \\ \text { lines and rules. }\end{array} \\ \begin{array}{l}\text { Main actors affected } \\ \begin{array}{l}\text { Main affected necessary } \\ \text { changes }\end{array}\end{array} & \begin{array}{l}\text { Producers, importers, recyclers, municipalities and other public authorities. } \\ \text { as possible increased share of textile-to-textile recycling. }\end{array} \\ \begin{array}{l}\text { Options for increasing } \\ \text { requirements }\end{array} & \begin{array}{l}\text { Yes, the criteria in the developed guidelines (e.g. percentage of recycled materials } \\ \text { in textiles) can be sharpened. }\end{array} \\ \begin{array}{l}\text { Key actors for imple- } \\ \text { mentation }\end{array} & \text { National governments, local/regional governments. }\end{array}$




\begin{tabular}{|c|c|}
\hline \multicolumn{2}{|c|}{$\begin{array}{l}\text { 13. Investigation of the need for and potentials of establishing an (automatic) sorting facility in the } \\
\text { Nordic region }\end{array}$} \\
\hline Short description & $\begin{array}{l}\text { There is a need for investigating prerequisites and potentials for improving the } \\
\text { infrastructure for sorting (and channelling) of textile flows within the Nordic } \\
\text { region. }\end{array}$ \\
\hline Type of instrument & Evaluation. \\
\hline Main actors affected & Sorters, collectors, recyclers. \\
\hline $\begin{array}{l}\text { Main affected necessary } \\
\text { changes }\end{array}$ & $\begin{array}{l}\text { Increased and improved sorting of collected textiles and (potentially) improved } \\
\text { management of used textile and textile waste flows for more coordinated and } \\
\text { efficient handling. }\end{array}$ \\
\hline $\begin{array}{l}\text { Options for increasing } \\
\text { requirements }\end{array}$ & No. \\
\hline $\begin{array}{l}\text { Key actors for imple- } \\
\text { mentation }\end{array}$ & The NCM/NAG and/or a Nordic coordinating body for textiles. \\
\hline
\end{tabular}

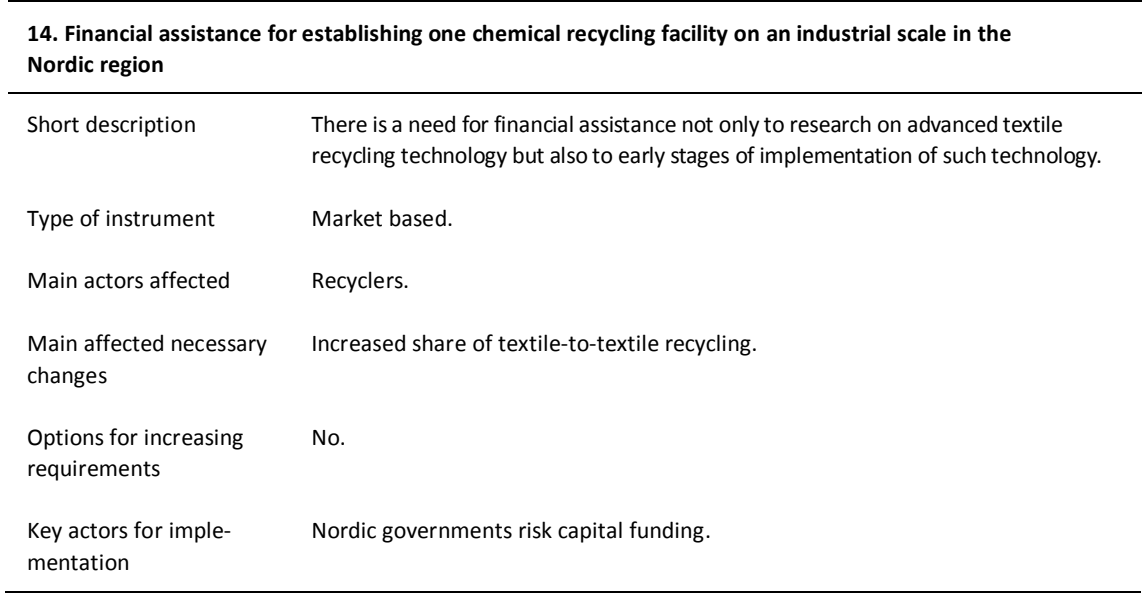

\subsection{Assessment of the selected policy mix}

\subsubsection{Mix of policy measures}

The selected policy mix includes five voluntary measures (measures 1,2 , 3,4 and 7), three regulatory measures (measures 5, 6 and 12), two evaluation measures (measures 8 and 13), two informative measures (measures 10 and 11) and two market based measures (measures 9 and 14).

There are no specific administrative measures in the Nordic Strategy, however the obligation for municipalities to secure that collection containers for used textiles are available (measure 5) could e.g. include administrative measures as to review of the rules on establishment of col- 
lection containers. Similar administrative measures will probably also be necessary for implementing several of the other measures.

\subsubsection{Coverage of the main priorities}

The selection of policy measures is judged to secure the four main priorities identified in section 5.2.

Eight of the selected measures (measures 1, 2, 3, 6, 7, 9, 10 and 12) are judged to prioritise reuse before recycling of textiles to some extent. For seven of the measures (measures 1, 3, 4, 7, 9, 11 and 12) the requirements can be increased ("tightened"). Further, for the two investigations (8 and 13), the results can be used for introducing new initiatives.

The selected measures cover all necessary changes defined in section 4 . Table 1 provides an overview on what necessary changes the individual policy measures are expected to contribute to. The selected measures also impact different actors in the value chain.

Table 2 provides an overview of the main actors affected by the suggested measures. 
Table 1. Overview of what necessary changes the individual policy measures are expected to contribute to

\begin{tabular}{|c|c|c|c|c|c|c|c|c|c|c|c|c|c|}
\hline & $\begin{array}{l}\text { Increased } \\
\text { transpa- } \\
\text { rency }\end{array}$ & $\begin{array}{l}\text { Increased } \\
\text { (active) } \\
\text { lifetime }\end{array}$ & 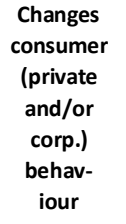 & $\begin{array}{l}\text { Increased } \\
\text { attracti- } \\
\text { veness of } \\
\text { collection }\end{array}$ & $\begin{array}{l}\text { Increa- } \\
\text { sed } \\
\text { collecti- } \\
\text { on }\end{array}$ & $\begin{array}{c}\text { Increased } \\
\text { de- } \\
\text { branding }\end{array}$ & $\begin{array}{l}\text { Increased } \\
\text { reuse }\end{array}$ & $\begin{array}{l}\text { Increased } \\
/ \text { im- } \\
\text { proves } \\
\text { sorting }\end{array}$ & $\begin{array}{l}\text { Improves } \\
\text { man- } \\
\text { agement } \\
\text { of textile } \\
\text { flows }\end{array}$ & $\begin{array}{l}\text { Increased } \\
\text { recycling }\end{array}$ & $\begin{array}{l}\text { Increased } \\
\text { textile- } \\
\text { to-textile } \\
\text { recycling }\end{array}$ & $\begin{array}{l}\text { Increased } \\
\text { market } \\
\text { for } \\
\text { recycled } \\
\text { textiles }\end{array}$ & $\begin{array}{l}\text { Reduced } \\
\text { use of } \\
\text { toxic } \\
\text { com- } \\
\text { pounds } \\
\text { in tex- } \\
\text { tiles }\end{array}$ \\
\hline $\begin{array}{l}\text { 1. Launch of the Nordic } \\
\text { Commitment }\end{array}$ & $x$ & & $x$ & $x$ & $x$ & & $x$ & $x$ & $x$ & $x$ & & & \\
\hline $\begin{array}{l}\text { 2. Expansion of Nordic } \\
\text { Commitment to } \\
\text { include de-branding }\end{array}$ & & & $x$ & & $x$ & $x$ & $x$ & & $x$ & $x$ & & & \\
\hline $\begin{array}{l}\text { 3. Engagement of } \\
\text { municipalities in the } \\
\text { Nordic Commitment }\end{array}$ & $x$ & & $x$ & $x$ & $x$ & & $x$ & $x$ & & $x$ & & & \\
\hline $\begin{array}{l}\text { 4. Development of } \\
\text { Nordic Commitment to } \\
\text { involve producers }\end{array}$ & $x$ & & & $x$ & $x$ & & $x$ & & & $x$ & $x$ & & \\
\hline $\begin{array}{l}\text { 5. Obligation of } \\
\text { municipalities to } \\
\text { secure collection } \\
\text { containers }\end{array}$ & & & $x$ & $x$ & $x$ & & $x$ & & & $x$ & & & \\
\hline $\begin{array}{l}\text { 6. Obligation to collect } \\
\text { textiles from public } \\
\text { activities }\end{array}$ & & & $x$ & $x$ & $x$ & $x$ & $x$ & & $x$ & $x$ & $x$ & & \\
\hline $\begin{array}{l}\text { 7. Voluntary commit- } \\
\text { ment for collection of } \\
\text { corporate textiles }\end{array}$ & & & $x$ & $x$ & $x$ & $x$ & $x$ & & $x$ & $x$ & $x$ & & \\
\hline
\end{tabular}




\begin{tabular}{|c|c|c|c|c|c|c|c|c|c|c|c|c|c|}
\hline & $\begin{array}{l}\text { Increased } \\
\text { transpa- } \\
\text { rency }\end{array}$ & $\begin{array}{l}\text { Increased } \\
\text { (active) } \\
\text { lifetime }\end{array}$ & $\begin{array}{l}\text { Changes } \\
\text { consumer } \\
\text { (private } \\
\text { and/or } \\
\text { corp.) } \\
\text { behav- } \\
\text { iour }\end{array}$ & $\begin{array}{l}\text { Increased } \\
\text { attracti- } \\
\text { veness of } \\
\text { collection }\end{array}$ & $\begin{array}{l}\text { Increa- } \\
\text { sed } \\
\text { collecti- } \\
\text { on }\end{array}$ & $\begin{array}{l}\text { Increased } \\
\text { de- } \\
\text { branding }\end{array}$ & $\begin{array}{l}\text { Increased } \\
\text { reuse }\end{array}$ & $\begin{array}{l}\text { Increased } \\
/ \text { im- } \\
\text { proves } \\
\text { sorting }\end{array}$ & $\begin{array}{l}\text { Improves } \\
\text { man- } \\
\text { agement } \\
\text { of textile } \\
\text { flows }\end{array}$ & $\begin{array}{l}\text { Increased } \\
\text { recycling }\end{array}$ & $\begin{array}{l}\text { Increased } \\
\text { textile- } \\
\text { to-textile } \\
\text { recycling }\end{array}$ & $\begin{array}{l}\text { Increased } \\
\text { market } \\
\text { for } \\
\text { recycled } \\
\text { textiles }\end{array}$ & $\begin{array}{l}\text { Reduced } \\
\text { use of } \\
\text { toxic } \\
\text { com- } \\
\text { pounds } \\
\text { in tex- } \\
\text { tiles }\end{array}$ \\
\hline $\begin{array}{l}\text { 8. Evaluation of } \\
\text { alternative business } \\
\text { models }\end{array}$ & & $x$ & $x$ & & & & $x$ & & & & & & \\
\hline $\begin{array}{l}\text { 9. Government funding } \\
\text { for start-ups alterna- } \\
\text { tive businesses }\end{array}$ & & $x$ & $x$ & & & & $x$ & & & $x$ & & $x$ & \\
\hline $\begin{array}{l}\text { 10. Consumer informa- } \\
\text { tion campaign }\end{array}$ & & $x$ & $x$ & & $x$ & & $x$ & & & $x$ & & $x$ & \\
\hline $\begin{array}{l}\text { 11. Nordic Task Force } \\
\text { for the Higg index }\end{array}$ & & $x$ & & & & & & & & & & & $x$ \\
\hline $\begin{array}{l}\text { 12. Public procure- } \\
\text { ment reuse/recycled } \\
\text { content }\end{array}$ & & $x$ & $x$ & & & & $x$ & & & $x$ & $x$ & $x$ & \\
\hline $\begin{array}{l}\text { 13. Evaluation of } \\
\text { potentials for automat- } \\
\text { ic sorting facility }\end{array}$ & & & & & & & $x$ & $x$ & $x$ & $x$ & $x$ & & \\
\hline $\begin{array}{l}\text { 14. Financial assistance } \\
\text { for establishing chemi- } \\
\text { cal recycling }\end{array}$ & & & & & & & & & & $x$ & $x$ & $x$ & \\
\hline
\end{tabular}


Table 2. Overview over stakeholders affected by the suggested policy measures in the Nordic Strategy

\begin{tabular}{|c|c|c|c|c|c|c|c|c|}
\hline & $\begin{array}{l}\text { Fashion and } \\
\text { textile industry }\end{array}$ & Consumers & $\begin{array}{c}\text { Collection } \\
\text { companies and } \\
\text { organisations }\end{array}$ & $\begin{array}{l}\text { Sorting compa- } \\
\text { nies and } \\
\text { organisations }\end{array}$ & $\begin{array}{c}\text { Reuse compa- } \\
\text { nies and } \\
\text { organisations }\end{array}$ & $\begin{array}{c}\text { Recycling } \\
\text { companies and } \\
\text { organisations }\end{array}$ & Municipalities & Entrepreneurs \\
\hline 1. Launch of the Nordic Commitment & $x$ & $x$ & $x$ & $x$ & $x$ & $x$ & $x$ & $\mathrm{x}$ \\
\hline $\begin{array}{l}\text { 2. Expansion of Nordic Commitment to } \\
\text { include de-branding }\end{array}$ & & $x$ & & & $x$ & $x$ & & $x$ \\
\hline $\begin{array}{l}\text { 3. Engagement of municipalities in the } \\
\text { Nordic Commitment }\end{array}$ & & $x$ & $x$ & $x$ & $x$ & $x$ & $x$ & \\
\hline $\begin{array}{l}\text { 4. Development of Nordic Commitment } \\
\text { to involve producers }\end{array}$ & $x$ & & & & & & & \\
\hline $\begin{array}{l}\text { 5. Obligation of municipalities to secure } \\
\text { collection containers }\end{array}$ & & $x$ & $x$ & $x$ & $x$ & $x$ & $\mathrm{x}$ & \\
\hline $\begin{array}{l}\text { 6. Obligation to collect textiles from } \\
\text { public activities }\end{array}$ & & $x$ & $\mathrm{x}$ & $\mathrm{x}$ & $x$ & $x$ & $x$ & $\mathrm{x}$ \\
\hline $\begin{array}{l}\text { 7. Voluntary commitment for collection } \\
\text { of corporate textiles }\end{array}$ & & $x$ & $x$ & $x$ & $x$ & $x$ & $x$ & $x$ \\
\hline $\begin{array}{l}\text { 8. Evaluation of alternative business } \\
\text { models }\end{array}$ & & $x$ & & & $x$ & & & $x$ \\
\hline $\begin{array}{l}\text { 9. Government funding for start-ups } \\
\text { alternative businesses }\end{array}$ & & $x$ & & & $x$ & & & $x$ \\
\hline 10. Consumer information campaign & & $x$ & & & & & & \\
\hline 11. Nordic Task Force for the Higg index & $x$ & $x$ & & & & & & \\
\hline $\begin{array}{l}\text { 12. Public procurement reuse/recycled } \\
\text { content }\end{array}$ & $x$ & $x$ & & & $x$ & & $x$ & \\
\hline $\begin{array}{l}\text { 13. Evaluation of potentials for automat- } \\
\text { ic sorting facility }\end{array}$ & & & $x$ & $x$ & $x$ & $x$ & & $x$ \\
\hline $\begin{array}{l}\text { 14. Financial assistance for establishing } \\
\text { chemical recycling }\end{array}$ & $x$ & & $x$ & $\mathrm{x}$ & $x$ & $x$ & & $x$ \\
\hline
\end{tabular}




\subsubsection{Potential evolvement of the policy mix}

If the defined targets for improved collection, reuse and recycling of textiles as sketched out in section 3 are not met, seven of the total 13 measures in the Nordic Strategy include options to increase the requirement. As an example, the Nordic Commitment (including the Voluntary Commitment and the Code of Conduct) could be made mandatory. With further development of the Nordic Commitment to more actively include producers (measure 4) it could serve as a first step towards a voluntary system for extended producer responsibility (EPR). In case the targets are not met under these conditions, such a voluntary EPR system could potentially be transformed into a mandatory system.

The Nordic Strategy focuses primarily on post-consumer textiles, both from private and corporate consumption. The Nordic Strategy could be expanded to include all textiles and textile wastes, e.g. also textiles and textile waste from importers, producers, wholesale and retail. These actors could then also be included in the Nordic Commitment as waste owners.

It is recommended that the Nordic Strategy is revised in 2020 at the latest. As a part of this revision, other or additional policy measures can be included. A selection of possible additional policy measures are listed in Annex D. 



\section{Supporting structures for implementation}

The Nordic Strategy includes common Nordic minimum targets for collection, reuse and recycling of used textiles as well as partly common policy measures to reach these targets. Supporting structures and measures are necessary for a harmonized and efficient implementation throughout the Nordic region. This includes e.g.

- Development of a common methodology for data collection regarding collected, reused and recycled textile flows as well as for calculation of target (and interim target) achievements.

- Annual publication of the level of target achievements for the Nordic countries respectively, accompanied by the current actions and initiatives carried out by the individual Nordic countries to fulfil the targets.

- Creation of a structure for Nordic cooperation within the field of textiles and textile wastes, including a forum - potentially under the umbrella of the NCM - with government officials from all Nordic countries. This forum should be used to discuss and decide on common issues such as e.g.

○ Methodologies for data collection and assessment.

- Communication activities on a Nordic level.

- Policy measures (or combination of measures) on a Nordic level.

- Exchange of best practices and other relevant information.

- (Strategic) coordination of Nordic textile flows in order to maximise reuse and recycling of collected textiles and to strengthen the position of Nordic actors selling textiles to European sorting and recycling facilities.

- Specification of needs for (strategic) common infrastructures for textiles recycling on a Nordic level. 



\section{Role of and impacts on stakeholders}

The Nordic Strategy will impact stakeholders throughout the whole value chain. As the strategy primarily includes soft policy measures, it is expected to provide most stakeholders with opportunities rather than limitations.

\subsection{Fashion and textile industry}

Increased reuse of clothing and textiles might result in new challenges for high street retailers and the fashion industry as the demand for new textiles may decrease. Companies that do not adjust and complement their business models might therefore be negatively affected by the increased circulation of reused textiles. With increased focus on environment and resource efficiency by consumers, it will be a competitive strength in the market for companies that can market textiles and clothing based on recycled materials with documentation of better environmental performance.

By engaging in the Nordic Commitment, the Higg index and other commitments, individual companies can increase their revenue through eco-branding. It is expected that the fashion and textile industry can improve their competitiveness by using more environmental friendly materials, which should be documented by Environmental Product Declarations (EPDs) and Ecolabels.

Increased recycling of textiles results in more recycled textiles available for the textile and fashion industry for the production of new textiles. With increased amounts being recycled, the Nordic industry can rely more on "local" and more environmentally sound materials. With the targets of increasing the share of reused, recycled and textile-totextile recycled textiles on the market, sales of products from virgin materials could possibly be expected to decrease in the long-term.

Due to the increasing public awareness of the importance to collect, reuse and recycle used textiles, the potential engagement in the Nordic Commitment and potential increased value of used textiles, companies 
and retailers in the fashion industry might decide to start collecting textile at their stores. However, the involvement of retailers in collection of used textiles is primarily expected to enhance recycling of textiles, not necessarily reuse.

\subsection{Consumers}

From a consumer's point of view, the Nordic Strategy will both contribute to increased transparency and access to information as well as increased attractiveness of textile collection.

The launch of the Nordic Commitment, consumer information campaigns and increased use of textile labelling will provide consumers with information e.g. regarding environmental impacts of textiles, durability of textiles, alternatives to buying new textiles, how and where to leave textiles for reuse and recycling as well as information regarding what happens to the collected textiles.

Along with the launch of the Nordic Commitment, the potential engagement of municipalities in the Nordic Commitment as well as the obligation for municipalities to collect used textiles at all (municipal) recycling centres will contribute to making textile collection more attractive and user friendly for consumers; e.g. by increased number of certified collection points.

By focusing on lifetime of textiles and prioritizing reuse over recycling, the increasingly popular second hand market is expected to expand. Additionally, the Nordic Strategy is expected to lead to a better availability of new products based on recycled materials.

\subsection{Collection companies and organisations}

The Nordic Strategy, and particularly the launch of the Nordic Commitment, is expected to strengthen the role of legitimate actors in collection as only they can be part of the commitment.

With significantly increased volumes of collected textiles it is expected that the market will need and allow for additional actors collecting for reuse and recycling (e.g. private companies, retailers and municipalities). Currently, charitable organisations have a dominating role in textile collection throughout the Nordic region. Charitable organisations promote reuse over recycling and have a direct link to the national markets through their stores which e.g. municipalities and private compa- 
nies generally do not possess. Measures increasing and improving the collection of textiles should therefore strive for active integration with the existing collection systems of charitable organisations.

Obliging municipalities to secure collection containers at all (municipal) recycling centres might in some cases and to some extent result in municipalities taking over markets currently operated by charitable organisations. Municipalities should be encouraged to cooperate with organisations operating as members of the Nordic Commitment. It is expected that a relatively large number of charitable organisations will join the Nordic Commitment. This would allow new and/or continued cooperation between e.g. charitable organisations and municipalities regarding textile collection.

\subsection{Sorting companies and organisations}

The Nordic Strategy is expected to increase the amounts of textiles for sorting. The Nordic Commitment includes criteria for sorting, including targets for reuse and recycling. Participation in the Nordic Commitment would benefit sorting companies and organisations by ensuring them business from companies higher up the value chain. As a result, legitimate companies and organisations engaged in sorting of used textile are expected to benefit from the Nordic Strategy and the launch of the Nordic Commitment. This would result in creation of green jobs and increased revenues.

By investigating the potentials of establishing a sorting facility in the Nordic region the Nordic Strategy might also pave the road for new actors in the sorting industry.

\subsection{Reuse companies and organisations}

The companies and organisations engaged in reuse in the Nordic countries are mostly charitable organisations and retro stores. These companies will benefit from the increased amounts of reused textile available in terms of increased possibilities to sell textiles for reuse in the Nordic countries and abroad. Large increases in available textiles for reuse might impact prices for reusable textiles. 


\subsection{Recycling companies and organisations}

The Nordic Strategy will improve the market conditions for recycled products through public procurement (pulling the recycling market). At the same time the amount of material available for recycling will increase along with the increased collection and sorting of textiles defined in the targets in section 3 (pushing the recycling market). It is expected that the Nordic Strategy will create green jobs and higher profits within the recycling sector.

Companies and organisations would benefit from joining the Nordic Commitment as an increasing number of actors are expected to define this as a prerequisite for handling the collected textiles.

Financial assistance for chemical recycling could, together with measures increasing collection and thereby creating a larger resource base for a new industry, become a game changer for recycling companies by reducing the risk of being the frontrunner in this area.

\subsection{Municipalities}

Six of the 13 measures included in the Nordic Strategy impacts municipalities directly. Three of them relate to the collection of textiles, which is expected to be the area where the Nordic Strategy will have the largest impact on municipalities. Municipalities often act as facilitators of textile; either by municipal collection of textiles or by granting permission for textile collection by private companies and charitable organisations. By engaging in the Nordic Commitment and/or by only granting permit for collection for actors in the Nordic Commitment municipalities would play an important role in contributing to a successful implementation of the Nordic Strategy. The obligation for municipalities to secure collection containers for textiles at all (municipal) recycling centres will either require new investments and increased operational costs for municipal collection (e.g. collection containers and service) or cooperation with companies and organisations collecting textiles. Cooperation with companies and organisations would not necessarily mean additional costs for the municipalities. It is in interest of the Nordic Strategy that cooperation only is entered with certified companies and organisations, i.e. companies and organisations acting under the umbrella of the Nordic Commitment. The obligation to collect used textiles for reuse and recycling from public activities and businesses require that the municipalities set up or contract an (internal) collection system for textiles. The 
municipalities can choose to both sort and sell these collected textiles themselves or to contract an external company or organisation to do this. Again, it is recommended that these textiles are handled by actors included in the Nordic Commitment. Depending on the chosen system and the revenues for the collected materials, municipalities might either face additional costs or revenues.

The municipalities need to develop/adopt/adjust and apply guidelines for public procurement of reuse textiles and textiles with recycled content. Depending on what textiles are procured (e.g. reused textiles or new textiles with recycled content), municipalities might face cost savings or additional costs. In an initial stage, there might be a lack of supply and choice of textiles with recycled content. The public procurement guidelines are expected to increase the demand for reused textiles and textiles with recycled content. As a result, however, it is expected that the supply of such products will increase.

Municipalities are expected to play a central role in consumer campaigns regarding textiles and textile wastes. They might also play a central role in the government funding for start-ups in the field of collective use, reuse and prolonged (active) lifetime. Both of these measures might lead to increased costs for municipalities, potentially shared with the national governments.

As more textiles are expected to be separately collected for reuse and recycling, decreasing volumes of textiles will be incinerated and landfilled in the most often municipally owned waste incinerators.

\subsection{Entrepreneurs}

The Nordic Strategy opens up for a range of increased and new business opportunities. It is expected to result in a more fertile ground for new businesses in the field of collective use, reuse and prolonged lifetime of textiles; both due to the funding of start-ups and because of potentially changed consumption patterns.

The expected increase in collection, sorting and recycling of textiles creates a demand for increasing operations of current actors as well as introduction of new actors in these markets. Another emerging business area is (certified) de-branding services for corporate textiles. 



\title{
8. Key actors for successful implementation of the Nordic Strategy
}

\begin{abstract}
Changes in production and consumption of textiles as well as changes in the handling of used textiles and textile wastes are necessary to reach the targets illustrated in section 3. Textile consumers play an obvious role in changing consumption patterns. They are also crucial for closing the textile material loops by handing used textiles and textile wastes to reuse and recycling instead of to waste management options resulting in incineration and landfill of textiles. The Nordic Strategy aims to enable the Nordic countries to work side by side in order to increase collection, reuse and recycling of textiles in a coordinated and harmonised way.

The project identified four main key actors for successful implementation of the Nordic Strategy:

- The NCM/NAG and a Nordic coordinating body for textiles.

- National governments.

- Municipalities.

- Entrepreneurs interested in engaging and applying new business opportunities within the field of textiles and textile wastes.
\end{abstract}

\subsection{The NCM/NAG and a Nordic coordinating body for textiles}

During the last years, the NCM and the NAG have initiated and funded several projects with the objective of improving collection, reuse and recycling of textiles and textile wastes. These projects and initiatives have substantially contributed to identifying the need for action as well as indicating possible courses of action for improved collection, reuse and recycling of textiles and textile wastes on a Nordic level. It is recommended that the NCM and the NAG continue to initiate activities within the textile field, e.g. as the already foreseen development of a Nordic Roadmap for sustainable textiles. 
It is also recommended that the NCM and the NAG make the most use of the results in the projects that have been carried out by following up on promising results and developments. Three examples of projects that with advantage could be supported by and carried out under the umbrella of the NCM and the NAG are explicitly mentioned in this strategy: The launch of the Nordic Commitment (measure 1), evaluation of business models in the field of collective use, reuse and prolonged (active) lifetime of textiles (measure section 8) and an investigation of the need for and potentials of establishing an (automatic) textile sorting facility in the Nordic region (measure 13).

The NCM and the NAG could also play a central role in developing minimum targets for collection, reuse and recycling of textiles (see section 3) as well as in establishing a structure for Nordic cooperation within the field of textiles and textile wastes (see section 6, point 3).

\subsection{National governments}

The national governments in the Nordic region play a central role in establishing Nordic minimum targets and in implementing them (or more ambitious targets) on a national level. They would be responsible for collecting and coordinating necessary data used for statistics and calculation of target achievements as well as for calculating and publishing target achievements.

Furthermore, the national governments would be responsible for developing and implementing (national) policy measures (or combinations of measures) to reach the set targets. Policy measures could potentially be developed in coordination with additional Nordic countries. Policy measures explicitly mentioned in this strategy include e.g. development and application of public procurement guidelines (measure 12) and national information campaigns (measure 10).

In order to secure effective work in and substantial results from the suggested structure for Nordic cooperation within the field of textiles and textile wastes (see section 6, point 3 ), the national governments should send officials with mandate to discuss and negotiate the issues addressed in the forum.

National governments can also through early high risk venture capital into textile-to-textile chemical recycling aid the transition from laboratory recycling to pilot and full scale recycling. 
Finally, the national governments play an important role in (financially) supporting start-ups in the area of de-branding, collective use, reuse and prolonged (active) lifetime (measure 9).

\subsection{Municipalities}

By engaging in the Nordic Commitment (measure 3), municipalities would significantly contribute to making the Nordic Commitment an effective measure and increasing the pressure for other actors involved in collection, reuse and recycling to also engage in the commitment.

The municipalities would be responsible for securing that textile containers are available at all (municipal) recycling centres and stations (measure 5). They would also be responsible for collecting used textiles from municipal operations (e.g. geriatric care, schools, municipal companies etc.) for reuse and recycling (measure 6). Finally, municipalities would have to develop and apply public procurement guidelines (measure 12).

\subsection{Entrepreneurs}

Entrepreneurs creating and applying new and alternative business models within the textile field could contribute to a successfully implemented strategy in terms of increasing collective use, reuse and prolonged (active) lifetime of textiles (measure 8).

They could also play an important role in improving waste management of textile wastes by creating new business opportunities and building new waste management infrastructures for sorting and de-branding of (corporate) textiles (measures 2 and 13). 

Prognosis for future amounts 



\section{Glossary}

\begin{tabular}{ll}
\hline Acronym & Full description \\
\hline CN & EU Combined Nomenclature \\
EUR & Euro \\
NACE & Statistical classification of economic activities in the European Community \\
NCM & Nordic Council of Ministers \\
SITC & Standard International Trade Classification \\
\hline
\end{tabular}





\section{Introduction}

In the development of a Nordic strategy for collection, sorting, reuse and recycling of textiles, a general overview of future amounts of textiles entering the material system is important. Making projections of future amounts of textiles available for collection, reuse and recycling enables better planning of future needs as well as how these needs can be met in an efficient way.

The objective for this subreport is to:

- describe current trends in textile import, production, consumption and waste generation

- provide prognoses for future amounts in the short term and medium term.

The findings of the subreport are divided into the following chapters:

- Chapter 3: Current trends in net import of new textiles.

- Chapter 4: Current trends in production of new textiles.

- Chapter 5: Current trends in textile waste management.

- Chapter 6: Prognosis of future net imports of new textiles.

- Chapter 7: Prognosis of future production of new textiles.

- Chapter 8: Prognosis for total consumption of new textiles.

- Chapter 9: Expected future amounts of used textiles potentially available for reuse and recycling.

- Chapter 10: Conclusions. 



\section{Scope}

The consumption of new textiles is regarded as the sum of the net import (import-export) and the production of new textiles in a country. Data have been collected from all Nordic countries based on statistics from the national statistical organisations. As far as possible, data for clothes as well as for household textiles (e.g. bed lines, blankets and curtains) were collected and analysed.

Statistics regarding foreign trade of products (import and export) are generally published in amounts (kg or tonnes). Statistics regarding production of textiles are generally published either as the value of the produced products (in Euro or national currency) or as the number of the produced products. This makes it difficult to compare foreign trade statistics with production statistics. As a result, the statistics and trends regarding net import of textiles and production of textiles are considered separately. These were subsequently combined in a prognosis for total consumption of new textiles in chapter 8 .

The amounts of textile waste generated in the Nordic countries 2010, 2011 or 2012 respectively were estimated and summarised in (Palm, et al., 2013) (see Table 3). This gives an overview of the current amounts of used textiles and textile wastes.

Table 3. Overview of used textiles and textile wastes from (Palm, et al., 2013)

\begin{tabular}{lccccc}
\hline & $\begin{array}{r}\text { Denmark } \\
(\mathbf{2 0 1 0 )}\end{array}$ & $\begin{array}{r}\text { Finland } \\
(\mathbf{2 0 1 0 )}\end{array}$ & $\begin{array}{r}\text { Iceland } \\
\mathbf{( 2 0 1 2 )}\end{array}$ & $\begin{array}{r}\text { Norway } \\
\mathbf{( 2 0 1 2 )}\end{array}$ & $\begin{array}{r}\text { Sweden } \\
\mathbf{( 2 0 1 1 )}\end{array}$ \\
\hline $\begin{array}{l}\text { Used textiles and textile } \\
\text { waste from separate } \\
\text { collection (tonnes) }\end{array}$ & 41,000 & 25,000 & 1,400 & 23,000 & 29,000 \\
$\begin{array}{l}\text { Not separately collected } \\
\text { used textiles and textile } \\
\text { wastes (tonnes) }\end{array}$ & 48,000 & 46,000 & 3,400 & 51,000 & 103,000 \\
\begin{tabular}{l} 
Separate collection rate \\
\hline
\end{tabular} & $46 \%$ & $35 \%$ & $29 \%$ & $32 \%$ & $22 \%$ \\
\hline
\end{tabular}

The future amounts of textile wastes, however, are strongly linked both to the strategy for collection, reuse and recycling of textiles and to different scenarios for future collection, sorting, reuse and recycling. Depending on how the planned strategy is formulated and im- 
plemented in the Nordic countries, future amounts of textile waste will vary significantly.

As an implication for this subreport it was decided to quantitatively describe trends and make prognoses for future amounts of consumption of new textiles (see chapters 3, 4, 6 and 7). Based on this consumption, estimations of future amounts of used textiles and textile wastes potentially available for reuse and recycling were made based on average life time of the textile products (see chapter 9). In addition, a general overview of current trends in textile waste management was made (see chapter 5). 


\section{Current trends in net imports of new textiles}

Net import of new textiles is calculated as the import of new textiles to a country minus the export of new textiles from the same country.

The net import of textiles is listed for the individual Nordic countries as well as for the Nordic region as a whole. The net import of textiles to the Nordic region is a sum of the net imports to the individual countries.

\subsection{Method and data availability}

The total consumption of textiles within a country can be calculated as the sum of textile production and the net import (e.g. total import - total export) of textiles.

All Nordic countries have statistics on exports and imports of textiles as a part of their national foreign trade statistics. The statistic is generally available in amount (kg or tonnes) as well as in value (EUR or national currency). The fact that the individual Nordic countries publish statistics regarding import and export of textiles in (slightly) different ways makes it difficult to compare data from the different countries.

The data regarding net-import of textiles to Denmark, Finland, Norway and Sweden include the following categories in the EU Combined Nomenclature $(\mathrm{CN})$ :

- Clothes:

○ 6101-6117:

Articles of apparel and clothing accessories, knitted or crocheted. 6201-6217:

- Articles of apparel and clothing accessories, not knitted or crocheted. 
- Household textiles:

○ 6301:

Blankets and travelling rugs.

- 6302:

Bedlinen, table linen, toilet linen and kitchen linen.

- 6303:

Curtains (including drapes) and interior blinds; curtain or bed valances.

○ 6304:

Other furnishing articles (e.g. bedspreads).

The data regarding net-import of textiles to Iceland include the following groups in the Standard International Trade Classification (SITC) Rev.4:

- Clothes:

○ 841 Men's wear of woven fabrics.

- 842 Women's wear of woven fabrics.

○ 843 Men's wear, knitted or crocheted.

○ 844 Women's wear, knitted or crocheted.

○ 845 Apparel, n.e.s.; babie's clothing.

○ 846 Accessories, of textile fabrics.

- Household textiles:

○ 658 Made-up articles, wholly or chiefly of textile materials.

Data were not available for the subgroups of the above mentioned groups. Group 658 includes the following subgroups:

- 658.1 Sacks and bags, of textile materials, of a kind used for the packing of goods.

- 658.2 Tarpaulins, awnings and sun-blinds; tents; sails for boats, sailboards or landcraft; camping goods.

- 658.3 Blankets and travelling-rugs (other than electric).

- 658.4 Bed linen, table linen, toilet linen and kitchen linen.

- 658.5 Curtains and other furnishing articles of textile materials.

- 658.9 Made-up articles of textile materials.

The products in the subgroups 658.1 and 658.2 are not included in the collected data for Denmark, Finland, Norway and Sweden. 


\subsection{Denmark}

The data were retrieved from the StatBank Denmark for the years of 2000-2012 (Statistics Denmark, 2014a). Data for selected years are illustrated in Table 4. Data for 2000-2012 are illustrated in Figure 1 as well as in Table 29 in Annex A.

\begin{tabular}{lrrrr}
\multicolumn{4}{l}{ Table 4. Net-import of textiles to Denmark for selected years in tonnes (Statistics Denmark, 2014a) } \\
\hline & $\mathbf{2 0 0 0}$ & $\mathbf{2 0 0 4}$ & $\mathbf{2 0 0 8}$ & $\mathbf{2 0 1 2}$ \\
\hline Clothes (in tonnes) & 55,091 & 68,467 & 65,158 & 62,961 \\
Household textiles (in tonnes) & 10,698 & 11,738 & 18,941 & 12,254 \\
Total & 65,789 & 80,206 & 84,099 & 75,215 \\
Comparison to 2000 & $100 \%$ & $122 \%$ & $128 \%$ & $114 \%$ \\
\hline
\end{tabular}

Figure 1. Net-import of textiles to Denmark 2000-2012 (Statistics Denmark, 2014a)

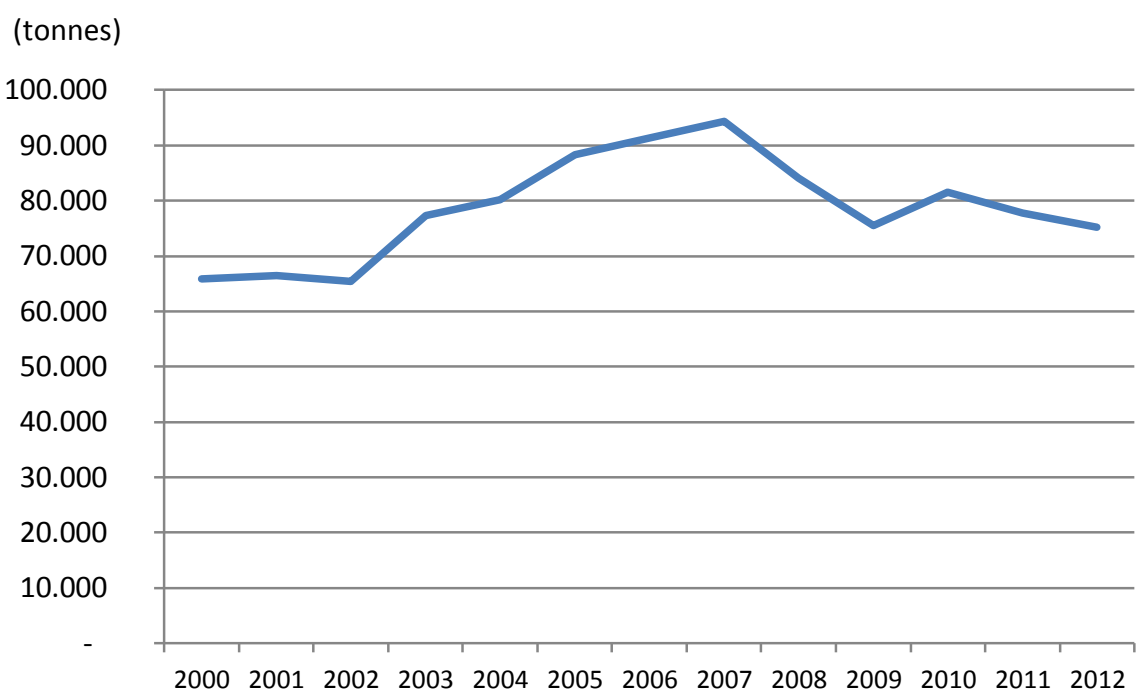

\subsection{Finland}

The data were retrieved from the Finland Customs Statistical Database ULJAS for the years of 2002-2012 (Tulli, 2014a). Data for selected years are illustrated in Table 5. Data for 2002-2012 are illustrated in Figure 2 as well as in Table 36 in Annex A. 
Table 5. Net-import of textiles to Finland for selected years in tonnes (Tulli, 2014a)

\begin{tabular}{lrrrr}
\hline & $\mathbf{2 0 0 2}$ & $\mathbf{2 0 0 4}$ & $\mathbf{2 0 0 8}$ & $\mathbf{2 0 1 2}$ \\
\hline Clothes (in tonnes) & 32,309 & 36,939 & 45,443 & 42,108 \\
Household textiles(in tonnes) & 7,121 & 8,300 & 12,269 & 10,646 \\
Total & 39,430 & 45,239 & 57,712 & 52,754 \\
Comparison to 2002 & $100 \%$ & $115 \%$ & $146 \%$ & $134 \%$ \\
\hline
\end{tabular}

Figure 2. Net-import of textiles to Finland 2002-2012 (Tulli, 2014a)

(tonnes)

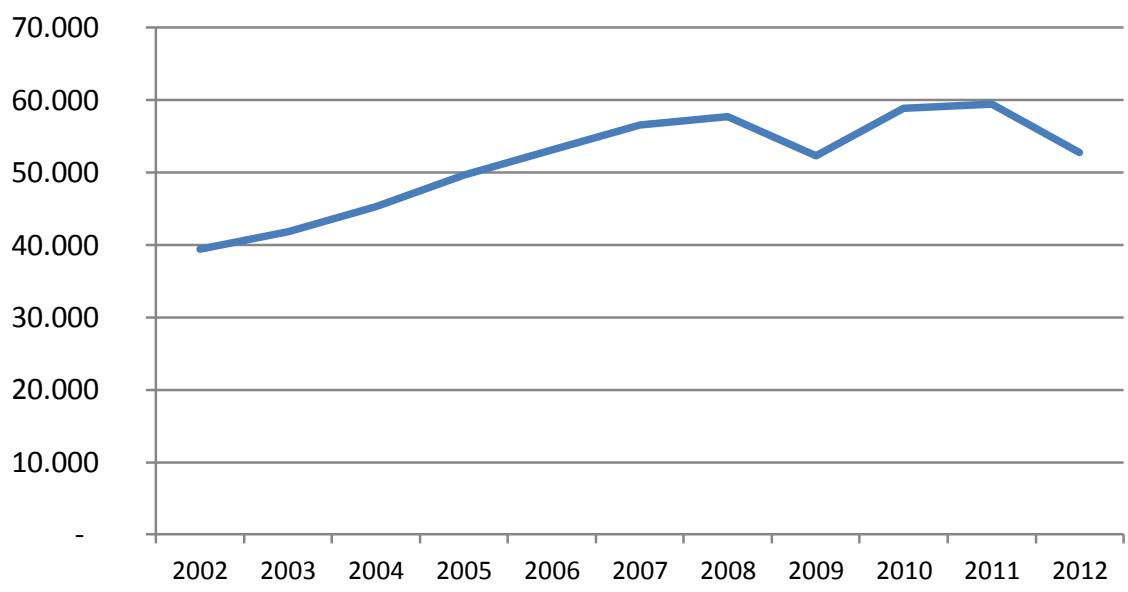

\subsection{Iceland}

The data were retrieved from the Statistics Iceland's Database on foreign trade for the years of 2000-2012 (Statistics Iceland, 2014a). Data for selected years are illustrated in Table 6. Data for 2000-2012 are illustrated in Figure 3 as well as in Table 37 in Annex A.

Table 6. Net-import of textiles to Iceland for selected years in tonnes (Statistics Iceland, 2014a)

\begin{tabular}{lllll} 
& $\mathbf{2 0 0 0}$ & $\mathbf{2 0 0 4}$ & $\mathbf{2 0 0 8}$ & $\mathbf{2 0 1 2}$ \\
\hline Clothes (in tonnes) & 2,641 & 3,021 & 3,025 & 2,326 \\
Household textiles (in tonnes) & 1,430 & 1,866 & 1,863 & 2,239 \\
Total & 4,070 & 4,887 & 4,888 & 4,565 \\
Comparison to 2000 & $100 \%$ & $120 \%$ & $120 \%$ & $112 \%$
\end{tabular}


Figure 3. Net-import of textiles to Iceland 2000-2012 (Statistics Iceland, 2014a) (tonnes)

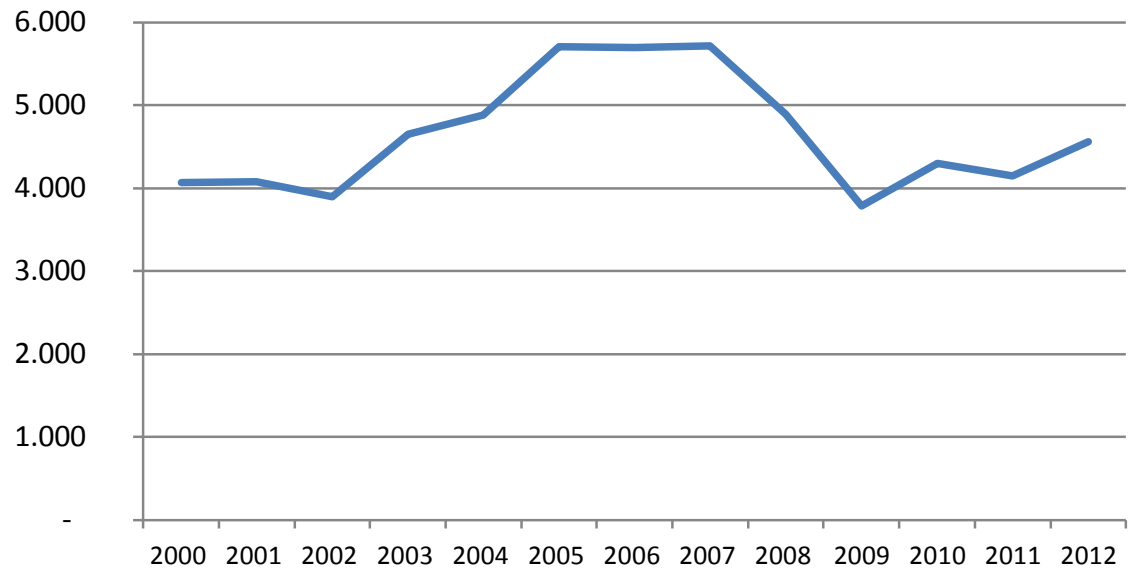

\subsection{Norway}

The data were retrieved from Statistics Norway's Statbank for the years of 2002-2012 (Statistics Norway, 2014a). Data for selected years are illustrated in Table 7. Data for 2000-2012 are illustrated in Figure 4 as well as in Table 38 in Annex A.

Table 7. Net-import of textiles to Norway for selected years in tonnes (Statistics Norway, 2014a)

\begin{tabular}{lrrrr}
\hline & $\mathbf{2 0 0 0}$ & $\mathbf{2 0 0 4}$ & $\mathbf{2 0 0 8}$ & $\mathbf{2 0 1 2}$ \\
\hline Clothes (in tonnes) & 49,403 & 55,625 & 66,856 & 59,534 \\
Household textiles (in tonnes) & 11,352 & 17,292 & 17,983 & 15,774 \\
Total & 60,755 & 72,917 & 84,839 & 75,308 \\
Comparison to 2000 & $100 \%$ & $120 \%$ & $140 \%$ & $124 \%$ \\
\hline
\end{tabular}


Figure 4. Net-import of textiles to Norway 2000-2012 (Statistics Norway, 2014a)

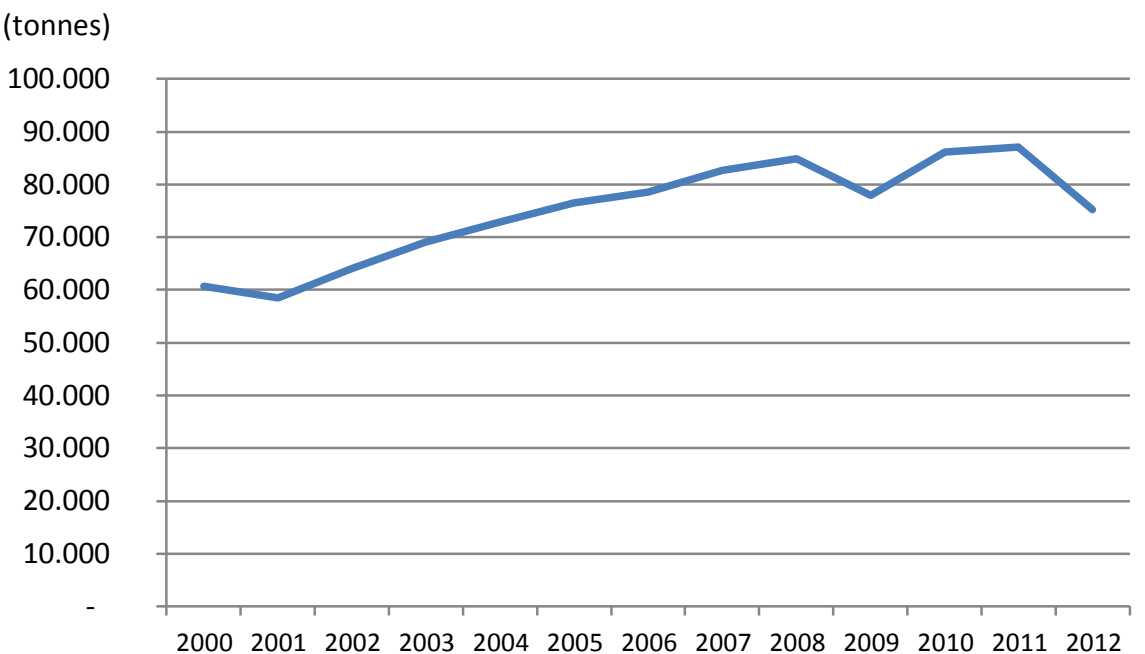

\subsection{Sweden}

The data were retrieved from Statistics Sweden's Statistical Database for the years of 2000-2012 (Statistics Sweden, 2014a). Data for selected years are illustrated in Table 8. Data for 2000-2012 are illustrated in Figure 5 as well as in Table 39 in Annex A.

Table 8. Net-import of textiles to Sweden for selected years in tonnes (Statistics Sweden, 2014a)

\begin{tabular}{lrrrr}
\hline & $\mathbf{2 0 0 0}$ & $\mathbf{2 0 0 4}$ & $\mathbf{2 0 0 8}$ & $\mathbf{2 0 1 2}$ \\
\hline Clothes (in tonnes) & 78,341 & 85,338 & 96,325 & 83,432 \\
Household textiles (in tonnes) & 15,522 & 22,001 & 30,037 & 24,519 \\
Total & 93,863 & 107,339 & 126,362 & 107,951 \\
Comparison to 2000 & $100 \%$ & $114 \%$ & $135 \%$ & $115 \%$ \\
\hline
\end{tabular}


Figure 5. Net-import of textiles to Sweden 2000-2012 (Statistics Sweden, 2014a)

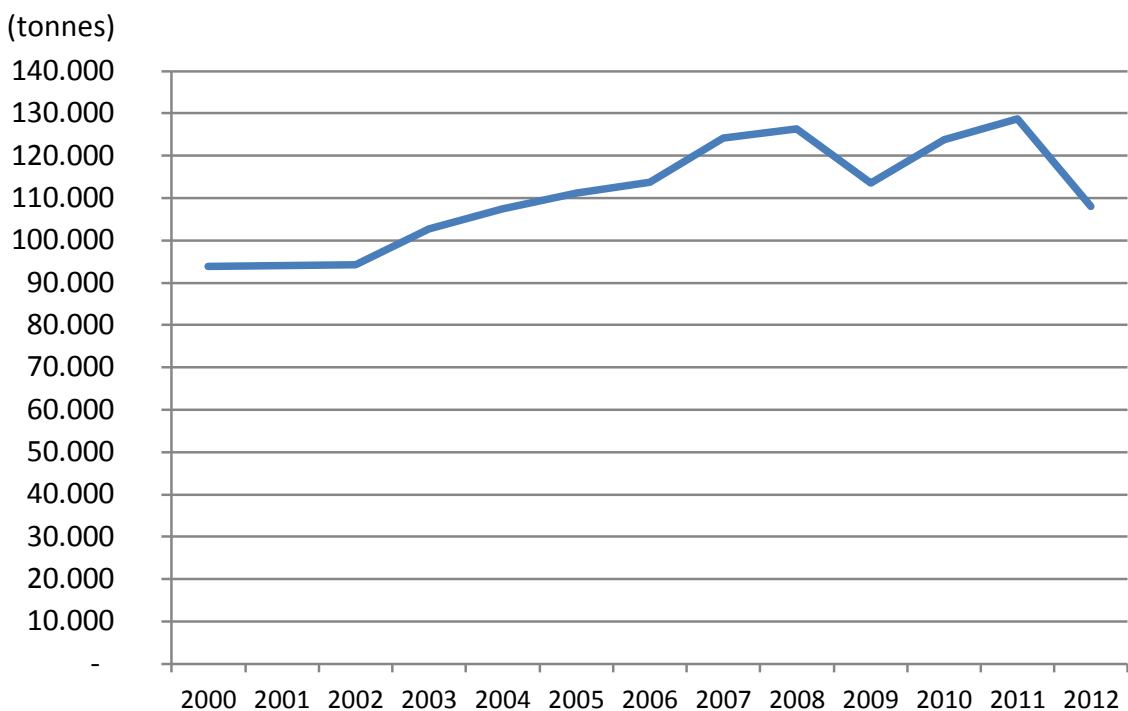

\subsection{Nordic region}

The data regarding net import of textiles to the individual Nordic countries were aggregated. Data for selected years are illustrated in Table 9. Data for 2000-2012 are illustrated in Figure 6 as well as in Table 40 in Annex A. Note that the data for the years 2000 and 2001 do not include the Finnish net import of textiles.

Table 9. Net-import of textiles to the Nordic region for selected years in tonnes (Statistics Denmark, 2014a) (Statistics Iceland, 2014a) (Statistics Norway, 2014a) (Statistics Sweden, 2014a) (Tulli, 2014a)

\begin{tabular}{lrrrr}
\hline & $\mathbf{2 0 0 0}$ & $\mathbf{2 0 0 4}$ & $\mathbf{2 0 0 8}$ & $\mathbf{2 0 1 2}$ \\
\hline Clothes (in tonnes) & 185,476 & 249,390 & 276,807 & 250,361 \\
Household textiles (in tonnes) & 39,002 & 61,197 & 81,093 & 65,432 \\
Total & 224,478 & 310,587 & 357,900 & 315,793 \\
Comparison to 2000 & $100 \%$ & $138 \%$ & $159 \%$ & $141 \%$ \\
\hline
\end{tabular}


Figure 6. Net-import of textiles to the Nordic region 2000-2012 (Statistics

Denmark, 2014a) (Statistics Iceland, 2014a) (Statistics Norway, 2014a; Statistics Norway, 2014b; Statistics Norway, 2014b; Statistics Norway, 2014b; Statistics Iceland, 2014b) (Statistics Sweden, 2014a) (Tulli, 2014a)

(tonnes)

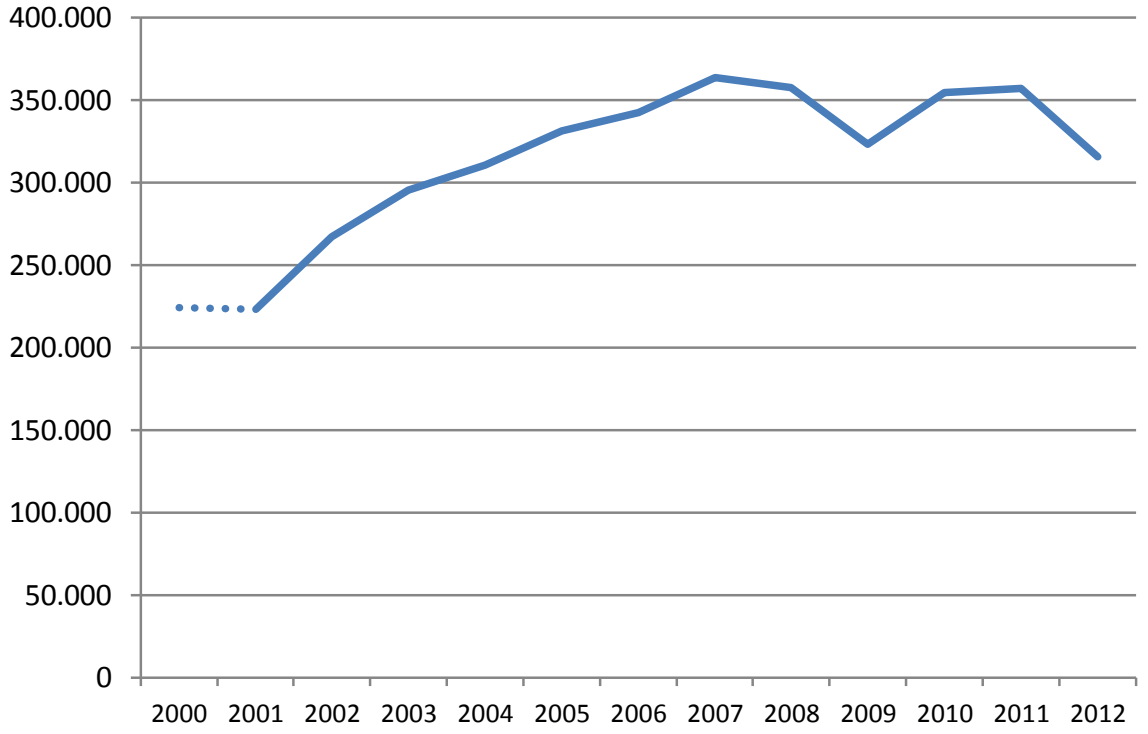




\section{Current trends in production of new textiles}

The production of textiles is listed for the individual Nordic countries as well as for the Nordic region as a whole. This allows for potential consideration of national differences in the planned strategy.

\subsection{Methods and data availability}

Nordic countries as well as Eurostat publish data on produced textiles. In some cases, however, it is not possible to differentiate between textiles, clothing and leather production. The statistic is generally available in value of the produced products (Euro or national currency) or in produced number of items (units). To a larger extent than the foreign trade statistics for textiles, the statistics on produced textiles are incomplete and/or classified (for reasons of secrecy). This makes it difficult to get complete and comparable analyses between countries.

Statistical data on production are available for industrial sectors in the Nordic countries according to the sectors defined in the nomenclature of the Statistical classification of economic activities in the European Community (NACE). For the production of textiles NACE groups 13-15 (earlier 17-19) are relevant. The main content of these industrial sectors are:

- Sector 13 (earlier 17):

Mainly wool, protective clothes, textile fibres, fishing nets, protective coated textiles (e.g. tarpaulins).

Some product groups included, covering household textiles and pullovers of wool.

- Sector 14 (earlier 18):

Mainly finished clothes and some household textiles which have all been included in the study.

- Sector 15 (earlier 19):

Producers of leather products, shoes etc. not covered in the study. 
As this project mainly focuses on finished clothes and household waste, data collected from the national Statistical Data Banks were thus limited to a few product groups in Sector 13 (earlier 17) and the whole Sector 14 (earlier 18), and presented in analyses of historical trends.

For Denmark, Sweden, Norway and Iceland economic data for production within the different sectors were available. Finland had available data for both economic value and unit of production (pieces). Sweden lacked data for 2012, which made it difficult to produce total Nordic statistics on production later than to 2011.

Economic value of production was used to present historical data on production of textiles in the Nordic countries, as no data are available for production in tonnages.

However, data on export of textiles and textile products from the different sectors were available both in tonnage and economic value from Iceland and Norway. These data were used to estimate a unit price per ton clothes exported for the main product groups in Sector 14 (earlier 18) from Norway. It was assumed that the same correlation between economic value and tonnages were valid for Iceland, Sweden, Denmark and Finland, as the export price should reflect the market price in international markets (not to be mixed with the sale price to end consumers. The factor use is EUR 28.80 per ton of clothes in export value. There were no large changes in this transformation factor over the period 2002-2012 and the factor used is an average for the period 2010-2012. It was thus assumed that the same factor could be used to estimate tonnages from economic production values as an approximation. The changes over time will thus reflect the changes in economic value of production. It was in the calculations assumed that the factor developed for clothes also reflects the corresponding factor for household textiles.

Data sources used are the Statistics Databanks in the Nordic Statistical Organisations respectively and the statistical information was retrieved from their data bases.

The project was guided to the best sources of information by experts in each of the Nordic Statistical organisations. However, it was not possible within the scope of the project to carry out deep investigations in all assumptions behind the data sets. As a result, the presented statistics must be regarded to have some uncertainties in comparisons of produced amounts between countries. The historical trends in each country, however, are assumed to be more valid. 


\subsection{Denmark}

The data were retrieved from Statistics Denmark for the years of 2008-2011 as data was not available for earlier years. Data for selected years are illustrated in Table 10. Data for 2008-2012 are illustrated in Figure 7.

Table 10. Production of finished clothes and household textiles in Denmark 2008-2011 (Statistics Denmark, 2014b)

\begin{tabular}{lrrrr} 
& 2002 & 2004 & 2008 & 2011 \\
\hline Clothes and textiles (tonnes) & - & - & 264 & 357 \\
Comparison to 2008 & - & - & $100 \%$ & $135 \%$ \\
\hline
\end{tabular}

Figure 7. Production trends for textiles in Denmark 2008-2011 based on data from (Statistics Denmark, 2014b)

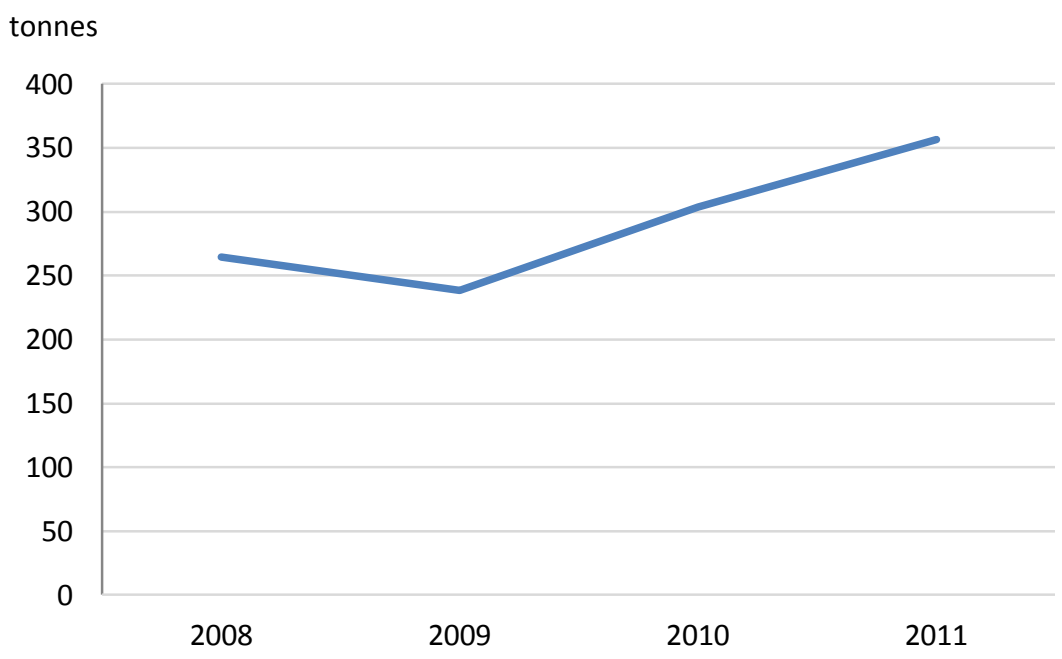




\subsection{Finland}

The data were retrieved from Statistic Finland for the years of 2002-2011. Data for selected years are illustrated in Table 11. Data for 2002-2011 are illustrated in Figure 8.

Data from Finland showed a steep decrease in production of clothes and household textiles based in data for economic value of production. There have been some changes in the number of subcategories over time and some potential data gaps, which might be part of the explanation for the steep decline.

Table 11. Production of finished clothes and household textiles in Finland 2002-2011 (Tulli, 2014b)

\begin{tabular}{lrrrr}
\hline & $\mathbf{2 0 0 2}$ & $\mathbf{2 0 0 4}$ & $\mathbf{2 0 0 8}$ & $\mathbf{2 0 1 1}$ \\
\hline Clothes and textiles (tonnes) & 13,703 & 10,088 & 42,98 & 3,633 \\
Comparison to 2002 & $100 \%$ & $74 \%$ & $31 \%$ & $27 \%$ \\
\hline
\end{tabular}

Figure 8. Production of finished clothes and household textiles from Finnish textile industry 2002-2011 data from (Tulli, 2014b)

tonnes

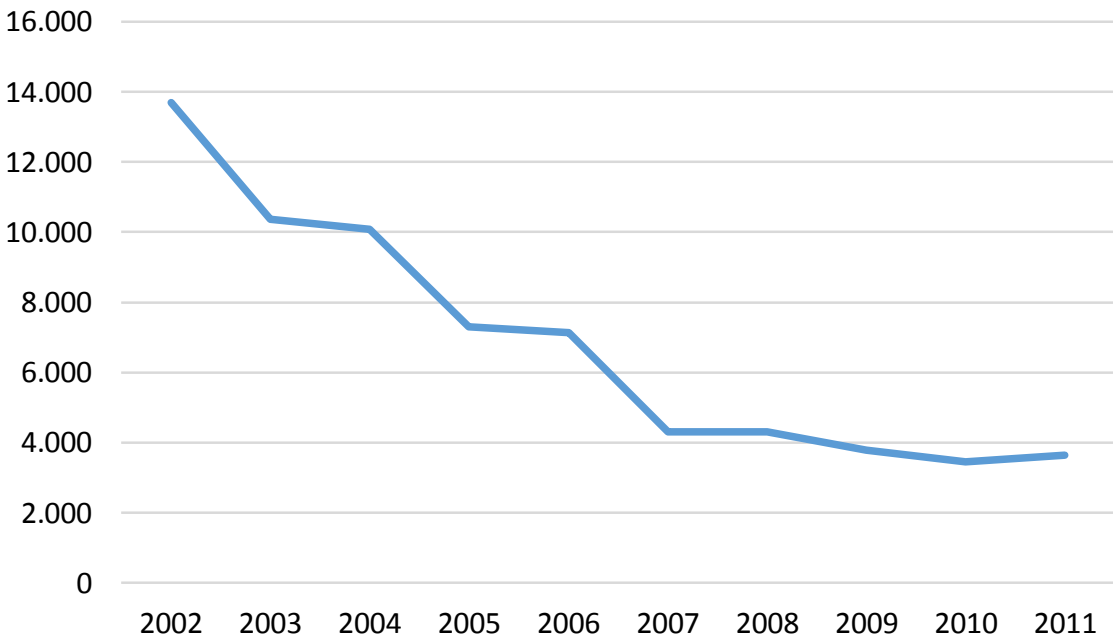




\subsection{Iceland}

The data were retrieved from Statistics Iceland for the years of 2002-2011. Data for selected years are illustrated in Table 12 Data for 2002-2011 are illustrated in Figure 9.

Table 12. Production of finished clothes and household textiles in Iceland 2002-2011 ( (Statistics Iceland, 2014b)

\begin{tabular}{lcccc}
\hline & $\mathbf{2 0 0 2}$ & $\mathbf{2 0 0 4}$ & $\mathbf{2 0 0 8}$ & $\mathbf{2 0 1 1}$ \\
\hline Clothes and textiles (tonnes) & 1,086 & 946 & 744 & 1,695 \\
Comparison to 2002 & $100 \%$ & $87 \%$ & $69 \%$ & $156 \%$
\end{tabular}

Figure 9. Production of finished clothes and household textiles from Icelandic textile industry 2002-2011 data from (Statistics Iceland, 2014b)

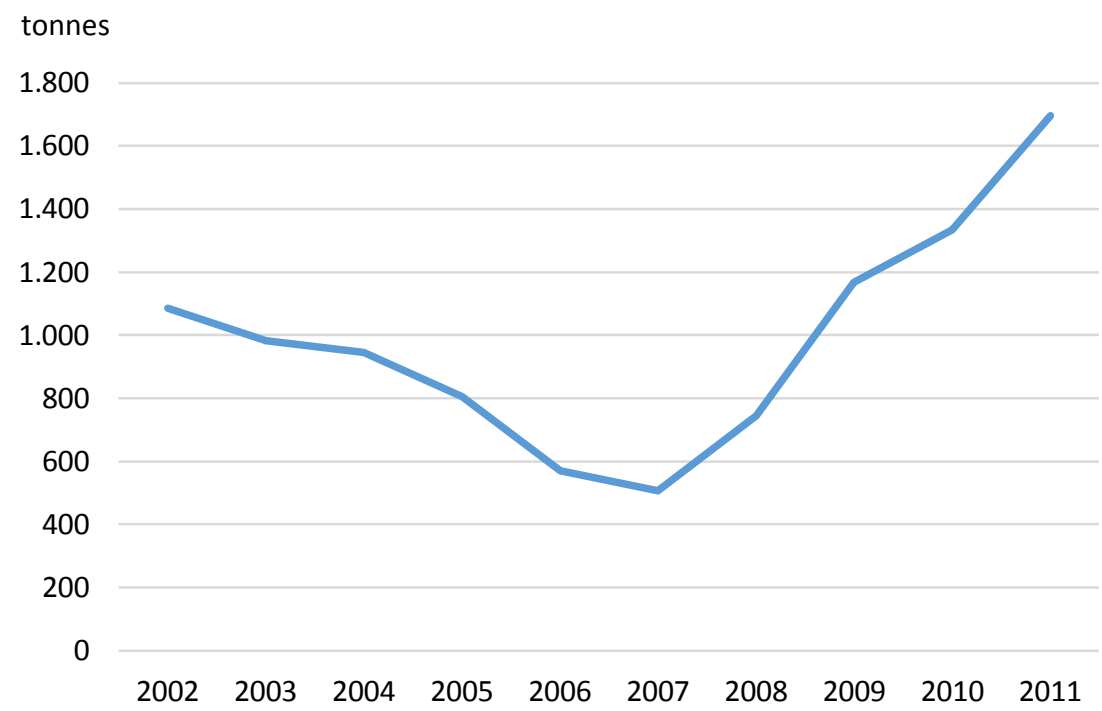




\subsection{Norway}

The data were retrieved from Statistics Norway for the years of 2002-2011. Data for selected years are illustrated in Table 13. Data for 2002-2012 are illustrated in Figure 10.

Table 13. Production of finished clothes and household textiles in Norway 2002-2011 ( (Statistics Norway, 2014b)

\begin{tabular}{lrrrr}
\hline & $\mathbf{2 0 0 2}$ & $\mathbf{2 0 0 4}$ & $\mathbf{2 0 0 8}$ & $\mathbf{2 0 1 1}$ \\
\hline Clothes and textiles (tonnes) & 1,445 & 1,412 & 1,732 & 1,340 \\
Comparison to 2002 & $100 \%$ & $98 \%$ & $120 \%$ & $93 \%$ \\
\hline
\end{tabular}

Figure 10. Production of finished clothes and household textiles from the Norwegian textile industry 2002-2011 data from (Statistics Norway, 2014b)

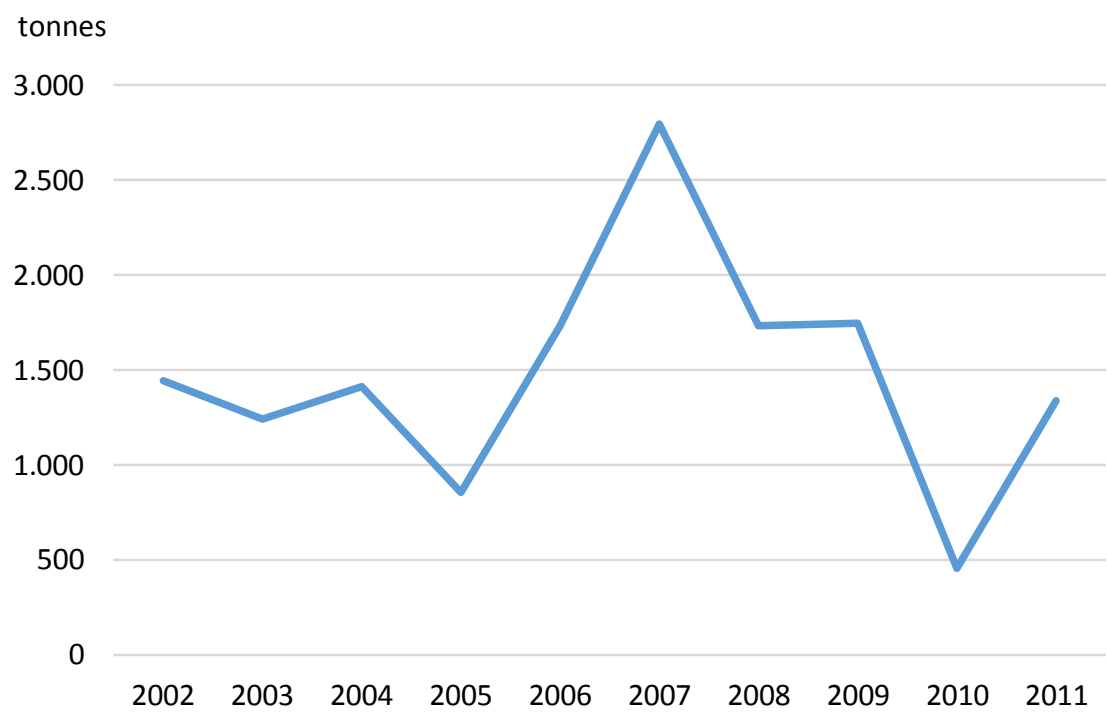




\subsection{Sweden}

The data were retrieved from Statistics Sweden for the years of 2002-2011. Data for selected years are illustrated in Table 14. Data for 2002-2011 are illustrated in Figure 11.

The statistics varies significantly, with big dips in 2006 and 2009, probably due problems with some companies lacking from one year to the next. Besides the big amplitudes, there is no large trend in the historical data.

Table 14. Production of finished clothes and household textiles in Sweden
(Statistics Sweden, 2014b))
\begin{tabular}{lrrrr} 
& & & \\
\hline & $\mathbf{2 0 0 2}$ & $\mathbf{2 0 0 4}$ & $\mathbf{2 0 0 8}$ & $\mathbf{2 0 1 1}$ \\
\hline Clothes and textiles (tonnes) & 27,597 & 26,662 & 28,805 & 27,375 \\
Comparison to 2002 & $100 \%$ & $97 \%$ & $104 \%$ & $99 \%$
\end{tabular}

Figure 11. Production of finished clothes and household textiles from the Swedish textile industry 2002-2011 based in data from (Statistics Sweden, 2014b)

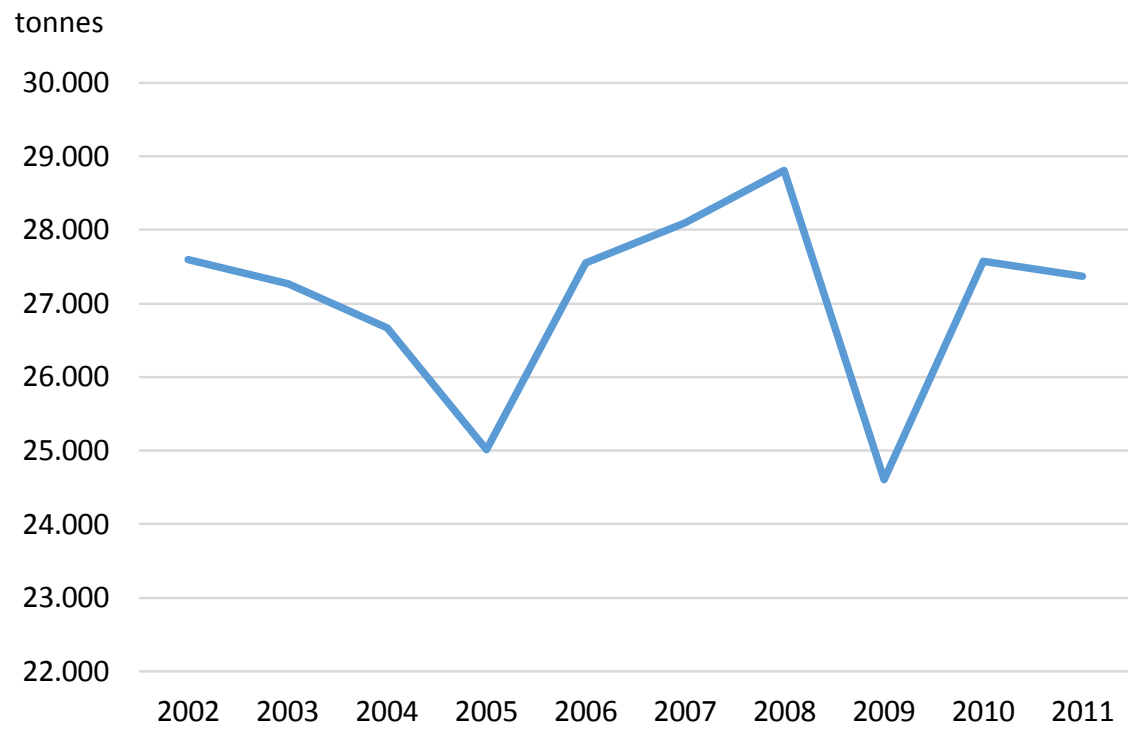




\subsection{Nordic region}

Data for production of household textiles and clothes for all Nordic countries is presented in Table 15 and Figure 12. The figures show a slightly decreasing trend from about 44,000 tons produced in 2002 to 35,000 tons in 2011.

Sweden is the main producing country in the Nordic region, and the relatively stable trend of production is mainly due to the low decrease in Swedish production over the whole period, compensating for a big decrease in Finnish production.

Table 15. Production of finished clothes and household textiles in the Nordic region 2002-2011 (data from Table 10 to Table 14)

\begin{tabular}{lrrrr} 
& $\mathbf{2 0 0 2}$ & $\mathbf{2 0 0 4}$ & $\mathbf{2 0 0 8}$ & $\mathbf{2 0 1 1}$ \\
\hline Clothes and textiles (tonnes) & 43,830 & 39,108 & 35,844 & 34,399 \\
Comparison to 2002 & $100 \%$ & $89 \%$ & $82 \%$ & $78 \%$ \\
\hline
\end{tabular}

Figure 12. Production of finished clothes and household textiles from the total Nordic textile industry 2002-2011 (data from Table 10 to Table 14)

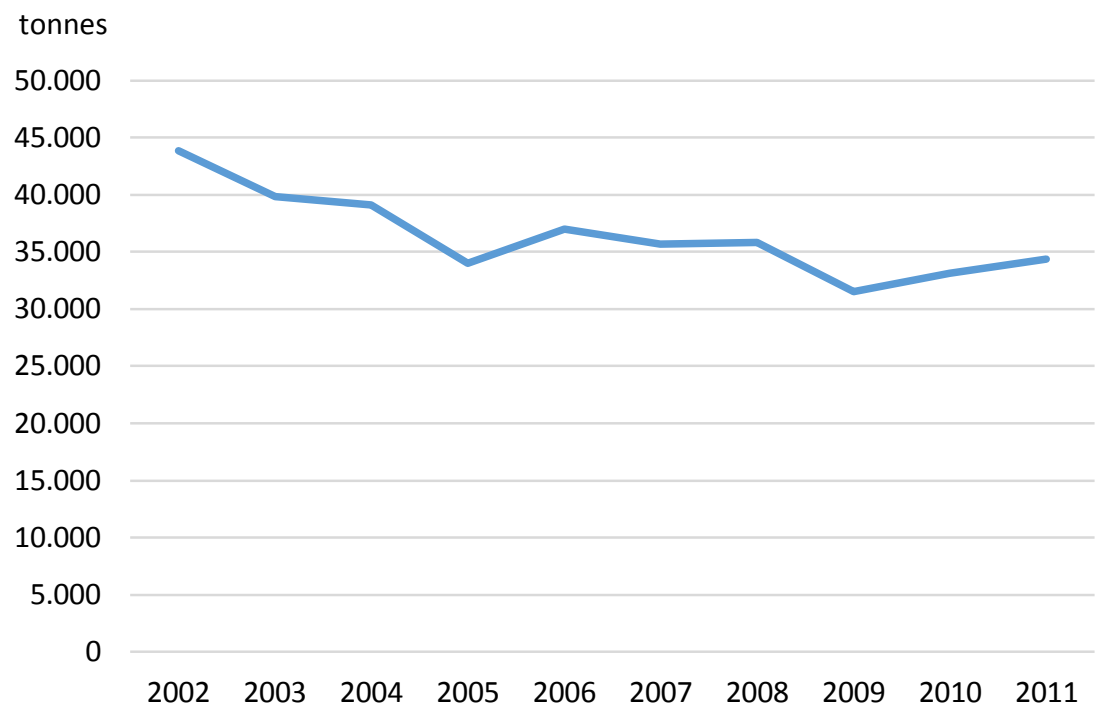

It is important to note that the availability and comparability of data both between countries and over time is rather uncertain. Changes in the categorization of textile production were registered over time in different countries. It was within the scope of the project not possible to investigate whether the exact same categories are included in the data sets before and after these changes. In addition, there seems to be some data gaps in the time series due to lack of reporting. This might to an 
extent explain the big amplitudes in the Norwegian data set. Finally, all data on tonnages are estimates based in transformation factors from economic data. This too increases the uncertainties of the data. The reason is that tonnage is not registered in most countries for textile production, as most statistics are either in economic value or in number of units (or $\mathrm{m}^{2}$ ) textile produced.

The total figures for textile production in the Nordic countries are low compared to the total import of textiles (less than $20 \%$ in 2002 and less than 10\% in 2011) based in data from section 3.7. In the big picture, some errors in the data on production of clothes and household textiles will thus have rather limited effect on the total figures for textiles available for recycling or reuse in the Nordic market.

It should also be noted that other types of textiles and textile fibres are significantly more important than the finished clothes and household textiles discussed in this context. The Norwegian production statistics showed that other product groups have significantly higher production, e.g. fishing nets, protective coated textiles (tarpaulins), wool fibres and synthetic textile fibres. Similar data were not investigated for the other Nordic countries within the project. 



\section{Current trends in textile waste management}

\subsection{Changing attitudes}

In the recent years, the consumption of clothing has increased dramatically. Although industrial development has moved towards less environmental impact, production as well as consumption has increased to levels where the benefits of technological development are reduced (Niinimäki \& Hassi, 2011). The reasons are among others easy access to cheap clothes (Gardetti \& Torres, 2013) and increased purchasing power. In addition, the short life span of textiles and especially clothing is one of the main problems in the current industrial system (Niinimäki \& Hassi, 2011) (Aftenposten, 2012). The prices are so low that many consumers consider the clothing to be disposable; e.g. called "fast fashion" equivalent to "fast food" (Cline, 2012) or "throwaway fashion" (Birtwistle and Moore, 2007, in (Gardetti \& Torres, 2013). Higher consumption of textiles results in increasing amounts of textile waste. At the same time, there is an increasing understanding of the environmental burdens of textiles both among the population and in the textile and clothing industry; and it is in the disposal phase these concerns are activated (Laitala, et al., 2012). In addition, our attitude towards clothes may have been affected by the revealed unacceptable worker's conditions and the deadly fires in clothing factories in Bangladesh in recent years. There is also a growing awareness of how much clothes and stuff we are gathering, resulting in initiatives like the Facebook initiative Shop-stop (Shoppestopp, 2014). Among young people, the Do it Yourself (DIY)-trend also contributes to increased focus on reuse and redesign. However, the effects of increasing consciousness related to the clothes we wear will probably not be determining on the amount of textile waste in the near future.

The amount of new textiles put on the market is increasing in all of the Nordic countries, see chapter 3 and 4 . The amount of used textiles being generated is likely to be lower than the amount of new textiles put on the market in any given year. This gap is made up of for instance accumulation in wardrobes and attics, and items which is given away to 
family and friends. Currently there are no data available of the end-oflife fate of all the textile items we are purchasing (Laitala, et al., 2012).

Palm et al. documents this gap between new textiles put on the market each year and what is separately collected following use (Palm, et al., 2013). The gap varies between the Nordic countries. The amount of separately collected textiles was $20 \%$ of the amount of new textiles put on the market in 2011 in Sweden. In Denmark the amount of separately collected textiles was $46 \%$. However, it is difficult to compare these figures. As pointed out by Elander et al. there is a need to increase compatibility of the data collected in order to be able to collect, aggregate and use data regarding used textiles from the different countries within the Nordic region (Elander, Kiorbøe, \& Palm, 2013). Also, Iceland only recently started to collect statistical data on textile waste with 2012 as the first year (Sigurðsson, 2014).

Rising public awareness on the textile waste fraction might change the disposal practice. Enabling the households to deposit the used textiles regardless of their state presumable will increase the separately collection rates considerable. According to research done by SIFO in Norway, consumers typically assume that $40 \%$ of their used textiles are not reusable. However, SIFO found that only $8 \%$ of these textiles are not reusable (Laitala, et al., 2012). This makes up a quite huge potential for reuse of textiles if the consumer could be exempted the decision of what textiles to be handed in via reuse collection systems, and what to be put in the residual.

A change in attitude towards textile waste is developing in the Nordic countries. This can be exemplified by several relatively new cooperations between charitable organisations and recyclers e.g. the Swedish Red Cross sending their unsellable textiles via KICI for sorting and reuse/recycling in the Netherlands, Human Bridge sending unsorted or unsellable textiles for sorting and reuse/recycling and the establishment of Returtex in order to create new sorting capacities in Sweden (Returtex, 2014).

There are also positive trends in the amount of separately collected used textiles. For instance, in Norway the two largest collectors, Fretex and UFF, reports $15 \%$ and $5 \%$ increase respectively in the amount of collected textiles in 2013. 


\subsection{Trends in sorting and recycling of used textiles}

The available technology for sorting and recycling of used textiles is currently very limited and have not until recent years been the focus of industry. In February 2014 a first recycling congress was organized in Lille, France, where the latest developments in sorting and recycling were presented. This chapter gives a summary of the trends in sorting and recycling of based on a report from the congress (Elander M. , 2014). See also (Palm D. , Dahlbo, Moliis, \& Tekie, 2014) and (Valente C. , Lyng, Palm, \& Rydberg, 2014) for further information on sorting and recycling technology.

\subsubsection{Sorting}

Apart from manual sorting there is only one project aiming for optical Near Infra-Red (NIR) sorting of textiles on an industrial scale, T4T INDENTITEX as mentioned in (Palm D. , Dahlbo, Moliis, \& Tekie, 2014), (Valente C. , Lyng, Palm, \& Rydberg, 2014) and (Elander M. , 2014). This sorting technology could be part of a solution for sorting textiles into fibres for recycling thus potentially lowering cost for textile recycling.

\subsubsection{Mechanical recycling}

The consultancy firm TKM studies patents and scientific articles in the area of textile sorting and recycling and has seen a large increase in the last decade, but focus still seems to lie in mechanical recycling rather than chemical recycling (Elander M. , 2014). This is in turn supported by the company Le Relais, which operate 90,000 textile containers in France and performing different types of mechanical recycling (shredding or tearing into insulation or cutting into wipers) of the textiles not suitable for reuse (ibid). Also SOEX, which is one of the largest actors in waste management of textiles, mostly have mechanical recycling for their non-reusable textiles with some exceptions for recycling research (ibid). SOEX are on a trial level testing mechanical recycling of cotton together with H\&M, but the results are still to come.

Au Dela Du Fil produce yarns from mostly industrial textile waste and also to some extent on post-consumer textile. They see mechanical recycling as an important part for recycling fibres since it is a more mature technology than the alternatives, but since it cannot produce a quality comparable with virgin fibre other technologies are needed for the future. 


\subsubsection{Chemical recycling}

Chemical recycling is not yet well developed and the recycling conference provided a presentation from French Valagro that similar to Re:newcell (see (Valente C. , Lyng, Palm, \& Rydberg, 2014)) use solvents to separate textile fibres. The technology is feasible on a laboratory scale but development into large scale industrial processes are uncertain with many trials still to come (Elander M. , 2014).

The only large scale chemical recycling remains to be TEIJIN which recycles polyester clothing together with PET bottles and production waste PET. The output quality is identical to polyester from mineral oil but the cost of the collected polyester clothing is two to three times higher than mineral oil making it a niche product. The Teijin Eco-circle system requires full control of the polyester products and does not accept all polyester products which is limiting both for volumes and for collection costs. 


\section{Prognosis of future net imports of new textiles}

The prognoses for future development of net import of textiles were made for the individual Nordic countries as well as for the Nordic region as a whole. The prognosis for the Nordic region is a sum of the expected amounts for the individual countries.

\subsection{Method for making prognosis}

Data were collected for 2000-2012 (except for Finland, where data for 2002-2012 were collected), see chapter 3. Based on these data the prognoses for future net imports of new textiles to the Nordic countries were made by linear projection. Additionally a logarithmic trend was analysed.

2015 was used for the short term prognosis representing a point in time three years after the collected data. 2020 was used for the short term prognosis representing an often used date for strategies and targets (e.g. for the target for collection, reuse and recycling of used textiles proposed by the Swedish Environmental Agency in December 2013).

Textiles included in the prognoses are clothes and household textiles according to chapter 4 . 


\subsection{Denmark}

The prognosis for the net import of clothes and household textiles to Denmark in 2015 and 2020 are illustrated with the dotted blue line in Figure 13. The green line in Figure 13 represents the logarithmic trend line.

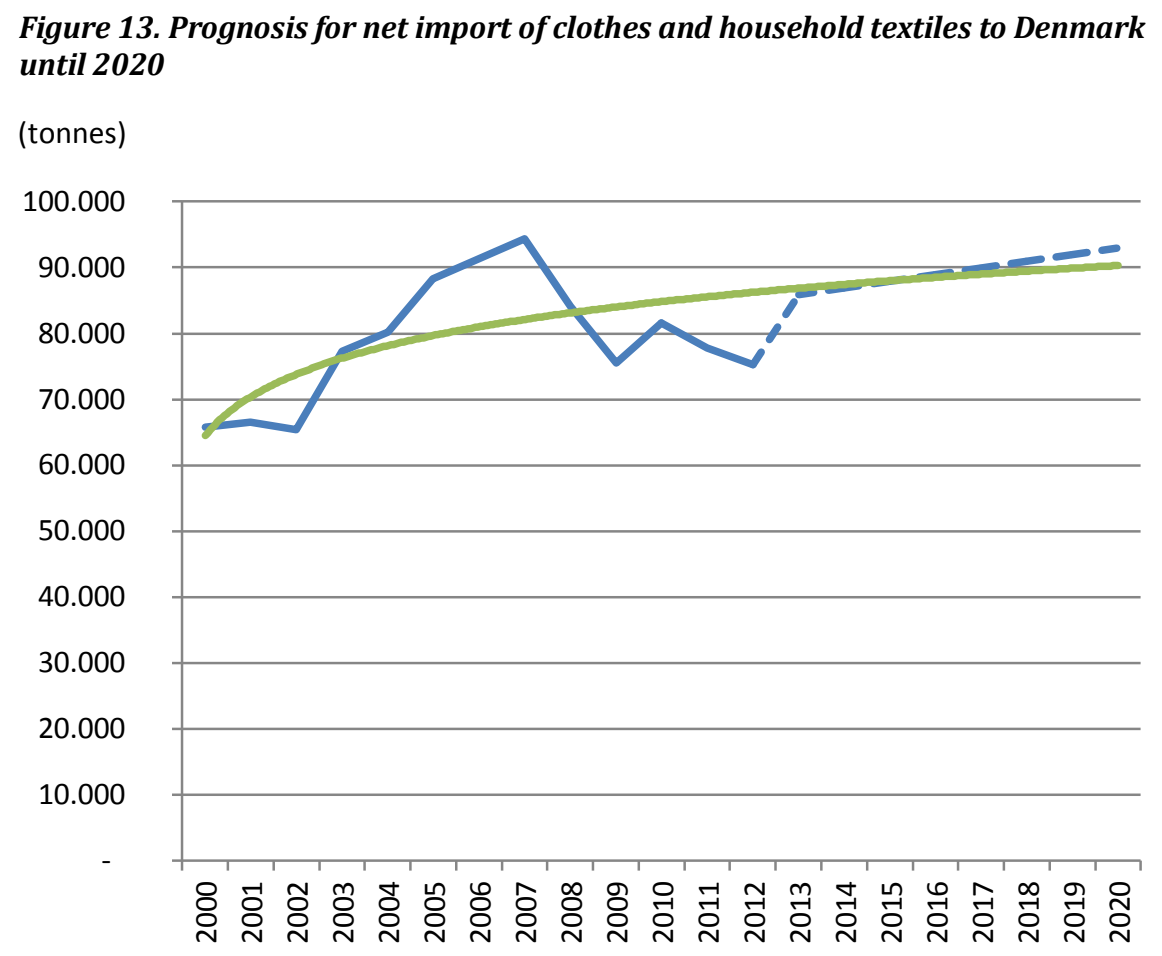

According to the linear prognosis the net import of textiles to Denmark correspond to 88,000 tonnes in 2015 and 93,000 tonnes in 2020. This represents an increase by $17 \%$ and $24 \%$ respectively compared to the 2012 level.

A logarithmic trend would correspond to textiles net import of 88,000 tonnes in 2015 and 90,000 tonnes in 2020. This represents an increase by $17 \%$ and $21 \%$ respectively compared to the 2012 level. 


\subsection{Finland}

The linear prognosis for the net import of clothes and household textiles to Finland in 2015 and 2020 are illustrated with the dotted blue line in Figure 14. The green line in Figure 14 represents the logarithmic trend line.
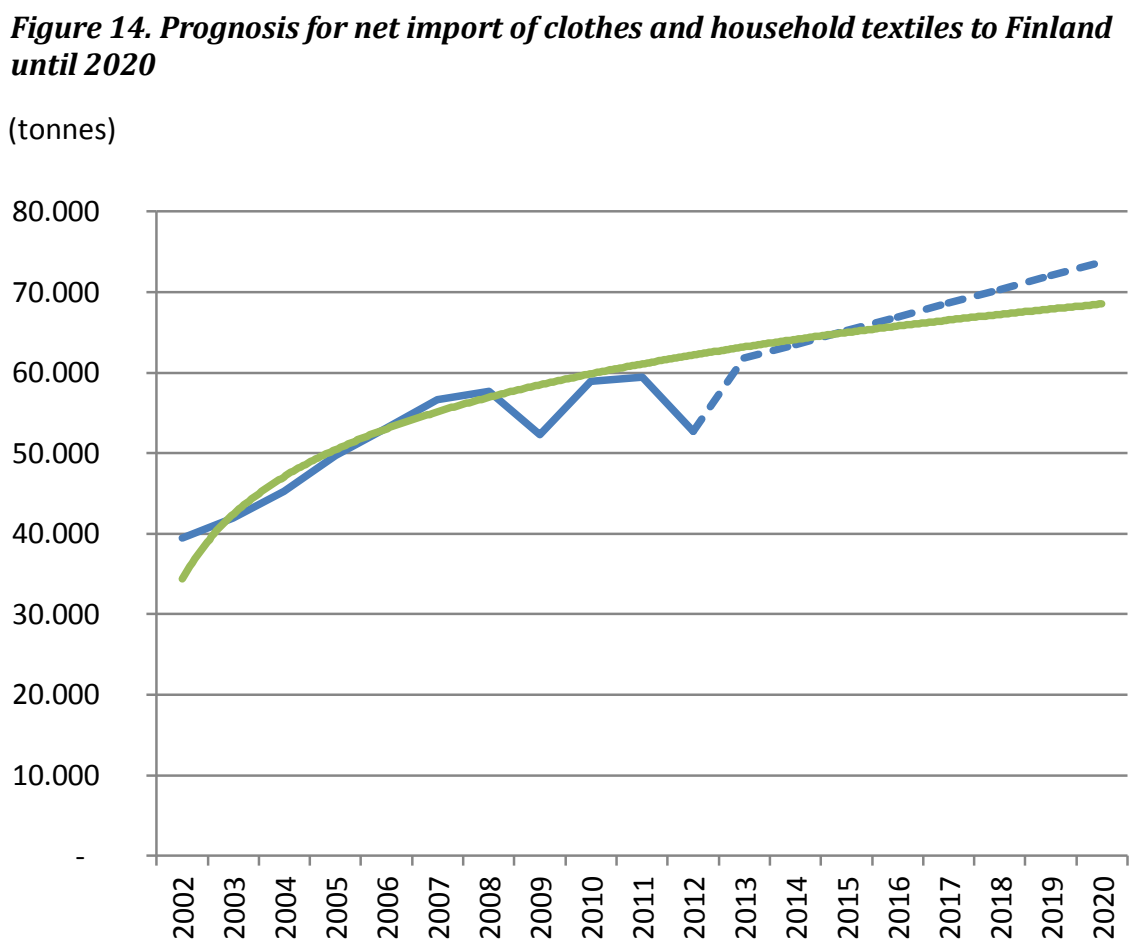

According to the linear prognosis the net import of textiles to Finland correspond to 65,000 tonnes in 2015 and 74,000 tonnes in 2020. This represents an increase by $24 \%$ and $40 \%$ respectively compared to the 2012 level.

A logarithmic trend would correspond to textiles net import of 65,000 tonnes in 2015 and 69,000 tonnes in 2020. This represents an increase by $23 \%$ and $31 \%$ respectively compared to the 2012 level. 


\subsection{Iceland}

The linear prognosis for the net import of clothes and household textiles to Iceland in 2015 and 2020 are illustrated with the dotted blue line in Figure 15 The green line in Figure 15 represents the logarithmic trend line.

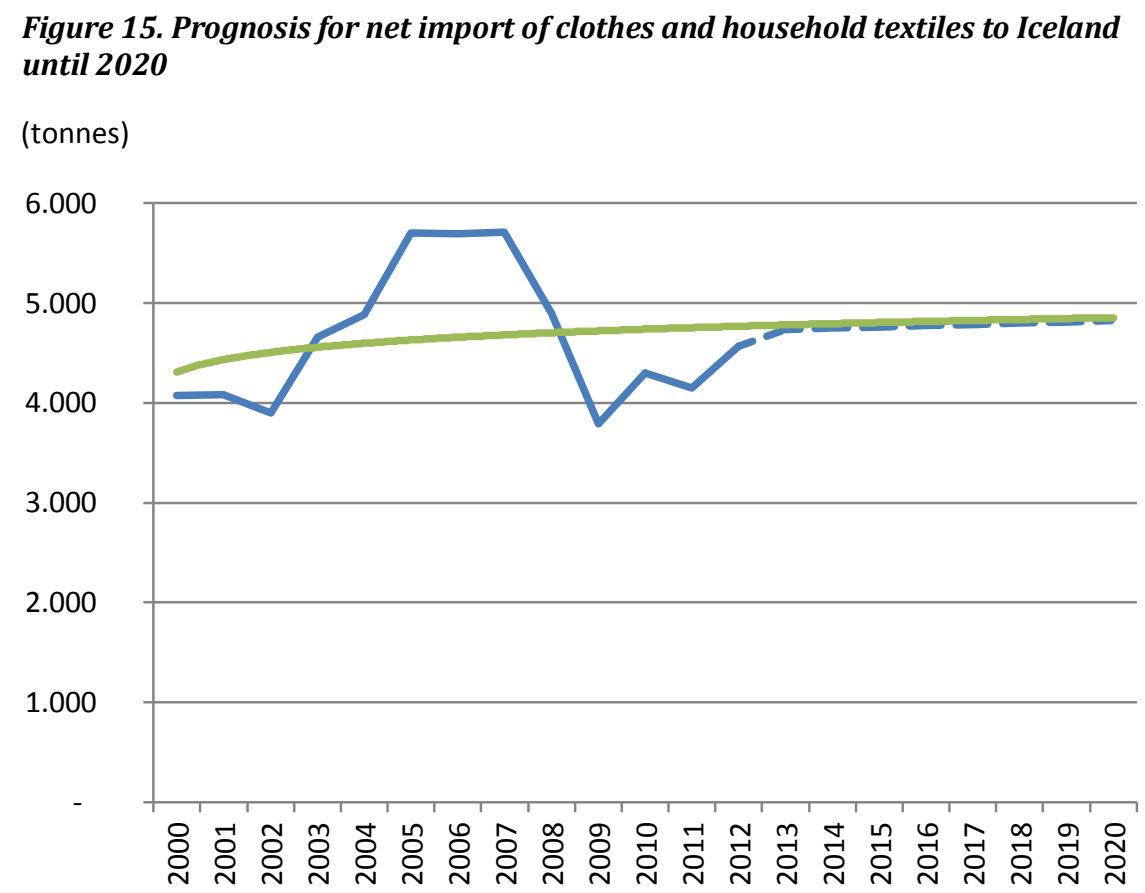

According to the linear prognosis the net import of textiles to Iceland correspond to 4,800 tonnes in 2015 and in 2020. This represents an increase by $4 \%$ and $6 \%$ respectively compared to the 2012 level.

A logarithmic trend would correspond to textiles net import of 4,800 tonnes in 2015 and 4,900 tonnes in 2020. This represents an increase by $5 \%$ and $7 \%$ respectively compared to the 2012 level. 


\subsection{Norway}

The linear prognosis for the net import of clothes and household textiles to Norway in 2015 and 2020 are illustrated with the dotted blue line in Figure 16. The green line in Figure 16 represents the logarithmic trend line.

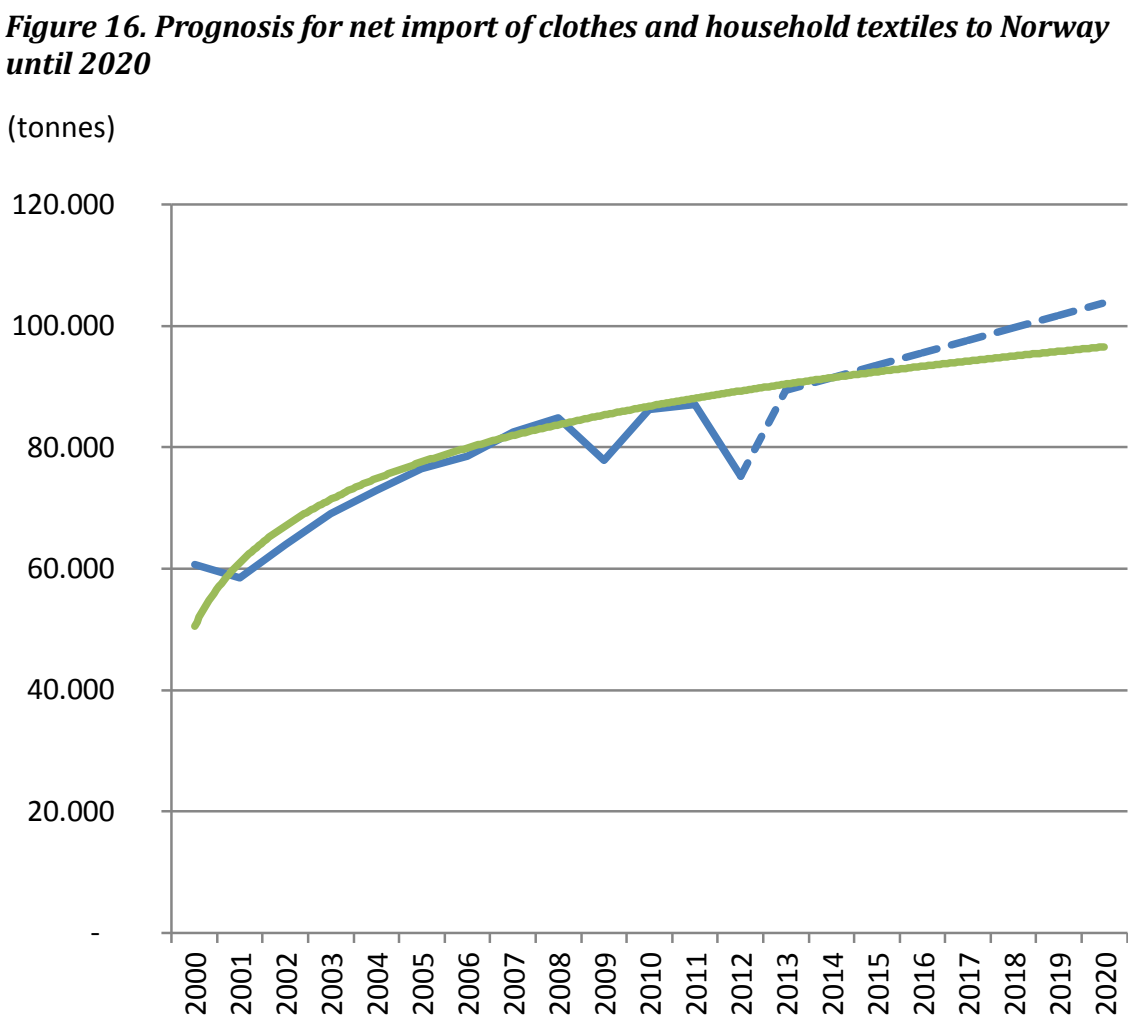

According to the linear prognosis the net import of textiles to Norway correspond to 94,000 tonnes in 2015 and 104,000 tonnes in 2020. This represents an increase by $24 \%$ and $38 \%$ respectively compared to the 2012 level.

A logarithmic trend would correspond to textiles net import of 92,000 tonnes in 2015 and 97,000 tonnes in 2020. This represents an increase by $22 \%$ and $29 \%$ respectively compared to the 2012 level. 


\subsection{Sweden}

The linear prognosis for the net import of clothes and household textiles to Sweden in 2015 and 2020 are illustrated with the dotted blue line in Figure 17. The green line in Figure 17 represents the logarithmic trend line.

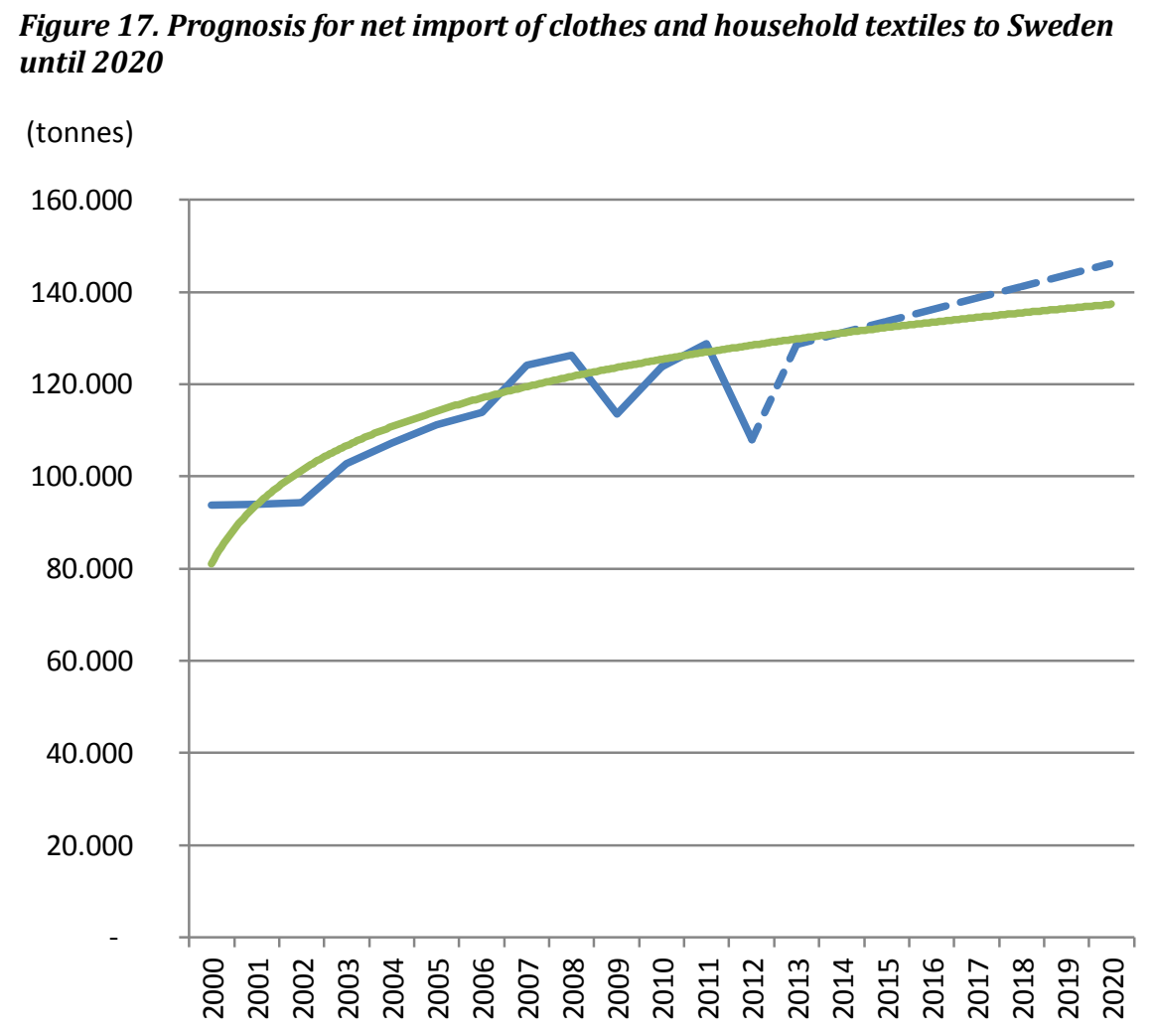

According to the linear prognosis the net import of textiles to Sweden correspond to 134,000 tonnes in 2015 and 146,000 tonnes in 2020. This represents an increase by $24 \%$ and $35 \%$ respectively compared to the 2012 level.

A logarithmic trend would correspond to textiles net import of 132,000 tonnes in 2015 and 137,000 tonnes in 2020. This represents an increase by $22 \%$ and $27 \%$ respectively compared to the 2012 level. 


\subsection{Nordic region}

The linear prognosis for the net import of clothes and household textiles to the Nordic region in 2015 and 2020 are illustrated with the dotted blue line in Figure 18. The green line in Figure 18 represents the logarithmic trend line.

Figure 18. Prognosis for net import of clothes and household textiles to the Nordic region until 2020

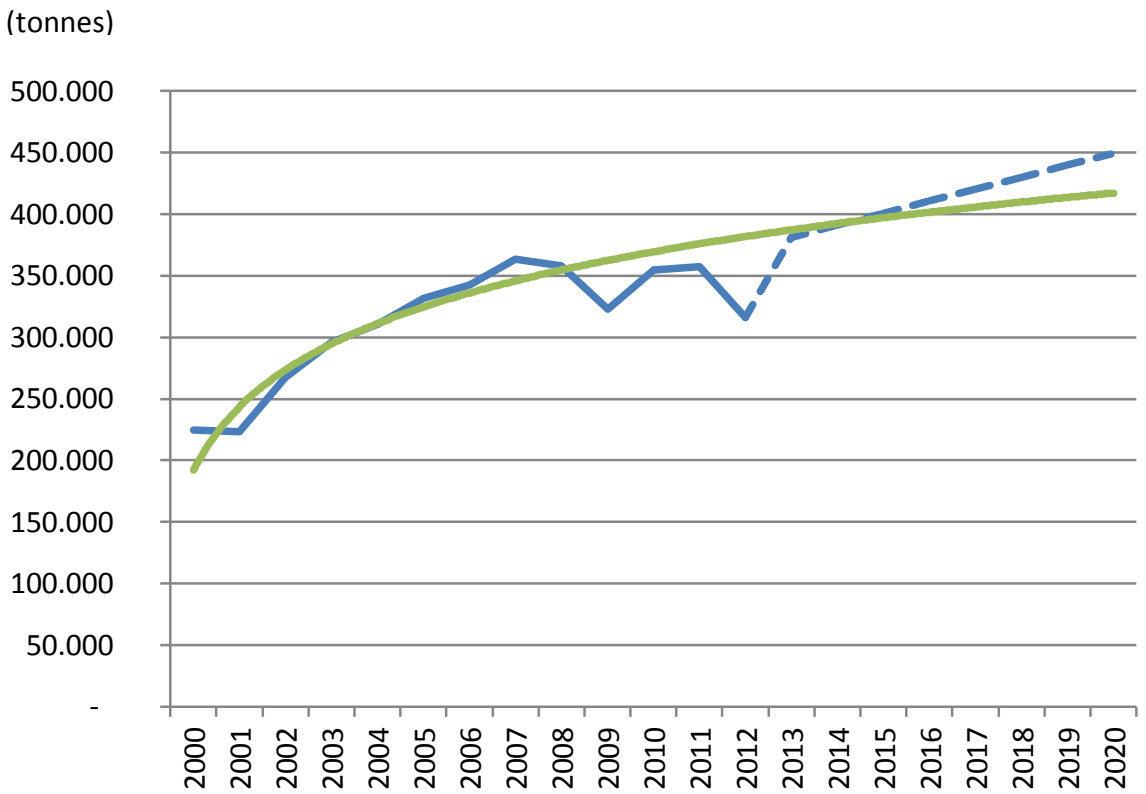

According to the linear prognosis the net import of textiles to the Nordic region correspond to 401,000 tonnes in 2015 and 450,000 tonnes in 2020 . This represents an increase by $27 \%$ and $42 \%$ respectively compared to the 2012 level.

A logarithmic trend would correspond to textiles net import of 397,000 tonnes in 2015 and 417,000 tonnes in 2020. This represents an increase by $26 \%$ and $32 \%$ respectively compared to the 2012 level. 



\section{Prognosis of future production of new textiles}

The prognoses for future development of production of textiles were made for the individual Nordic countries as well as for the Nordic region as a whole. The prognosis for the Nordic region is a sum of the expected amounts for the individual countries.

\subsection{Method for making prognosis}

The method applied for making prognosis is based in trend prolongation based in models available in Excel spreadsheet. The two models that have been applied are the linear model and the logarithmic model, based in historical data available from 2002-2012 For Denmark data was only available for 2008-2012 and Sweden from 2002-2011). It seems in most cases that the logarithmic model make a better fit with the data (higher $\mathrm{R}^{2}$ values) than the linear model. For the different countries, only the logarithmic line is shown in the figures, whereas the linear model is used to estimated future production in 2015 and 2020 in the Nordic region. 


\subsection{Denmark}

Historical data from Denmark were only available for the rather short time period 2008-2012 (see section 4.2). This makes the trend line more uncertain than for longer time series. The logarithmic line indicates a slightly increasing production in the Danish textile industry until 2020 to about 410 tonnes (see Figure 19).

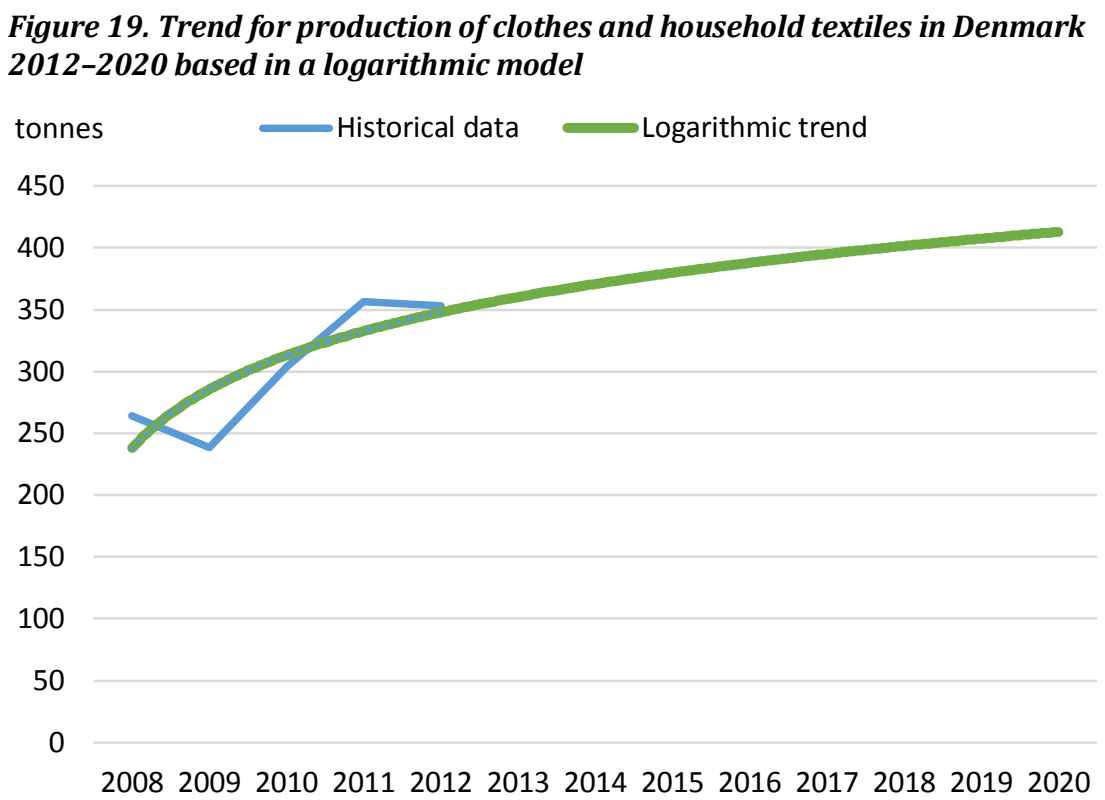




\subsection{Finland}

The historical trend for production of clothes and household textiles in Finland shows a dramatic decrease in production (see section 4.3). The logarithmic extrapolation of this trend would indicate that there will be a production of about 460 tonnes in Finland in 2020 (see Figure 20).

Figure 20.Trend for production of clothes and household textiles in Finland 2012-2020 based in a logarithmic model

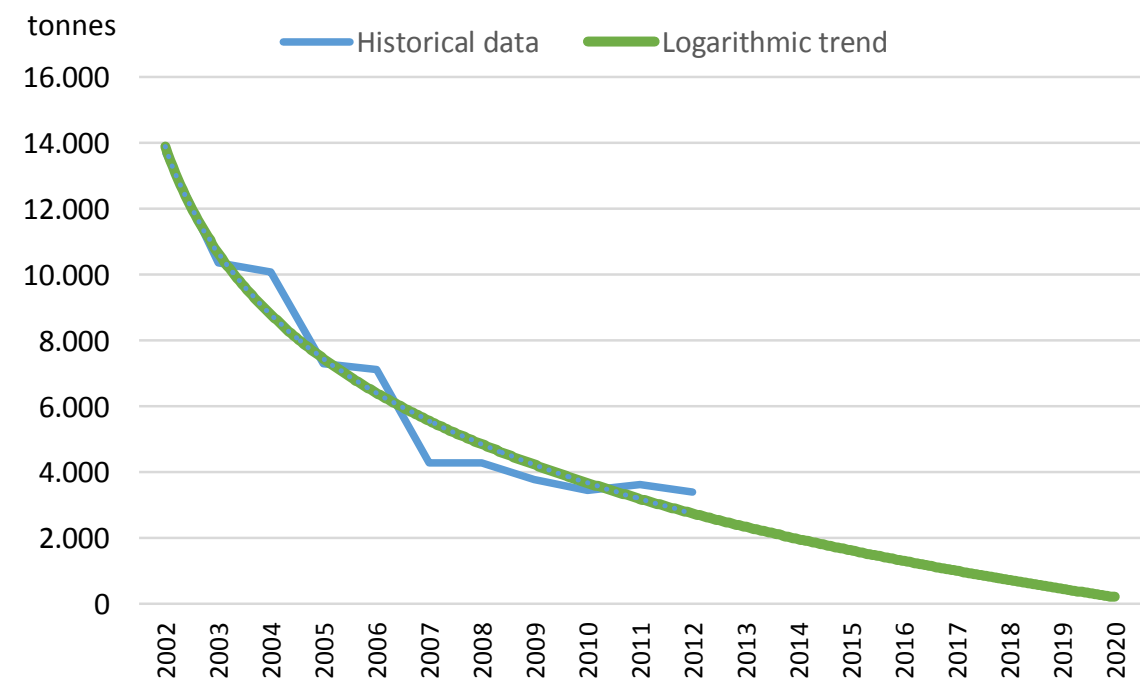




\subsection{Iceland}

The trend line for the Icelandic textile production is based on historical data that showed a negative trend until 2007, and then a sharp increase in production from 2008-2012 (see section 4.4). The trend line for the whole period shows an increase over time, with a relatively low $\mathrm{R}^{2}$ value, due to the trend shift (see Figure 21).

A logarithmic extrapolation will give a production volume of about 1,300 tonnes in 2020, which is significantly lower than in 2011. A polynomic trend line with a better $\mathrm{R}^{2}$ value indicates a much higher production volume in 2020, of about 6,000 tonnes. This is however based on an assumption that the steep increase in production from 2007 to 2012 is prolonged.

Figure 21. Trend for production of clothes and household textiles in Iceland 2012-2020 based in a logarithmic model

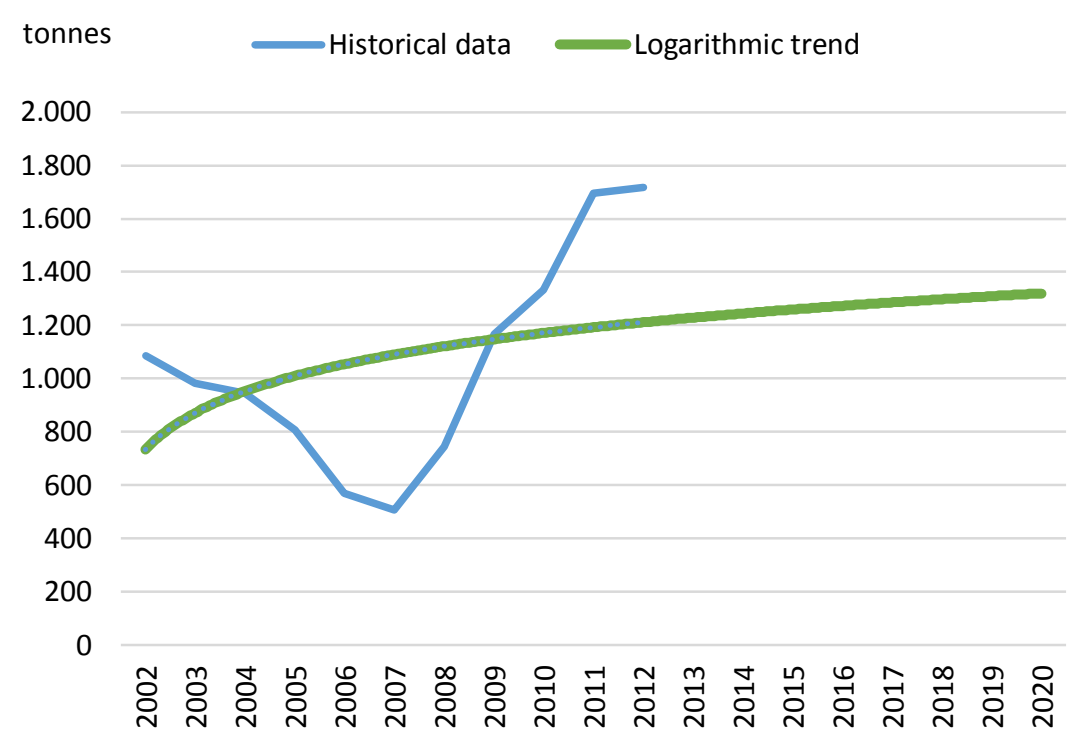




\subsection{Norway}

The historical data from Norway indicate that the production varies from year to year (see section 4.5). The long term trend shows a slight decrease until 2020, to about 1,350 tonnes (see Figure 22).

Figure 22. Trend for production of clothes and household textiles in Norway 2012-2020 based in a logarithmic model

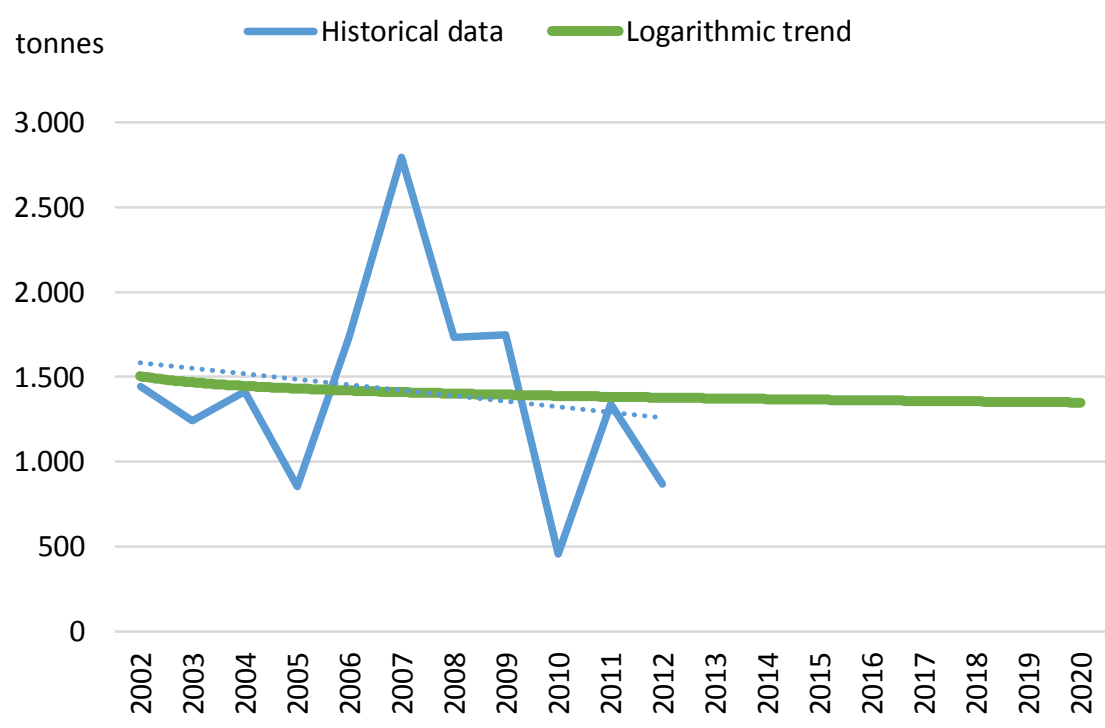




\subsection{Sweden}

The trend line for Swedish production based on the logarithmic model does also show quite a stable production over time, prolonged also until 2020 (Figure 23). Production in 2020 is estimated to be about 27,000 tonnes, more or less on the same level as in 2011.

Figure 23. Trend for production of clothes and household textiles in Sweden 2011-2020 based in a logarithmic model

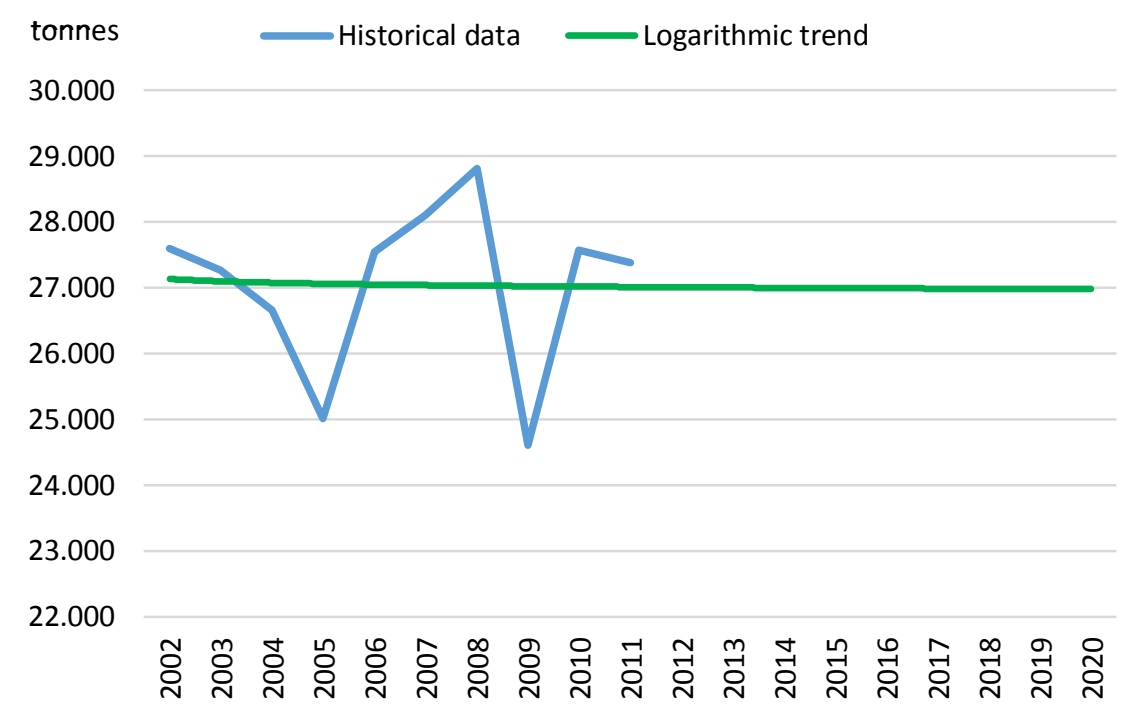




\subsection{Nordic region}

The logarithmic trend model for the whole Nordic region illustrated in Table 16 shows a slight decrease in total production in the Nordic region until 2020, from about 34,000 tons in 2011 to about 31,000 tons in 2020. This is first of all influenced by the stable production in Sweden, who contributes to a large share of the Nordic production. This compensates for a strong decrease in the Finish textile industry, as indicated by Figure 24, a slight decrease in the Norwegian industry and an increase in the Icelandic industry.

Table 16. Summarizing prognoses for production of finished clothes and household textiles in the Nordic Region 2015 and 2020 based in logarithmic models

\begin{tabular}{lrrr}
\hline Clothes and textiles (tonnes) & $\mathbf{2 0 1 1}$ & $\mathbf{2 0 1 5}$ & $\mathbf{2 0 2 0}$ \\
\hline Denmark & 357 & 389 & 411 \\
Finland & 3,633 & 1,976 & 465 \\
Iceland & 1,695 & 1,244 & 1,309 \\
Norway & 1,340 & 1,369 & 1,352 \\
Sweden & 27,375 & 26,998 & 26,980 \\
Nordic region & 34,399 & 31,977 & 30,518 \\
\hline
\end{tabular}

Figure 24. Trend for production of clothes and household textiles in Nordic region 2012-2020 based in a logarithmic model

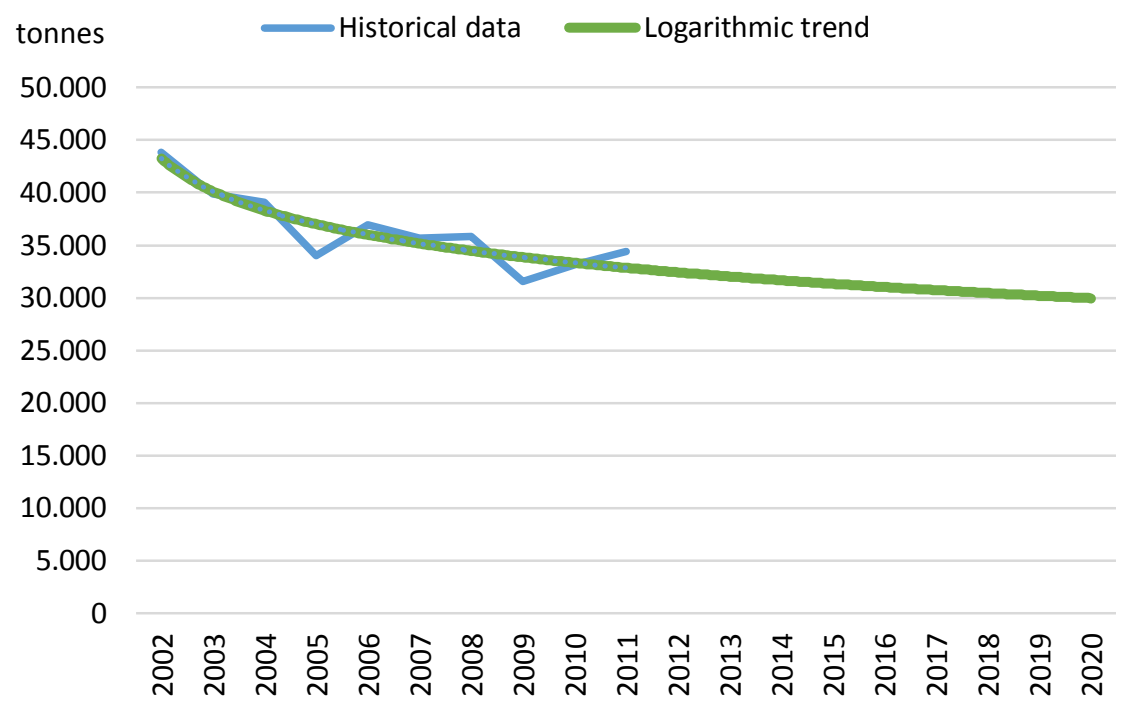

Different models for the trends were tested (see Annex B). 



\section{Prognosis for total consumption of new textiles}

The trends for the total consumption (i.e. the sum of net import and production) of textiles in the Nordic region, calculated with linear progression as described in chapters 6 and 7 is summarized in Table 17. The projections of total consumption show an increase of $19 \%$ to 2015 and $29 \%$ to 2020 compared to 2012 levels.

Table 17. Summary of prognosis for total textile consumption in the Nordic region 2015 and 2030 (using linear projection)

\begin{tabular}{|c|c|c|c|}
\hline & & 2015 & 2020 \\
\hline \multirow[t]{3}{*}{ Denmark } & Net import & 87,919 & 93,029 \\
\hline & Production & 599 & 747 \\
\hline & Total consumption & 88,518 & 93,776 \\
\hline \multirow{3}{*}{ Finland } & Net import & 65,207 & 73,735 \\
\hline & Production & - & - \\
\hline & Total consumption & 65,207 & 73,735 \\
\hline \multirow{3}{*}{ Iceland } & Net import & 4,759 & 4,822 \\
\hline & Production & 1,564 & 1,931 \\
\hline & Total consumption & 6,323 & 6,753 \\
\hline \multirow{3}{*}{ Norway } & Net import & 93,504 & 103,815 \\
\hline & Production & 1,194 & 1,032 \\
\hline & Total consumption & 94,129 & 104,451 \\
\hline \multirow{3}{*}{ Sweden } & Net import & 133,630 & 146,254 \\
\hline & Production & 26,998 & 26,980 \\
\hline & Total consumption & 160,628 & 173,234 \\
\hline \multirow{3}{*}{ Nordic region } & Net import & 385,019 & 421,655 \\
\hline & Production & 30,355 & 30,690 \\
\hline & Total consumption & 415,374 & 452,345 \\
\hline
\end{tabular}

The corresponding proportions of net import and production of total consumption are illustrated in Table 18. The share of production of new textiles compared to the total consumption of new textiles will remain low, declining from average $10 \%$ in the Nordic region in 2012 to $7 \%$ in 2015 and 2020 respectively. The only exemption is Iceland, where the share of production will remain between 25 and $30 \%$. However, the total consumption of textiles in Iceland corresponds to only $2 \%$ of the total consumption of textiles in the Nordic region. 
Table 18. Proportion of net import and production of total consumption of new textiles in the Nordic region 2015 and 2030 (using linear projection)

\begin{tabular}{|c|c|c|c|}
\hline & & 2015 & 2020 \\
\hline \multirow[t]{2}{*}{ Denmark } & Net import in \% & $99 \%$ & $99 \%$ \\
\hline & Production in \% & $1 \%$ & $1 \%$ \\
\hline \multirow{2}{*}{ Finland } & Net import in \% & $100 \%$ & $100 \%$ \\
\hline & Production in \% & $0 \%$ & $0 \%$ \\
\hline \multirow{2}{*}{ Iceland } & Net import in \% & $75 \%$ & $71 \%$ \\
\hline & Production in \% & $25 \%$ & $29 \%$ \\
\hline \multirow{2}{*}{ Norway } & Net import in \% & $99 \%$ & $99 \%$ \\
\hline & Production in \% & $1 \%$ & $1 \%$ \\
\hline \multirow{2}{*}{ Sweden } & Net import in \% & $83 \%$ & $84 \%$ \\
\hline & Production in \% & $17 \%$ & $16 \%$ \\
\hline \multirow{2}{*}{ Nordic region } & Net import in \% & $99 \%$ & $99 \%$ \\
\hline & Production in \% & $1 \%$ & $1 \%$ \\
\hline
\end{tabular}




\section{Expected future amounts of used textiles potentially available for reuse and recycling}

Based on the prognoses of future consumption of new textiles (net import and production) and average lifetime of the textile products, estimations of future amounts of used textiles and textile wastes potentially available for reuse and recycling can be made.

The amount of used textiles potentially available for reuse and recycling is listed for the individual Nordic countries as well as for the Nordic region as a whole. This allows for potential consideration of national differences in the planned strategy. The trend curves are shown from 2014 to 2020.

These amounts could be influenced by disruptive trends related to the consumption of clothing and household textiles, for instance that these become more expensive, shop-stop trends, the DIY-trend (Do It Yourself) among youngsters which supports more extensive reuse and re-design, and decreased purchasing power.

\subsection{Method}

Textiles consumed in year 1 will probably not be discarded in year 1, but a couple of years later when they are worn out or out of fashion. The estimation of life time used in the calculations in order to see when the textiles potentially would be available for reuse and recycling is 2 years for clothes and 5 years for household textiles (Laitala, et al., 2012). In comparison, Statistics Norway uses 1-5 years for clothes, footwear and leather goods, and 5-10 years for household textiles. (Laitala, et al., 2012)

The data is further based on past and prognosis for future consumption which are to be found in chapter 3, 4, 6 and 7 . 


\subsection{Denmark}

The prognosis for the expected future amounts of used textiles (clothes and household textiles) potentially available for reuse and recycling in Denmark in the period 2013 to 2020 are illustrated in Figure 25. The blue line is based on the linear future prognosis in chapter 6.2 and chapter 7.2, and the green line is based on the logarithmic trend lines in chapter 6.2 and 7.2.

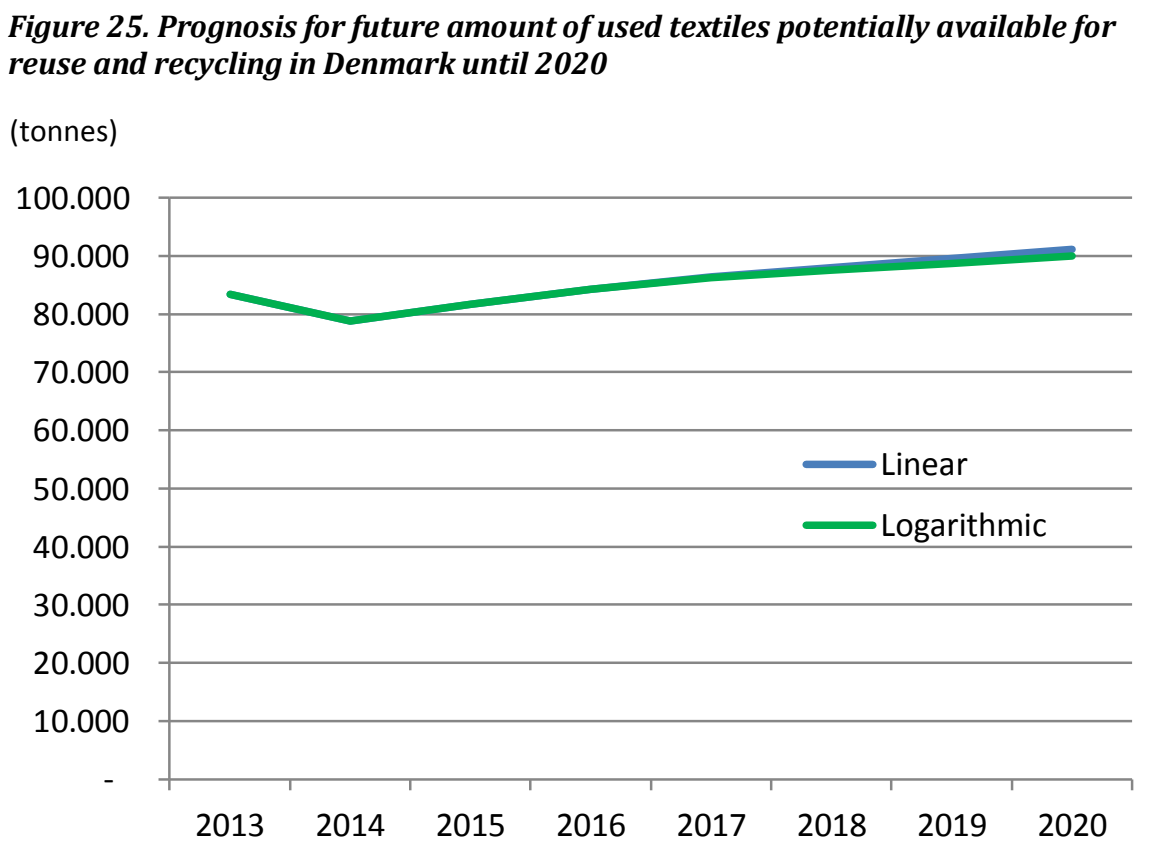

The linear prognosis of future amount of used textiles (clothes and household textiles) potentially available for reuse and recycling in Denmark is shown in Table 19; the corresponding logarithmic trend is shown in Table 20.

Table 19. Future amounts of used textiles potentially available for reuse and recycling in Denmark, linear prognosis

\begin{tabular}{lrrr}
\hline & 2013 & $\mathbf{2 0 1 5}$ & $\mathbf{2 0 2 0}$ \\
\hline Linear prognosis & 83,400 & 81,600 & 91,200 \\
Comparison to 2013 & - & $98 \%$ & $109 \%$ \\
\hline
\end{tabular}


Table 20. Future amounts of used textiles potentially available for reuse and recycling in Denmark, logarithmic prognosis

\begin{tabular}{lrrr}
\hline & 2013 & 2015 & 2020 \\
\hline Logarithmic prognosis & 83,400 & 81,600 & 89,900 \\
Comparison to 2013 & - & $98 \%$ & $108 \%$
\end{tabular}

\subsection{Finland}

The prognosis for the expected future amounts of used textiles (clothes and household textiles) potentially available for reuse and recycling in Finland in the period 2013 to 2020 are illustrated in Figure 26. The blue line is based on the linear future prognosis in chapter 6.3 and chapter 7.3 , and the green line is based on the logarithmic trend lines in chapter 6.3 and 7.3.

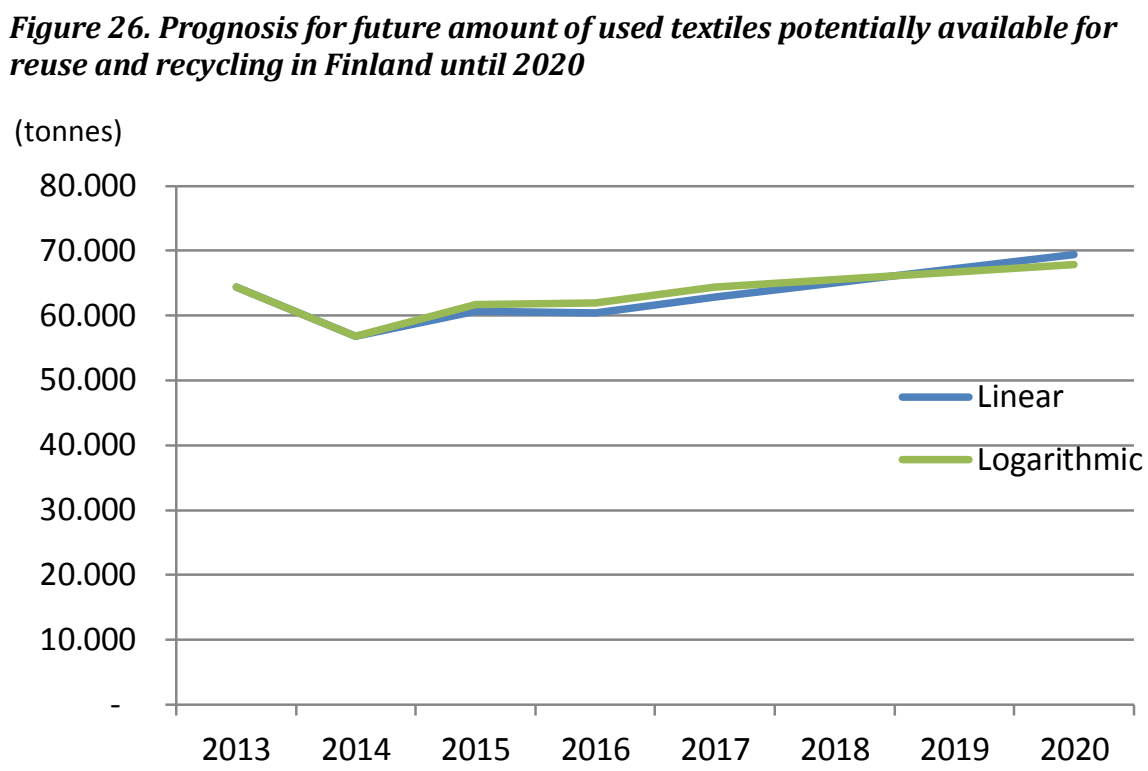

The linear prognosis for future amounts of used textiles (clothes and household textiles) potentially available for reuse and recycling in Finland is shown in Table 21; the corresponding logarithmic trend is shown in Table 22. 
Table 21. Future amounts of used textiles potentially available for reuse and recycling in Finland, linear prognosis

\begin{tabular}{lccc}
\hline & 2013 & 2015 & 2020 \\
\hline Linear prognosis & 64,400 & 60,700 & 69,500 \\
Comparison to 2013 & - & $94 \%$ & $108 \%$
\end{tabular}

Table 22. Future amounts of used textiles potentially available for reuse and recycling in Finland, logarithmic prognosis

\begin{tabular}{lccc}
\hline logarithmic prognosis & $\mathbf{2 0 1 3}$ & $\mathbf{2 0 1 5}$ & $\mathbf{2 0 2 0}$ \\
\hline Logarithmic prognosis & 64,400 & 61,700 & 67,900 \\
Comparison to 2013 & - & $96 \%$ & $105 \%$ \\
\hline
\end{tabular}

\subsection{Iceland}

The prognosis for the expected future amounts of used textiles (clothes and household textiles) potentially available for reuse and recycling in Iceland in the period 2013 to 2020 are illustrated in Figure 27. The blue line is based on the linear future prognosis in chapter 6.4 and chapter 7.4 , and the green line is based on the logarithmic trend lines in chapter 6.4 and 7.4 .

Figure 27. Prognosis for future amount of used textiles potentially available for reuse and recycling in Iceland until 2020

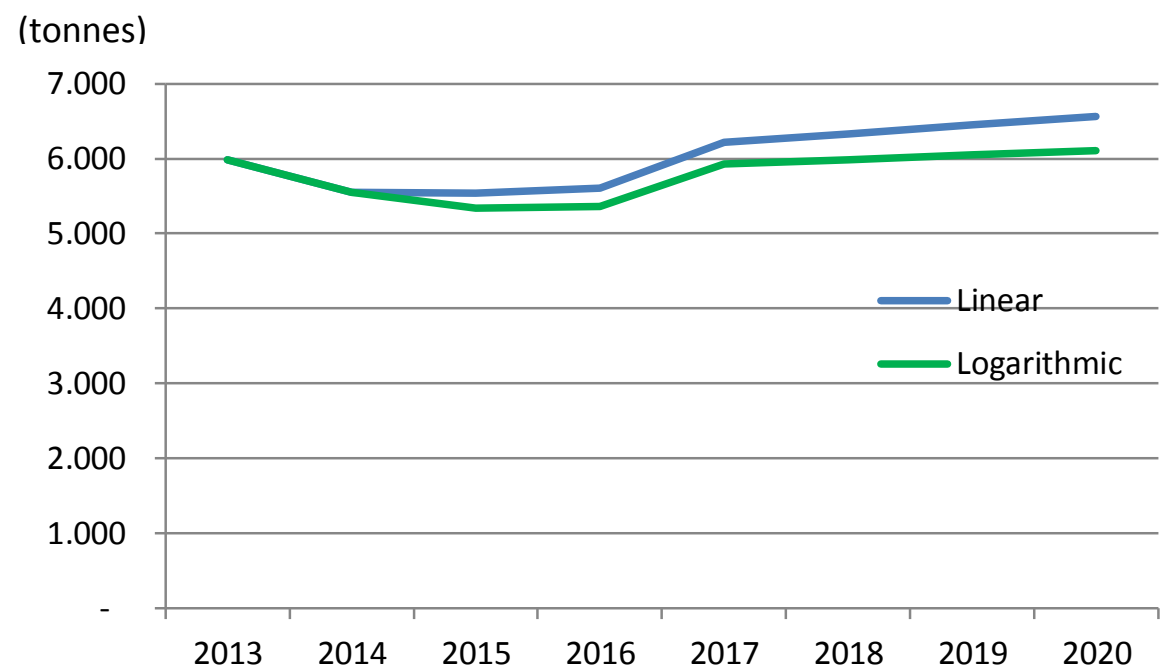


The linear prognosis for future amounts of used textiles (clothes and household textiles) potentially available for reuse and recycling in Iceland is shown in Table 23; the corresponding logarithmic trend is shown in Table 24.

Table 23. Future amounts of used textiles potentially available for reuse and recycling in Iceland, linear prognosis

\begin{tabular}{lrrr}
\hline & 2013 & $\mathbf{2 0 1 5}$ & $\mathbf{2 0 2 0}$ \\
\hline Linear prognosis & 6,000 & 5,500 & 6,600 \\
Comparison to 2013 & - & $93 \%$ & $110 \%$
\end{tabular}

Table 24. Future amounts of used textiles potentially available for reuse and recycling in Iceland, logarithmic prognosis

\begin{tabular}{lrrr}
\hline & $\mathbf{2 0 1 3}$ & $\mathbf{2 0 1 5}$ & $\mathbf{2 0 2 0}$ \\
\hline Logarithmic prognosis & 6,000 & 5,300 & 6,100 \\
Comparison to 2013 & - & $89 \%$ & $102 \%$ \\
\hline
\end{tabular}

\subsection{Norway}

The prognosis for the expected future amounts of used textiles (clothes and household textiles) potentially available for reuse and recycling in Norway in the period 2013 to 2020 are illustrated in Figure 28. The blue line is based on the linear future prognosis in chapter 6.5 and chapter 7.5 , and the green line is based on the logarithmic trend lines in chapter 6.5 and 7.5.

Figure 28. Prognosis for future amount of used textiles potentially available for reuse and recycling in Norway until 2020

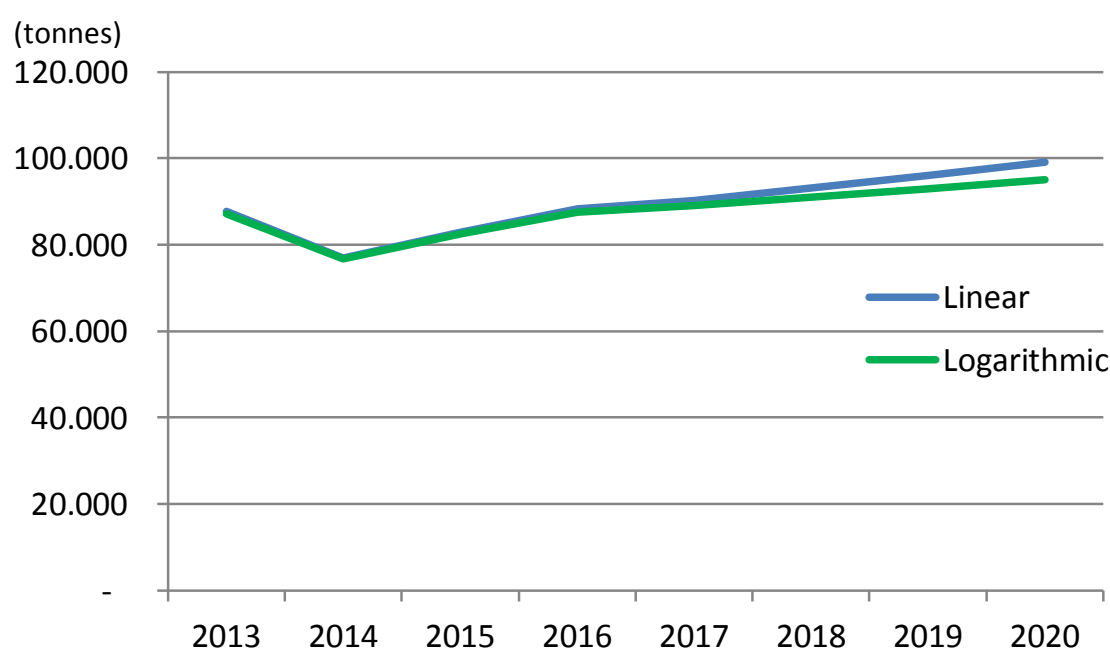


The linear prognosis for future amounts of used textiles (clothes and household textiles) potentially available for reuse and recycling in Norway is shown in Table 25; the corresponding logarithmic trend is shown in Table 26.

Table 25. Future amounts of used textiles potentially available for reuse and recycling in Norway, linear prognosis

\begin{tabular}{lrrr}
\hline & 2013 & $\mathbf{2 0 1 5}$ & $\mathbf{2 0 2 0}$ \\
\hline Linear prognosis & 87,800 & 82,800 & 99,000 \\
Comparison to 2013 & - & $94 \%$ & $113 \%$
\end{tabular}

Table 26. Future amounts of used textiles potentially available for reuse and recycling in Norway, logarithmic prognosis

\begin{tabular}{lrrr}
\hline & $\mathbf{2 0 1 3}$ & $\mathbf{2 0 1 5}$ & $\mathbf{2 0 2 0}$ \\
\hline Logarithmic prognosis & 87,200 & 82,400 & 95,000 \\
Comparison to 2013 & - & $95 \%$ & $109 \%$ \\
\hline
\end{tabular}

\subsection{Sweden}

The prognosis for the expected future amounts of used textiles (clothes and household textiles) potentially available for reuse and recycling in Sweden in the period 2013 to 2020 are illustrated in Figure 29. The blue line is based on the linear future prognosis in chapter 6.6 and chapter 7.6 , and the green line is based on the logarithmic trend lines in chapter 6.6 and 7.6.

Figure 29. Prognosis for future amount of used textiles potentially available for reuse and recycling in Sweden until 2020

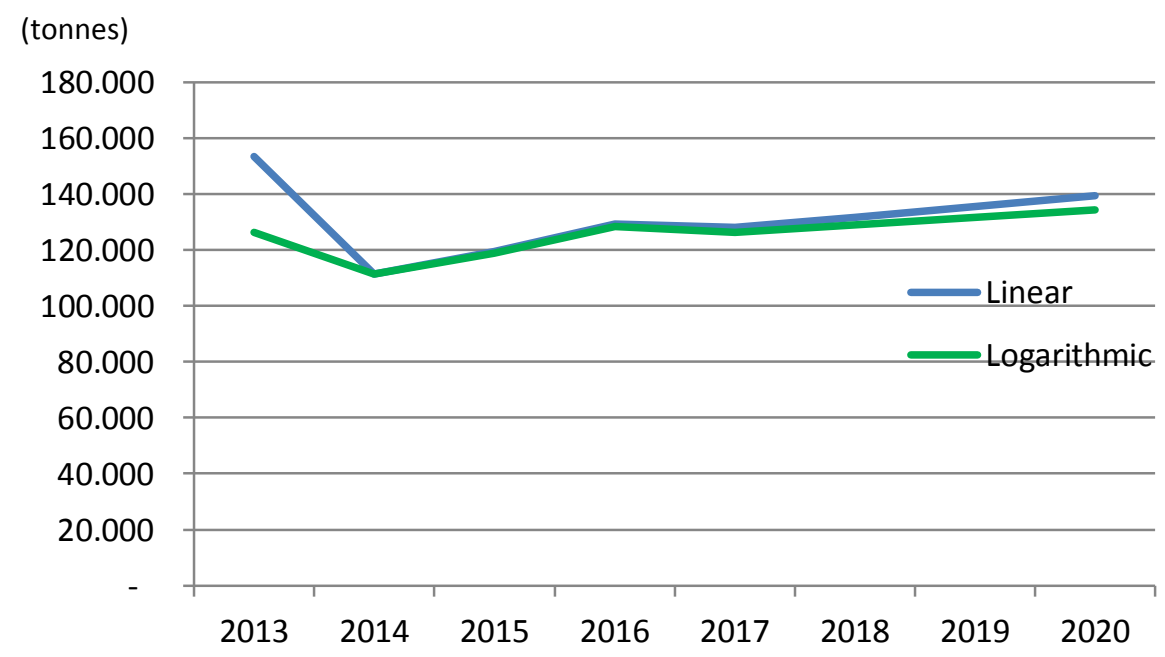


The linear prognosis for future amounts of used textiles (clothes and household textiles) potentially available for reuse and recycling in Sweden is shown in Table 27; the corresponding logarithmic trend is shown in Table 28.

Table 27. Future amounts of used textiles potentially available for reuse and recycling in Sweden, linear prognosis

\begin{tabular}{lrrr}
\hline & 2013 & 2015 & 2020 \\
\hline Linear prognosis & 153,600 & 119,500 & 139,400 \\
Comparison to 2013 & - & $78 \%$ & $91 \%$ \\
\hline
\end{tabular}

Table 28. Future amounts of used textiles potentially available for reuse and recycling in Sweden, logarithmic prognosis

\begin{tabular}{lrrr} 
& $\mathbf{2 0 1 3}$ & $\mathbf{2 0 1 5}$ & $\mathbf{2 0 2 0}$ \\
\hline Logarithmic prognosis & 126,200 & 119,000 & 134,200 \\
Comparison to 2013 & - & $94 \%$ & $106 \%$ \\
\hline
\end{tabular}

\subsection{Nordic region}

The prognosis for the expected future amounts of used textiles (clothes and household textiles) potentially available for reuse and recycling in the Nordic region in the period 2013 to 2020 are illustrated in Figure 30. The blue line is based on the linear future prognosis in chapter 6.7 and chapter 7.7, and the green line is based on the logarithmic trend lines in chapter 6.7 and 7.7 .

Figure 30. Prognosis for future amount of used textiles potentially available for reuse and recycling in the Nordic region until 2020

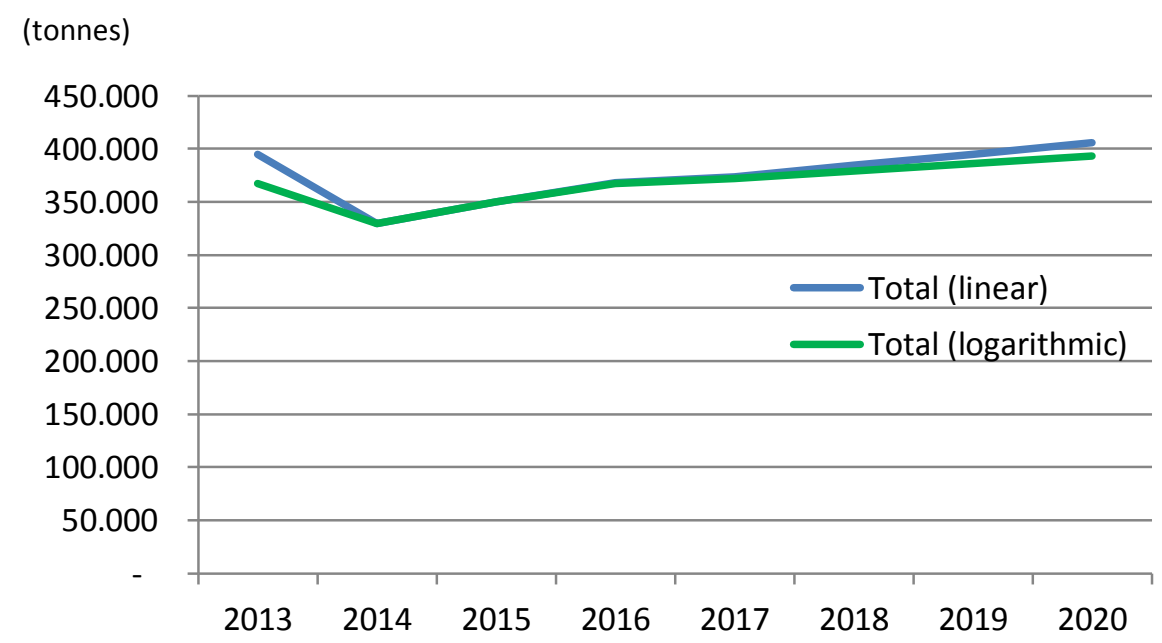


The linear prognosis for future amounts of used textiles (clothes and household textiles) potentially available for reuse and recycling in the Nordic region is shown in Table 29; the corresponding logarithmic trend is shown in Table 30.

Table 29. Future amounts of used textiles potentially available for reuse and recycling in Nordic region, linear prognosis

\begin{tabular}{lrrr}
\hline & $\mathbf{2 0 1 3}$ & $\mathbf{2 0 1 5}$ & $\mathbf{2 0 2 0}$ \\
\hline Linear prognosis & 395,100 & 350,200 & 405,600 \\
Comparison to 2013 & - & $89 \%$ & $103 \%$
\end{tabular}

Table 30. Future amounts of used textiles potentially available for reuse and recycling in the Nordic region, logarithmic prognosis

\begin{tabular}{lrrr}
\hline & 2013 & 2015 & 2020 \\
\hline Logarithmic prognosis & 367,100 & 350,000 & 393,100 \\
Comparison to 2013 & - & $95 \%$ & $107 \%$ \\
\hline
\end{tabular}




\section{Conclusions}

The work has shown some challenges in collecting and comparing data from different countries as well as from foreign trade statistics and production statistics. Nevertheless, the data presented on current trends as well as the prognoses made within this project are considered to give a good overview of the situation in the Nordic region.

The prognoses and trends are based on historical data from $2000 / 2002$ to 2012. It should be noted, that the use of shorter or longer time periods might have impacted the prognoses and trends to some extent. It is also clear that the financial crisis that started in 2008 has had a clear impact on the consumption of textile, as for many other products. The future economic development in the Nordic region will surely have an effect on consumption of new textile. Sensitivity analyses for this were not within the scope of the project.

The trends for the total consumption of textiles in the Nordic region are increasing. According to the prognoses made the total consumption of clothes and household textiles will increase by $19 \%$ to 2015 and by $29 \%$ to 2020 in the Nordic region as a whole compared to the 2012 level.

According to the linear prognosis the net import of textiles to the Nordic region correspond to 401,000 tonnes in 2015 and 450,000 tonnes in 2020 . This represent an increase by $27 \%$ and $42 \%$ respectively compared to the 2012 level. A logarithmic trend would correspond to textiles net import of 397,000 tonnes in 2015 and 417,000 tonnes in 2020 . This represent an increase by $26 \%$ and $32 \%$ respectively compared to the 2012 level.

The logarithmic prognosis for the production of clothes and household textiles in the Nordic region shows decreases by 5\% to 2015 and by 9\% to 2020 compared to 2012 level. The linear trend shows a continuous decrease in total production until 2020, from about 33,000 tons in 2012 to about 30,000 tons in 2020 .

The production of clothes and household textiles is small compared to the total textile industry in each country and especially compared to the net import. The prognoses illustrate that the proportion of production of total consumption of new textiles in the Nordic region will decrease from $10 \%$ in 2012 to $7 \%$ in 2015 and 2020 respectively. The only exemption is

Iceland, where the share of production compared to total consumption of 
clothes and household textiles will remain between 25 and 30\%. However, the total consumption of textiles in Iceland corresponds to only $2 \%$ of the total consumption of textiles in the Nordic region.

According to the prognoses made, the expected amounts of used textiles (clothes and household textiles) are increasing. The linear prognosis predicts the future amounts potentially available for reuse and recycling in the Nordic region to be 350,000 tonnes in 2015 and 406,000 tonnes in 2020. This corresponds to $89 \%$ and $103 \%$ of the calculated amount available in 2013 respectively. The future amounts of used textiles potentially available for reuse and recycling in the Nordic region based on a logarithmic trend corresponds to 350,000 tonnes in 2015, and 393,000 tonnes in 2020. This corresponds to $95 \%$ and $107 \%$ of the calculated amount available in 2013 respectively.

For future waste management of textiles, recycling technology still needs to be developed further. With only a few niche closed loop recycling technologies, downcycling will likely be the only industrial scale recycling option for the near future. 


\section{References}

Aftenposten. (2nd August 2012). Nordmenn er søppel-verstinger. Retrieved from http://www.aftenposten.no/okonomi/Nordmenn-er-soppel-verstinger6953951.html

Brismar, A. (2014). Textila Strömmar och förbehandlingsmetoder för textilfiberåtervinning. Green Strategy.

Cassidy, T. D., \& Han, S. L.-C. (2013). Upcycling fashion for mass production. In M. A. Gardetti, \& A. L. Torres, Sustainability in Fashion and Textiles (pp. 148-163). Sheffield: Greenleaf Publishing Limited.

Chua, J. M. (2014, 1). Ecouterre. Retrieved 2 17, 2014, from Ecouterre: http://www.ecouterre.com/san-francisco-launches-city-wide-zero-waste-textilerecycling-initiative/

Cline, E. (2012). Overdressed. The shockingly high cost of cheap fashion. . New York: Penguin Group.

Elander, M. (2014). Participation in the 1st Congress of the Textile Recycling Valley "The second life for textile materials".

Elander, M., Kiorbøe, N., \& Palm, D. (2013). Literature review of the tracebility of global textile flows. IVL.

Elander, M., Kiorbøe, N., \& Palm, D. (2013). Litterature review of the traceability of global textile flows. IVL.

Fletcher, K. (2008). Sustainable fashion and textiles. London, UK.

Gardetti, M. A., \& Torres, A. L. (2013). Sustainability in Fashion and Textiles. Values, Design, Production and Consumption. Sheffield: Greenleaf Publishing Limited.

Goworek, H., Hiller, A., Fischer, T., Cooper, T., \& Woodward, S. (2013). Consumers' attitude towards sustainable fashion. Clothing usage and disposal. In M. A. Gardetti, \& A. L. Torres, Sustainability in Fashion and Textiles (pp. 376-392). Sheffield: Greenleaf Publishing Limited.

Kiorbøe, N., Watson, D., Elander, M., Lyng, K.-A., Gislason, S., \& Palm, D. (2013). Mapping of current actors in the collection, sorting, reuse and recycling of used textiles and the management of textile wastes.

Laitala, K., Klepp, I. G., Morley, N., Meistad, T., Chapman, A., Chen, W., et al. (2012). $\emptyset k t$ materialgjenvinning av tekstilavfall og andre avfallstyper (papir/papp, metall og glass). Oslo: SIFO Statens Institutt for forbruksforskning.

Niinimäki, K., \& Hassi, L. (2011). Emerging design strategies in sustainable production and consumption of textiles and clothing. Journal of Cleaner Production (19), pp. 1876-1883.

Palm, D., Dahlbo, H., Moliis, K., \& Tekie, H. (2013). Collection and sorting systems. Gothenburg: IVL.

Palm, D., Dahlbo, H., Moliis, K., \& Tekie, H. (2014). Collection and sorting systems.

Palm, D., Elander, M., Watson, D. K., Salmenperä, H., Dahlbo, H., Moliis, K., et al. (2013). A Nordic strategy for collection, sorting, reuse and recycling of textiles. IVL Svenska Miljöinstitutet. 
Palm, D., Harris, S., \& Ekvall, T. (2013). Livscykelanalys av svensk textilkonsumtion Underlagsrapport till Naturvårdsverkets regeringsuppdrag om nya etappmål. Göteborg: IVL Svenska Miljöinstitutet.

Returtex. (2014). Alla vinner på återvinning. Retrieved from http://www.returtex.se/\#front

Shoppestopp. (2014). Facebook group: Shoppestopp 2014. Retrieved from https://www.facebook.com/Shoppestopp2014?fref=ts

Sigurðsson, A. (2014, 2 21). Personal communication.

Statistics Denmark. (2014a, January). StatBank Denmark. Copenhagen.

Statistics Denmark. (2014b, February). StatBank Denmark, Manufacturing sales by SITC groups. Copenhagen.

Statistics Iceland. (2014a, January). Imports and exports by groups of the SITC Rev. 4. Reykjavík.

Statistics Iceland. (2014b, February). Income from manufacturing in the industry. Reykjavik.

Statistics Norway. (2014a, January). Statbank: External trade in goods. Oslo.

Statistics Norway. (2014b, February). Statbank: Sold production from industrial companies in Norway. Oslo.

Statistics Sweden. (2014a, January). Statistical Database Trade in goods and services Foreign trade - exports and imports of goods. Stockholm.

Statistics Sweden. (2014b, February). Statistical Database Income from industrial production in companies based in SNI 2007. Stockholm.

Swedish EPA. (2013). Förslag till etappmål - Textil och textilavfall. Retrieved April 2014, from Textil och textilavfall - förslag till nytt etappmål i miljömålssystemet: http://www.naturvardsverket.se/upload/miljoarbete-i-samhallet/miljoarbete-isveri-ge/regeringsuppdrag/2013/etappmal2013forslag/etappmal2013forslagtextilavfall.pdf

Tulli. (2014a, January). ULJAS Statistical database (Foreign Trade Statistics CN). Espoo.

Tulli. (2014b, February). ULJAS Statistical database. Industrial Production Statis-tics. Espo. Helsinki.

Valente, C., Lyng, K.-A., Palm, D., \& Rydberg, T. (2013). Technology review of sorting and recycling of textiles. IVL.

Valente, C., Lyng, K.-A., Palm, D., \& Rydberg, T. (2014). Technology review of sorting and recycling of textiles.

Virgin, K. (2014). Jakten på det vita guldet. Ingenjören, p. 41.

Zamani, B. (2011). Carbon footprint and energy use of textile recycling techniques Case study Sweden MSc Thesis. Gothenburg: Chalmers University of Technology. 
Collection, sorting, reuse and recycling scenarios 



\section{Introduction}

The trend in textile consumption shows increasing per capita consumption. This results in higher expected amounts of used textiles (clothes and household textiles). In the previous subreport, linear and logarithmic prognoses were made for future amounts of used textiles potentially available for reuse and recycling in Nordic region. According to these prognoses, annually 393,000-406,000 tonnes of used textiles will be available by 2020 . This corresponds to an increase by $3-7 \%$ compared to 2013 level.

The objective of this subreport was to develop four different scenarios based on the assumption of increasing volumes used textiles potentially available for reuse and recycling. The different scenarios will affect different parts in the value chain in different ways; there will be winners and losers; trade-offs might be necessary to reach a positive development of key factors. This is addressed in the developed scenarios.

The findings of this subreport are divided into the following chapters:

- Chapter 4: Different parts of the value chain for used textiles and textile wastes.

- Chapter 5: Scenario 1: Business as usual.

- Chapter 6: Scenario 2: Nordic cooperation.

- Chapter 7: Scenario 3: National strategies.

- Chapter 8: Scenario 4: Nordic innovation. 



\section{Definition of scenarios}

The time frame used for the scenarios is 2020 . This represents the mid-term perspective used in the development of prognoses for textile consumption.

Four scenarios were developed along two axes (see Figure 31):

- Level of change.

- Level of cooperation (between the countries in the Nordic region).

Figure 31. Mapping of the four different scenarios according to their level of change and their level of cooperation between the countries in the Nordic region

\begin{tabular}{|c|c|c|c|}
\hline \multirow{2}{*}{ 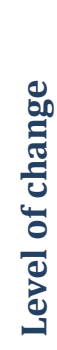 } & \multirow{2}{*}{$\begin{array}{l}\text { High } \\
\text { Low }\end{array}$} & $\begin{array}{c}\text { Scenario 3: } \\
\text { Multiple strategies }\end{array}$ & $\begin{array}{c}\text { Scenario 4: } \\
\text { Nordic innovation }\end{array}$ \\
\hline & & $\begin{array}{c}\text { Scenario 1: } \\
\text { Business as usual }\end{array}$ & $\begin{array}{c}\text { Scenario 2: } \\
\text { Nordic cooperation }\end{array}$ \\
\hline & & Low & High \\
\hline
\end{tabular}

It was assumed that different aspects of collection, sorting, reuse and recycling would change within the scenarios. For all scenarios aspects from all these areas were described and combined, building the scenarios. 



\section{Key factors for the scenarios}

The four scenarios and their implications for selected key factors are described in chapters 5-8. The key factors identified correspond to the key factors in the proposal:

- Attractive collection

Attractive collection includes that collection of used textiles and textile wastes should be easy for the consumers to use. The consumers can be private and corporate consumers.

- Collection for both reuse and recycling

The collection of used textiles and textile wastes should include flows for reuse as well as flows for recycling. Regarding used textiles the collection should allow and include elements to prioritize reuse.

- Collection securing high quality flows

Collected textiles should be uncontaminated as far as possible by other wastes to ensure the possibility for both reuse, high-grade recycling and a proper waste management of residues following sorting.

- Cost efficient collection, sorting and reuse/recycling Collection, sorting and reuse/recycling should be cost efficient to ensure a long term functioning textile collection.

- Minimising overall environmental impacts from collection, sorting and reuse/recycling

Collection, sorting and reuse/recycling should be arranged in a manner where lowest possible overall environmental impact is aimed for when considered from a lifecycle perspective.

- Creation of green jobs

Collection, sorting and reuse/recycling should if possible create green jobs within the Nordic region. 



\section{Different parts of the value chain for used textiles and textile wastes}

This chapter describes the different parts and the different actors in the value chain for used textiles and textile wastes.

The main steps of the value chain of pre-consumer textile wastes can be divided into production, wholesale and retail. The main steps of the value chain of post-consumer used textiles and textile wastes (including corporate used textiles and textile wastes) can be divided into collection, de-branding, pre-sorting, trading, sorting, reuse, recycling and waste treatment (excluding recycling).

\subsection{Pre-consumer textile wastes}

Pre-consumer textile waste consists of by-product materials from the textile and clothing industries.

\subsubsection{Production in the Nordic region}

The textile manufacturing industry generates different types of textile waste in the manufacturing process; e.g. seam waste, scraps from the cutting and making up processes, end of rolls waste and defective items. Waste reduction could for instance be realized by reduction of cuts and by using left-over fabrics as by-products. The manufacturing waste streams can to some extent be recycled in-house for fibre and yarn manufacture (Cassidy \& Han, 2013). The remaining waste is either sent to recycling or other waste treatment. Within this project, no information could be found regarding the extent of in-house recycling in the Nordic textile industries.

Recycled textile fibres (e.g. polyester, wool and cotton) can be used in the production of new textiles and in the manufacturing of new clothing and household textiles. Some larger Nordic clothing manufacturers have started to use recycled materials in their clothing production. However, 
it was not possible within this project to define to which extent recycled textile fibres are used in the Nordic textile industries.

In addition, used and recycled textiles are to smaller extent used by handicraftsmen and artisans in the Nordic region. These actors use the used or recycled textiles for producing new, high-value products (i.e. upcycling fashion) (Cassidy \& Han, 2013).

Recycled textile fibres are also used to produce lower grade products (downcycling); e.g. industrial wipes, paper, thermal and acoustic insulation.

\subsubsection{Wholesale and retail sale}

Both wholesalers and retailers will generate textile waste in the form of unsold, never worn surplus stock (Cassidy \& Han, 2013) as well as damaged and defect garments and textiles. Sales (with lower prices) are typically used by retailers to decrease the amount of un-sold garments. The flows of unsold textiles and textile waste from wholesalers and retail sale are currently not known. Neither is it known where these flows go and how they are treated. Even though being out of scope of this project, this is an interesting area where there might be high potential for improvement.

\subsection{Post-consumer used textiles and textile wastes}

\subsubsection{Consumption}

Textiles can be consumed by households (private consumption) or by organisations, companies, authorities and institutions (corporate consumption).

\section{Private consumption}

The private consumer can follow different strategies when buying textile products, such as clothes and household textiles. The most common strategy is to buy new textiles. However, consumers can also buy used textiles or swop used textiles. There is a large range of possibilities to buy used garments (including online options).

In the user phase, the consumer can prolong the life of the textiles through careful washing, cleansing, drying, and ironing in line with the declaration label found at the specific item. Repair of damaged items is rarely done by consumers due to insufficient time or skills and the low price of replacing it (Goworek, Hiller, Fischer, Cooper, \& Woodward, 2013). Clothes and household textiles which are either damaged or not 
found suitable for use can be reworked or restyled by the consumer. Other ways to extend the life of garments is to use it for other purposes, as for decorating or gardening or as cleaning rags or dusters (Goworek, Hiller, Fischer, Cooper, \& Woodward, 2013).

Clothes and household textiles are typically discarded because they are worn out, damaged, outgrown or have gone out of fashion. How the used textiles are discarded vary e.g. dependent on consumer's habits, economy and collection opportunities. The main part of the used textiles and textile wastes from households in the Nordic region is not collected separately, but rather disposed of via the residual waste collection, in spite of options for separate textile collection (see section 4.2.2).

There are also many options for donating or selling used textiles to other consumers (see section 4.2.7).

\section{Corporate consumption}

Used clothes and textiles are also arising from the business and public sectors. This could be linen, towels and other household-like textiles from business laundries, hotels, hospitals, restaurant and institutions like home for elderly, nursing homes, kindergartens and prisons. Used clothes as uniforms also arise from all sorts of organisations like transport companies, police, fire fighter departments, military, municipal companies, security companies and craftsmen. All of these textiles are interesting in terms of reuse and/or recycling, since they constitute a relatively large and homogenous group of textiles with high quality which could be relatively easy to collect (Elander, Kiorbøe, \& Palm, Literature review of the tracebility of global textile flows, 2013). However, the collection of used corporate clothes and textiles is very limited, and according to Elander et al. (2013) these textiles are mostly incinerated or exported. Especially the laundries could provide a homogenous fraction for recycling, but amounts are fairly small compared to the overall textile flows. ${ }^{3}$

The actors would probably act differently in the disposal phase if the used clothes and textiles could be securely collected and de-branded (see section Fejl! Henvisningskilde ikke fundet.). Better information regarding the benefits of reusing or recycling the used items could probably also alter current practice towards increased collection.

${ }^{3}$ In Sweden the potential was estimated by (Brismar, 2014) to be close to 800 tonnes annually. 


\subsubsection{Collection}

There is a range of actors collecting used textiles in the Nordic countries. The collection can be based on kerbside collection outside the citizens' homes, door-step bag collection, via containers placed in municipal recycling centres, at business centres or parking areas, and in shops to which people can bring their used textiles. Some collectors only collect clothes and textiles which are still usable, i.e. undamaged and clean. Some collectors collect all used textiles independent of state.

In the following different actors which collects used clothes and household textiles are described.

\section{Charitable organisations}

The most common way to separately collect used textiles is to donate them to charitable organisations. The collection is typically carried out via textile containers placed at recycling centres, public places or business centres and via second hand shops. Emptying of the containers and transportation of the collected textiles can either be done by the municipality or by the charity organisation. The charitable organisations uses the money raised from the collection and trade of used textiles to help fund their activities and achieve their charitable missions.

\section{Private companies}

The used textiles can also be donated (or sold) to different types of private companies. The actors use different ways to collect the used textiles, including kerbside collection, textile container collection and in shop collection. Examples of these actors are:

- Commercial collectors (e.g. recycling companies and private waste companies).

- Second-hand stores (not run by municipalities and charitable organisations).

- Clothing retailer stores collecting textiles for reuse/recycling (e.g. H\&M and Jack \& Jones cooperating with I:Collect).

- Clothing retailer stores collecting used textiles for second-hand sale and campaigns (e.g. Swapstories by Haglöfs).

- Clothing banks.

These actors could be purely commercial or collaborate with charity organisations (i.e. passing on the collected textiles). 


\section{Municipalities}

Municipal waste companies can collect used textiles via kerbside collection, textile containers or recycling centres. Another possibility for separate collection is that municipalities contract (private) waste collectors for the collection of used textiles and textile wastes.

Municipalities can also cooperate with charitable organisations, e.g. by allowing them to place collection containers at recycling centres and other public places. In these cases, the municipalities can either be responsible for emptying the containers (e.g. Fretex in Norway) or the charitable organisations do this on their own (e.g. UFF in Norway).

The municipal waste companies collect the textiles which have been deposed of in the residual waste.

\section{Other actors}

Used textiles can also be collected by other actors, typically for fund raising or disaster/emergency relief purposes. Examples of such actors are:

- Sports teams and other leisure organisations.

- Schools.

- Churches.

- Private disaster/emergency relief initiatives (not led by charitable organisations).

The textiles can be collected via kerbside collection or container collection. Some actors are collaborating with a charity organisation or a private company, passing on the collected textiles to their collaborator. The collected textiles could also be used for instance for arranging flea markets/jumble sales. The items remaining after such events are often handed over to a charity organisation and/or delivered to a waste management facility.

\subsubsection{De-branding}

Secured de-branding services, i.e. removal of names, logos and other identifiable material, are needed for most textile waste deriving from corporate consumption. For the most sensitive used textile the debranding would mean shredding the materials, which then can be used for mechanical recycling. The de-branding service will ensure that sensitive textile materials are managed in a way acceptable to their donators.

Currently, there are not many actors offering this service in the Nordic region. However, this is a service which could be provided by both 
charitable and private actors. The most appropriate would probably be for the collector of the corporate used textiles to provide this service, or at least be accountable if this is a sub-contacted service.

\subsubsection{Pre-sorting}

A part of the used textiles collected in the Nordic region is pre-sorted into a small number of textile fractions. This is e.g. the case when a part of the collected textiles is intended for sale on the Nordic second-hand market. The pre-sorting is carried out manually. In some cases the presorting is only carried out in terms of textiles that are suitable for direct reuse in the collector's own shops, leaving the rest of the textiles relatively unsorted to be sold as bulk to sorters abroad (Kiorbøe, Watson, Elander, Lyng, Gislason, \& Palm, 2013).

In the Nordic region, predominantly charitable organisations carry out pre-sorting. Typical textile fractions from pre-sorting are:

- Textiles suitable for reuse on the domestic market/in own stores.

- Textiles suitable for reuse and/or recycling elsewhere.

- Textiles not suitable for reuse and/or recycling.

\subsubsection{Sorting}

The actors involved in sorting of separately collected textiles sort these in different fractions, i.e. suitable for reuse, recycling or disposal. Some sorting companies use semi-automated or fully automated sorting technologies (Palm D. , Dahlbo, Moliis, \& Tekie, 2013). However, the most common way to sort the collected textiles is by manual sorting. Reusable clothes in very good condition, still fashionable or clothes having retro value are sorted to be sold in the country of origin or in other European markets, e.g. in second-hand stores. Clothes that are still wearable and in good condition are often sorted into a fraction that is given for charity or sold in developing countries. Products are typically graded according to their condition, colour, type, season (for instance winter clothing), composition, target group (for instance gender, children), to name a few possible categories. (Palm D. , Dahlbo, Moliis, \& Tekie, 2013)

\section{Charitable organisations}

The sorting is mostly done by volunteers or by social firms, whose objective is to activate the long-term unemployed (Kiorbøe, Watson, Elander, Lyng, Gislason, \& Palm, 2013). Collectors like UFF, Red Cross and the 
Salvation Army also operate sorting centres. Some of the charitable organisations run their own second-hand stores, selling the collected and sorted items suitable for reuse. These actors are thus dependent on sorting facilities (most often their own) to identify sellable items.

\section{Private companies}

The commercial sorting facilities used by Nordic actors are mainly situated in Central and Eastern Europe (Kiorbøe, Watson, Elander, Lyng, Gislason, \& Palm, 2013). From these central sorting plants textiles are either sent for reuse in countries around the world or recycling (either inhouse or at external facilities) or sent for waste treatment like incineration or landfilling. (Kiorbøe, Watson, Elander, Lyng, Gislason, \& Palm, 2013).

\section{Municipalities}

The municipal waste associations which themselves collects used clothes and textiles could operate their own sorting facilities, or hand over the collected used textiles to charities or other sorting actors.

Potential sorting of textile waste from residual waste could be relevant in the future (e.g. in new, more centralized sorting plants, could include the use of NIR or other types of sorting technologies).

\subsubsection{Trading}

Small Nordic collectors tend to cooperate with larger collectors regarding the export of textiles since the larger collectors have more resources to run the export. The larger charitable organisations and private collectors often implement the export via European partners such as logistics firms and/or directly with the sorting facilities. (Kiorbøe, Watson, Elander, Lyng, Gislason, \& Palm, 2013).

Several organisations operate as traders in this market. Some examples are:

- Fretex International.

- KICI Foundation.

- German SOEX Group.

- Belgian Rimatex.

- The Boer Group.

- Red Cross in Iceland (operating as middle man for the other charity organisations (Kiorbøe, Watson, Elander, Lyng, Gislason, \& Palm, 2013). 
- Private textile export and trading actors (e.g. http://www.martinrood.eu/).

- UFF.

- HUMANA in Finland.

\subsubsection{Reuse}

The reusable clothes and textiles can be sold on the second-hand market as they are or used to produce redesigned products. The actors involved in reuse could be purely commercial or run by charities.

\section{Charitable organisations}

Charitable organisations can have multiple roles in the reuse market for textiles. Some of these roles are related to their domestic market, such as second hand shops and upcycling activities. However, the largest proportion of the wearable clothes and usable textiles are typically sold or donated for reuse on the international market.

Some examples of roles and activities run by charitable organisations are:

- Second hand shops.

- Clothing/textile libraries.

- Upcycled product making.

- Sell, donate or facilitate for reuse and disaster/emergency relief.

- Sheltered workshops for rag production.

\section{Private companies}

Private companies can have multiple roles in the reuse market for textiles. Some actors are involved in the domestic reuse markets, e.g. via second-hand shops and upcycling. Some actors are mainly selling reusable textiles on the international market. Other actors are more facilitators, establishing platforms for reuse.

Some examples of actors are: 
- Second hand shops (not run by charitable organisations).

- Clothing retail stores with second-hand corner.

- Clothing/textile libraries.

- Upcycling actors.

- Private companies selling for reused outside the Nordic countries.

- Online market-places.

\section{Consumer to consumer}

There is also a variety of consumer to consumer interactions related to reuse of clothes and textiles. Some of these do not include any financial transactions. Examples of this could be exchange of clothes between friends and family, or swapping or "swish" parties.

Examples of alternatives which include financial transactions are:

- Car boot sales and private garage sales.

- Private sales via online market-places and auctions.

- Private sales via second-hand shops ("on commission").

- Platforms which facilitate peer-to-peer exchanges (e.g. clothing libraries).

- Online swapping (swishing) services.

- Exchange of clothes between family and friends, for instance swapping or "swish" parties.

These are all alternatives which demand for the consumer to take on a more active role in the disposal phase. The willingness to do this is probably dependent on for instance the consumer's consciousness related to consumption, economy and the state and value of the unwanted clothes or textiles.

\subsubsection{Recycling}

The recyclers will receive used clothes and textiles not suitable for reuse. In Europe, the available large scale recycling is mechanical. The recyclers can have two different roles; either as producer of raw material for further processing elsewhere, or both as producer of raw materials and new products from the recycled materials. Textile recycling in the Nordic countries is currently almost inexistent due to lack of available recycling technologies and high operating costs (Valente C. , Lyng, Palm, \& Rydberg, 2013). 
The issue of hazardous substances in the recycling of textiles is to a far extent unexplored but will likely become increasingly important in a situation with textile to textile recycling. The issue is however, as for most recycling, best handled by removing the substances from the virgin production. Researchers at the Royal Institute of Technology have investigated the issue of hazardous chemicals in relation to the Re:newcell recycling process and found that most chemicals have been washed out of the textile or will be removed when textile is decolorized. The one exception being bromated flame retardants which are still an issue. (Virgin, 2014).

In the following text, a distinction is made between textile to textile recycling and other textile recycling. In textile to textile recycling the recycled textile fibres are used to manufacture new textiles; e.g. clothing and household textiles. In other textile recycling the recycled textile fibres are used to manufacture lower grade textile products; e.g. acoustic and thermal insulation.

\subsubsection{Textiles to textiles recycling}

\section{Upcycling/reworking}

Upcycling of used clothes and textiles to new clothing, household textiles and other textile products has started to gain ground in the market. This is today also often called reworked fashion/clothes. Reworkers typically takes used clothes (or clothes which has not been sold i.e. never used) transforming and revitalising them into new fashion clothes or accessories. Accessories could be handbags, shopping bags and glasses cases. Activities included in the reworking process will typically be sorting of the textiles, deconstruction/unpicking, cleaning and manufacturing of new products. Reworkes/upcycling actors are typically small-scale, independent private companies operating on a local market. However, also some charities are making new, high-value products from used textiles (i.e. Fretex in Norway, TRAID in UK). These actors could be important in creating a new markets based on usable; however not directly reusable, textiles.

\section{Mechanical recycling}

Most of the textile waste in Europe is recycled mechanically (Valente C. , Lyng, Palm, \& Rydberg, 2013). The recycling process typically includes sorting by type of material and potentially colour sorting, shredding and potentially re-spinning (yard or thread). The materials produced could 
be used to produce new textiles and hence, new clothes (e.g. recycled materials used in collections from for instance H\&M and Lindex).

\section{Chemical recycling}

Chemical recycling is used for synthetic fibres (polyester, nylon etc.), mixed fibre (synthetic and natural) or cellulose fibers in order to produce new fibres, and hence new textiles (e.g. Teijin process for chemical recycling of polyester, Re:newcell for cellulose fibers).

\section{Other textile recycling}

Other types of recycling most often comprise down-cycling; i.e. the material is used to produce lower grade products (Cassidy \& Han, 2013). Also within this category the recyclers could have two different roles; either as producer of raw material for further processing elsewhere, or both as producer of raw materials and producer of new products from the recovered materials.

\section{Mechanically recycling}

Down-cycled mechanically recycled fibres are used for e.g. non-woven products and paper (Kiorbøe, Watson, Elander, Lyng, Gislason, \& Palm, 2013). Simple cutting into rags is also a common recycling. (Valente C. , Lyng, Palm, \& Rydberg, 2013)

\section{Chemical recycling}

Fibres recovered via chemical recycling could also be used in final (down-cycled) products as upholstery in the car sector and home furnishing. (Valente C. , Lyng, Palm, \& Rydberg, 2013)

\subsubsection{Waste management excluding recycling}

Not separately collected used textiles from households are collected via the municipal waste collection and incinerated or landfilled. It is assumed that most of the corporate used textiles and textile wastes are incinerated. This is also assumed to be the case for textiles that are not found useful for reuse and/or recycling at various stages in the value chain (i.e. pre-sorting, sorting etc.).

Incineration could be done with or without energy recovery. The textiles could also be cut in pieces, compacted, pelletized and used as fuels in boilers or used in ethanol or biogas production (Valente C. , Lyng, Palm, \& Rydberg, 2013).

The waste management facilities are either operated by municipal waste associations or private waste management companies. 



\section{Scenario 1: Business as usual}

\subsection{Description of the scenario}

Figure 32. Scenario 1 "Business as usual" is characterized by low level of change and low level of cooperation between the countries in the Nordic region

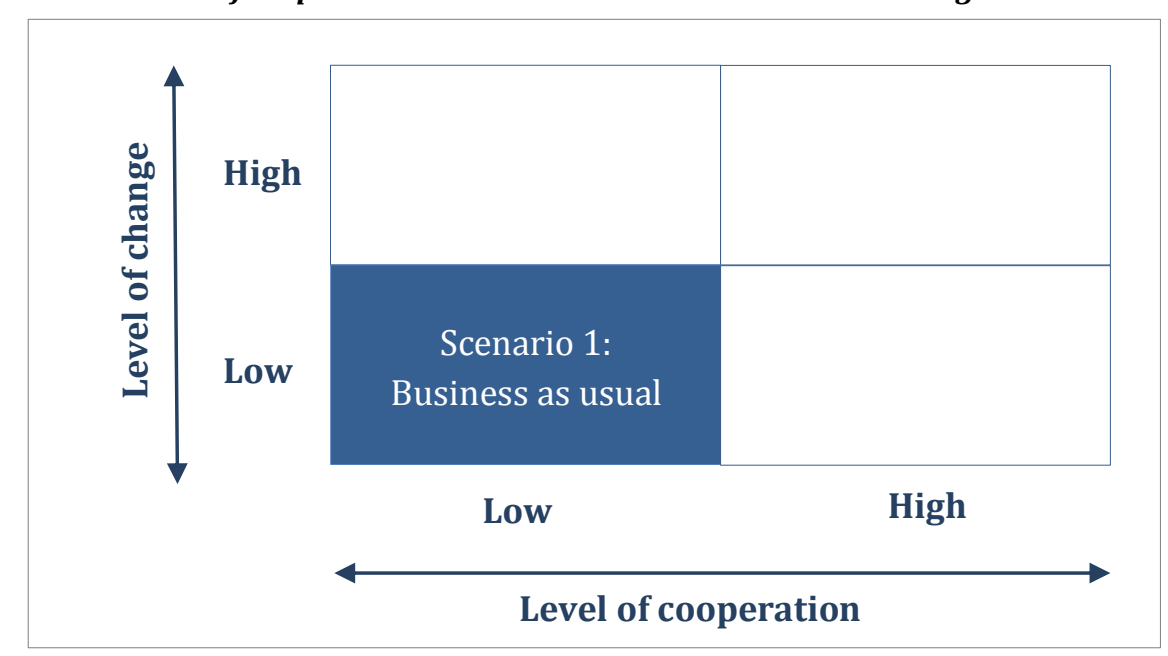

\subsubsection{General description}

The scenario reflects the likely development in collection, sorting, reuse and recycling of textiles under the assumption that current trends and developments continue, but no major change in technologies, structures and policy are implemented in the Nordic region.

The scenario is characterized by:

- Collection is predominantly carried out by charitable organisations.

- Collection focus on post-consumer textiles.

- The main objective for collection is reuse.

- Lack of enforcement of illegal collection practices (e.g. textile containers without permits, kerbside collection without permit, theft from textile containers etc.).

- Collected non-reusable textiles are increasingly sorted and recycled. 
- The sorting carried out in the Nordic region is predominantly carried out by charitable organisations sorting the collected textiles into a limited number of textile fractions (e.g. reusable in the Nordic countries and rest).

- Technique for recycling of textiles is mechanical recycling mostly outside the Nordic region, almost exclusively for insulation and other lower grade products.

- Incineration and landfill of separately collected textiles has decreased.

- Differences between Nordic countries (e.g. regarding consumption patterns, collection rates, actors in the value chain, targets for textile collection and treatment etc.) remain.

- No implementation of a Nordic strategy for increased collection, sorting, reuse and recycling.

- Limited implementation of national strategies for increased collection, sorting, reuse and recycling (political priority on national level but not implemented on local, regional or national level in a coordinated way).

- No binding targets or quality criteria for actors engaged in collection, sorting, recycling of used textiles and textile wastes.

\subsubsection{Specific description}

\section{Collection}

There are only very small changes regarding different actors involved in the collection of textiles compared to the current situation. Collection by charitable organisations is most common, even if private actors are active on some markets to higher or lesser extent. The collection of textiles (independent of brand) via textile retailers for sorting, reuse and recycling has increased but still corresponds to a small proportion of the total volume of collected textiles. Two to three retail chains in each country offer collection of old textiles (independent of brands) in most or all of their stores. The collection of textiles of the own brand via textile retailers for reuse or recycling is still a niche market.

The most common practice of collection is textile containers followed by collection in second-hand shops (often operated directly by the actors engaged in collection). An increasing number of textile containers (but not all) have been improved or exchanged in order to reduce the risk of theft from the containers (i.e. locked, not possible to climb into etc.) 
and/or to increase the quality of the collected materials (e.g. water proof, clear instructions on what textiles should go where etc.). Local authorities offer no or little support to reduce illegal collection practices (e.g. by granting permits, removing textile containers without permits, follow up on reported cases of theft from textile containers etc.).

There is a limited increase (ca. 10\% compared to current levels) in the total number of textile containers available for consumers in public places, primarily at recycling stations (also used for the collection of producer responsibility materials). However, not all recycling stations have a textile container. Textile containers are available at most (ca. 90\%) of all municipal recycling centres. These containers are primarily operated by charitable organisations, but to some extent also by municipalities. The density of textile containers differs for different countries, regions and municipalities. The additional textile containers are primarily set up in areas where the market for collection is considered high and usually in areas where other collection actors are active (i.e. primarily increased convenience in densely populated areas and only small additional geographical coverage).

The collection of corporate textiles (e.g. from hospitals, hotels, companies etc.) is very small. The main reason is a lack of knowledge of the economic and environmental benefits of separate collection of textiles as well as a lack of de-branding services.

The statistics and transparency regarding collected, sorted, reused and recycled amounts of used textiles and textile wastes are still relatively poor.

Over all, there is only a small increase in the collected amounts of used textiles and textile wastes (less than $10 \%$ more compared to current levels).

\section{Sorting}

Most of the sorting carried out in the Nordic region can be characterized as pre-sorting from the actors engaged in collection (i.e. primarily charitable organisations). These actors carry out a manual sorting (pre-sorting) into a limited number of textile fractions (usually two to three fractions). Main objective of this sorting (pre-sorting) is to identify reusable textiles that can be sold on the Nordic countries respectively. Not all collected textiles are sorted (pre-sorted) in this way due to lack of capacity to do so. There is no or only a limited increase (less than $10 \%$ of current levels) in the amounts of textiles that are sorted (pre-sorted) in this way.

Cooperation of actors engaged in collection (primarily charitable organisations) with certified sorters has increased. These sorters use semiautomated sorting techniques and are based in the EU; however, with 
one or two exceptions not in the Nordic countries. Within this context, both pre-sorted and mixed ("original") used textiles are sent for sorting.

There are no national coordination and/or channelling of textile flows. However, some actors engaged in collection increasingly cooperate in a way that smaller collectors forward collected textiles that were not sold to larger actors with cooperation agreements with certified sorters.

Over all, the proportion of used textiles and textile wastes (either pre-sorted or mixed) that are sent to and sorted by certified sorters has increased (ca. $50 \%$ of totally collected amounts).

\section{Recycling}

The amount of used textiles and textile wastes that are recycled is increased. The increase is primarily a result of the increased sorting of collected textiles, channelling more textiles to recycling instead of incineration. A smaller increase is the result of the limited increase in the total amount of collected textiles that due to the limited capacities for pre-sorting predominantly is directed to sorting.

The recycling technique used is mechanical recycling. To a very limited extent (less than $0.1 \%$ of the recycled amounts) textiles recycled into yarn and new textiles. This is limited to certain pilots/test products and promotion campaigns of retail chains. Textiles are predominantly recycled into low quality products such as insulation (downcycling). There is no or very limited recycling on an industrial scale in the Nordic region.

\section{Reuse}

There are small increases in reuse of used clothes and household textiles in the Nordic countries due to somewhat increased demand for second-hand textiles. The total increase is less than $10 \%$ compared to current levels.

There are somewhat larger increases in reuse outside of the Nordic countries due to the increased amount of textiles that are sorted by certified sorters.

\subsection{Supporting incentives, instruments and measures}

The scenario is characterized by no or very limited supporting incentives, instruments and measures in order to increase collection, sorting, reuse and recycling of used textiles.

Increased cooperation between different actors engaged in collection as well as between actors in collection and certified sorters is carried out on a voluntary basis. These initiatives are primarily driven by a general demand for higher transparency and lower environmental impacts. In 
addition, the increased amount of textiles not suitable for reuse in the Nordic countries sent to sorting (and reuse/recycling) reduce the waste management costs for the actors engaged in collection.

Improvements of textile containers (e.g. theft proof, better communication etc.) are also made on a voluntary basis but driven by the intent of decreasing losses in terms for theft and damaged textiles and increasing the amounts of collected textiles. This objective could be further supported by local authorities by better enforcement of illegal collection practices.

Local authorities can also directly influence the number of available textile containers by speeding up the process of granting permission for setting up textile containers and by ensuring that textile containers are set up on all recycling centres and potentially additional public places. Exchange of experiences and best practice between municipalities could be facilitated by national associations of local authorities and regions.

\subsection{Implications on the key factors}

\subsubsection{Attractive collection}

The collection of textiles is still based on bring systems. There is some improvement in the attractiveness of collection for households due to the increased number of textile containers (e.g. at recycling centres and at recycling stations). However, the increase in the number of textile containers is rather limited (less than $10 \%$ increase compared to current levels) and additional textile containers are primarily set up in areas where systems for collection are already in place (e.g. densely populated areas).

No new/coordinated collection system is set up for corporate textiles.

\subsubsection{Collection for both reuse and recycling (with priority to reuse)}

The collection defined in this scenario differs very little to the current collection. The primary objective of the collection is to collect used textiles to sell for reuse. The rest is increasingly directed to sorting and reuse/recycling. Hence, a collection for both reuse and recycling is secured.

The actors engaged in collection of used textiles have adjusted the pre-sorting capacities to be able to sort out enough used textiles to supply the second-hand markets in the Nordic countries respectively. More 
textiles are collected than demanded on the domestic markets for second-hand textiles.

Increased sorting by certified sorters results in increased amounts of textiles - both for reuse abroad and for recycling.

\subsubsection{Collection securing high quality flows}

The collection defined in this scenario differs very little to the current collection. The means of collection is to some extent further improved by the fact that an increasing number of textile containers have been improved or exchanged in order to reduce the risk of theft and damage of the collected textiles.

\subsubsection{Cost efficient collection, sorting and reuse/recycling}

In this scenario, the limited increase in collection is primarily the result of increased collection via textile containers and, to some extent, increased collection in second-hand shops. In such bring systems the consumers bring their textiles to a limited number of collection points, resulting in relatively low costs for collection.

The pre-sorting (within the Nordic region) is carried out by actors engaged in collection (primarily charitable organisations). The objective of the pre-sorting is to sort out reusable textiles for the domestic market. In case more textiles are collected than can be sold on the domestic market, these are increasingly sold for sorting (and reuse/recycling) to certified sorting facilities (primarily in the EU). These sorting facilities operate on the global textile market with assumingly high cost efficiency. Improvements of the cost efficiency for the Nordic actors engaged in collection could be reached by increased coordination and channelling of the textile flows (e.g. optimised transports, better prices etc.). This scenario foresees a limited coordination of such flows (on a voluntary basis).

\subsubsection{Minimising overall environmental impacts}

Reuse is generally more beneficial than recycling, which in turn, generally is more beneficial than incineration and landfill from an economic and environmental point of view. By sorting a higher proportion of the collected textiles (instead of incineration and landfill) more textiles are channelized into reuse and recycling. These potentials would be even better realized if the total collection and the proportion of the collected textiles sent to sorting were increased to a larger extent. 
Environmental potentials from recycling of textiles could be increasingly realized if the textiles are recycled into textiles (instead of into products of lower quality). This is, however, an exception in this scenario.

By coordinating textile flows better, the environmental impacts from transports could be reduced. This is only to a very small extent foreseen in this scenario (on a voluntary basis).

\subsubsection{Creation of green jobs}

The increase in collection (less than 10\% increase compared to current levels) is primarily a result of the collection via more textile containers. A very limited number of green jobs will be created in collection.

The scenario foresees no or only a limited increase in the amounts of textiles that are pre-sorted by actors engaged in collection. The objective of the pre-sorting is to sort out reusable textiles for the domestic market. Already at present, more used textiles are collected than demanded on the second-hand markets for textiles in the Nordic countries respectively. A very limited number of green jobs will be created in pre-sorting in the Nordic countries.

The scenario foresees an increased sorting (on industrial scale) and recycling of collected textiles from the Nordic countries. However, the predominant part of this sorting and recycling is foreseen to be carried out outside of the Nordic region. Therefore, a limited number of green jobs will be created in sorting and recycling of used textiles and textile wastes in the Nordic countries.

\subsection{Winners and losers in the value chain}

The scenario is characterized by rather limited changes in the collection, sorting, reuse and recycling of used textiles compared to the current situation. Hence, the implications in terms of winners and losers in the value chain are too rather limited. However, some (minor) trends can be identified:

- Consumers in densely populated areas are foreseen to get a limited increase in available textile containers (winners).

- Municipalities are foreseen to engage more actively in the collection of used textiles (winners). This might lead to increased competition for and reduced market shares of current actors engaged in 
collection; predominantly charitable organisations but also some private companies (losers).

- Certified sorting and recycling facilities (in the EU) will get somewhat increased amounts for sorting and recycling from the Nordic countries (winners).

- Actors engaged in collection, that coordinate and channel their textiles that cannot be sold and reused on the domestic market to sorting and reuse/recycling instead of incineration and/or landfill might get reduced waste management costs (winners).

- An increased demand for and business opportunities for traders might arise (potential winners).

\subsection{Trade-offs}

The scenario reflects primarily the extrapolation of current trends in collection, sorting, reuse and recycling of used textiles. Hence, it does neither require any (or much) political engagement, nor any additional commitment of different actors in the value chain. In this context, the largest trade-off is the missed opportunity to significantly increase the collection of textiles and, as a result, the reuse and recycling of textiles.

Regarding the six identified key factors, the scenario foresees that the collection is suitable for both reuse and recycling (giving priority to reuse) and secure high quality of the collected textiles. The collection, sorting and reuse/recycling can also be seen as relatively cost efficient. However, the attractiveness of the collection is not increased in order to achieve a significant increase in collection of (private) textiles. Also, the scenario neither includes measures to collect corporate textiles, nor preconsumer wastes. Further, the scenario fails to realize the potentials for minimising the overall environmental impacts from textiles. Finally, it fails to create a significant number of green jobs in the Nordic countries.

\subsection{Effects on collection, sorting, reuse and recycling in summary}

Table 31 reflects in brief overview the foreseen effects on collection, presorting, sorting, reuse and recycling of used textiles and textile wastes in the scenario. 
Table 31. Changes in amounts and quality of the separately collected used textiles and textile wastes from the Nordic region in the Scenario "Business as usual" compared to the current situation

\begin{tabular}{lcc} 
& Changes in amounts & Changes in quality \\
\hline Collection & + & 0 \\
Pre-sorting & 0 & 0 \\
Sorting in total, thereof & + & + \\
in Nordic region & 0 & 0 \\
in other countries & + & + \\
Reuse in total, thereof & + & 0 \\
in Nordic region & + & 0 \\
in other countries & + & 0 \\
Recycling in total, thereof & + & + \\
in Nordic region & 0 & 0 \\
in other countries & + & + \\
\hline
\end{tabular}

Changes range from --- to +++.

0 indicate no or very little change. 



\section{Scenario 2: Nordic cooperation}

\subsection{Description of the scenario}

Figure 33. Scenario 2 "Nordic cooperation" is characterized by low level of change and high level of cooperation between the countries in the Nordic region

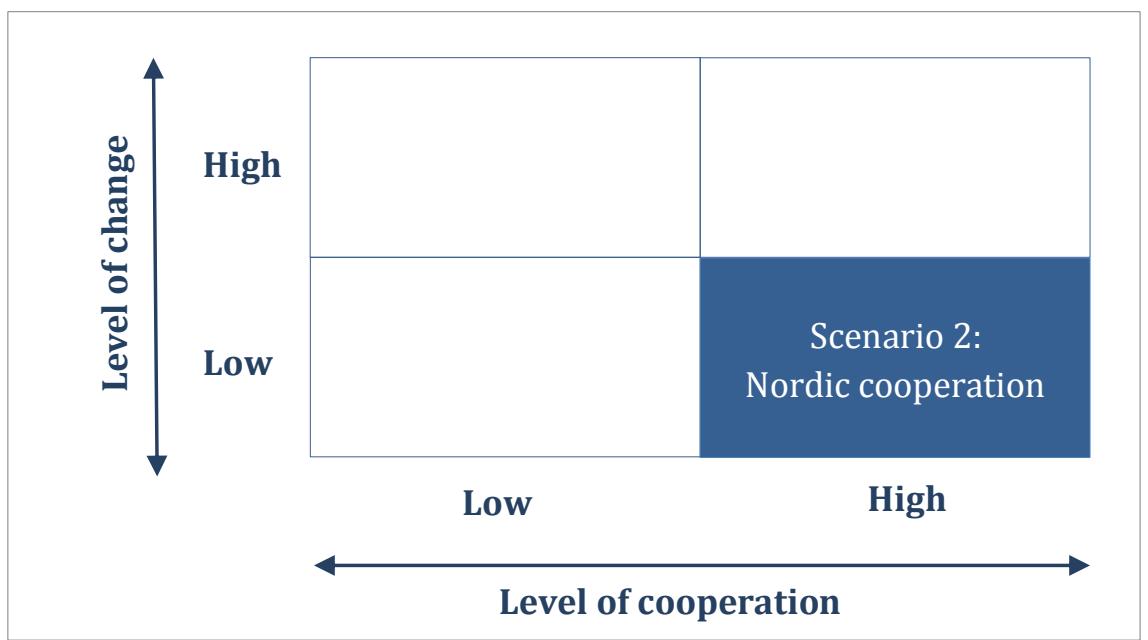

\subsubsection{General description}

In this scenario, the Nordic countries established common goals and strategies for collection, reuse and recycling of used textiles and textile wastes in 2015. However, except for the establishment of a common voluntary certification system for collection, de-branding, sorting, transport, reuse and recycling of used textiles and textile waste only minor changes has been carried out compared to the current situation.

The certification system was introduced to improve the trustworthiness of the system. It was established based on cooperation between the different actors involved in the collection, sorting, reuse and recycling of used textiles and textile wastes on the Nordic market. The certification system includes quality and transparency criteria for the collection, debranding, sorting, transport, reuse and recycling of used textiles and textile waste. Certified actors shall also accept also non-reusable textiles. 
It also includes improvements in statistics regarding used textiles and textile wastes as well as registration of the certified actors and an online-list of actors which are not (yet) certified. ${ }^{4}$

Due to the certification scheme and better control routines both the volume and the proportion of used textiles collected by actors which can document their practice have steadily increased. This is a result of that more actors have improved their systems to fulfil the certification criteria. The operation of unserious actors is limited and foreseen to be kept at a very low level. This is due to the steady increase in actors choosing to get certified and due to over time increased public knowledge about the certified actors. An easy recognizable logo of "Certified textile operator" with link and barcode to more information is used at all collection solution operated by certified collectors.

Higher confidence to the system in the society has increased the collected volumes of textiles for reuse and recycling. Better quality of the system has made it easier to involve citizens in reuse and recycle. This has had a positive effect both on the system's economy as well as on the environmental impacts.

Except for the certification system (including the "be noted"-list of actors which are active on the market, but not (yet) certified) no other means have been implemented to exclude unserious actors. The certification system was initiated on a Nordic level, but has in some countries been further developed into national systems based on mandatory agreements with environmental authorities and development of national system operators.

The certification system of collectors, de-branding services, sorters, transporters, reuse dealers, recyclers and waste management companies has led to decreases in incineration and landfill of collected used textiles and textile waste. This is due to the requirements for directing, as far as possible, the collected used textiles and textile wastes to reuse and recycling.

\footnotetext{
${ }^{4}$ E.-g modelled after the "Be noted"-list (OBS-lista) to the Norwegian organisation Innsamlingskontrollen http://www.innsamlingskontrollen.no/emner/obs-lista
} 


\subsubsection{Specific description}

\section{Common Nordic targets for collection, reuse and recycling}

The results of this project was used as a basis for the Nordic governments to develop a common Nordic strategy for increased collection, reuse and recycling of used textiles and textile wastes.

The Nordic governments defined the following minimum targets for collection, reuse and recycling:

- Securing convenient collection systems ensuring that textiles are reused as far as possible by 2018 .

- $30 \%$ of the textiles put on the market are reused by 2020 .

- $20 \%$ of the textiles put on the market are recycled, primarily into new textiles by 2020 .

These targets were commonly agreed upon as minimum targets. However, more ambitious targets have been developed at national levels in some of the Nordic countries.

The Nordic targets have recently been evaluated and results are awaited shortly. Following the evaluation, new (more ambitious) targets will be set for 2030 .

\section{Certification system}

A Nordic certifying organisation was created in 2015 based on a voluntary agreement between the major actors in the value chain. The certification system comprises companies and organisations engaged in collection, de-branding, sorting, transport, selling for reuse and recycling of used textiles and textile wastes. It includes pre-consumer textile wastes as well as post-consumer used textiles and textile waste from households, companies and public institutions.

The Nordic certifying organisation has the overall responsibility for establishment of quality standards which includes terms for and contracts for collection, de-branding, sorting, transport, reuse and recycling of used textiles and textile waste. The main objectives of the certification scheme are to: 
- Eliminate the illegal collection, export and trading of post-consumer textiles. This is supported by encouraging actors to get certified and by publishing a "be noted"-list of unserious actors. ${ }^{5}$

- Develop and update quality and transparency criteria for collection, de-branding, sorting, transport, reuse and recycling of used textiles and textile wastes.

- Test and certify actors in the value chain with regards to the defined criteria and publish a list of certified actors.

- Development and operation of a register for volumes of used clothes and textiles being collected, sorted, reused and recycled from certified Nordic actors.

- Support national, regional and local governments in the Nordic countries on how to communicate and inform about the systems for collection, reuse and recycling of used textiles and textile wastes as well as the environmental and social benefits of collection, reuse and recycling of these textiles.

- Monitor the overall performance of the system regarding achieved levels of collection, reuse and recycling regarding the common Nordic minimum targets.

Quality and transparency criteria for the different types of actors in the value chain was developed and agreed upon as part of the certification system. There are minimum criteria that the different actors have to fulfil in order to be certified. Certified actors must collaborate with other certified actors upsteam and/or downstream of their own area of operation. This ensures that the flow of collected textiles follows routes between certified actors all the way through the value chain.

The main effects that have been achieved in the Nordic countries due to the certification system are:

${ }^{5}$ Note that unserious does not equal not certified, as there are actors which are not certified (yet) but still operates in a serious way (i.e. has transparent operation). 
- Increase in the volume of separately collected used textiles and textile wastes both for reuse and recycling.

- Increased transparency on the fate of collected textiles.

- Increase in the knowledge about and public confidence in collecting organisations and the overall system.

The Nordic certification system and the certifying organisation works with issues of common interest for all Nordic countries directed towards both the public and private sector, such as:

- Better and harmonized documentation and statistics of textile consumption as well as of used textiles and textile waste flows.

- Common information campaigns.

- Development and implementation of "best practice" guidelines and systems for collection, de-branding, sorting, transport, reuse and recycling of used textiles and textile wastes (meant for actors in the market, both those which are certified and those which want to get certified or operate according to these criteria).

- An on-line "best- practice"-library which is reported on a voluntary basis from the different Nordic countries (supports the exchange of best practice between countries and/or municipalities in order to choose the best solutions).

\section{Collection of used textiles}

The certification system has only resulted in minor changes in the design and technological basis for collecting and sorting systems for used clothes and textiles. Collection via charitable organisations is still the dominant way of collecting used textiles in the Nordic region, but there is a medium increase in private collectors for the most valuable flows as well as a small/medium increase in textile retailers collecting for export.

The certification of collectors, de-branding services, sorters, transporters, reusers and recyclers was introduced in a way that the organisations and companies got a chance of complying before they met penalties (e.g. introductory period of three years).

Municipalities can choose to link the permit to collect used textiles to the certification system (i.e. only certified actors may collect used textiles on municipal land). This enables municipalities to end contracts with not certified collectors and to sanction collection from not certified actors. Sanctions could e.g. include collecting penalties and removing collection containers. 
The citizens can still choose from a variety of ways to hand over their used clothes and textiles. The collection is done primarily via textile collection containers. Those operated by certified actors are all fulfilling design-criteria for reducing theft defined by the Nordic certifying organisation. The proportion of containers from certified collectors has increased significantly the last three years (as the end of the introductory period was closing up). The total number of containers has also increased in the years between 2015 and 2020. This is because the economy in the system has improved both due to increased volumes and increased quality, as well as better prices especially for reusable clothes.

Most actors that were present in the market before 2015 are now in 2020 certified and some new private, certified actors have started with collection. The number of collection points operated by certified organisations has subsequently increased significantly over time. A drop in the number of available collection points compared to the pre-Nordic certification scheme was avoided by the three year introductory time. This allowed for sufficient time for most of the actors to comply with the quality criteria and get approved as certified collectors. A small drop in collection points was experienced in some areas in the Nordic countries in 2018 after the introductory period had ended, but this was quickly restored as the certified actors expanded their market to these areas. Containers are typically available at:

- Public places (e.g. recycling stations, parking areas etc.).

- Municipal and private recycling centres.

- Parking areas in shopping centres.

- Some larger private and public workplaces.

The larger charity organisations also collect used clothes and textiles via new collection schemes, as ready-made postal packages solutions, ${ }^{6}$ which were introduced in 2014. This has contributed to increased consumer's attractiveness for collection of used textiles also in areas which is sparsely populated with few available collection points.

The municipalities actively promote the certified collectors by informing about how and where their citizens can discard used textiles and sim-

\footnotetext{
${ }^{6}$ Fretex in Norway launched their new collection solution 24.04.14. Consumers can pick up a collection bag at their postal office, fill it with up to $8 \mathrm{~kg}$ of used textiles and return it to Fretex by mail by paying NOK 50 (EUR 6 ) in postage.
} 
ultaneously support certified actors. The municipalities use their traditional information channels to the citizens regarding waste collection to disseminate information. Information is made available both online at the municipalitie's homepages and included in the municipalitie's waste management information brochures which are distributed to the citizens and public and private corporations. In their information work, municipalities also use the logo "Supporting certified textile collection, sorting, recycling and reuse" with link/barcode to more information.

Local authorities have an important role in reducing collection performed by not-certified actors. However, their possibility to remove collection containers from collectors which is not certified is limited to public places. Not-certified collection is thus in 2020 still done through collection containers placed on private property and via door-step bag collection. However, the extent of collection via not-certified collectors has steadily decreased since the beginning of 2018 (the end of the introductory period). This is due to better information about the certified collection system, and the list of certified actor including the "be-noted"list of unserious actors provided by the certifying organisation. Most municipalities also urge all actors potentially offering land for textile containers to only allow this for certified actors.

There is an increased level of voluntary cooperation between the collectors due to the requirements in the certification system to reduce the amount of textiles being incinerated and landfilled. As an example: when one (smaller) actor is not able to sell all collected used textiles, this actor typically can hand it over to another (larger) collector for export instead of incinerating it.

The overall collection volume of used textiles has increased slightly since 2015 by the introduction of the voluntary certification system for collectors. Increases in collected amounts are primarily exported for reuse/recycling elsewhere, but to some extent also sorted out for reuse in the Nordic region.

\section{Importers and producers of textiles}

Companies that introduce new textiles on the Nordic market are encouraged to only cooperate with certified actors with regard to collection, sorting, reuse and recycling of textiles. They are further encouraged to communicate information about the voluntary certification system in stores, websites or via other communication channels as an encouraged way for consumers to discard used textiles. Information may include a reference to additional information about the system, e.g. a link/tag to the website of the certification organisation. They may cooperate directly with a certified collector. Importers and producers may also perform 
collection, sorting, reuse and recycling and certify their own systems such as in-store collection.

\section{Municipalities}

Municipalities can choose to only granting permits for and promoting certified actors involved in collection, de-branding, sorting, reuse and recycling of used textiles and textile wastes. Municipalities are further encouraged to promote separate collection of textile and textile waste and inform the consumers about environmental benefits of separate collection. ${ }^{7}$ Most municipalities in the Nordic region have established own public procurement criteria to match criteria in the common Nordic commitment for managing of used textile and textile waste. Municipalities performing collection, sorting, reuse and recycling are encouraged to become certified actors in the Nordic system.

\section{Sorting}

Sorting of collected textiles is done more or less by use of the same processes as before 2015. Separate collection of used clothes and textiles is dominated by manual pre-sorting, separating reusable items for domestic reuse and the remaining into a few different fractions. This is still mainly done by the collectors (i.e. mainly charitable organisations). Due to the slightly increased volumes of used textiles collected, the amount available for reuse has also increased to some extent, increasing the economic benefits for the actors.

Further sorting of pre-sorted and/or mixed textiles is still done primarily in the EU, outside the Nordic region. However, there has been an increase in sorting out of clothes for reuse due to the requirement for prioritizing reuse for certifying sorters. Two semi-automated certified sorting plants have been established handling medium amounts of textiles with promising quality and economy of operation. This makes it possible to increase the value back to those certified charity organisations and other certified collectors which have chosen to start using these sorting plants.

Smaller actors (small producers and importers, retailers and professional users of clothes and textiles etc.) have increased collaboration with certified collectors and/or sorters ensuring that both usable and unusable textiles are sorted, reused and/or recycled.

\footnotetext{
${ }^{7}$ Separate collection of textile and textile waste means collection separated from materials with the risk of degrading the collected textile. It does not specifically mean separate collection of textile from textile waste.
} 


\section{Recycling}

The amount of used textiles and textile waste that is recycled has also increased. This is due to increased amounts of used textiles and textile waste being collected, both from private, public and corporate consumption.

The industrial scale of recycling is still done outside the Nordic region i.e. the fractions identified for recycling are still exported for trading and recycling on an international market.

There is a slight increase in recycling in form of upcycling of collected used clothes in the Nordic region due to the blooming consumer trend in purchasing upcycled/reworked fashion clothes and accessories, as well as clothes made of recycled materials. This has also resulted in slightly increased mechanical and chemical recycling of used textiles and textile waste into new textile materials. This is also due to improved technologies for recycling and the industrialisation process of these technologies. The actual reprocessing of the recycled materials is done outside the Nordic region.

The main recycling technique used is mechanical recycling, and the largest proportion of products made of the recycled materials is still down-cycled products such as insulation. This is to a very limited extent done in the Nordic region, then mainly in sheltered workshops for instance for rag production.

\section{Reuse}

There is a medium increase in reuse of clothes and textiles within the Nordic region, due to higher market response to "second-hand" fashion as well as more conscious citizens. Availability of reusable clothes and textiles of good quality has increased due to better sorting, higher volumes collected and requirements to higher reuse rates in the certified quality systems.

There is also an increase in reuse outside the Nordic countries due to the increased amount of textiles of good quality that is sorted out and further exported.

\subsection{Supporting incentives, instruments and measures}

Since the system implemented in 2015 was a voluntary certification system, there have been no new common regulations implemented from environmental authorities in the Nordic region. The status of used clothes and textiles as "gifts" or "donations" and not as waste has not changed, implying that municipalities are still not in position to regulate the activity of collectors directly. However, the voluntary certification 
system has made it easier for municipalities to cooperate with local property owners to develop common requirements to collectors of used clothes and textiles, and to exclude collectors which are not certified. Both municipalities and other property owners are encouraged by the national (and Nordic) authorities to cooperate only with certified collectors. This is mainly done by granting permission for collection containers owned by certified collectors to be placed at the municipality's recycling centres/stations and other public areas. After the three years introductory period had passed, some municipalities started to remove collection containers from collectors which were not certified and that have placed the collection containers at public property.

Costs to establish the certification system was financed by Nordic authorities, while operation of the system is financed through a membership fee accrued to those organisations that have been certified for collecting, de-branding, sorting, transporting, reuse and recycling of used textiles and textile wastes (each certified organisation can cover one or several parts of the value chain). The fee is a fixed amount per organisation which shall cover the cost of operating the system, with differentiation between small and large organisations. It is also a differentiation with higher fee for private profit-making actors and a relatively low membership fee for charity organisations. The membership fee system is set up to be easy, transparent and cost effective to manage. Eventual surplus will go into a fund that can be used to further development of the system.

The collection has become more attractive for consumers due to the year by year steadily increasing availability of collection points and other collection schemes served by certified collectors (more collection points is due of better economy in running the system for the certified collects). Higher confidence in the system from the public and private actors combined with an increased motivation through better and more information about how and why to reuse and recycle, has increased the citizens' motivation to participate. The most significant effects in collection levels will likely be seen in the Nordic countries with the lowest previous level of collection e.g. the effects will be larger in Sweden than in Denmark. 


\subsection{Implications on the key factors}

\subsubsection{Attractive collection}

The collection of used clothes and textiles is to a large extent based on the systems existing as of today, i.e. mainly based on bring systems to collection points operated by charity organisations. In all Nordic countries there has been a slightly, but stable increase in number of the collection points available for the citizens. New collection points have also been located close to some larger public and private working places, making it easier to discharge used clothes and textiles. New collection schemes, as ready-made postal packages for collection of used textiles offered by the larger collectors, have also increased the availability considerably.

Through increased collaboration between municipalities and certified collectors, collection containers are found both at typical recycling centres and recycling stations for other waste fractions. This has increased the availability of collection points and made it easier to combine dropping off used clothes and textiles when recycling other waste fractions based on bring systems (e.g. glass and metal).

The trustworthiness in the collectors and the collection and treatment systems has increased due to the certification scheme and increased information to the public. There are national and local campaigns run by the certification organisation in collaboration with national and local authorities to increase focus on and support of textile reuse and recycling.

The system is more attractive due to better registration and higher transparency about the amounts of collected textiles, the further use and treatment of these textiles and the required transparency with regard to economic transactions. This information is mandatory for certified actors to supply to the certifying organisation and to anyone who asks for this information. The information is further made available to the public through the operator of the Nordic certification system (via websites, annual reports etc.). National and local authorities can choose to supply with additional and more detailed information related to their geographical area. This is made available via the public information channels (websites, social media etc.). 


\subsubsection{Collection for both reuse and recycling (with priority to reuse)}

Related to collection for both reuse and recycling, there are no big changes compared to existing systems, although more clothes has been made available as more citizens have chosen to participate in the systems. Collection of non-reusable textiles has increased due to the certification system.

There is a slightly increase in used textile sorted out for reuse in the Nordic countries due to an increase in the demand for second-hand clothes and textiles and a slight increase in the use of low impact reprocessing (upcycling/reworking trend).

The certification system has improved the quality of the sorting processes (both pre-sorting and main sorting) resulting in a higher amount of the used textiles available for reuse abroad and recycling.

\subsubsection{Collection securing high quality flows}

Better and more information to consumers combined with a collection system with certified collectors have been crucial for securing high quality flows.

Consumers (both private and corporate) are informed on how to sort, package and where to deliver used textiles.

The collections containers from certified collectors are well secured to reduce the risk of theft from the containers (i.e. for instance locked and not possible to climb into) and to increase the quality of the collected materials (e.g. water proof, clear instructions on what textiles should go where etc.).

Other collection practices (in shops etc.) are secured through the quality requirements set up by the certification scheme supplied by the certification system.

Good practice with traceability throughout the rest of the value chain (de-branding services, sorters, transporters, reuse dealers and recyclers) is also secured through the quality requirements set up by the certification scheme supplied by the certification system.

Actors in the market which are not certified generally do not meet the same quality requirements as certified actors. Being very far from meeting the quality requirements of certified organisations, they might end up at the "be-noted"-list provided by the Nordic certifying organisation. 


\subsubsection{Cost efficient collection, sorting and reuse/recycling}

There are no big changes in the collection and sorting system compared to the current situation. No new, big costs have been implied on the actors in the value chains. Higher quality and larger volumes of used clothes have made collection and sorting more profitable after 2015.

The certified collectors are enabled to increase their incomes through increased amounts of collected used textiles and textile waste. Over time some of the certified collectors have been enabled to increase their number of collection points (through better economy in the system).

The big part of collected clothes and textiles is still based on bring systems, which has a relatively low cost of collection. Postal packages collection as also proofed to be a successful, low cost collection option for the collectors.

The increased amounts of collected used textiles have led to some increased cost for pre-sorting for the collectors that do this operation themselves. However, this is evened out by increased income from the increased amounts of used clothes and textiles which are sold for further sorting, reuse and/or recycling.

The major sorting facilities (primarily in the EU) operate on the global textile market with assumingly high cost efficiency.

In this scenario there are no major alternations in the collaboration between the different actors in the value chain, i.e. there are no gained cost efficiency compared to today's practice.

\subsubsection{Minimising overall environmental impacts}

The certified quality system ensure qualified collection, de-branding, sorting, transport, reuse and recycling of used textiles based on the best available knowledge. Higher quality in the collection systems might result in higher fractions of clothes sent to reuse instead of recycling and more to recycling than to incineration/landfilling, with better environmental performance of the overall system.

\subsubsection{Creation of green jobs}

The scenario is not of a character that generates a large number of new green jobs. Volumes of collected textiles for reuse and recycling has increased slightly over time without creating many new jobs by the collectors or other actors in the value chain in the Nordic region. However, a few new jobs related to certification and follow-up controls of collectors, 
de-branding services, sorters, transporters, reuse dealers and recyclers have been created.

Increased reuse and recycling of clothes have moved some jobs from conventional companies to companies that are focused on "green clothing" based on reused clothes and recycled materials. This has first of all be the case in countries with low production costs. In the Nordic region, more jobs will probably be mainly created related to reuse and upcycling/reworking.

An increased demand for de-branding services has been a result of the increase in collected used clothes and textiles from corporate consumption. However, within this scenario only a small number of new jobs is created in this part of the value chain until 2020.

\subsection{Winners and losers in the value chain}

The actors getting most out of the changes that have been introduced (a common Nordic certification system) are actors that are able and willing to fulfil the criteria for certification. More used textiles and clothes will be channelled to reuse and recycling, which also have reduced the amount of new virgin materials used. Although the change have taken time, by 2020 there is a clear trend to import more clothes with recycled textile fibres. This has also a big effect on the environmental impacts of the textile products, making "the environment" a winner by saved virgin resources and lower emissions.

Consumers will get better information about (and increase the trust in) the collection systems. There will be a slightly increase in available collection containers.

Municipalities have a more active role both as facilitator for certified collectors by for instance permitting collection containers at public property. They are also encouraging private land owners to work with certified collectors, and they provide information to the public.

The serious actors (both charitable organisations and private actors) have increased their accountability through the certification system. They have also gained from the increase in the amount of collected used textiles.

Also a number of local and smaller collectors (leisure organisations etc.) operating in the current market have been able to fulfil the certification criteria in order to continue their collection activities (potential losers). This has mainly been achieved through cooperation with larger certified actors. 
A small increase in demand for de-branding services will probably continue to increase after 2020 and will create new business opportunities.

Increased amounts of sorted used textiles available for reuse can also create more business opportunities for different types of second-hand shops, upcyling/reworking actors and similar actors (potential winners) after 2020.

The potential losers in the new system are first of all actors not able of not willing to fulfil the certification criteria, neither alone nor in collaboration with other organisations. In a longer time perspective, companies that are producing virgin materials and clothing with no reuse of textiles can also be potential losers in the global market.

\subsection{Trade-offs}

In the short run up to 2020 there are no big trade-offs in this scenario, as there are relatively small changes being made to the system. The main difference from the current practice is the certification system for collectors, de-branding services, sorters, transporters, reuse dealers and recyclers. The most important trade-off is thus the division between those actors which enter the certification system, and the actors which choose not to. There will be less room for the latter ones in this scenario.

The collection systems will not be altered significantly as from today's practice. The number of collection points will in some areas slightly decrease in early 2018 when the three year introductory period has ended. Collection containers operated by not-certified actors were then removed by (some) local authorities. The market quickly restored the situation, since already certified actors then used these market opportunities to increase their own market share. Up to 2020 the numbers of collection points steadily increased due to better conditions for the certified actors and an increased awareness among both public and private sector. The collection system also proved more reliable due to the quality criteria set by the certification scheme. The trade-off is between availability of collection points and introduction and enforcement of the certification scheme.

The collection, sorting and reuse/recycling in this scenario can also be seen as relatively cost efficient. The attractiveness of the collection is increased in order to achieve a slightly increase in collection of used textiles and textile waste. The scenario neither includes specific measures to collect corporate textiles, nor pre-consumer wastes. However, collection containers will be placed outside public and larger private working placing 
which might increase the collection of corporate textiles over time. The trade-off is between increased cost for collection, (and pre-sorting), and the possibility for increased income from more and higher quality of used textiles available for sale (domestic and export).

The scenario will increase the possibility to realize the potentials for minimising the overall environmental impacts from textiles due to the increased quality and control of the system provided by the certification system. The trade-off is between the actual use of the collected material and the environmental impact of increased collection, de-branding, sorting and transportation.

There has not been seen a significant increase in number of green jobs in the Nordic countries created by the system's changes proposed in this scenario. The trade-off is between how extensive and "rigid" the certification scheme is built up, the enforced changed by the quality criteria set up and the market response to the imposed changes. A trend shift towards reduced amounts of virgin textile materials due to a shift towards reuse of parts of clothing and recycled materials will continue after 2020, resulting in significantly more jobs in companies being early users of those types of materials. Those jobs will first of all be established in low cost production countries outside the Nordic region.

\subsection{Effects on collection, sorting, reuse and recycling in summary}

Table 32 reflects in brief overview the foreseen effects on collection, presorting, sorting, reuse and recycling of used textiles and textile wastes in the scenario. 
Table 32. Changes in amounts and quality of the separately collected used textiles and textile wastes from the Nordic region in the Scenario "Nordic cooperation" compared to the current situation

Changes in amounts

Changes in quality

Collection

Pre-sorting

Sorting in total, thereof

in Nordic region

in other countries

Reuse in total, thereof

in Nordic region

in other countries

Recycling in total, thereof

in Nordic region

in other countries

$+/++$
0
$+/++$
$0 /+$
$+/++$
$+/++$
$0 /+$
$+/++$
$+/++$
$0 /+$
$+/++$

$+$

o/+

$+$

$+$

0

$0 /+$

$++$

+ +++

Changes range from --- to +++.

0 indicate no or very little change. 



\section{Scenario 3: Multiple strategies}

\subsection{Description of the scenario}

Figure 34. Scenario 3 "Multiple strategies" is characterized by high level of change and low level of cooperation between the countries in the Nordic region

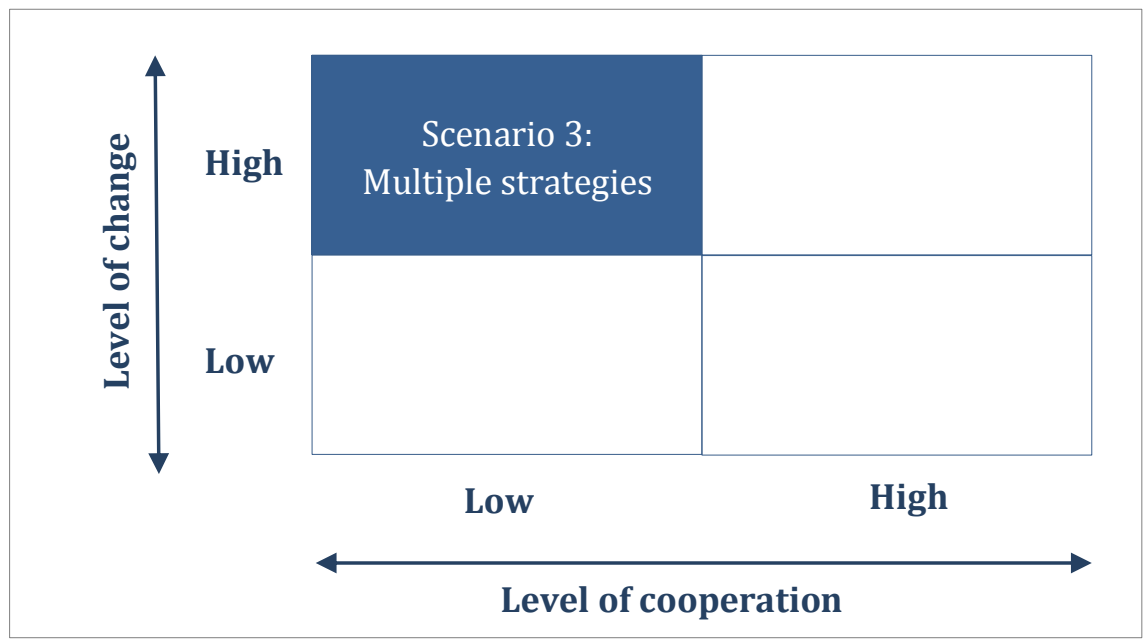

\subsubsection{General description}

In this scenario, each Nordic country has its own strategy for textile collection, reuse and recycling. Hence the detailed contents of systems may vary from country to country. The system is based on voluntary commitments of the different operators. The collection and sorting phases include the current players and new ones. Existing container network of charity organizations will be maintained or even boosted. Extra collection is provided by private companies. Municipalities are also allowed to participate. Collection is wide-ranging and diverse, and sites are located close to the textile waste producers making disposal attractive and convenient. Pre-sorting, that separates reusable clothes from non-reusable can be performed by the collectors, securing the possibilities of e.g. charity organisations to continue with their current activities. Several coun- 
tries provide centralised half-automated sorting, taking care of mainly the non-reusable, but also to some extent of the reusable textiles sorting.

Textiles are reused as today, within the Nordic countries and sent abroad to e.g. developing countries. Recycling is mainly down-cycling, i.e. mechanical recycling producing e.g. insulation materials, industry wipes, oil absorbent mats etc.

The efficiency of collection and sorting is higher than today and hence somewhat higher amounts of textiles are reused and significantly higher amounts are recycled.

In each country there is a secured de-branding system on the market which ensures that sensitive used and surplus textiles (such as uniforms and patterns from textile producers) are managed in a way acceptable to their producer.

\subsubsection{Specific description of the scenario}

\section{Collection of used and surplus textiles}

Used textile from households, public institutions and laundries are collected by charity organisations, private companies and/or by municipalities. Public institutions include e.g. the police, the fire service, public transports or prisons, who dispose of uniforms or corporate clothing. Laundries manage and take care of textiles and clothing used by various organisations and enterprises, such as hospitals, hotels, restaurants and offices.

Surplus textiles from industry (materials from textile production) and retailers (unsold textiles) are collected directly from the properties or they can be announced for sale through the material bank net service.

All textile waste producers except for households have need for debranding for some of their textile wastes. De-branding needs to be provided as a first step in the recycling chain, in order to assure the producers of the safety of the chain. In practice this means collecting the textiles in secured containers and delivering the material for shredding in a process provided by a sorting facility operator. The shredded material can directly be used for mechanical recycling. De-branding services can be offered by any actors, but most probably by private companies. Each country can have national agreements or certifications for securing the de-branding.

The collection system includes four main bricks, namely: 
1. Container collections.

2. Kerbside collections in sparsely populated areas.

3. Collection directly from properties (of companies, offices, institutions etc.).

4. Material bank net service (which actually functions without collection, channelling materials from one actor to another).

Containers for textile collection are located at recycling centres and recycling points (or eco-points), serving for other recyclable materials as well. Containers are also located at large public workplaces such as libraries and public offices. Although the places for locating the containers are owned by municipalities, chains of shops or others, the containers can be owned by charity organisations, private companies or municipalities. Agreements on placing the containers have to be made with the owner of the site. The existing network of containers provided by charity organisations shall be maintained and boosted, and extensions to the network shall be planned in co-operation between charity organisations, private companies and municipalities. The container network should cover the whole countries, but in sparsely populated areas there will inevitably be fewer containers. In order to fill this deficiency, kerbside collection is introduced in sparsely populated areas once or several times a year. Households are provided the possibility to put out their textiles on a certain day and the collector (who can be either municipal or private) will collect the textiles.

Collection directly from property is a service that is taken care of by private companies. They provide:

1. the properties with appropriate containers (separately for textiles to be de-branded and other textiles)

2. transport of the textiles to a sorting facility, where the material that needs de-branding is shredded and then delivered to mechanical recycling and the material not needing de-branding is sorted appropriately.

Material banks can operate like waste dealers who buy waste from other businesses to sell on. It is also possible that a material bank does not buy the waste but offers a dealer service for companies to offer their waste as a raw material to other businesses. Dealers do not necessarily take physical possession of the waste. Net service material banks can be managed by public organisations or private companies. Traditional 
waste dealers are already an established trade guild. They might also be interested in certain textile flows especially waste with economic value. The operational area of material bank can be one country, Nordic area or even larger, but in this scenario a national area of operation is considered. One material bank per country is eligible in order to enhance the encountering of the offers and demand for used textiles.

The actors taking care of the collection within each Nordic country can be charity organisations, private companies (waste management companies, recycling companies etc.) or municipalities. Charity organisations will focus on collecting reusable textiles, like today. However, they will unavoidably also receive non-reusable textiles. For the textiles collected, all the collectors can introduce pre-sorting, where they separate the reusable fraction for sales and direct the non-reusable fraction to mechanical recycling. A share of the reusable fraction will be exported as today. The collectors commit to operate in an open way and report yearly the amounts collected, sorted, reused, recycled and de-branded on a national basis.

Containers should be designed and located on the one hand to prevent steeling from them and on the other hand to prevent the textiles from getting wet during storing and emptying. Sanctions may be introduced e.g. for illegal containers or stealing from containers, but it will be up to each country to decide what methods and on what level they want to enforce sanctions. Requirements or guidelines may be included in the municipal level waste management rules or on national level waste decrees, or somewhere between these.

\section{Sorting}

The actors taking care of the collection can all introduce pre-sorting for separating the reusable and non-reusable fractions. This will guarantee that they benefit from the system as they do today. Each Nordic country will thus have several pre-sorting locations, but at maximum one centralised, half-automated sorting facility per country. The aim in the scenario is that as much as possible of the collected textiles go through sorting in the Nordic countries. This way the material exported for e.g. charity will be of higher quality and there will be more material left to deliver to recycling.

In order to avoid putting up new and overlapping structures, the reusable fraction from the sorting facility could be directed to existing charity organisations for sales or donating. This needs to be fixed among the operators. 


\section{Recycling}

The existing Nordic mechanical recycling facilities (two small facilities located in Southern and Central Finland) continue operating as today, and can to some extent expand their activity due to increase in the collected amounts of textiles. Improved sorting will enable the facilities to obtain the specific materials they need for their processes (e.g. wool, cotton) from a closer distance than today. Nevertheless, there have been several other limiting factors for the profitability of recycling textiles, such as lack of demand for recycled products. Hence it is not sure how much these facilities are able to expand. The majority of the textiles from the Nordic sorting facilities are transported to Central Europe for mechanical recycling producing e.g. insulation materials, industry wipes, oil absorbent mats etc. The material flows from de-branding can either be transported to the recycling facilities directly after de-branding or stored at the centralised sorting facilities and combined with material flows from other collectors to be shipped to the recycling facilities. From the environmental and economic points of view the latter may be more profitable, but book-keeping for charges and payments for different collectors may become complicated if several actors combine material flows.

\section{Reuse}

All actors taking care of collection can direct reusable textiles to secondhand shops or alike for sale or as charity. Reuse can take place domestically or outside the Nordic countries. The reusable fraction originates mainly from households, since institutions, industry and retailers will most probably want to direct their textile flows through de-branding.

\section{Disposal}

Non-reusable and non-recyclable textiles from the recycling chain will be disposed of in waste incinerators. This fraction can include e.g. textiles contaminated with permanent dirt or textiles treated with hazardous substances. Some of this material will be put in the mixed waste by the waste producers (households, laundries, etc.) but most of it will originate from the recycling chain operators. Amounts of disposed textiles are smaller than today.

\subsection{Supporting incentives, instruments and measures}

The current textile collection systems are in all Nordic countries operated mainly by charity organisations, which can finance their operations through selling the reusable textiles at their second-hand shops and can 
help the needing people by directly donating collected clothes. New actors and operations are needed in order to set up a more comprehensive and efficient system for increasing reuse and recycling of textiles. In order to make this happen, there needs to be a strong commitment from the textile chain actors. In this scenario the commitment is based on voluntary agreements which can be in the form of e.g., a voluntary extended producer responsibility (EPR) or branch-specific material efficiency agreement. All the actors along the textile chain should commit themselves to these agreements. Targets for collection, reuse and recycling should be set according to the national strategies given in e.g., national waste plans. The system could work without the participation of municipalities, but they should be given the possibility to join. Clear agreements should also be made on who owns the textile in the various phases of the chain.

In addition, several supporting and guiding policy measures are needed at least in the beginning. There is a need for financial support for companies to invest in a de-branding system, in a centralised sorting facility and in recycling technologies. When the system has started working, and increased textile flows are collected and quality of the flows is known, it will be appealing for enterprises to begin activities around textiles, and supporting funding can be ceased.

People are willing to act, when they know that their effort supports increased reuse and recycling and they can rely on the textile chain to operate towards these goals. This is similar to the time spent on source sorting of recyclables where the actual financial incentive to sort is low but participation is high. All producers of textile wastes should be engaged in the reuse and recycling system by repeated communication on why the system is put up, how the system works (what actually happens to the textiles after collection points) and how the producers can participate. There should be different communication material for the households, laundries, public institutions, industries and retailers. The communication program can include several phases beginning before the system has been established and continuing with certain intervals when the system is already fully operating.

Consumers should be advised to put reusable textiles primarily in the charity organisations containers in order to maintain the possibility for charities to continue their operations.

There is no use in recycling if there is no demand for the recycled products. There is a need for policy pulling the use of recycled textiles in addition to policy pushing recycling of fibers. This problem should be given high priority on the policy agendas. Public procurements by municipal- 
ities or by governmental institutions should lead the way in requiring the use of recycled materials in all procurements. This demand could generate supply through convincing the manufacturing industry of the possibilities to find markets for their products containing recycled materials.

\subsection{Implications on the key factors}

\subsubsection{Attractive collection}

The collection container network is wide-spread and extensive, but in sparsely populated areas there will be fewer containers. These areas will be covered by kerbside collection. The collection in containers requires some effort from consumers, but since the containers are located in diverse places, it is quite easy to deliver the textiles e.g. on ones way to the grocery or other errands. The kerbside collection in sparsely populated areas is convenient, but must be taken care of promptly and repeated with a fixed frequency to give the consumers the possibility of planning their house cleaning and emptying. The possibility of leaving both the reusable and non-reusable textiles to the containers will attract people.

\subsubsection{Collection for both reuse and recycling (with priority to reuse)}

Collection serves both reuse and recycling. With more wide-ranging and diverse collection points, increased amounts of textiles are collected. The secured de-branding system increases the amounts of corporate clothing and other sensitive textile materials entering the collection. However, potential for reuse comes mainly from the textiles collected from households, and to some extent laundries. The de-branded materials can only be used for mechanical recycling after shredding.

The system can introduce somewhat higher amounts of textiles to reuse, but the increase will be much higher for recycled amounts.

\subsubsection{Collection securing high quality flows}

Consumers are encouraged to bring reusable textiles to the charity organisations containers. The bring system most likely ensures that the quality of the donated textiles is high. Increases in the collection of nonreusable textiles might cause increases in the collection of non- 
recyclable textiles (e.g. spoiled by paint or oil).These will be removed within the sorting process.

Collection from public institutions, industry and retailers directly from property secures high quality of these flows.

\subsubsection{Cost efficient collection, sorting and reuse/recycling}

Cost-efficient operations need strong co-operation between operators. Therefore all collection and sorting operations need to be planned and managed as a whole. There is a risk of overlapping collection systems, when several actors introduce containers on the same markets.

In a bring system the materials can be collected in a cost-efficient way by planning and timing the emptying so that the containers become full during the intervals.

Pre-sorting to separate reusable and non-reusable fractions is voluntarily provided by collectors (at least charity organisations who have high interest in sorting out the reusable textiles) and in addition centralised half-automated sorting is done for the non-reusable fraction in several facilities in the Nordic countries. Several sorting steps may not be the most cost-efficient way of operating.

\subsubsection{Minimising overall environmental impacts}

Bring system requires transportations from households, but if the containers are located wisely, the textile drop-in can be combined with doing other businesses. The collection directly from properties for public institutions, industry and retailers can be taken care of in connection to other waste fractions; hence no extra transportation is needed. Material bank services make it possible to plan transportations in an efficient way. Nevertheless increased collection, centralised sorting and transportations of materials to Central Europe will increase transportations compared to the current situation. With full loads and well-planned logistics the environmental impacts of transports remain low.

Highest environmental benefits per ton textiles will be gained from the reuse of textiles, since this can, in an optimal system, reduce the production of textiles production from virgin materials. Retaining the current system operated by charity organisations as a basis for the scenario will guarantee reuse with as little collection, transportation or sorting as possible. However, in this scenario reuse will not increase very much. Instead down-cycling of textiles through mechanical recycling will increase; while incineration and landfilling of used textiles and textile 
wastes will decrease. Mechanical processing consumes energy and generates environmental impacts, but the products produced may compensate for products made of other materials, such as plastics, hence decreasing impacts from this production. The magnitude of the overall environmental impacts will depend on what materials the products produced through mechanical recycling substitute.

\subsubsection{Creation of green jobs}

This scenario will create new jobs in collection and sorting (both in presorting and centralised sorting) in the Nordic countries. Increased recycling will generate green jobs in the recycling operations in Central Europe. Some jobs may be lost in Asia due to decreased production of new textiles. However, this effect will be small, since this model increases primarily down-cycling of textiles into products which do not compensate textile products.

\subsection{Winners and losers in the value chain}

Unambiguous identification of winners and losers in the value chain is very difficult, since it is very uncertain how a system looking quite different from the current system will be realised. In a voluntary system e.g. the number of private companies engaging themselves in the operations may be none or tens. Pros and cons of the system for different actors are discussed below.

Producers of textile wastes will have a larger selection of collection containers in various collection points available than today, and it will be easier to dispose of both reusable and non-reusable textiles.

Charity organisations will probably be able to keep their incomes constant, since in a voluntary system, they may be the strongest operators and may get hold of the most valuable textiles in addition to the increased sorting costs with larger flows. However, if new actors enter the system, there will be increased competition.

Increased employment can help municipalities in their obligations concerning management of unemployment. In addition, municipalities may gain increased tax income through increased employment and increased entrepreneurship. Whether the profits are higher than investments needed, cannot be assessed. Municipalities will lose combustible waste when textiles currently going to incineration are directed to recycling. 
Private companies will need to invest in de-branding services, collection and recycling. In the long run they will win from selling services for management of a new waste material.

The recycling industry will receive more material for processing and more products produced. This will increase their activities, produce more jobs and more profits.

\subsection{Trade-offs}

Instead of channelling all non-reusable textiles to mechanical downcycling, some flows could already in this scenario be directed to upcycling processes, where products compensate for virgin material textiles. Homogenous and clean flows suitable for this may originate from e.g. laundries, public institutions, industry and retailers. This would increase the environmental benefits gained and hence decrease the overall environmental impacts of the system.

Cost-efficiency of the system could be enhanced by decreasing different types or points for collecting the textiles and decreasing the sorting steps. The first point can, however, lead to decrease in collected amounts. 


\subsection{Effects on collection, sorting, reuse and recycling in summary}

Table 33reflects in brief overview the foreseen effects on collection, presorting, sorting, reuse and recycling of used textiles and textile wastes in the scenario.

Table 33. Changes in amounts and quality of the separately collected used textiles and textile wastes from the Nordic region in the Scenario "National strategies" compared to the current situation

\begin{tabular}{lcc}
\hline & Changes in amounts & Changes in quality \\
\hline Collection & ++ & + \\
Pre-sorting & ++ & ++ \\
Sorting in total, thereof & ++ & ++ \\
in Nordic region & ++ & $\%$ \\
in other countries & 0 & 0 \\
Reuse in total, thereof & 0 & $\%$ \\
in Nordic region & 0 & $\%$ \\
in other countries & 0 & ++ \\
Recycling in total, thereof & ++ &. \\
in Nordic region & ++ & $\%$ \\
in other countries & ++ & $\%$ \\
\hline
\end{tabular}

Changes range from --- to +++.

0 indicate no or very little change.

./. indicate change that could not be assessed within this project. 



\section{Scenario 4: Nordic innovation}

\subsection{Description of the scenario}

Figure 35. Scenario 4 "Nordic innovation" is characterized by high level of change and high level of cooperation between the countries in the Nordic region

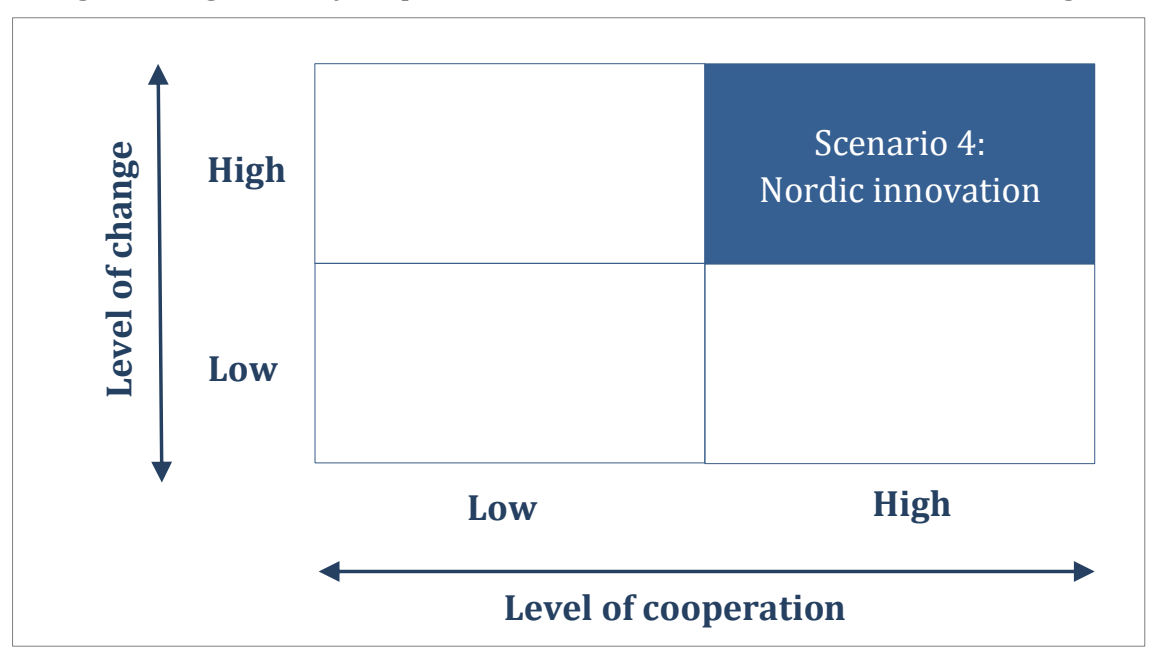

\subsubsection{General description}

Nordic countries have a common Nordic strategy for textile collection, reuse and recycling. Due to the common targets of the Nordic commitment, the level of co-operation between Nordic countries is high. Policy measures in use to promote textile waste reuse and recycling are stronger than today and new business around textiles arise. Measures that have been successful in one Nordic country is quickly copied and adapted to the other Nordic countries and operations where cooperation is needed to reach sufficient flows and scale effects are multiplying in the region.

Increased reuse activities in Nordic area calls for co-operation between several operators, like municipalities and recycling centres, charity organisations, eco-design companies, textile libraries, other new business for reuse and consumers. Co-operation in recycling is normal commercial activity between suppliers and producers. Before recycling is economically viable activity, operational environment has to be made 
supportive by legal measures. The support or involvement of Nordic Council of Ministers during starting period of the implementation of the strategy could be useful and it must be looked into.

The collection and sorting phases include the current players and several new ones. Collection is wide-ranging and diverse, and sites are located close to the textile waste producers making disposal attractive and convenient. Especially households have a high level of service on collection. The efficiency of collection and sorting is significantly higher than today and hence higher amounts of textiles are reused and recycled. The competition in collection previously only seen in Denmark is now commonplace in all Nordic countries.

Certified de-branding of corporate clothing will increase the collection of used textiles from public institutions and private companies.

Reuse activities of charity organisations are strengthened. The role of these organisations is not merely reuse. They can be involved in presorting or de-branding operations as well. Textiles are reused to some extent even more than today within the Nordic countries and also sent abroad to e.g. developing countries. The concept of textile libraries will expand to all areas. In addition other business concepts on reuse will become common. Consumers role is important. Reasonable use of longlasting and repairable clothes and textiles is common activity. Consumers are advised and encouraged to reuse more, for example via internet trading sites (e.g. Ebay) and flea markets.

Recycling is concentrated on upcycling due to advanced sorting technology using facility situated in Nordic region. In addition new business ideas around eco design sector will increase. Waste that is not suitable for upcycling processes is directed to down-cycling, i.e. mechanical recycling producing e.g. insulation materials, industry wipes, oil absorbent mats etc.

\subsubsection{Specific description}

\section{Implementation of a Nordic strategy and Nordic Targets for increased collection, sorting, reuse and recycling on the Nordic level}

High level of change in all Nordic countries requires adopting common strategy including targets for collection, sorting, reuse and recycling of textiles. Nordic Commitment should include numeral targets for reuse and recycling and common goals for collection and sorting.

The strategy and targets should be approved by Nordic Council of Ministers. To strengthen the effect, the strategy needs also validation by legislative procedure of each Nordic country. In order to increase the 
commitment, all important stakeholders (textile producers, distributers, retailers, charity organisations, municipalities, waste management companies) should be encouraged to participate in the strategy process and commit to meet the targets. One option for boosting the effectiveness of the Commitment is to introduce simultaneously the mandatory producer responsibility for textiles at Nordic level.

Commitment will increase the co-operation between operators in Nordic countries, since there are joint treating facilities and reuse operations.

\section{Collection}

Along with the new reuse and recycling targets, collection rates need to be significantly increased. This is done by different operations from collection with containers to retailer's take-back obligation. Textile flows from households, public organisations, private companies and industry are all within the range of the collection. Collectors have to send the collected textiles to sorting facilities, if they do not have a facility of their own. Through an intensive collection system, amounts of collected textile waste is much larger than today.

- Collection containers

Extensive collection container network will be established. Collection containers are placed at all recycling centres, all recycling points and also at all large, public workplaces. Existing container network of charity organizations will be maintained or even boosted. Extra collection is done by private companies or by municipalities.

- Introduction of kerbside collection

Kerbside collection of textiles is performed in connection of other wastes and recyclables from larger properties by introducing a specific container for used textiles. Collection from households at a limited number of times per year can also be run by "special collection". Kerbside collection will be extended to cover $50 \%$ of households. Collection is probably managed by private companies or charity organisations, but maybe also by municipalities.

- Collection of clothing and textiles from public institutions and private companies with secured de-branding

Significant textile waste flows are generated in public organisations and private companies. Collection from those places will create a clean and homogenous waste which is easier to recycle. Mandatory collection of corporate clothing from public institutions is introduced in connection with the Nordic Commitment. Public institutions represents e.g. public transport, police and other 
authorities, health and social care, prisons, armed forces. Binding obligation is probably easier to establish for public organisations than for private companies. Secured de-branding is needed to prevent the misuse of identifiable material. Collection will be run by companies, charity organisations or municipalities.

Next to the mandatory collection from public institutions also voluntary based collection from private companies is introduced. Collection of used textiles from private companies will be an easy to use option with secured de-branding. Private companies represent e.g. transport companies, security companies, restaurants, hotels etc. Collection can be performed by secured collection containers or straight from properties. Collection can be free for participating companies to make the collection attractive. Obligation to use these options can be introduced later.

Secured de-branding is very important operation for both public organisations and private companies. Neither of these stakeholders will accept the situation that textile wastes like corporate clothing end up accidentally on wrong hands. Therefore there is a need for a facility that converts all corporate clothing and other identifiable material to unrecognizable form. Secured de-branding facilities will also decrease the amount of textile waste ending to waste incineration. De-branding needs to be provided as a first step in the recycling chain. This service could be introduced and managed by private companies or charity organizations. In order to decrease the possible doubts on the security facilities could operate at the initiation phase on a national level. Later Nordic level operations could be possible depending also on the collected amounts. The operations of the secured de-branding facility should be certified to prevent misuse. Certification will create confidence among waste producers and makes the participation easier, even in the situation when participating is optional. The clients of secured de-branding services can agree upon the terms how the textile wastes are treated. Some might require that for example official uniforms must be recycled not reused in order to avoid the possibility of abuse.

- Collection of surplus textiles from industry and retailers in the Nordic region

Surplus textiles from industry (materials from textile production) and retailers (unsold textiles) are collected directly from the properties or they can be announced for sale through the material bank net service. This material might also need the secured debranding operation. 
- Obligation for retailers selling clothes and household textiles to collect used textiles and fulfil certain reuse/recycling criteria

For retailers selling clothes and textiles an obligation to collect used textiles is introduced. At the same time when buying new clothes or textiles customers can bring used textiles to the shop. Obligation will also include reuse and recycling criteria for the collected textiles. Retailers can either donate all collected textiles to charity organisations or to certified sorting facilities. In case there is a producer responsibility system in use, the transportation cost is paid by producers. Otherwise retailers are responsible for the costs. Transparency and a proper documentation are important in order to secure that collected textiles will not end up for example to incineration. The requirements and criteria will be written in the collection permit of the retailer.

- Material banks

Material banks can operate like waste dealers who buy waste from other businesses to sell on similar to e.g. RecycleMatch in the USA. ${ }^{8}$ It is also possible that material bank do not buy the waste but offers a dealer service for companies to offer their waste as a raw material to other businesses. Dealers do not necessarily take physical possession of the waste. Net service material banks can be managed by public organisations or private companies. Traditional waste dealers are already an established trade guild. They might also be interested in certain textile flows especially waste with economic value. The operational area of material bank can be one country, Nordic area or even larger. Aim is that a common Nordic material bank would serve all operators in Nordic area. This would make the activity efficient through sufficient volumes.

\section{Sorting}

One relatively large half-automatic and NIR-sorting facility is set up. NIR spectroscopy is an optical sorting technology used widely in plastic recycling. This enables the production of high quality materials which can substitute for virgin raw materials in the manufacture of new items. Used textiles from all Nordic countries are channelled to this facility (i.e. not everything that is collected but large parts of it). Charity organisations will still do the manual pre-sorting on national level in order to

${ }^{8} \mathrm{http}: / /$ www.recyclematch.com/marketplace 
make sure that their operational conditions remain. The share which is not suitable for reuse goes to the sorting facility also from charity organisations. Pre-sorting can be done by other operators than charities as well. It is possible that the sorting facility could purchase textiles also by importing from other European countries. First the facility will sort all reusable textiles. After that textiles will be sorted on the basis of the composition of material. This will ensure the upcycling possibilities. The facility is run by private company in co-operation with recyclers. Also municipalities can take part in setting up this facility. Sorting facility can co-operate with charity organisations and send sorted reusable clothes back to charity.

Additional sorting facilities for half-automated sorting can also be established in the Nordic region.

Sorting facilities are certified in order to ensure that the sorting process will make the meeting of the recycling targets possible. There is an obligation for collectors to send pre-sorted or mixed textiles to certified sorting facilities. Charity organisations can still pre-sort the reusable clothes and textiles for their own purposes.

Through an efficient sorting scheme, amounts and quality of sorted textile waste is high.

\section{Recycling}

Optical Near Infra-Red (NIR) sorting facility sorts textiles based on their quality and composition. Along with the process clean and homogenous waste section can be gained. This will enable the upcycling of the textile waste into new materials, clothes or textiles for better environmental and economic value. One chemical recycling facility on an industrial scale is established in the Nordic region. Materials not suitable for chemical recycling are directed to mechanical recycling.

Part of the textile waste from sorting facilities goes to mechanical recycling facilities. Textiles are downcycled to different products like isolation materials or industrial wipes. Mechanical recycling operations are located either in Nordic or EU area.

The material flows from de-branding can either be transported to the recycling facilities directly after de-branding or stored at the centralised sorting facilities and combined with material flows from other collectors to be transported to the recycling facilities.

Used textiles suitable for eco-design is coming from material banks, straight from companies, charity organisations or municipalities or from sorting facilities. Eco-design turns used textiles into new textile products or clothes. Possible producer responsibility of textiles will emphasize the product design phase to make textiles more suited for recycling. The 
profession of eco design is growing and the sector will turn towards more commercial and industrial direction.

The key path to free textiles from hazardous substances will be in the virgin production to keep them from ever entering the system. Processes for textile to textile recycling will have quality management systems ensuring production of a safe product.

\section{Reuse}

Different reuse activities of clothes and textiles will grow in the Nordic area because of the change in consumer's attitudes. People are buying more second hand clothes, using textile libraries and using textile rental services. Textile library concept is expanded to all Nordic countries and services are offered by different operators, for example private companies or recycling centres. In addition different new business concepts around the reuse will increase. One example is company's take-back and resell system for own brand. Reuse is increasing a little bit because of increased collection and sorting.

It is important that along the growing business around the textile waste, the traditional charity organizations will keep their market share of the reuse operations. This will be ensured by advising the households to sort usable textiles to containers of charity organisations. The reusable textiles coming from sorting facilities must find its routes back for consumers. Owner of sorting facilities could co-operate with charity organisations in order to direct the reusable share or some part of it back to charity network.

Export for reuse is also growing. Reusable textiles are exported to European logistic centres and also to developing countries. Certified sorting facilities will secure the quality of the exported textiles.

\section{Disposal}

Small amount of dirty or wet textiles goes to incineration. Also textiles containing hazardous substances must be disposed safely. These textiles which are unfit for reuse or recycling will be generated in households, companies and in sorting facilities. However, amounts of disposed textiles are much smaller than today.

\subsection{Supporting incentives, instruments and measures}

On the whole, the Nordic commitment is a high level policy instrument which aims at increasing the reuse and recycling of textiles. Commitment that is validated by each country's government will strongly steer 
the textile waste flows. The strategy outlined in this project "A Nordic strategy for collection, sorting, reuse and recycling of textiles" could be used as a basis for Nordic Governments to develop the strategy and the possible new instruments and measures. Background information for the composition of the strategy and targets could also be adopted from the proposal of Swedish EPA (Swedish EPA, 2013):

- There are convenient collection systems that ensure that textiles are primarily reused by 2018 .

- $40 \%$ of the textiles put on the market are reused by 2020 .

- $25 \%$ of the textiles put on the market are recycled, primarily into new textiles by 2020 .

- The textile cycle should be coordinated so that substances with undesirable properties are no longer present in virgin textiles by 2020 .

Common strategy in all Nordic Countries will make the management of bigger waste streams possible and lead to more cost-efficient way of handling the used textiles. Previous Nordic studies on textile wastes have expressed that one obstacle for industrial scale recycling is the lack of suitable materials. Commitment will also include the certification criteria for sorting facilities and de-branding operations.

In order to meet the targets of the Nordic Commitment, there is a need to increase the collection. Collection will increase if there is demand for the material and if collection is convenient for households. To promote the generation of new sorting and recycling facilities and also new eco-design operators, it might be necessary to introduce some economical instruments to strengthen the business.

Obligation for retailers to receive used clothes is introduced. Although collected amounts may not be large, it is used to increase the consumers awareness that used textiles is a valuable resource.

Mandatory collection of corporate clothing from public organizations is one instrument to increase the collection. Mandatory collection requires the de-branding of the clothing. This collection will direct the disposed textiles from incineration to recycling.

There is also an obligation for collectors to send the collected textiles to certified sorting facilities. This obligation makes sure that there is sufficiently waste material to be processed.

Public procurements by municipalities or by governmental institutions should be committed to require the use of recycled materials in procurements. This would generate demand for used textiles as raw material. The strengthening of the demand might need other instru- 
ments as well. Producer responsibility system will create a suitable setting to support the operational environment.

Intense information campaign for all operators and consumers is needed. Consumers need to be advised about the collection sites and collection criteria.

One option to fulfil the targets of the Nordic commitment is to put a mandatory producer responsibility system into operation. Through the EPR, all elements and actors through the whole life cycle of textiles would be involved and there would be no need for separate obligations directed to different actors or phases. Textile waste is not and will not by itself become a very valuable waste section and it is likely that businesses around the textile waste will not arise without some kind of support. There is therefore a need for strong incentives or obligations to get the ball rolling.

\subsection{Implications on the key factors}

\subsubsection{Attractive collection}

Extensive network of collection containers will make the disposal of the used textiles easy for consumer compared to the present situation. Kerbside collection will make the collection even more attractive for $50 \%$ of households. The cooperation between collectors, producers and municipalities will give a unified picture to consumers on the importance of collection, reuse and recycling.

\subsubsection{Collection for both reuse and recycling (with priority to reuse)}

Collection serves both reuse and recycling. With more wide-ranging collection points, increased amounts of textiles are collected. The secured de-branding system increases the amounts of corporate clothing and other sensitive textile materials entering the collection. However, potential for reuse comes mainly from the textiles collected from households, and to some extent private companies. The de-branded materials can be used for chemical or mechanical recycling after shredding.

Municipalities must be encouraged to co-operate within the textile collection and responsibilities on the textile waste management must be agreed. 


\subsubsection{Collection securing high quality flows}

Collection expands to retailers, industry and public institutions and private companies which are producers of homogenous textile surplus and waste. This secures the supply of high quality textile flow. On the whole, high quality textile flow is increasing because of the NIR sorting system.

In order to avoid loss during emptying the containers in rainy days, there is a need for developing the collection containers and collection sites. Wet textiles are not suitable for reuse or recycling.

Consumers are encouraged by municipalities, producers and collectors to bring reusable and recyclable textiles to the collection containers. The bring system most likely ensures that the quality of the donated textiles is high. Increases in the collection of non-reusable textiles might cause increases in the collection of non-recyclable textiles (e.g. spoiled by paint or oil). These will be removed within the sorting process.

\subsubsection{Cost efficient collection, sorting and reuse/recycling}

Upcycling is cost-efficient and it saves money and also promotes sustainable business.

One large scale NIR sorting facility will sort most of the used textiles collected in the Nordic region (after potential pre-sorting for reuse by charitable organisations or other operators). By centralizing the waste flow to one facility, cost-efficiency will be high. Despite of long transport distances in Nordic countries, the distances are still shorter than transportation to Central Europe. The location of the NIR sorting facility has to be planned to serve the whole Nordic area with minimum transportation distances.

Reuse operations of clothes and textiles are still mainly taken care by the charity organisations. Next to that textile libraries and other new business opportunities regarding reuse of textiles become more common.

Cost efficient operations need a strong co-operation between different operators. Therefore all operations need to be planned and managed as a whole. However, there is a risk of overlapping collection systems.

\subsubsection{Minimising overall environmental impacts}

Reuse with as few collection or sorting phases as possible brings the biggest environmental benefits for this system. Therefore it is important to maintain the pre-sorting possibility for charity organisations.

There are more possibilities to upcycle textile waste than before. Upcycling saves energy and helps reduce $\mathrm{CO}_{2}$ emissions by using waste 
materials instead of virgin materials. It also helps preserve natural resources. In general textile recycling brings environmental benefits when virgin materials can be substituted with waste.

Bring system requires transportations from households, but if the containers are located wisely, the textile drop-in can be combined with doing other businesses. The collection directly from properties for public institutions, industry and retailers can be taken care of in connection to other waste fractions; hence no or little extra transportation is needed. Material bank services make it possible to plan transportations in an efficient way. Nevertheless increased collection, centralised sorting and transportations of materials to Central Europe will increase transportations from the current situation. With full loads and well-planned logistics the environmental impacts of transports remain low. However, possible overlapping collection systems to some extent might cause negative environmental effects, like more greenhouse gas emissions.

Hazardous substances in textiles should be prevented from ever entering the flows in the Nordic region increasing the possibility for closed loop reuse and recycling. Recycled textile products should not have increased contents of hazardous chemicals compared to virgin products.

\subsubsection{Creation of green jobs}

There is a big potential of new jobs in the whole system. New jobs can develop around collection, transportation, material bank services, sorting, upcycling, recycling, eco design and reuse businesses. Creation of green jobs depends also on the effectiveness of the policy measures. Without strong policy measures it is unlike that markets alone would create new business and jobs.

\subsection{Winners and losers in the value chain}

There are many $\mathrm{X}$-factors for a prediction concerning winners and losers. However, some things are evident. Producers of textile wastes will have a larger selection of collection containers in various collection points available than today, and it will be easier to dispose of both reusable and non-reusable textiles.

Charity organisations should be able to keep their incomes constant as their operations are secured even boosted but there will be increased competition if several new actors enter the system. 
Municipalities will gain from increased employment and increased entrepreneurship. However there might also be negative effects for municipalities due to decreased amount of mixed waste suitable for incineration. Some municipalities have agreements with incineration plants to bring certain amount of waste. If waste amounts are below agreed, municipalities have to pay penalty fees. Because municipalities have the legal control over waste from households, there conflicts can arise on collection of the textile waste straight from properties. An EPR system could contribute to define the responsibilities.

Private companies will need to invest in de-branding services, collection and recycling. In the long run they will profit from selling services for management of a new waste material.

The recycling industry will receive more material for processing and more products produced. This will increase their activities, lead to new business opportunities, lead to more jobs and higher profits.

\subsection{Trade-offs}

Cost-efficiency of the collection system would probably be better with more centralized logistics. By securing and even boosting the activities of charity organisations and simultaneously creating new collection activities, there will in parts overlapping operations potentially resulting in lower cost-efficiency. However, since reuse is more profitable in a socioeconomic perspective, parallel collection and sorting systems enabling and securing increased reuse of textiles are in most cases still beneficial.

\subsection{Effects on collection, sorting, reuse and recycling in summary}

Table 34 reflects in brief overview the foreseen effects on collection, presorting, sorting, reuse and recycling of used textiles and textile wastes in the scenario. 
Table 34. Changes in amounts and quality of the separately collected used textiles and textile wastes from the Nordic region in the Scenario "Nordic innovation" compared to the current situation

\begin{tabular}{lcc}
\hline & Changes in amounts & Changes in quality \\
\hline Collection & +++ & ++ \\
Pre-sorting & ++ & ++ \\
Sorting in total, thereof & +++ & +++ \\
in Nordic region & +++ &.$/$ \\
in other countries & 0 &.$/$ \\
Reuse in total, thereo & +++ & ++ \\
in Nordic region & +++ &.$/$. \\
in other countries & + &.$/$ \\
Recycling in total, thereof & +++ & ++ \\
in Nordic region & +++ &.$/$. \\
in other countries & ++ &.$/$. \\
\hline
\end{tabular}

Changes range from --- to +++.

0 indicate no or very little change.

./. indicate change that could not be assessed within this project. 



\section{References}

Brismar, A. (2014). Textila Strömmar och förbehandlingsmetoder för textilfiberåtervinning. Green Strategy.

Cassidy, T. D., \& Han, S. L.-C. (2013). Upcycling fashion for mass production. In M. A. Gardetti, \& A. L. Torres, Sustainability in Fashion and Textiles (pp. 148-163). Sheffield: Greenleaf Publishing Limited.

Elander, M., Kiorbøe, N., \& Palm, D. (2013). Literature review of the tracebility of global textile flows. IVL.

Goworek, H., Hiller, A., Fischer, T., Cooper, T., \& Woodward, S. (2013). Consumer's attitude towards sustainable fashion. Clothing usage and disposal. In M. A. Gardetti, \& A. L. Torres, Sustainability in Fashion and Textiles (pp. 376-392). Sheffield: Greenleaf Publishing Limited.

Kiorbøe, N., Watson, D., Elander, M., Lyng, K.-A., Gislason, S., \& Palm, D. (2013). Mapping of current actors in the collection, sorting, reuse and recycling of used textiles and the management of textile wastes.

Laitala, K., Klepp, I. G., Morley, N., Meistad, T., Chapman, A., Chen, W., et al. (2012). $\emptyset k t$ materialgjenvinning av tekstilavfall og andre avfallstyper (papir/papp, metall og glass). Oslo: SIFO Statens Institutt for forbruksforskning.

Palm, D., Dahlbo, H., Moliis, K., \& Tekie, H. (2013). Collection and sorting systems. Gothenburg: IVL.

Swedish EPA. (2013). Förslag till etappmål - Textil och textilavfall. Retrieved April 2014, from Textil och textilavfall - förslag till nytt etappmål i miljömålssystemet: http://www.naturvardsverket.se/upload/miljoarbete-i-samhallet/miljoarbete-isveri-ge/regeringsuppdrag/2013/etappmal2013forslag/etappmal2013forslagtextilavfall.pdf

Valente, C., Lyng, K.-A., Palm, D., \& Rydberg, T. (2013). Technology review of sorting and recycling of textiles. IVL.

Virgin, K. (2014). Jakten på det vita guldet. Ingenjören, p. 41. 

Evaluation of scenarios 



\section{Introduction}

The objective of this subreport was to evaluate the four scenarios for collection, reuse and recycling which were developed and described under the previous subreport:

- Business as Usual.

- Nordic Cooperation.

- Multiple Strategies.

- Nordic Innovation.

The scenarios are evaluated with respect to the degree to which they promote:

- Increased collection rates as a whole, and of different fractions of used textiles.

- Reuse rather than recycling as far as possible.

- Recycling rather than down-cycling of the recycled fraction.

The evaluation of each scenario has been qualitative rather than quantitative. Attention has been given to the suggested incentives, regulation and measures which might be used to promote each of the scenarios. The expected environmental gains associated with the scenarios have also been discussed. 



\section{Scenario 1: Business as usual}

The Business as Usual scenario reflects the likely development in collection, sorting, reuse and recycling of textiles under the assumption that current trends and developments continue, but no major change in technologies, structures and policy are implemented in the Nordic region.

The Business as usual scenario is expected to result in the following effects.

\subsection{Effect on collection rates as a whole and of different fractions of used textiles}

Over all, there is only a small increase in the collected amounts of used textiles and textile wastes (less than 10\% more compared to current levels). This change is mainly due to:

- increased collection of textiles (independent of brand) via textile retailers

- two to three retail chains in each country which offer collection of used textiles (independent of brands) in most or all of their stores

- a limited increase (ca. 10\% compared to current levels) in the total number of textile containers available for consumers in public places, primarily at recycling stations.

The (small) increase in collection is thus mainly due to an increase in collected household textiles, especially since no new/coordinated collection system set up for corporate textiles.

\subsection{Effect on reuse compared to recycling}

The collected amounts are expected to be sorted to an increasing extent. By sorting a higher proportion of the collected textiles (instead of sending them to incineration and landfill) more textiles are channelled into both reuse and recycling: 
- Small increases in reuse of used clothes and household textiles in the Nordic countries are expected due to somewhat increased demand for second-hand textiles due to increased consumer awareness. The total increase is however expected to be less than $10 \%$ compared to current levels.

- There are somewhat larger increases in reuse outside of the Nordic countries due to the increased amount of textiles that are sorted by certified sorters.

- The quantity of used textiles and textile wastes that are recycled is also expected to increase, though to a small degree. The increase is primarily a result of the increased sorting of collected textiles, potentially channeling more textiles to recycling instead of to incineration.

The increase is thus expected to be in both reuse and in recycling, but mainly for markets abroad. Since the fraction of textiles is more or less expected to be the same as the fraction which is collected today, no major change in the proportion between reuse and recycling is expected.

\subsection{Effect on recycling compared to down-cycling for the recycled fraction}

The predominant recycling technique which is expected to be used under the Business as Usual scenario is mechanical recycling similar to today. Only to a very limited share (less than $0.1 \%$ of the recycled amounts) is recycled into yarn and new textiles. The latter option is limited to certain pilots/test products and promotion campaigns of retail chains. Textiles are therefore predominantly recycled into low quality products such as insulation (down-cycling). There is no or very limited recycling on an industrial scale in the Nordic region. This is not expected to change. 


\subsection{Summary}

The development which is expected to take place is primarily driven by a general demand for higher transparency and lower environmental impacts. Initiatives are however voluntary and sporadic and no overall supporting incentives, instruments or measures are introduced to push this development. The Business as Usual scenario is thus, not surprisingly, not expected to give any major environmental improvements compared to the current status in the Nordic region.

\begin{tabular}{ll}
\hline Increased collection & Minor increase in collection of household textiles \\
Reuse before recycling & $\begin{array}{l}\text { Increase on reuse and recycling on markets abroad. No major change } \\
\text { on Nordic market }\end{array}$ \\
Recycling before down-cycling & $\begin{array}{l}\text { Very little, positive effect on upcycling or closed loop recycling is } \\
\text { expected. Down-cycling continues to dominate }\end{array}$
\end{tabular}





\section{Scenario 2: Nordic Cooperation}

In this scenario, the Nordic countries have established common goals and strategies for collection, reuse and recycling of used textiles and textile wastes.

The certification system is introduced to improve the trustworthiness of the system. It includes quality and transparency criteria for the collection, de-branding, sorting, transport, reuse and recycling of used textiles and textile waste. It also includes improvements in statistics regarding used textiles and textile wastes as well as registration of the certified actors and an online-list of actors which are not (yet) certified. An easy recognizable logo of "Certified textile operator" with link and barcode to more information is used at all collection solution operated by certified collectors.

The certification system is initiated on a Nordic level, but has in some countries been further developed into national systems based on mandatory agreements with environmental authorities and development of national system operators. Otherwise, apart from the voluntary certification system only minor changes have been carried out compared to business as usual. No other means have been implemented to exclude unserious actors, for example.

The Nordic Cooperation scenario is expected to result in the following effects.

\subsection{Effect on collection rates as a whole and of different fractions of used textiles}

The certification system has only resulted in minor changes in the design and technological basis for collecting and sorting systems for used clothes and textiles.

However, an overall increase in collected volumes is expected to have occurred by 2020 compared to 2015 as the result of a number of developments: 
- The total number of containers is expected to have increased due to increased stability in the more regulated system for the certified collectors. This after a small decrease just after the 3 year introductory period phased out and sanctions against uncertified actors began to appear.

- Better prices for reusable clothes resulting from general increased consumer awareness also encourages certified collectors to increase their collection point densities. This is not concerned with this particular scenario but is a general background trend.

- Many of the new containers are also now found along with containers for other types of recyclables at recycling stations run by municipalities due to the increased cooperation between the municipalities and certified collectors. This increases the likelihood that citizens will drop off their used textiles when delivering other used goods and waste fractions at the centres.

- The awareness of consumers over available collection possibilities has been increased due to more active promotion by municipalities and by the operator of the Nordic certification system (via websites etc.)

- The visibility and clarity of certified collectors has also been increased as a result of having a common logo and common goals and levels of transparency. This reduces confusion and doubt among potential donators of used textiles.

- The requirement for certified collectors to clearly invite citizens to deliver non-reusable worn out or damaged textiles along with reusable textiles at their collection points, should increase the total collection of textiles. Currently most collectors actively discourage donation of non-reusable/worn out textiles.

The effect noted in the final bullet above will also affect the composition of collected used textiles. The amount of non-reusable textiles is likely to increase significantly by 2020 compared to 2015 levels, while amounts of recovered reusable textiles will only increase moderately. These nonreusable textiles will have been diverted from mixed waste streams for incineration or landfill (Finland only). 


\subsection{Effect on reuse compared to recycling}

As noted above the composition of collected textiles is likely to have changed, with a higher share of (what citizens consider to be) nonreusable textiles being collected. Collected reusable textiles have also increased but only moderately.

It would be expected that this development should increase the quantities of textiles available for recycling. But not at the expense of reuse; rather at the expense of incineration/landfill.

The degree to which collected non-reusable textiles are actually recycled, depends on a number of other factors; the availability of markets, the price of recycling compared to incineration/landfill and transport possibilities.

Better cooperation between certified organisations, under this scenario, should at least result in greater exchanges of textiles between organisations. One type of exchange will be from small organisations without the transport systems, textile volumes or contacts to send textiles for recycling, to donate (or sell if there is a market) these to the large organisations who do have these facilities, contacts and volumes. This will tend to divert collected non-reusable textiles away from incineration/landfill to recycling.

The diversion from incineration to recycling may also be supported by the common Nordic recycling target of $20 \%$ of textiles put on the market being recycled by 2020 . However, the scenario does not include any direct requirement on individual organisations to fulfil these targets so this effect may be minimal.

The increased volume of collected non-reusable textiles has the potential to encourage developments of new recycling technologies and thus increase the demand and market price for these textiles. However, recycling markets tend to operate at the European or even global scale, rather than locally (Palm et al. 2014). Increases in collection volumes in the Nordic region are not expected to have a noticeable effect on European recycling markets or technologies. However, as noted under 3.3 below, there are likely to be background developments in recycling technology over this period which will indeed increase the likelihood that collected non-reusable textiles are recycled instead of incinerated.

Overall a medium increase in recycled textiles is expected.

The quantity of reused textiles is also expected to increase though only to a moderate level. This will result from a number of drivers: 
- The absolute volumes of collected reusable textiles is likely to increase as a result of the drivers identified in section 2.1.

- The certificate system includes overall goals for reuse which may be higher than reuse currently achieved by some organisations. This, however, depends on the degree of ambition of the goals.

- As noted earlier, one expected background trend is a higher price for second-hand textiles as a result of higher consumer awareness. This could potentially result in a better level of sorting which may increase the fraction of collected textiles which is reused. Having said that, the market price for collected textiles having risen steadily between 2005-2012 reduced by 5\% during 2013. Increased market prices are, therefore, not guaranteed.

\subsection{Effect on closed loop recycling compared to down-cycling for the recycled fraction}

In this scenario, the industrial scale of recycling is still done outside the Nordic region i.e. the fractions identified for recycling are still exported for trading and recycling on an international market.

There is a slight increase in recycling in form of upcycling of collected used clothes in the Nordic region due to the blooming consumer trend in purchasing upcycled/reworked fashion clothes and accessories, as well as clothes made of recycled materials.

Generally improved technologies for mechanical and chemical closed loop recycling in part as a result of increasing available volumes in Europe, have somewhat increased the proportion of non-reusable textiles which are recycled back into new textiles.

However, under this scenario most recycled textiles are still expected to end in down-cycled products such as insulation

\subsection{Summary}

The scenario leads to an increase in collected textiles, in particular collection of non-reusable textiles. Volumes of recycled textiles are also set to increase, while volumes of reused textiles may also see a small increase.

The Nordic cooperation scenario mainly provides environmental improvements via this small increase in quantity of reused textiles which offset new production. The size of environmental gains depend to a great extent on the degree to which purchases of used textiles substitutes new. 
WRAP (2013) found a displacement rate of only $28 \%$ for textiles but Farrant (2008) found much higher rates, particularly in Eastern Europe and Africa. The area is largely unstudied.

Upcycled textiles are likely to have a similar environmental gain to reused textiles per article but the increase in this is thought to be fairly marginal compared to the increase in reused textiles.

The diversion of non-reusable textiles from incineration to downcycling, although medium under this scenario, is likely to have little overall environmental gain: LCA's for down-cycling typically show only slightly better results for energy use and climate change impact as incineration with energy recovery, depending on replaced material and country where incineration takes place (Zamani, 2011) (Palm, Harris, \& Ekvall, 2013).

However, the increased level of collected non-reusables under this scenario gives the potential for much greater gains when closed loop recycling technologies have become mature.

\begin{tabular}{ll}
\hline Increased collection & $\begin{array}{l}\text { Overall increase in collected volumes is expected. Non-reusable } \\
\text { textiles are likely to increase significantly, while recovered reusable } \\
\text { textiles will only increase moderately }\end{array}$ \\
Reuse before recycling & $\begin{array}{l}\text { Although a significant increase in collected recyclable textiles is } \\
\text { expected, only a medium increase in textiles actually recycled is likely } \\
\text { due to a continued low market price. The quantity of reused textiles } \\
\text { is expected to increase moderately }\end{array}$ \\
$\begin{array}{l}\text { Closed loop recycling before down- } \\
\text { cycling }\end{array}$ & $\begin{array}{l}\text { A slight increase in upcycled and closed loop recycled textile waste is } \\
\text { expected. However, most recycled textiles are still expected to be } \\
\text { down-cycled }\end{array}$ \\
\hline
\end{tabular}





\section{Scenario 3: Multiple strategies}

In this scenario, each Nordic country has its own strategy for textile collection, reuse and recycling. Hence the characteristics of systems may vary from country to country. The system is based on voluntary commitments of the different operators.

The collection and sorting phases include the current players and new ones. Existing container networks of charity organizations will be maintained or even boosted. Extra collection is provided by private companies. Municipalities are also allowed to participate. Collection is wide-ranging and diverse, and sites are located close to the textile waste producers making disposal attractive and convenient.

Pre-sorting, that separates reusable clothes from non-reusable can be performed by the collectors, securing the possibilities of e.g. charity organisations to continue with their current activities. Several countries provide centralised half-automated sorting, taking care of mainly the non-reusable, but also to some extent of the reusable textiles sorting.

The Multiple Strategies scenario is expected to result in the following effects.

\subsection{Effect on collection rates as a whole and of different fractions of used textiles}

The collection system includes four main bricks, namely:

- Container collections.

- Kerbside collections in sparsely populated areas.

- Collection directly from properties (of companies, offices, institutions etc.).

- Material bank net service (which actually functions without collection, channelling materials from one actor to another). 
This improvement from the existing system will ensure a higher flow of collected amounts. The increase in textiles collected from households, however, will be minor compared to the amounts collected from other actors, such as private companies and public entities.

\subsection{Effect on reuse compared to recycling}

The reusable fraction originates mainly from households, since institutions, industry and retailers will most probably want to direct their textile flows through de-branding systems. Reuse can take place domestically or outside the Nordic countries.

Each Nordic country will thus have several pre-sorting locations, but at maximum one centralised, half-automated sorting facility per country. The aim in the scenario is that as much as possible of the collected textiles go through sorting in the Nordic countries. This way the material exported for e.g. charity will be of higher quality and there will be more material left to deliver to recycling.

Collection serves both reuse and recycling. With more wide-ranging and diverse collection points, increased amounts of textiles are expected to be collected. The secured de-branding system also increases the amounts of corporate clothing and other sensitive textile materials entering the collection. However, potential for reuse comes mainly from the textiles collected from households, and to some extent laundries. The de-branded materials collected from business can only be used for mechanical recycling after shredding.

The system can moderately increase amounts of textiles for reuse, but the increase will be much higher for recycled textiles, due to i.e. the need for de-branding. De-branding of all textile wastes from businesses needs to be provided as a first step in the recycling chain, in order to assure the producers of the safety of the chain. In practice this means collecting the textiles in secured containers and delivering the material for shredding, which hereafter can be used for mechanical recycling.

Due to this need for de-branding (and the rise of material banks), recycling will increase significantly more than reuse in this scenario. However, the recycled textiles will have been diverted from incineration and landfill - not from reuse. 


\subsection{Effect on closed loop recycling compared to down-cycling for the recycled fraction}

The majority of the textiles from the Nordic sorting facilities are transported to Central Europe for mechanical recycling i.e. down-cycling producing e.g. insulation materials, industry wipes, oil absorbent mats etc.

The material flows from de-branding can either be transported to the recycling facilities directly after de-branding or stored at the centralised sorting facilities and combined with material flows from other collectors to be shipped to the recycling facilities. From the environmental and economic points of view the latter may be more profitable, but bookkeeping for charges and payments for different collectors may become complicated if several actors combine material flows.

\subsection{Summary}

In conclusion, the scenario of multiple strategies does not provide strong environmental gains compared to the existing system (and also compared to the business as usual scenario). With respect to the mechanical recycling (rather than e.g. incineration) it is difficult to clearly name an environmentally preferable option. The magnitude of the overall environmental impacts will, amongst other things, depend on what materials the products produced through mechanical recycling substitute. LCA's for down-cycling typically show slightly better results for energy use and climate change impact as incineration.

As mentioned in the scenario subreport, some flows could already in this scenario be directed to closed loop recycling processes, where products compensate for virgin material textiles, instead of channelling all non-reusable textiles to mechanical down-cycling. Homogenous and clean flows from e.g. laundries, public institutions, industry and retailers, could increase the environmental benefits gained and hence decrease the overall environmental impacts of the system.

\begin{tabular}{ll}
\hline $\begin{array}{l}\text { Increased collection } \\
\text { A higher flow of collected amounts is expected, mainly due to increased } \\
\text { collection from private companies and public institutions }\end{array}$ \\
$\begin{array}{l}\text { The system will give moderate increases in textiles for reuse, and a } \\
\text { medium to high increase in textiles for recycling. }\end{array}$ \\
$\begin{array}{l}\text { Closed loop recycling before } \\
\text { down cycling }\end{array}$ & Only a moderate increases in closed loop recycling is expected.
\end{tabular}





\section{Scenario 4: Nordic innovation}

Under this scenario, Nordic countries have a common Nordic strategy and a Nordic Commitment to targets for textile collection, reuse and recycling which have been legislatively adopted in the individual countries. The level of co-operation between Nordic countries is high.

Policy measures in use in individual countries to promote textile waste reuse and recycling are stronger than today and new business around textiles arise.

All important stakeholders (textile producers, distributers, retailers, charity organisations, municipalities, waste management companies) have been invited to participate in the strategy process and to commit to meeting the targets.

Co-operation between several operators, like municipalities and recycling centres, charity organisations, eco-design companies, textile libraries, other new business for reuse and consumers have increased.

Collection is wide-ranging and diverse, and sites are located close to textile waste producers to allow convenient discarding into separated streams. Mandatory collection of clothing, linen and uniforms from public institutions is introduced in connection with the Nordic Commitment. Voluntary collection from private companies is also introduced in parallel with certified de-branding of corporate clothing.

Collectors have to send the collected textiles to sorting facilities, if they do not have a facility of their own. The efficiency of collection and sorting is significantly higher than today and legal measures have been adopted to improve the economically viability of recycling.

Alternative business models based on reuse and longer lives have become common as have higher quality and repairable clothes. Consumers are advised and encouraged to reuse more, for example via internet trading sites (e.g. Ebay) and flea markets.

Recycling is concentrated on recycling back into textile products due to an advanced sorting facility situated in the Nordic region, using NIR technology or similar. Charity organisations will still do the manual presorting on national level in order to make sure that their operational conditions remain. The share which is not suitable for reuse is transferred to the advanced sorting facility. 
One chemical recycling facility on an industrial scale is established in the Nordic region. Waste that is not suitable for closed loop recycling processes is directed to down-cycling e.g. insulation materials, industry wipes, oil absorbent mats etc.

Online material banks have been established by public organisations and/or private companies to allow efficient trading in materials between sorters, recyclers and producers.

Public procurements by municipalities or by governmental institutions are committed to require the use of recycled materials in procured textiles to increase the demand for recycled fibres.

The Nordic Innovation scenario is expected to result in the following effects.

\subsection{Effect on collection rates as a whole and of different fractions of used textiles}

A significant increase in the share of new textiles put on the market which is separately collected following use is expected by 2020, as the result of a number of developments:

- The total number and density of containers and collection points having increased significantly as a result of the Nordic commitment and improved market prices for both reusable and recyclable textiles.

- There is mandatory collection of used textiles from public organisations.

- Collection of corporate clothing, uniforms etc. from private companies is made more attractive by certified de-branding services.

- A much greater awareness of consumers over available collection possibilities and the importance of reuse and recycling of textiles.

- Retailers of textiles are obliged to offer a used textile collection service to their customers.

- A requirement for collectors to clearly invite citizens to deliver nonreusable worn out or damaged textiles along with reusable textiles at their collection points.

Whether or not this leads to an increase in volumes of collected textiles is dependent on developments in the quantities of textiles put on the market. Under this scenario it is expected that this quantity could reduce due to a number of drivers: 
- A more commonplace demand for higher quality, more durable and repairable clothing by consumers.

- A greater prevalence of businesses whose business model is based on extending the active lifetime of textile products i.e. leasing, clothing libraries, repair shops, higher quality clothing etc. Some of these models will also divert used textiles away from the central collection system i.e. companies that take back and resell their own clothes. It isn't clear whether these quantities would be registered as having being collected.

- Public procurement policy requiring higher quality textiles for public institutions.

Overall a net increase in collected volumes could be expected. This is because trends in increased quality and durability and the spread of new business models are expected to be slower than developments in increased collection convenience and intensity.

Many of the drivers will also affect the composition of collected used textiles but in different ways.

On the one hand, increased awareness and a requirement for collectors to clearly invite citizens to deliver worn out or damaged textiles, should increase the share of non-reusable textiles in total collected quantities. On the other hand, an increase in average quality and durability of textiles would tend to increase the share of used textiles which are reusable.

At least in the shorter term, the net result is expected to be an overall larger increase in the share of collected textiles which are not reusable compared to the reusable amounts.

\subsection{Effect on reuse compared to recycling}

As noted above the composition of collected textiles is likely to have changed, with a higher share of (what citizens consider to be) nonreusable textiles being collected. Collected reusable textiles have also increased but only moderately with a higher increase in e.g. Sweden and lower in e.g. Denmark due to different starting points.

It would be expected that this development should increase the quantities of textiles available for recycling. But not at the expense of reuse; rather at the expense of incineration/landfill.

The degree to which collected non-reusable textiles are actually recycled, depends on a number of other factors; the availability of markets, 
the price of recycling compared to incineration/landfill and transport possibilities.

Under this scenario, a high technology material and fibre sorting facility has been established in the Nordic region to sort non-reusable textiles by fibre type and make them available for recycling back into textile products. A chemical recycling centre has also been established with quality systems ensuring a recycled product with acceptable levels of hazardous substances. Furthermore, public procurement which requires recycled fibre content in procured textiles has increased the market demand for recovered fibres. Therefore, a reasonably healthy market for recycling is expected. It is expected that the great majority of separately collected non-reusable textiles will be recycled rather than incinerated/landfilled.

It is not expected that the market price for recyclable textiles will compete with the price for reusable textiles i.e. that textiles will begin to be diverted from reuse to recycling. Particularly since the average quality of textiles is expected to increase.

The net quantity of reused textiles is, therefore, expected to increase due to the drivers described under 4.1. Of perhaps more importance, an increasing share of this reuse within the Nordic region is expected to occur rather than being exported for reuse elsewhere. This is due to a number of drivers:

- An increased prevalence of business models which are based on local reuse i.e. resell of own brand, clothing libraries, repair, leasing etc.

- An improvement in the average quality of new textiles purchased by increasingly aware consumers. These higher quality textiles will be more attractive for the Nordic market following first use

- An increased Nordic consumer demand for used textiles both via charity shops and other second-hand shops but also via online $\mathrm{C} 2 \mathrm{C}$ trading sites and flea-markets etc. It will be hard to gain data on $\mathrm{C} 2 \mathrm{C}$ trading.

\subsection{Effect on closed loop recycling compared to down-cycling for the recycled fraction}

Under this scenario, as already described, a high technology material and fibre sorting facility has been established in the Nordic region to sort fibres and make them available for closed loop recycling. A chemical recycling centre has been established. Public procurement which re- 
quires recycled fibre content in procured textiles has increased the market demand for recovered fibres.

There is also a blooming consumer trend in purchasing upcycled/reworked fashion clothes and accessories, as well as clothes made of recycled materials.

The market prices for materials suitable for closed loop cycling and upcycling are likely to be much higher than for down-cycled products such as industrial rags. Therefore, a significant increase in closed loop recycling and upcycling at the expense of down-cycling or incineration is expected.

\subsection{Summary}

The scenario is expected to lead to a significant increase in the share of new textiles put on the market which is separately collected. Although total volumes of new textiles put on the market is expected to drop, the net volumes of separately collected textiles is likely to increase somewhat.

A net increase in the share of collected textiles which are non-reusable is expected. These will be recycled back into reworked upcycled clothing, or into new textiles to a far greater extent than occurs today. Closed loop recycling will occur at the expense of down-cycling or incineration.

With respect to reused textiles, the total quantity of reuse will increase, but perhaps more importantly a higher share of these will be reused in the Nordic countries rather than exported, compared to the situation today.

The Nordic Innovation scenario will provide environmental gains via many different pathways. Firstly, the reduction in new textiles put on the market will give significant reductions in environmental impacts caused by Nordic consumption of textiles. This reduction in new textiles put on the market will have resulted from increases in the demand for higher quality and durable clothing, combined with higher collection and Nordic reuse rates of used textiles. Consumer behaviour will have been affected by a large number of communication channels including information campaigns, collection efforts and clear environmental goals for the sector.

Further environmental gains will result from the diversion of nonreusable textiles away from incineration, landfill and down-cycling towards closed loop recycling and upcycling. 
Increased collection

Reuse before recycling

Closed loop recycling before downcycling
A significant increase in the share of new textiles put on the market which is separately collected. Total volumes of new textiles put on the market is expected to drop but, the net volumes of separately collected textiles is will increase moderately.

The net quantity of reused textiles is expected to increase. This will result in an increasing share of reuse within the Nordic region rather than being exported for reuse elsewhere.

A significant increase in closed loop recycling and upcycling at the expense of down-cycling or incineration is expected. 


\section{References}

Farrant, L. (2008). Environmental benefits from reusing clothes. Master Dissertation. Danish Technical University (DTU).

Palm, D., Elander, M., Watson, D., Kiørboe, N., Salmenperä, H., Dahlbo, H., Moliis, K., Lyng, K., Valente, C., Gíslason, S., Tekie, H., and Rydber, T., (2014a) Towards a Nordic textile strategy: Collection, sorting, reuse and recycling of textiles. Report for the Nordic Council of Ministers http://dx.doi.org/10.6027/TN2014-538

Palm, D., Harris, S., \& Ekvall, T. (2013). Livscykelanalys av svensk textilkonsumtion Underlagsrapport till Naturvårdsverkets regeringsuppdrag om nya etappmål. Göteborg: IVL Svenska Miljöinstitutet.

Watson, D., Kiørboe N., Palm D., Tekie, H., Harris, S., Ekvall, T., Lindhqvist, T. and Lyng, K. (2014). EPR systems and new business models: Reuse and recycling of textiles in the Nordic region. Report for the Nordic Council of Ministers. http://dx.doi.org/10.6027/TN2014-539

WRAP (2013), Study into consumer second-hand shopping behaviour to identify the reuse displacement effect, WRAP March 2013, Project Code MDP007-001.

Zamani, B. (2011). Carbon footprint and energy use of textile recycling techniques Case study Sweden MSc Thesis. Gothenburg: Chalmers University of Technology. 

Competitiveness and green jobs 



\section{Introduction}

This subreport aims to provide a written description of effects on the competiveness of the Nordic region and possible development of new jobs. It is approached from a circulation economic perspective, trying to show how the different measures can be put into a circulation economic frame. The proposed measures in the Nordic Strategy is put in context by using examples of existing organisations and solutions.

Circulation economics (Ingebrigtsen and Jakobsen, 2007) is a development from ecological economics. It is based on an understanding that the world is not mechanical but organic. Unlike neo-classical economics, circulation economics includes the laws of thermodynamics in its theoretical foundation. When we include the laws of thermodynamic we acknowledge that resources are losing some of its potential for use in each cycle.

From waste to resources is a slogan in the recycling business. These businesses are built up to take care of our waste in a way that does not hurt the environment, and they are based on an idea that it exists willingness to pay for the resources from the sector. An effect of this is that we also solve some of the problems with the waste. However, the main problem is that we use too many resources. All of the resources used in the textile business come from somewhere, and someone is producing, distributing and consuming the products. 



\section{Possible consequences and impacts on competitive advantage for the Nordic countries}

In this part the consequences of enhanced textile reuse and recycling on individual companies (e.g. more economic sourcing of green materials, new markets for textile sorting and vending of used textile) is elaborated. As examples on how it can be done we use the company Patagonia and Plusminusnoll. The examples have several connections to the measures proposed in the Nordic Strategy.

In the strategy - the full list of measures are:

- Launch of the Nordic Commitment.

- Expansion of the Nordic Commitment to include de-branding services.

- Engagement of municipalities in the Nordic Commitment.

- Further development of the Nordic Commitment to more actively involve and include textile producers.

- Obligation for municipalities to secure that collection containers for textiles are available at all (municipal) recycling centres.

- Obligation to collect textiles from public activities.

- Introduction of a voluntary commitment for private companies to collect used textiles.

- Evaluation of alternative business models.

- Government funding for start-ups alternative businesses.

- Consumer information campaign.

- Nordic Task Force for the Higg index.

- Public procurement for reuse of textiles and textiles with recycled content. 
- Evaluation of potentials for automatic sorting facility.

- Financial assistance for establishing one chemical recycling facility on an industrial scale in the Nordic region.

\subsection{Examples for increased competitiveness using the Strategy measures}

Patagonia is suitable as an example because they have worked systematically to improve their products towards more environmentally friendly products. This work includes aspects from cradle to grave, starting with what type of textiles used and an ability to create a market for used clothing. Plusminusnoll because they are established on an interesting, new business model which shows a different way of thinking, where the goal is to reduce the amount of clothing sold.

Patagonia was established as an off-spring of the climbing equipment company Chouinard Equipment (today Black Diamond). The company has successfully put weight on developing new and more environmentally friendly clothes for the outdoor market.

According to Patagonia themselves they have succeeded due to their philosophies on how to run an environmentally sound business. A fundamental idea is that products should have the best quality, and according to Yvon Chouinard in Patagonia (2006), quality and taste is not the same. Taste means individual preference while quality is the best degree of excellence - in the meaning that the products are made to last, be durable and fulfill their specific function. According to Chouinard (2006) a designer in Patagonia should ask the following questions (and some others) to see if the product fits their standard:

- Is it functional? - Start by asking what the product should be used for, and be sure that it has a function.

- Is it multifunctional? -Multifunctional products are another philosophy in Patagonia. This means that one chooses to go against the trend were products are more and more diversified.

- Is it durable? The durability of a product is only as good as its weakest element. Therefore, one goal can be to make the product so the different parts wear out at the same time.

- Is it as simple as possible? A functionality driven design is usually minimalistic, because: "Complexity is often a sure sign that the functional needs have not been solved" (Chouinard, 2006 p. 94) 
Keeping the design simple also make it easy to repair. An analogy here can be Georgescu - Roegens (1975) early bioeconomical program that pointed out that due to a necessity for creating a sustainable future one had to get rid of fashion and make things durable - "in many cases nowadays, we have to throw away a pair of shoes merely because a one lace has broken" (p.104).

- Is it easy to care for and clean? According to Chouinard (2006) cleaning is, together with transportation, one of the most environmentally unfriendly parts of the products life cycle. What really wear a product down is washing and drying, not to be wore. This also means that what we make clothes of, and how they are taken care of is an important part of the process (Chouinard, 2006).

\subsection{Higgs, sorting and recycling}

Patagonia also focuses on avoiding unnecessary harm. This includes going an extra round or more to find better alternatives through the use of Life cycle assessment (LCA) ${ }^{9}$, finding a way to design the product from cradle to cradle. A Nordic task force for the HIGG index (measure 11) can expand the tool into something better and standardized for the global textile sector. Another example used is nylon 6 .

"When it is finally worn out, melting down the pants to a resin and creating another pair from the same resin - over and over again" (Chouinard, 2006 p. 115).

One can discuss the overall efficiency of the process, but the general idea is good. It can however presently only be done for syntetic fibers. For viscose and cotton, a similar recycling is missing and this gap can be filled by implementation of measure 14 in the proposed strategy, "Financial assistance for establishing one chemical recycling facility on an industrial scale in the Nordic region".

9 LCA: "A Life Cycle Assesment of a product is defined as a systematic survey and assesment of environmental and resource affects throughout the whole life cycle of the product, "from cradle to grave". (Rønning etal., 2002 p. 20) 


\subsection{New business models}

An idea from Patagonia that should have some value for the companies in the Nordic countries already collecting their own brand can be found in Tokyo - where there are stores that deal only in vintage Patagonia clothing. Similar business models is proposed to be assessed under measure eight in the strategy, "Evaluation of business models in the field of collective use, reuse and prolonged (active) lifetime of textiles" to see if and how it can be more profitable to resell high-quality textiles.

However, Patagonia have gotten where they are because they have visionary leaders with a genuine passion for finding better solutions. The transferability to companies in the Nordic region is present; we already see that especially companies working towards the outdoor market are in the forefront in finding good solutions.

Another business model that could be evaluated further under measure eight, and if viable and adaptable perhaps supported by measure nine "Government funding for start-ups in the field of collective use, reuse and prolonged (active) lifetime of textiles" is Plusminusnoll. Plusminusnoll was established in the northern part of Sweden in 2011, in an area where we also find other companies producing outdoor clothing.

Measure 8 and 9 must be seen in relation. The evaluated business models are mostly focusing on reuse and prolonged life. However, all the business examples have an idea about making the product last longer than average, and the companies focus on this in their marketing. Focusing on prolonged life of clothing means that fast fashion cannot be an issue for the producer or consumer. However, today almost all clothing is sent to waste management or recycling while it still is functional. The previous example connected to Plusminusnoll can be used to illustrate a business model which can lead to less material use and prolonged use of textiles. A main criterion for business in this sector should be that new products cannot be based on perceived obsolescence, but on new systems thinking and innovation with respect to functionality and reuse and recyclability.

These two companies all have a commitment to the environment. They have some similarities - all of them focusing on finding materials with good quality and low environmental risk, and they also try to educate their customers towards a more environmentally friendly lifestyle. There are also some quite clear differences. Plusminusnoll have so far mainly focused on only producing the amount needed, and have not made a recycling opportunity available. Patagonia is priced in a medium to high level and is a big actor. Unlike Plusminusnoll, Patagonia have 
sales and gives discounts as an ordinary brand, but still trying to commit to the environment.

Even though similar ideas can be found from these two examples, the potential in the ideas for the mass market are different, and they can be models for different consumer segments.

\subsection{Collection measures}

When it comes to measure 2 on de-branding, and 7 on commitment for private companies to collect used textiles - they can be seen together. The idea of a voucher when you deliver used clothes give an incentive for private companies to collect their used textiles. For the producers it gives an incentive to create a solution that makes de-branding easy. If we also combine this with the pre-ordering idea from Plusminusnoll, it is possible to create a value-chain where the producer creates and offer branded clothing to the professional market. When these clothes are worn out, they will be returned to the same company that have a system for de-branding, including a system for using parts of the clothing or repairing them for future use and a system for recycling them. For the buying company the incentive to deliver the used clothing is the voucher that can be used on a new order. A system like this will create incentives for both parties to improve an overall system for reuse and recycling.

\subsection{The combined measures}

Competitiveness depends on the consumers, and some groups are more concerned with environmental issues than others. Middlemiss (2011) has constructed an ecological footprint describing our responsibilities as consumers to be built up by four different capacities.

These are:

- Our organizational capacity, i.e. the support we get from organizations we are a member of to act in an ecological responsible way.

- Our cultural capacity, i.e. the way our culture are enabling us to act in a sustainable way. 
- Our personal capacity, i.e. how we as persons are equipped for acting responsible, e.g. through our knowledge, values and virtues, and finally.

- Infrastructural capacity, i.e. the ability we have for acting sustainable by offers from business, state and other suppliers of goods and services.

An increased opportunity to reuse and recycle textiles or buy reused and recycled textiles will in this picture increase the infrastructural capacity, but it also demands that the consumers achieve information (increase knowledge) about the opportunities and consequences of choosing to do it. It is also needed to be embedded in culture how to choose and what to do when the product has reached its end of use the first time. Therefore it is important to see the proposed measures as a unit rather than separate parts. The Nordic Commitment can together with measures supporting increased collection of textiles support both the infrastructural capacity and the personal capacity by making it easier to donate used textiles and by clearly showing the benefits for others of doing so. The consumer information campaign can help us find and understand the hows and whys of textile collection. Measures for sorting and recycling (measures 13 and 14) are needed to enable changing business models but must be combined with longer lifetimes by e.g. collective use and reuse (measures 8 and 9) not to create a suboptimized system. This while measures for public textile collection (measure 6) and public procurement of textiles with recycled content (measure 12) are needed as enablers for increased and improved recycling in the initial phase.

The examples shown (Patagonia and Plusminusnoll) are mainly directed towards a group of consumers with an interest in nature and ecology. The culture they belong in will help strengthen their choice. More ordinary consumer - or even, the same consumers when they buy ordinary textiles, will not have the same interest or capacities. This means that if we want to transfer ideas tried out by niche businesses we must address it through incentives and solutions that implements all the four capacities, and heightens the individual awareness and willingness to do something extra. Here measures both towards new business models (8 and 9) and information (10) are needed but also measures for collection (1-7) to clearly show that used textiles are a valuable resource and not only for incineration.

Looking on the examples, there is Patagonia which in a Nordic context would be one of the biggest actors in the outdoor industry if they where Nordic and Plusminusnoll which is one of the smallest actors in 
their market segment. These companies have in different ways potential that can be transferred to the mass market, but on different levels.

Measure 10 consumer information campains is probably one of the most crucial measures to be taken together with other measures, and very few of the measures would work if the consumers are not taking part. We see in the business examples that education of the consumer is part of the marketing. For other companies that choose to commit it is crucial that they communicate their new approach to their customers. By making information a part of marketing, the producers will take their part of the responsibility, in addition to campaigns led by governmental organizations. Consumers are the main key to success and need to be educated. In the region Salten in Norway, the local waste management company reports that after sending out information about their cooperation with UFF, including hand out of plastic bags for textiles, UFF experienced an increase in delivered textiles. The increase is explained by the information about this possibility given to the households. The proposed Nordic Commitment (measures 1-4) can make the choice of collection partner easier for municipalities and regions. 



\section{Effect on labour and potential for creating green jobs}

The theoretical foundation for this chapter is circulation economics (Hopfenbeck, 1992; Ingebrigtsen and Jakobsen, 2007). Circulation economics is built on the idea that the input and output in the economic process has many similarities, but one problem, that makes it hard to reuse and recycle, is the production process with several different actors that do not cooperate to create an overall optimal solution.

Circulation economics suggests that we change the economic theory on four levels, and all of them are relevant:

The first change is on a metaphysical level; a move from a mechanical understanding of the world to an organic understanding. The idea that the world can be narrowed down to a mechanic system implies that the earth is machine like, made up by different and independent parts, and can be repaired and restored to its natural state when the damages is done. That is not what happens, when nature is restored it is something else than it used to be. The organic worldview, on the other hand, implies that the world cannot be reduced to a mere mechanical system, and that everything is interconnected. This change is on a more abstract level, but it can be related to the way we think about problem solving. One way of solving a problem might cause new problems if we see the world in bits and pieces.

The second change is on a more practical level; a change from a linear perspective on the value chain to a circular value chain. Normally, the understanding of the economic process is that we put energy and matter into production; this is distributed, consumed and disposed. In a typical textile example, we would start with growing cotton, process it, sew it into clothing, distribute it, use it and throw it away. When one starts talking about recycling or reuse one has already acknowledged that the overall process and the connected mental models need to be changed. Circulation economics focuses on the fact that when you start with matter and energy in the beginning, what is disposed is also energy and matter. When this is understood, it opens for a new part in the process after consumption called redistribution. Redistribution implicates that instead of disposing a product when we are done using it we need to de- 
velop some kind of system to ensure that the matter and energy are distributed for future use.

The third change is described as a change from competition to cooperation. In mainstream economics, the idea of competition is fundamental. The problem is not that different companies compete amongst customers. However, it becomes problematic when competition functions as an obstacle to find good solutions, which demands that all parts of the value-chain are present.

The last change is related to how we calculate value. Instead of a singular focus on the monistic value, one should try to see what other types of values that also are created.

When we use this frame we can see that consequences, competitiveness and new jobs mean more than just the economic output. We will therefore sort the measures and policies from the strategy into the categories:

- Input.

- Production.

- Distribution.

- Consumption.

- Redistribution.

It should be pointed out that a real progress towards sustainable development demands more than fixing the problem, primarily being overproduction and overconsumption. The scope of the strategy does not fully cover the issue but focuses on some parts, with a clear focus on redistribution.

The process of making textiles recyclable starts when the materials for the clothes are grown or extracted. We choose to narrow this down to the development phase at the producers, since this phase typically happens in the Nordic country, while most other phases are executed in other parts of the world.

We use the circular flow in circulation economics as a theoretical foundation to sort the measures and initiatives potential for green jobs in each phase. An important point is that cooperation and communication between the different actors, businesses, governmental actors and consumers are necessary to bring the best solutions forward. 


\subsection{Input}

The strategy is not focused on the input part of the textile value chain but measures 11 Nordic task force for the Higg index and 14 Financial assistance for establishing one chemical recycling facility on an industrial scale in the Nordic region are closely related.

The Higg index is still under development and with a Nordic push it can be expanded to include life cycle assessment or similar tools to show environmental hotspots for input materials. The obvious example here is to closely investigate the environmental performance of different new recycling technologies and be the frontrunner in developing them. This can in turn create high tech jobs in environmental assessment and development of recycling technology in the short term and possibly industrial jobs connected to a chemical textile recycling facility. The latter will likely be less that what one might expect since the processing is similar to paper pulp. Pulp production is intensive for capital but lean on labour. A comparison could be the pulp mill Rockhammar in Sweden which in 2010 produced close to 70,000 tonnes of pulp with only 40 employees (Dagens Arbete, 2011).

\subsection{Production}

Measure 4 Further development of the Nordic Commitment to more actively involve and include textile producers connects to the production through design. As we see in the example of Patagonia, the designer can do much to make the product more environmentally friendly. Therefore, they also have a lot of power when it comes to finding out how the product should be designed to be easy recyclable, repairable and for a longer active lifetime. However, new skills and new sets of thinking together with rediscovering old skills are necessary to be able to design a product in this way. Together with measure 11 on the Higg index they create a basis for creating jobs in other parts of the value chain, but maybe not to any large extent in the production and design.

There a more likely effect due to measures 8 and 9 connecting to new business models since production then could include redesign and addi- 
tive redesign ${ }^{10}$. Given the fact that there are certain parts of a piece of clothing that gets worn out before the total product; it could be possible to plan how still useful pieces of the clothing can be collected and reused/recycled in another product. To put a number on the possible number of green jobs is difficult since the various business models would be diverse in nature. It is however clear that these jobs will act in a, minor, shift from production outside the Nordic region towards production within the Nordic region. Studies on the possibility of additive redesign as a business case are currently being done at the Swedish School of textiles under the topic sub-industrialized redesign (Karlsson, 2014).

\subsection{Distribution}

Plusminusnoll tries to establish itself as an outdoor clothing company that only produces what they sell. At the same time they sell durable products. Plusminusnoll's business model shows an opportunity for smaller companies to establish themselves as innovative actors, because the risk of failing is quite low if you have the orders ready before you produce anything. This model makes it possible to market and try out new designs. It can be connected to measures 8 and 9 for new business models, given that one actually is willing to give some start-up finance to small, innovative companies.

The Plusminusnoll example is one where there is no store present and this might be counterproductive from a labour increasing perspective. There are however a number of business models that includes repair shops, resell of used textiles within a brand and similar where a store and staff performing repairs, sorting and similar that will still remain in the current sales paradigm. This with the difference that they will use less material resources for the same turnover.

The potential for new companies like this are hard to calculate, especially since the business seems to take longer time to establish in the market than expected (Copp and Neimann, 2012). It is also heavily dependent on the business models that will be implemented and how the support system will be implemented.

\footnotetext{
${ }^{10}$ Additive redesign is when something is added to an old garment to increase its life. It could be a label or flower to cover a hole or simply to add value again. Less of a labourinput that full redesign.
} 
The sales of second hand textiles are traditionally done with a high degree of job training and volunteers which makes the direct translation into green jobs difficult. The Nordic Commitment in measure 1 has a goal doubling the share of separate collection of used textiles and textile waste within ten years from roughly $30 \%$ in 2012 to $60 \%$ in 2022 equal to approximately 120,000 tonnes based on the prognosis for future amounts. If the target is reached and by using the employee figures for Myrorna (2014) and putting it in relation to their collected amounts (about 11,000 tonnes), this would imply creating 4,400 jobs and 30,000 work training opportunities, internships and community service opportunities. This is of course a very rough estimate including also jobs in collection and sorting (redistribution below). It is highly dependent on which organisations that manage the increased collected amounts, the amount of reuseable items on the Nordic market and several other factors and should only be seen as an indicator for an increase in employment. If it was to be calculated based on the Swedish Red Cross, which is based solely on volunteers, the result would obviously be much different.

\subsection{Consumption}

The most important contribution from the consumers is that they use the products, and then return them. We can therefore include the measures covering different systems for collection of used clothes (measures 1, 3, 4, 5, 6, and 7). Measure 3 and 5 are directed at the municipalities. Availability of collection systems and information about how textiles can be delivered are important and has the potential for creating new jobs, e.g. people emptying and collecting the textiles from the containers. These job opportunities are included in the estimate under distribution above. The collection of textiles from public activities will demand that someone are responsible in the public institutions for performing this task, but given the lack of numbers on return percentage it is not possible to give a reasonable calculation.

Consumer information campains (measure 10) are critical for most of the other measures to be successful but are themselves very limited as a creator of green jobs. 


\subsection{Redistribution}

The strategy has a strong focus on redistribution of used textiles and textile waste and all measures related to collection of textiles from various sources and sorting of textiles are relevant here. Since green jobs related to collection are assessed under distribution, redistribution will focus on measures 12 Public procurement for reuse of textiles and textiles with recycled content and 13 Investigation of the need for and potentials of establishing an (automatic) sorting facility in the Nordic region. Measure 12 will not in itself lead to an increase in green jobs but may very well be a prerequisite for establishing a sorting facility in the Nordic region. It can create an increased demand for recycled content in textiles as well as reused textiles which are important for the income side of a sorting facility. Public procurement alone cannot achieve a sufficient demand, by may initiate a shift where products become more easily available and thus creating a demand from a wider array of actors.

Based on sorting performance given by UFF Norway on a Slovenian sorting facility the current collection levels $(120,000$ tonnes) in the Nordic region corresponds to about 1,400 person-years of labour in sorting. With a doubling of collection levels as aimed for in the Nordic Commitment, the available amount would be 240,000 tonnes annually. This would equal a sorting facility in the size of 1,200 tonnes per day which is three times larger than the currently largest sorting facility globally today (400 tonnes daily) (Soex, 2014).

A more conservative estimate would be do base the size of the sorting facility on the flow of recyclable textiles to be sorted automatically. Since no functional facility for automated textile sorting exists, a sorting facility for plastics could be used as a base. The Swerec plastics sorting facility in Sweden sort about 40,000 tonnes annually (Fråne et al. 2014). With an estimated $50 \%$ of collected textiles being reuseable (Palm et al. 2014), the sorting facility would then be designed for 80,000 tonnes annually. This would then equal creating around 900 jobs in sorting. This estimate cannot be stacked together with the estimate based on Myrorna under Distribution above since that estimate includes an undefined amount of sorting.

A sorting facility in the Nordic region would struggle with regular wages in the Nordic countries and to be successful there is likely a need for some kind of subsidised labour or synergies possibly created by working closely with chemical recycling of textiles. 


\section{Possible need for new incentives, instruments and measures}

Given the increase in textile waste from households over the last 20 years, it is clear that changes in the system are necessary to maintain and reuse the resources. However, before we make any conclusions related to incentives, instruments and measures it is appropriate to be a bit normative and ask the question about where the process should start. If we only focus on the textiles after use and the exchange between first and secondary users, we miss out on the full problem - which is the production of waste. As we have seen, Plusminusnoll addresses this problem in their own way, but we need to figure out more wide spread ways to reduce the total amount of textiles produced.

A solution should lead to a consumption pattern that does not have negative ecological and cultural consequences and at the same time have an economical contribution. In this perspective we see that there have been performed evaluations of sorting solutions, recycling etc. which is founded on an idea that we should take care of used resources, and that it is used very little time on limiting the use of resources.

The waste hierarchy can be a good start here, since it shows that reducing, repairing and reusing is better than recycling.

\subsection{Incentives and instruments for producers}

Producers are not a uniform group. The incentives that would get already committed companies to do their share are not the incentives that would get equally the producers of cheaper clothes to act.

The main incentive for producers to act are the consumers, as they have a key role in increasing the demand for more durable clothing that is produced in a more sustainable and social way including a system for taking care of reuse and recycling. The main challenge is therefore how the consumers will react. If consumers do not buy reused and recycled products or choose to return textiles for reuse and recycling - it does not 
help what is offered. Opposite if they cannot find producers they think are doing a good job - they cannot find what they want. The strategy focuses on the reuse and recycling part and less on the quality of textiles which might need additional policy to complete the circular flows of textiles. Including the producers more clearly in the Nordic commitment as in measure 4 can be a starting point.

Instruments as mentioned in the strategy on the Higg index, can give valuable information on how to improve the products. LCA and similar tools can be used to improve the production process.

\subsection{Incentives and instruments for consumers}

The fact that we buy and throw away twice as much clothing as 20 years ago show us that the problem begin in peoples mind. In addition, simply put, clothing is too cheap, fashion changes to often and the quality of textiles is overall poor. From a governmental perspective, the key thing to change here is price.

In Beyond Growth (1996: 15) Herman Daly comments the following:

"Why tax what we want more of - employment and income? Why not tax

what we want less of - depletion and pollution"

So ideally, incentives for the consumer should:

- motivate the consumer to reduce consumption of new textiles,

- motivate the consumer to search for high quality products which will be used for a longer period

- motivate the consumer to deliver the textiles for reuse or recycling.

Good incentives are therefore incentives which lead the consumer away from textiles with low quality, low reuse potential and low potential for recycling to textiles that reduce the amount of textiles sold, and at the same time lead to more recycling and reuse.

One could consider a higher tax on textiles - since textiles has become relatively cheap the past 20 years. This should in theory lead to less consumption since people's resources are limited. The problem is that it might lead to consumption of textiles with lower quality and make it harder for new businesses (like Plusminusnoll) and businesses with great environmental performance to put their product on the market since they also must increase the value added. A better, but more com- 
plex option, is the proposed material fee and recycling certificates in $A n$ extended producer responsibility (EPR) system and new business models to increase reuse and recycling of textiles in the Nordic region" (Watson et al. 2015) where the fee connects to material use.

Repairing is another important issue. Repairing is fundamental for effective reuse, but repairing is also taxed. The VAT on such services can be removed so people again can find it cheaper to repair than to buy something new. It is from a circulation economic point of view quite contradictory to tax consumption of new goods and services at the same level as repair services. Consumption of new products create overuse and should be taxed, repairing helps solve part of the problem and should not be taxed.

Instruments for the consumer is hard to find, but the environmental evaluation results the companies get from the LCA or Higg index should be made publicly available with a good explanation so the customer would be given the opportunity to make an informed choice.

\subsection{Incentives and instruments for reuse traders}

With somewhat different regulation in the various Nordic countries, as a general rule all non charity reuse is subject to VAT on second hand sales which makes the business less profitable. This is especially interesting considering that used cars are always free from VAT. An obvious solution here is to remove VAT from used clothing regardless of the charity status of the shop.

Another incentive that could be explored is location. Stores selling new clothes are usually in exposed areas while the stores that sell used clothes are often on the back streets. Some kind of subsidy or other measure enabling reuse stores on the high streets could be interesting to explore. It could also be an important signal to nudge the norm from buy and throw to reuse.

It is important that the instruments applied do not only give incentives to recycle as much as possible. The focus must be to resell and reuse most of the clothing as it is, and recycle what is not possible to reuse. 



\section{Conclusion}

Given that the measures proposed in the Nordic strategy are successfully implemented, it can strengthen and build a more competitive textile sector in the Nordic region. If one is able to educate the consumers towards more sustainable choices one will likely see that brands that choose the more sustainable path will have a more loyal customer base which return to the same producer. This creates competitive power based on a more environmentally friendly strategy. For the Nordic region it will be a competitive advantage if one is able to lead the purchasing power towards the brands and producers which is based in the Nordic region, whether selling high quality new products or reused and recycled products.

The competitiveness of the Nordic region can be strengthen by focusing on niche ideas based in new innovative business models, high quality products with producers that actively take responsibility for their products and are targeting a customer group with interest in sustainability.

The proposed strategy provides measures that can create new green jobs. The clear opportunities are mostly in sorting and trading of reused textiles. These jobs are however not the most high-end which instead can be found in recycling $R \& D$ and environmental assessment. These jobs also connect well to the international retail actors present in the Nordic region and can therefore affect also textiles outside of the Nordic countries towards increased sustainability.

A sorting and recycling facility in the Nordic region can be the basis for a new Nordic industry but require further evaluation and studies both from an economical and technical standpoint. 



\section{References}

Aldrigde, Øystein (2012). Dumper nye klær rett til Fretex. Aftenposten 14.11.2012 Aquafil: http://www.econyl.com/facts-figures/ (Accessed: 24.10.2014).

Choiunard, Yvon (2006). Let my people go surfing, the education of a reluctant business man. Penguin Books.

Copp, Stephen and Neimann, Fredrik (2012): Personal communication with Stephen Copp and Fredrik Neimann in Plusminusnoll 23.10.12.

Dagens Arbete (2011). Ökningen bruk för bruk. Available at: http://www.da.se/home/da/home.NSF/files/produktivitet-lista_stor.pdf/ \$FILE/produktivitet-lista_stor.pdf accessed 2014-11-18.

Daly, Herman (1996). Beyond Growth. Boston: Beacon Press.

Fråne, A. Stenmarck, Å. Gíslason, S. Lyng, K-A. (2014) Collection \& recycling of plastic waste: Improvements in existing collection and recycling systems in the Nordic countries. Nordic Council of Ministers Temanord 2014:543.

http://dx.doi.org/10.6027/TN2014-543

Hopfenbeck, Waldemar (1992). The Green Management Revolution. Hertfordshire: Prentice Hall.

Ingebrigtsen and Jakobsen (2007). Circulation Economics. London: Peter Lang.

Jakobsen, Ove and Nystad, Øystein (2010). Collaborative Waste management in: Tencati, Antonio and Zsolnai, Lazlo (eds) (2010). The Collaborative Enterprise. London: Peter Lang.

Karlsson, J. (2014). Personal communication with Jan Karlsson at the Swedish School of textiles.

Klättermusen: http://klattermusen.se/companysoul.php?id=5\&lang=SE\&curr= NOK\&sex= (Accessed 22.10.2014).

Middlemiss, L. (2010). Reframing Individual Responsibility for Sustainable Consumption: Lessons from Environmental Justice and Ecological Citizenship. Environmental Values 19: 147-167.

http://dx.doi.org/10.3197/096327110X12699420220518

Myrorna (2014). Om Myrorna. Available at: http://myrorna.se/om-myrorna/ accessed 2014-11-18.

Plusminusnoll: http://plusminusnoll.se/sv/sidor/om-oss.html (Accessed: 14.10.2014).

Palm, D. Elander, M, Watson, D. Kiørboe, N. Rubach, S. Hanssen, O-J. Gíslason, S. (2015). The Nordic reuse and recycling commitment. Nordic Council of Ministers TemaNord in press.

Rønning. Anne; Hanssen, Ole Jørgen and Nyland, Cecilia Askham (2002). Product Oriented Environmental Management Strategies. An Input to disscuccions in companies. Arbeidsrapport Østfoldforskning. 
Soex (2014). Soex Locations - The Wolfen plant. Available at:

http://www.soexgroup.com/us/locations.html accessed 2014-11-18.

Watson, D. Kiørboe, N. Palm, D. Tekie, H. Ekvall, T. Lindhqvist, T. Tojo, N. Salmenperä, H. Hanssen, O-J. Rubach, S. Lyng, K-A. Gíslason, S. (2015). Proposals for and assessment of policy packages that support EPR-systems and new business models for reuse and recycling of textiles. Nordic Council of Ministers. TemaNord in press. 


\section{Sammanfattning av rapporterna}

I denna rapport presenteras arbetet från det sista året av projektet och dess underrapporter som beskriver vägen mot en nordisk strategi som en del av en kommande nordisk handlingsplan för textil- och modebranschen.

De delrapporter som ingår i denna rapport är:

- Den föreslagna nordiska strategin.

- Prognos för framtida mängder.

- Insamlings-, sorterings-, återanvändnings- och återvinningsscenarier.

- Utvärdering av scenarier.

- Konkurrenskraft och gröna jobb.

Rapporten ingår i de nordiska statsministrarnas initiativ för grön tillväxt: "Norden - ledande i grön tillväxt" - läs mer i webbtidningen "Green Growth the Nordic Way" på adressen www.nordicway.org eller www.norden.org/sv/tema/green-growth

\section{Den föreslagna nordiska strategin}

Den föreslagna strategin omfattar incitament, styrmedel och åtgärder som behövs på lokal, regional, nationell och nordisk nivå för att säkerställa ett framgångsrikt genomförande. Den innehåller nationella skillnader i genomförandet samt övergripande lösningar för Norden. Den roll som nuvarande aktörer som deltar i insamling, återanvändning och återvinning av textilier i genomförandet av den nordiska strategin har samt utvärdering av effekter på dessa aktörer. Slutligen har nyckelaktörer för ett framgångsrikt genomförande av den nordiska strategin identifieras.

De nordiska länderna har kommit olika långt kring val och utvärdering av politiska åtgärder för att öka insamling, återanvändning och återvinning av textilier och textilavfall. Som ett resultat av det syftar den nordiska Strategin till att formulera (kortsiktiga) mål och åtgärder som anses realistiskt för genomförande i samtliga nordiska länder. Den nordiska strategin ska kunna tjäna som utgångspunkt för framtida strategiskt samarbete inom textilavfall. 
Det är rekommenderat att utveckla och formulera en uppsättning mål avseende:

- Insamling som andel av textilier satta på marknaden.

- Återanvändning som andel av textilier sätta på marknaden.

- Återanvändning på nationella/nordiska marknaderna som andel av total återanvändning.

- Återvinning som andel av textilier satta på marknaden.

- Textil till textil-återvinning som andel av den totala återvinningen.

- Antal kommuner med certifierade insamlingsplatser.

- Del/antal insamlingsställen som drivs av certifierade organisationer (t.ex. engagerade The Nordic textile reuse and recycling commitment).

\section{Nödvändiga förändringar}

För att nå målet med projektet har 13 nödvändiga förändringar identifierats. De nödvändiga förändringarna är:

- Ökad transparens, t.ex. gällande textilflöden och datainsamling.

- Ökad aktiv livslängd på textilprodukter, det vill säga hur länge textilprodukter används i praktiken.

- Ändrat konsumentbeteende för textilprodukter, t.ex. (aktiv) livslängd, kollektiv användning, återanvändning och avyttringsbeteende.

- Mer attraktiv insamling, t.ex. lättare att göra rätt samt ökat förtroende och tillförlitlighet i samlingen.

- Ökad insamling av begagnade textilier.

- Införd/ökad service för (certifierad) av-märkning av företagstextilier för återvinning i Norden.

- Ökad återanvändning, framför allt i Norden.

- Ökad och förbättrad sortering av insamlade textilier.

- Förbättrad hantering av textil och textilavfallsflöden för mer samordnad och effektiv hantering.

- Ökad återvinning, särskilt i Norden.

- Ökad andel textil till textil-återvinning.

- Ökad marknad för återvunna textilier.

- Minskad användning av giftiga ämnen i textilier. 


\section{Föreslagna politiska åtgärder}

I strategin föreslås 14 styrmedel. Dessa styrmedel täcker alla nödvändiga förändringar enligt definitionen ovan och prioriterar att återanvända samt ger möjlighet att öka kraven efterhand. De politiska åtgärderna är indelade i fyra olika avsnitt nedan:

\section{The Nordic Commitment}

The Nordic textile reuse and recycling commitment (se rapporter från systerprojektet) kan delas upp i fyra olika delar:

1. Lansering av The Nordic commitment.

2. Utökning av det nordiska åtagandet till att omfatta avmärkningstjänster.

3. Ökat engagemang av kommuner i the Nordic commitment.

4. Vidareutveckling av det nordiska åtagandet för att mer aktivt involvera och inkludera textilproducenter.

\section{Åtgärder som stödjer en ökad insamling av textilier}

- Skyldighet för kommuner att säkerställa att insamlingsbehållare för textilier finns på alla (kommunala) återvinningscentraler.

- Skyldighet att samla in använda textilier från offentlig verksamhet och offentliga företag.

- Införande av ett frivilligt åtagande för privata företag att samla in använda textilier.

\section{Åtgärder som stödjer nya affärsmodeller}

- Utvärdering av affärsmodeller inom området kollektiv användning, återanvändning och längre (aktiv) livslängd för textilier.

- Offentlig finansiering för nystartade företag inom området för kollektiv användning, återanvändning och längre (aktiv) livslängd för textilier. 


\section{Andra stödåtgärder}

- Konsumentinformationskampanj.

- Nordisk arbetsgrupp för Higg-index.

- Offentlig upphandling för återanvändning av textilier och textilier med återvunnet innehåll.

- Utredning av behovet av och möjligheterna för upprättande av en (automatisk) sorteringsanläggning i Norden.

- Ekonomiskt stöd för att etablera en kemisk återvinningsanläggning i industriell skala i Norden.

\section{Viktiga aktörer för ett framgångsrikt genomförande}

Projektet identifierade fyra nyckelaktörer för framgångsrikt genomförande av den nordiska strategin:

- Nordiska ministerrådet, Nordiska avfallsgruppen och ett nordiskt samordningsorgan för textilier.

- De nationella regeringarna.

- Kommuner.

- Företagare som är intresserade av att satsa på och tillämpa nya affärsmöjligheter inom området textil och textilavfall.

\section{Prognos för framtida mängder}

Denna underrapport ger en inblick i eventuella framtida mängder av textilier och textilavfall genom att studera:

- Aktuella trender i nettoimport av nya textilier.

- Aktuella trender i produktionen av nya textilier.

- Aktuella trender inom hantering av textilavfall.

- Prognos av den framtida nettoimporten av nya textilier.

- Prognos för den framtida produktion av nya textilier.

- Prognos för den totala konsumtionen av nya textilier.

- Förväntade framtida mängder av begagnade textilier potentiellt tillgängliga för återanvändning och återvinning.

Produktionen av kläder och hushållstextilier är liten jämfört med den totala textilsektorn i respektive land och särskilt jämfört med nettoimporten. Prognoserna visar att andelen produktion av den totala förbrukningen av nya textilier i Norden kommer att minska från 10 \% år 2012 
till $7 \%$ under 2015 respektive 2020. Det enda undantaget är Island. Men den totala konsumtionen av textilier i Island motsvarar endast $2 \%$ av den totala konsumtionen av textilier i Norden.

\section{Slutsatser}

- Den allmänna ekonomiska utvecklingen har en inverkan på konsumtion av nya textilier. Detta har en direkt inverkan på de textilier som finns tillgängliga för återanvändning och återvinning.

- Den övergripande trenden är en ökad konsumtion av textilier, men till följd av den allmänna ekonomiska utvecklingen, är ökningen långsammare än under det senaste decenniet.

- Mängden textilier som produceras i Norden fortsätter att minska i alla länder, utom Island.

Insamling, sortering, återanvändning och materialåtervinning scenarier och utvärdering av scenarier

Denna korta sammanfattning omfattar både de utvecklade scenarier och utvärdering av de scenarier som utförts i en egen delrapport. Utvärderingen sammanfattas i slutet av scenariobeskrivningarna.

Scenarierna har utvärderats kvalitativt med avseende på i vilken utsträckning de främjar:

- Ökade insamlingsnivåer som helhet och olika fraktioner av begagnade textilier.

- Återanvändning framför återvinning så långt det är möjligt.

- Återvinning i stället för downcycling.

Trenden för textilkonsumtion visar ökande konsumtion per invånare. Detta resulterar i högre förväntade mängder av begagnade textilier (kläder och hushållstextilier). I den tidigare underrapporten gjordes linjära och logaritmiska prognoser för framtida mängder av begagnade textilier potentiellt tillgängliga för återanvändning och återvinning i Norden. Enligt dessa prognoser kommer årligen 393,000-406,000 ton begagnade textilier att finnas tillgängliga 2020.

Syftet med denna underrapport är att beskriva fyra olika scenarier som bygger på antagandet om ökade volymer begagnade textilier potentiellt tillgängliga för återanvändning och återvinning. De olika scenarierna kommer att påverka olika delar i värdekedjan på olika sätt; det kommer att finnas vinnare och förlorare; avvägningar kan vara nödvändigt att nå en positiv utveckling av nyckelfaktorer. 
Figuren nedan beskriver de fyra utvecklade scenarierna:

- Scenario 1: Business as usual.

- Scenario 2: Nordiskt samarbete.

- Scenario 3: Nationella strategier.

- Scenario 4: Nordic innovation.

\begin{tabular}{|c|c|c|c|}
\hline \multirow{3}{*}{ 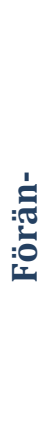 } & Hög & $\begin{array}{c}\text { Scenario 3: } \\
\text { Nationella strategier }\end{array}$ & $\begin{array}{c}\text { Scenario 4: } \\
\text { Nordisk innovation }\end{array}$ \\
\hline & Låg & $\begin{array}{c}\text { Scenario 1: } \\
\text { Business as usual }\end{array}$ & $\begin{array}{c}\text { Scenario 2: } \\
\text { Nordiskt samarbete }\end{array}$ \\
\hline & & Låg & Hög \\
\hline
\end{tabular}

\section{Scenario 1: Business as usual}

Scenariot speglar den troliga utvecklingen inom insamling, sortering, återanvändning och återvinning av textilier under antagandet att nuvarande trender och utveckling fortsätter, men ingen större förändring av teknik, strukturer och politik genomförs i Norden.

Tabellen nedan visar förändringar i scenariot

\begin{tabular}{lcc}
\hline & Förändringar i mängder & Förändringar i kvalitet \\
\hline Insamling & + & 0 \\
För-sortering & 0 & 0 \\
Sortering totalt, varav & + & + \\
inom Norden & 0 & 0 \\
i andra länder & + & + \\
Återanvändning totalt, varav & + & 0 \\
inom Norden & + & 0 \\
i andra länder & + & 0 \\
Återvinning totalt, varav & + & + \\
inom Norden & 0 & 0 \\
i andra länder & + & + \\
\hline
\end{tabular}

Förändringar varierar från --- till +++.

0 indikerar ingen eller mycket liten förändring. 


\begin{tabular}{ll} 
Utvärdering & \\
\hline Faktor & Effekt \\
\hline Ökad insamling & Mindre ökning av insamling av hushållens textil \\
Återanvändning före återvinning & $\begin{array}{l}\text { Ökad återanvändning och återvinning utanför Norden. Ingen större } \\
\text { förändring inom Norden }\end{array}$ \\
Återvinning framför downcycling & $\begin{array}{l}\text { Väldigt liten påverkan på kvalitetsåtervinning. Downcycling fortsätter } \\
\text { dominera }\end{array}$ \\
\hline
\end{tabular}

\section{Scenario 2: Nordiskt samarbete}

I detta scenario, etablerar de nordiska länderna gemensamma mål och strategier för insamling, återanvändning och återvinning av begagnad textil och textilavfall till 2015. Men, med undantag för inrättandet av ett gemensamt frivilligt certifieringssystem för insamling, avmärkning, sortering, transport, återanvändning och återvinning av begagnade textilier och textilavfall har endast mindre förändringar gjorts jämfört med den nuvarande situation.

Tabellen nedan visar förändringar i scenariot.

\begin{tabular}{lcc}
\hline & Förändringar i mängder & Förändringar i kvalitet \\
\hline Insamling & $+/++$ & + \\
För-sortering & 0 & 0 \\
Sortering totalt, varav & $+/++$ & + \\
inom Norden & $0 /+$ & $0 /+$ \\
i andra länder & $+/++$ & + \\
Återanvändning totalt, varav & $+/++$ & + \\
inom Norden & $0 /+$ & 0 \\
i andra länder & $+/++$ & + \\
Återvinning totalt, varav & $+/++$ & $0 /+$ \\
inom Norden & $0 /+$ & + \\
i andra länder & $+/++$ & 0 \\
\hline
\end{tabular}

Förändringar varierar från --- till +++.

0 indikerar ingen eller mycket liten förändring.

$\underline{\text { Utvärdering }}$

\begin{tabular}{ll}
\hline Faktor & Effekt \\
\hline Ökad insamling & $\begin{array}{l}\text { Total ökning av insamlade volymerna förväntas. Icke återanvändnings- } \\
\text { bara textilier kommer sannolikt att öka väsentligt, samtidigt som } \\
\text { återvunna återanvändbara textilier bara kommer att öka måttligt. }\end{array}$ \\
Återanvändning före återvinning & $\begin{array}{l}\text { Trots en betydande ökning av insamlade återvinningsbara textilier } \\
\text { väntas, troligen bara ett medelstor ökning av textilier som faktiskt } \\
\text { återvinns på grund av ett fortsatt lågt marknadspris. Mängden } \\
\text { återvunna textilier väntas öka måttligt. }\end{array}$ \\
Återvinning framför downcycling & $\begin{array}{l}\text { lätt ökning av kvalitetsåtervinning av textilavfall förväntas. Men de } \\
\text { flesta återvunna textilier fortfarande förväntas vara downcyclade. }\end{array}$ \\
\hline
\end{tabular}




\section{Scenario 3: Flera strategier}

I det här scenariot har varje nordiskt land sin egen strategi för textilinsamling, återanvändning och återvinning. Det detaljerade innehållet $\mathrm{i}$ systemen kan därmed variera från land till land. Systemet bygger på frivilliga åtaganden av olika aktörer. Insamling och sortering innefattar såväl nuvarande aktörer som nya. Befintlig containerinsamling av främst välgörenhetsorganisationer kommer att upprätthållas eller till och med att öka. Ökad insamling tillhandahålls av privata företag. Kommunerna deltar även i ökad insamling. Insamlingen är omfattande och varierande, och platserna ligger nära där textilavfallet uppstår vilket gör omhändertagandet attraktivt och bekvämt.

Tabellen nedan visar förändringar i scenariot.

\begin{tabular}{lcc}
\hline & Förändringar i mängder & Förändringar i kvalitet \\
\hline Insamling & ++ & + \\
För-sortering & ++ & ++ \\
Sortering totalt, varav & ++ & ++ \\
inom Norden & ++ &.$/$ \\
i andra länder & 0 &. \\
Återanvändning totalt, varav & 0 &.$/$ \\
inom Norden & 0 & $/$. \\
i andra länder & 0 & ++ \\
Återvinning totalt, varav & ++ &.$/$. \\
inom Norden & ++ &.$/$. \\
i andra länder & ++ & \\
\hline
\end{tabular}

Förändringar varierar från --- till +++.

0 indikerar ingen eller mycket liten förändring.

./. indikerar förändring som inte kunnat utvärderas inom projektet.

\begin{tabular}{ll} 
Utvärdering & Effekt \\
\hline Faktor & $\begin{array}{l}\text { En större mängd insamlade mängder väntas, främst beroende på } \\
\text { ökad insamling från privata företag och offentliga institutioner. }\end{array}$ \\
Återanvändning före återvinning & $\begin{array}{l}\text { Systemet kommer att ge måttliga ökningar av textilier för återan- } \\
\text { vändning, och en medelhög till hög ökning av textilier för återvinning. }\end{array}$ \\
Återvinning framför downcycling & Endast en måttlig ökning av högkvalitatetsåtervinning förväntas. \\
\hline
\end{tabular}

\section{Scenario 4: Nordic innovation}

Norden har en gemensam nordisk strategi för textilinsamling, återanvändning och återvinning. Tack vare högt satta gemensamma mål, är samarbetet mellan de nordiska länderna starkt. Politiska åtgärder som används för att främja återanvändning och återvinning av textilavfall är starkare än idag och nya affärer kring textilier uppstår. Åtgärder som har varit framgångsrika i ett nordiskt land kopieras snabbt och anpassas till de öv- 
riga nordiska länderna och verksamheter där det behövs samarbete för att nå tillräckliga flöden och skaleffekter multiplicera i regionen.

Tabellen nedan visar förändringar i scenariot.

\begin{tabular}{lcc}
\hline & Förändringar i mängder & Förändringar i kvalitet \\
\hline Insamling & +++ & ++ \\
För-sortering & ++ & ++ \\
Sortering totalt, varav & +++ & +++ \\
inom Norden & +++ &.$/$ \\
i andra länder & 0 &.$/$ \\
Återanvändning totalt, varav & +++ & ++ \\
inom Norden & +++ &.$/$. \\
i andra länder & + &.$/$ \\
Återvinning totalt, varav & +++ & ++ \\
inom Norden & +++ &.$/$. \\
i andra länder & ++ &.$/$. \\
\hline
\end{tabular}

Förändringar varierar från --- till ++++

0 indikerar ingen eller mycket liten förändring.

./. indikerar förändring som inte kunnat utvärderas inom projektet.

\section{Utvärdering}

\begin{tabular}{ll}
\hline Faktor & Effekt \\
\hline Ökad insamling & $\begin{array}{l}\text { En betydande ökning av andelen av nya textilier som släpps ut på } \\
\text { marknaden som samlas in separat. Totala volymer av nya textilier } \\
\text { som släpps ut på marknaden förväntas sjunka, men nettovolymer } \\
\text { separat insamlade textilier ökar måttligt. }\end{array}$ \\
Återanvändning före återvinning & $\begin{array}{l}\text { Nettomängden återanvända textilier förväntas öka. Detta kommer } \\
\text { att resultera i en ökande andel av återanvändning inom Norden i } \\
\text { stället för att exporteras för återanvändning på annat håll. }\end{array}$ \\
Återvinning framför downcycling & $\begin{array}{l}\text { En betydande ökning av sluten återvinning och högkvalitetsåtervin- } \\
\text { ning på bekostnad av downcycling eller förbränning förväntas. }\end{array}$ \\
\hline
\end{tabular}

\section{Konkurrenskraft och gröna jobb}

\section{Konkurrenskraft}

Konkurrenskraften beror på konsumenterna, och vissa grupper är mer intresserade av miljöfrågor än andra. Middlemiss (2011) har konstruerat ett ekologiskt fotavtryck som beskriver vårt ansvar som konsumenter och byggs upp av fyra olika kapaciteter.

Dessa är:

- Vår organisationskapacitet.

- Vår kulturella kapacitet.

- Vår personliga kapacitet.

- Infrastrukturkapacitet. 
En ökad möjlighet att återanvända och återvinna textilier eller att köpa återanvända och återvunna textilier kommer öka vår infrastrukturella kapacitet, men det kräver också att konsumenterna får information (öka kunskapen) om möjligheterna och konsekvenserna av att välja att återanvända och återvinna. Det behövs också vara inbäddat i kulturen hur man väljer och vad man ska göra när produkten har nått slutet av sin första användning. Därför är det viktigt att se de föreslagna åtgärderna som en enhet istället för separata delar. Den nordiska åtagandet kan tillsammans med åtgärder som stödjer en ökad insamling av textilier stödja både infrastrukturkapaciteten och den personliga kapaciteten genom att göra det enklare att donera begagnade textilier och genom att tydligt visa fördelarna för andra att göra det. Konsumentinformationskampanjen kan hjälpa oss att hitta och förstå hur och varför textilinsamling genomförs. Det behövs åtgärder för sortering och återvinning (åtgärderna 13 och 14) för att möjliggöra förändrade affärsmodeller men dessa måste kombineras med längre livslängd genom t.ex. kollektiv användning och återanvändning (åtgärder 8 och 9) att inte skapa ett suboptimerat system. Detta medan åtgärder för offentlig textilsamling (åtgärd 6) och offentlig upphandling av textilier med återvunnet material (åtgärd 12) behövs som drivkrafter för ökad och förbättrad återvinning.

Åtgärd 10 är förmodligen en av de mest avgörande åtgärder som skall vidtas tillsammans med andra åtgärder, och mycket få av åtgärderna skulle fungera om konsumenterna inte deltar.

\section{Gröna jobb}

\section{Råvaror och produktion}

Higg indexet är fortfarande under utveckling och med nordisk påverkan kan det utvidgas till att omfatta livscykelanalys eller liknande verktyg för att visa potentiella miljöproblem för insatsvaror. Det tydligaste exemplet är att noga undersöka miljöprestanda för olika nya återvinningstekniker och vara en föregångare i att utveckla och använda dem. Detta kan i sin tur skapa högteknologiska arbetstillfällen i miljöutvärdering och utveckling av återvinningsteknik på kort sikt och eventuellt industrijobb vid en kemisk textilåtervinningsanläggning. Det senare kommer sannolikt dock att vara färre än vad man kan förvänta sig eftersom en sådan anläggning liknar pappersmassaproduktion med kanske 40 jobbtillfällen för en anläggning. 


\section{Distribution}

Försäljningen av begagnade textilier har traditionellt utförts med en hög grad av arbetsträning och volontärer som gör den direkta översättningen till gröna jobb svårt. Den nordiska åtagandet i åtgärd 1 har ett mål att fördubbla andelen separat insamling av begagnade textilier och textilavfall inom tio år från cirka 30 procent 2012 till 60 procent under 2022. Om målet nås och genom att använda personalstatistik för Myrorna (2014) och sätta det i relation till Myrornas insamlade mängder (ca 11,000 ton/år), skulle detta innebära att skapa 4,400 jobb och 30,000 arbetsutbildningsmöjligheter, praktik och möjligheter till samhällstjänst. Detta är naturligtvis en mycket grov uppskattning inkluderande även jobb i insamling och sortering (Återdistribution nedan). Om det istället skulle beräknas baserat på Svenska Röda Korset, som enbart använder frivilliga, skulle resultatet naturligtvis vara mycket annorlunda.

\section{Återdistribution}

Baserat på sorteringsprestanda från UFF Norge om en slovensk sorteringsanläggning skulle de nuvarande insamlingsnivåerna (120,000 ton) i Norden motsvara cirka 1,400 årsarbetare för sortering. En uppskattning för en automatiserad sorteringsanläggning skulle kunna baseras på storleken på flödet av återvinningsbara textilier som ska sorteras automatiskt. Eftersom ingen funktionell anläggning för automatisk textilsortering finns, kan en sorteringsanläggning för plast användas som utgångspunkt. Med uppskattningsvis $50 \%$ av insamlade textilier som återanvändbara (Palm et al. 2014), skulle sorteringsanläggningen då utformas för 80,000 ton per år. Detta skulle då lika skapa cirka 900 arbetstillfällen i sorteringen.

\section{Slutsatser}

Konsekvenserna av att anta strategin är att det kan leda till en mer konkurrenskraftig sektor. För Norden blir det en konkurrensfördel om man kan leda köpkraften mot varumärken och tillverkare som är baserade i Norden, vare sig de säljer högkvalitativa nya produkter eller återanvända- och återvunna produkter.

Den föreslagna strategin ger åtgärder som kan skapa nya gröna jobb. De klara möjligheterna är mestadels i sortering och försäljning av återanvända textilier. Dessa jobb är dock inte de mest avancerade som i stället återfinns i återvinnings FoU och miljöbedömning. En sortering och återvinningsanläggning i Norden kan ligga till grund för en ny nordisk industri men kräver ytterligare utvärdering och studier både ur ett ekonomiskt och tekniskt perspektiv. 

Annex A: Net-import of textiles 2000-2012 
Table 35. Net-import of textiles to Denmark 2000-2012 (Statistics Denmark, 2014a)

\begin{tabular}{|c|c|c|c|c|c|c|c|c|c|c|c|c|c|}
\hline & 2000 & 2001 & 2002 & 2003 & 2004 & 2005 & 2006 & 2007 & 2008 & 2009 & 2010 & 2011 & 2012 \\
\hline Clothes (in tonnes) & 55,091 & 56,076 & 55,344 & 66,799 & 68,467 & 73,164 & 75,632 & 78,501 & 65,158 & 59,989 & 66,839 & 64,063 & 62,961 \\
\hline Household textiles (in tonnes) & 10,698 & 10,426 & 10,077 & 10,530 & 11,738 & 15,071 & 15,719 & 15,856 & 18,941 & 15,526 & 14,722 & 13,724 & 12,254 \\
\hline Total & 65,789 & 66,502 & 65,421 & 77,329 & 80,206 & 88,235 & 91,351 & 94,357 & 84,099 & 75,515 & 81,561 & 77,787 & 75,215 \\
\hline Comparison to 2000 & $100 \%$ & $101 \%$ & $99 \%$ & $118 \%$ & $122 \%$ & $134 \%$ & $139 \%$ & $143 \%$ & $128 \%$ & $115 \%$ & $124 \%$ & $118 \%$ & $114 \%$ \\
\hline
\end{tabular}

Table 36. Net-import of textiles to Finland 2002-2012 (Tulli, 2014a)

\begin{tabular}{|c|c|c|c|c|c|c|c|c|c|c|c|c|c|}
\hline & 2000 & 2001 & 2002 & 2003 & 2004 & 2005 & 2006 & 2007 & 2008 & 2009 & 2010 & 2011 & 2012 \\
\hline Clothes (in tonnes) & .. & .. & 32,309 & 33,749 & 36,939 & 39,815 & 42,813 & 44,319 & 45,443 & 40,953 & 45,285 & 48,488 & 42,108 \\
\hline Household textiles (in tonnes) & .. & .. & 7,121 & 8,147 & 8,300 & 9,893 & 10,355 & 12,300 & 12,269 & 11,319 & 13,627 & 10,984 & 10,646 \\
\hline Total & .. & .. & 39,430 & 41,896 & 45,239 & 49,709 & 53,168 & 56,619 & 57,712 & 52,271 & 58,912 & 59,473 & 52,754 \\
\hline Comparison to 2000 &.. & 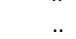 & $100 \%$ & $106 \%$ & $115 \%$ & $126 \%$ & $135 \%$ & $144 \%$ & $146 \%$ & $133 \%$ & $149 \%$ & $151 \%$ & $134 \%$ \\
\hline
\end{tabular}

Table 37. Net-import of textiles to Iceland 2000-2012 (Statistics Iceland, 2014a)

\begin{tabular}{|c|c|c|c|c|c|c|c|c|c|c|c|c|c|}
\hline & 2000 & 2001 & 2002 & 2003 & 2004 & 2005 & 2006 & 2007 & 2008 & 2009 & 2010 & 2011 & 2012 \\
\hline Clothes (in tonnes) & 2,641 & 2,494 & 2,441 & 2,706 & 3,021 & 3,507 & 3,484 & 3,485 & 3,025 & 2,274 & 2,534 & 2,422 & 2,326 \\
\hline Household textiles (in tonnes) & 1,430 & 1,588 & 1,460 & 1,949 & 1,866 & 2,197 & 2,209 & 2,229 & 1,863 & 1,512 & 1,762 & 1,726 & 2,239 \\
\hline Total & 4,070 & 4,082 & 3,901 & 4,655 & 4,887 & 5,704 & 5,694 & 5,714 & 4,888 & 3,786 & 4,297 & 4,149 & 4,565 \\
\hline Comparison to 2000 & $100 \%$ & $100 \%$ & $96 \%$ & $114 \%$ & $120 \%$ & $140 \%$ & $140 \%$ & $140 \%$ & $120 \%$ & $93 \%$ & $106 \%$ & $102 \%$ & $112 \%$ \\
\hline
\end{tabular}

Table 38. Net-import of textiles to Norway 2000-2012 (Statistics Norway, 2014a)

\begin{tabular}{|c|c|c|c|c|c|c|c|c|c|c|c|c|c|}
\hline & 2000 & 2001 & 2002 & 2003 & 2004 & 2005 & 2006 & 2007 & 2008 & 2009 & 2010 & 2011 & 2012 \\
\hline Clothes (in tonnes) & 49,403 & 47,539 & 50,864 & 54,402 & 55,625 & 58,640 & 61,398 & 64,523 & 66,856 & 61,446 & 68,287 & 68,466 & 59,534 \\
\hline Household textiles (in tonnes) & 11,352 & 11,013 & 13,103 & 14,622 & 17,292 & 17,915 & 17,213 & 18,061 & 17,983 & 16,452 & 17,924 & 18,591 & 15,774 \\
\hline Total & 60,755 & 58,552 & 63,967 & 69,024 & 72,917 & 76,555 & 78,612 & 82,583 & 84,839 & 77,898 & 86,211 & 87,057 & 75,308 \\
\hline Comparison to 2000 & $100 \%$ & $96 \%$ & $105 \%$ & $114 \%$ & $120 \%$ & $126 \%$ & $129 \%$ & $136 \%$ & $140 \%$ & $128 \%$ & $142 \%$ & $143 \%$ & $124 \%$ \\
\hline
\end{tabular}


Table 39. Net-import of textiles to Sweden 2000-2012 (Statistics Sweden, 2014a)

\begin{tabular}{|c|c|c|c|c|c|c|c|c|c|c|c|c|c|}
\hline & 2000 & 2001 & 2002 & 2003 & 2004 & 2005 & 2006 & 2007 & 2008 & 2009 & 2010 & 2011 & 2012 \\
\hline Clothes (in tonnes) & 78,341 & 75,503 & 77,120 & 84,208 & 85,338 & 86,388 & 87,029 & 93,744 & 96,325 & 85,545 & 94,285 & 96,144 & 83,432 \\
\hline Household textiles (in tonnes) & 15,522 & 18,545 & 17,155 & 18,478 & 22,001 & 24,813 & 26,788 & 30,473 & 30,037 & 28,048 & 29,414 & 32,603 & 24,519 \\
\hline Total & 93,863 & 94,048 & 94,275 & 102,686 & 107,339 & 111,201 & 113,817 & 124,217 & 126,362 & 113,593 & 123,699 & 128,747 & 107,951 \\
\hline Comparison to 2000 & $100 \%$ & $100 \%$ & $100 \%$ & $109 \%$ & $114 \%$ & $118 \%$ & $121 \%$ & $132 \%$ & $135 \%$ & $121 \%$ & $132 \%$ & $137 \%$ & $115 \%$ \\
\hline
\end{tabular}

Table 40. Net-import of textiles to the Nordic countries 2000-2012 (Statistics Denmark, 2014a) (Statistics Iceland, 2014a) (Statistics Norway, 2014a) (Statistics Sweden, 2014a) (Tulli, 2014a)

\begin{tabular}{|c|c|c|c|c|c|c|c|c|c|c|c|c|c|}
\hline & 2000 & 2001 & 2002 & 2003 & 2004 & 2005 & 2006 & 2007 & 2008 & 2009 & 2010 & 2011 & 2012 \\
\hline Clothes (in tonnes) & 185,476 & 181,612 & 218,078 & 241,864 & 249,390 & 261,514 & 270,356 & 284,572 & 276,807 & 250,207 & 277,230 & 279,583 & 250,361 \\
\hline Household textiles (in tonnes) & 39,002 & 41,572 & 48,916 & 53,726 & 61,197 & 69,889 & 72,284 & 78,919 & 81,093 & 72,857 & 77,449 & 77,628 & 65,432 \\
\hline Total & 224,478 & 223,184 & 266,994 & 295,590 & 310,587 & 331,403 & 342,640 & 363,491 & 357,900 & 323,064 & 354,679 & 357,211 & 315,793 \\
\hline Comparison to 2000 & $100 \%$ & $99 \%$ & $119 \%$ & $132 \%$ & $138 \%$ & $148 \%$ & $153 \%$ & $162 \%$ & $159 \%$ & $144 \%$ & $158 \%$ & $159 \%$ & $141 \%$ \\
\hline
\end{tabular}





\section{Annex B: Test of different types of models for prediction of future trends in production of textile and clothes}

To test how well different types of models for prediction of future trends in production of textile and clothes, $\mathrm{R}^{2}$ values for each model were estimated based in the Excel curve fitting function. As shown in Table 41, the polynomic model was the best for most countries, giving rather high $\mathrm{R}^{2}$-values for each type of models (lowest values for Sweden and Norway. The polynomic model seems thus to give the best prediction for future trends in production of textiles. However, as the logarithmic model has been used in the other part of study together with the linear model, those two are also used in estimating future production of textiles and clothes.

Table 41. $\mathbf{R}^{2}$ values for fit to model for trends in future production of clothes and textiles in the Nordic region based in three different types of models

\begin{tabular}{lrrr}
\hline & Logaritmic & Linear & Polinomic \\
\hline Denmark & 0,6788 & 0,7935 & 0.8 \\
Finland & 0,9589 & 0,852 & 0,9751 \\
Iceland & 0,1332 & 0,3583 & 0,8761 \\
Norway & 0,0041 & 0,0305 & 0,245 \\
Sweden & 0,0006 & 0,0009 & 0,0093 \\
Total & 0,8239 & 0,6932 & 0,8185 \\
\hline
\end{tabular}

The prediction of future trends in production of textile and clothes according to the different models are presented in Fejl! Henvisningskilde ikke fundet. 
Table 42. Trends in production of textiles and clothes in Nordic countries 2015 and 2020 based in different models

\begin{tabular}{lrrrrrr}
\hline & \multicolumn{2}{c}{ Logaritmic } & \multicolumn{2}{c}{ Linear } & \multicolumn{2}{c}{ Polinomic } \\
\cline { 2 - 6 } & $\mathbf{2 0 1 5}$ & $\mathbf{2 0 2 0}$ & $\mathbf{2 0 1 5}$ & $\mathbf{2 0 2 0}$ & $\mathbf{2 0 1 5}$ & $\mathbf{2 0 2 0}$ \\
\hline Denmark & 389 & 411 & 599 & 747 & 820 & 1,250 \\
Finland & 1,976 & 465 & 0 & 0 & 4,833 & 12,628 \\
Iceland & 1,244 & 1,309 & 1,564 & 1,931 & 2,796 & 6,162 \\
Norway & 1,369 & 1,352 & 1,194 & 1,032 & 0 & 0 \\
Sweden & 26,998 & 26,980 & 27,135 & 27,189 & 27,898 & 29,542 \\
Total & 31,977 & 30,518 & 30,492 & 30,899 & 37,006 & 48,855 \\
\hline
\end{tabular}




\section{Annex C: Base of selection of policy measures}

The following policy measures were used as a base for the selection of policy measures to include in the Nordic Strategy. In the formulation of the strategy, some of the policy measures were elaborated on and/or adjusted.

\section{Overarching policy measures}

- Nordic Commitment as developed in the NCM financed project The Nordic textile reuse and recycling commitment.

- (Voluntary) certification scheme for collection, sorting, de-branding, reuse and recycling activities (including e.g. third party certification and demand for exclusive co-operation with certified actors).

- Adjustment of legislation on ownership of waste.

- Standard method for collecting data regarding consumption, collection, sorting, reuse and recycling of textiles.

- Mandatory EPR.

- Voluntary EPR.

\section{Policy measures supporting increased collection}

- Minimum requirement regarding number of collection sites.

- Deposit for textiles.

- App with data about collection sites.

- Blacklisting of non-certified collectors.

- Voluntary collection of corporate clothing from private organisations.

- Mandatory collection of corporate clothing from public organisations.

- Obligation from retailers to take back used clothes.

- Regulated collection systems, e.g. quality requirements on collection containers.

- Review of rules on establishment of collection containers.

- Mandatory kerbside collection of textiles. 
- Financial assistance for development and establishment of material banks.

- Information campaigns.

Policy measures supporting increased reuse, collective use and prolonged active life time

- Financial assistance and demands for inclusion of sustainable design courses in design schools (earmarked financing).

- Label with durability information/criteria.

- Minimum warranty periods for (certain types of) clothing/textiles.

- Knowledge hub and advice bureau for start-up of new business models.

- Nordic awards for new business models in textiles.

- VAT reductions/removal for second-hand goods and repair services.

- Government funding pool for start-up investments in new business models within textiles.

- Support for second hand in selected locations.

- Long-term unemployed wage subsidies earmarked for sustainable business models plus tax benefits for social enterprises.

- Minimum reuse rate of collected textiles.

- Obligation for collectors to send the materials to certified sorting facilities.

- Information campaigns.

\section{Policy measures supporting increased recycling}

- Requirement of using recycled materials in public procurement criteria.

- Obligation for collectors to send the materials to certified sorting facilities.

- Obligation to collect both for reuse and recycling.

- Minimum recycling rate of collected textiles.

- Recycling certificates.

- Information campaigns.

- Chemical tax on textiles.

- Material exchange.

- Raw material fee on new textiles.

- Financial assistance for establishing one chemical recycling facility on an industrial scale in the Nordic region. 


\section{Annex D: Additional policy measures}

In the following, additional policy measures are listed according to the necessary changes defined in section 4 . These measures could be adopted in case a single (or several) necessary change(s) are not met by the measures suggested in the Nordic Strategy.

- Increased transparency:

- To make the voluntary parts of the strategy mandatory.

- Increased active life time of products:

- A voluntary or mandatory EPR.

- Financial assistance and demands for inclusion of sustainable design courses in design schools (earmarked financing).

- Voluntary or mandatory label with durability information/criteria.

- Minimum warranty periods for (certain types of) clothing/textiles.

- Changed consumer behaviour:

- App with data about collection sites/solutions.

- New, innovative collection solutions.

- Increased attractiveness of collection:

- Min requirement to number of collection sites or mandatory collection of textiles (covering both urban and rural, smaller and larger municipalities as well as all regions in each country).

- Increased collection of used textiles:

- Economic support to collectors according to availability, fee based.

○ Deposit for textiles.

- Blacklisting of non-certified collectors.

- Obligation from retailers to take back used clothes.

- Regulated collection systems, e.g. quality requirements on collection containers.

- Review of rules on establishment of collection containers.

- Mandatory kerbside collection of textiles (e.g. $50 \%$ coverage). 
- Increased de-branding:

- Mandatory to have de-branding service (or contracting partner for this service) in order to be certified collector of corporate used textiles and textile waste.

- Increased reuse:

- Knowledge hub and advice bureau for start-up of new business models.

- Nordic awards for new business models in textiles.

- VAT reductions/removal for second-hand goods and repair services (and leasing?).

- Support for second hand in selected locations.

- Long-term unemployed wage subsidies earmarked for sustainable business models plus tax benefits for social enterprises.

- Obligation for collectors to send the materials to certified sorting facilities.

- Increased and improved sorting of collected textiles:

- Obligation for collectors to send the materials to certified sorting facilities.

- Improved management of textile and textile waste flows:

- Financial assistance for development and establishment of Material Banks.

○ Material exchange.

- Increased recycling:

- Obligation to collect both for reuse and recycling.

- Min amount of recycled textiles in new textiles.

- Increased share of textile-to-textile recycling:

- Recycling certificates.

- Increased market for recycled textiles:

- Raw material fee on new textiles.

- Reduced use of toxic compounds in textiles:

- Financial assistance and demands for inclusion of sustainable design courses in design schools (earmarked financing).

- Chemical tax on textiles. 
Ved Stranden 18

DK-1061 Copenhagen K

www.norden.org

\section{A Nordic textile strategy}

The proposed strategy for increased reuse and recycling of textiles provides a starting point for the work towards a more sustainable textile and fashion sector in the Nordic region. It is focused on the increased collection, sorting, reuse and recycling in the region and thereby provides one part of the sustainability puzzle in the sector.

The proposed strategy includes incentives, policy measures and measures needed on local, regional, national and Nordic levels to ensure successful implementation.

The report is part of the Nordic Prime Ministers' overall green growth initiative: "The Nordic Region - leading in green growth" - read more in the web magazine "Green Growth the Nordic Way" at www.nordicway.org or at www.norden.org/ greengrowth

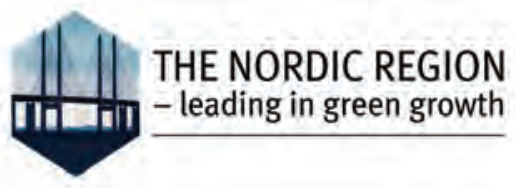

TemaNord 2015:513

ISBN 978-92-893-3968-1 (PRINT)

ISBN 978-92-893-3970-4 (PDF)

ISBN 978-92-893-3969-8 (EPUB)

ISSN 0908-6692

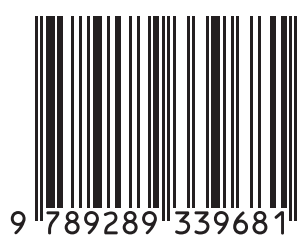

